\title{
A Highly Efficient, Linear and Broadband GaN MMIC Power Amplifier
}

By

\author{
Xing Zhou, B.Eng
}

\begin{abstract}
A thesis submitted to the
Faculty of Graduate and Postdoctoral Affairs

in partial fulfillment of the requirements for the degree of

Master of Applied Science in Electrical and Computer Engineering

in
\end{abstract}

Ottawa-Carleton Institute for

Electrical and Computer Engineering

Department of Electronics

Faculty of Engineering

Carleton University

Ottawa, Ontario, Canada

Copyright (C2012

Xing Zhou 
Library and Archives

Canada

Published Heritage

Branch

395 Wellington Street

Ottawa ON K1A ON4

Canada
Bibliothèque et

Archives Canada

Direction du

Patrimoine de l'édition

395 , rue Wellington

Ottawa ON K1A ON4

Canada
Your file Votre référence

ISBN: 978-0-494-93637-5

Our file Notre référence

ISBN: $978-0-494-93637-5$
NOTICE:

The author has granted a nonexclusive license allowing Library and Archives Canada to reproduce, publish, archive, preserve, conserve, communicate to the public by telecommunication or on the Internet, loan, distrbute and sell theses worldwide, for commercial or noncommercial purposes, in microform, paper, electronic and/or any other formats.

The author retains copyright ownership and moral rights in this thesis. Neither the thesis nor substantial extracts from it may be printed or otherwise reproduced without the author's permission.
AVIS:

L'auteur a accordé une licence non exclusive permettant à la Bibliothèque et Archives Canada de reproduire, publier, archiver, sauvegarder, conserver, transmettre au public par télécommunication ou par l'Internet, prêter, distribuer et vendre des thèses partout dans le monde, à des fins commerciales ou autres, sur support microforme, papier, électronique et/ou autres formats.

L'auteur conserve la propriété du droit d'auteur et des droits moraux qui protege cette thèse. $\mathrm{Ni}$ la thèse ni des extraits substantiels de celle-ci ne doivent être imprimés ou autrement reproduits sans son autorisation.
In compliance with the Canadian Privacy Act some supporting forms may have been removed from this thesis.

While these forms may be included in the document page count, their removal does not represent any loss of content from the thesis.
Conformément à la loi canadienne sur la protection de la vie privée, quelques formulaires secondaires ont été enlevés de cette thèse.

Bien que ces formulaires aient inclus dans la pagination, il n'y aura aucun contenu manquant. 


\section{Abstract}

This thesis presents a novel $1 \mathrm{~W}$ high PAE Linear Broadband monolithic microwave Asymmetric Distributed Power Amplifier (ADPA) design, which could be suitable for a wide range of $0.5 \mathrm{GHz}-6.5 \mathrm{GHz}$ communication systems, such as LTE, CDMA, WIFI, WiMAX and GPS.

This design is based on GaN500 technology, and was fabricated at the Canadian Photonics Fabrication Centre (CPFC). The ADPA achieves a broadband performance by employing a distributed topology employing asymmetric tapered lines. The ADPA layout area is $2 \mathrm{~mm} \times 2 \mathrm{~mm}$, and consumes a total peak current of $369 \mathrm{~mA}$ from a 15 $\mathrm{V}$ voltage supply. Over the entire bandwidth, the device delivers more than IW output power and higher than $20 \%$ PAE; a peak saturated output power of $33.45 \mathrm{dBm}$ and $38.1 \%$ peak PAE exists at $0.5 \mathrm{GHz}$. By sweeping the bias voltages together with the input power, $52.69 \%$ PAE is achieved when output power is $31.96 \mathrm{dBm}$ at $0.5 \mathrm{GHz}$. With the same device, $45.96 \%$ PAE is obtained at $1 \mathrm{GHz}$.

In addition, a stage-scaled ADPA is studied in simulation. $A$ $0.17 \mathrm{dBm} P_{\text {out }}$ variation and $1.90 \%$ PAE variation is achieved over the $1 \mathrm{GHz}-7.5 \mathrm{GHz}$ bandwidth, while 10 $\mathrm{dB}$-gain and $30 \mathrm{dBm} \mathrm{P}_{\text {out }}$ are obtained over $0.5 \mathrm{GHz}-10 \mathrm{GHz}$ bandwidth. 


\section{Acknowledgements}

Firstly, I would like to express my gratitude to my supervisor, Professor Langis Roy, and my co-supervisor, Professor Rony E. Amaya for their encouragement and support. I appreciate the precious time they spent helping me design and test the chip. The completion of this thesis would not have been possible without their help.

I would also like to thank Tyler Ross, Nathan Jess, Zhanjun Bai and Dr. Dianyong Chen who have provided me with many ideas and with whom I had many discussions about engineering and life.

Finally, on a personal note, I would like to dedicate this work to my dear parents (Yi Zhou and Qing Fang Wang), and to thank them for their financial support and the encouragement they provided in my life. Love you. 
Table of Contents

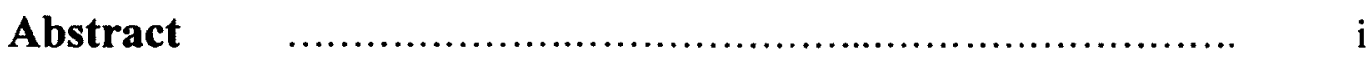

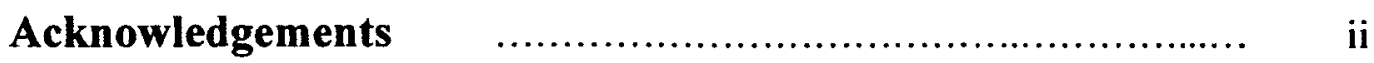

Table of Contents $\quad$............................................ iii

List of Tables $\quad$ T................................................ $v$

List of Figures $\quad$.............................................. vi

List of Abbreviations $\quad$.................................... viii

Chapter 1: Introduction

1.1 Motivation and Overview $\quad$................................ 1

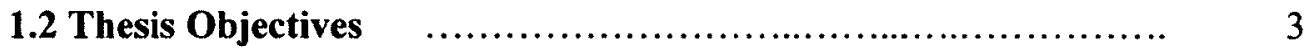

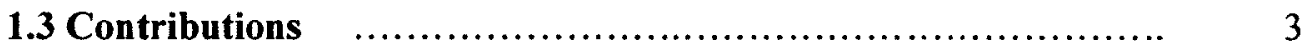

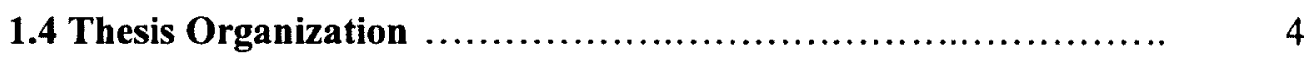

Chapter 2: PA Concepts and GaN Technology

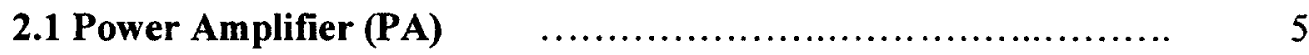

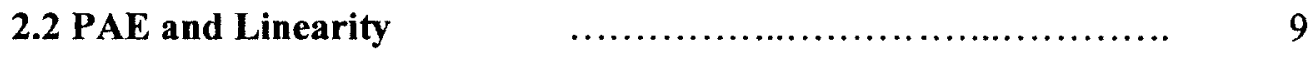

2.3 Gallium Nitride Process and Device Characteristic $\quad \ldots \ldots \ldots \ldots . .14$

2.4 Literature Review $\quad$.................................... 19

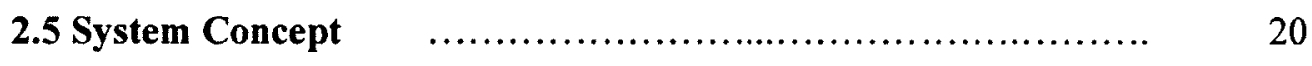

Chapter 3: Principles of Distributed Power Amplifier

3.1 Conventional Distributed Power Amplifier (DPA) $\quad \ldots \ldots \ldots \ldots \ldots .22$

3.2 Tapered Line Asymmetric Distributed Power Amplifier (ADPA) .... 32 
Chapter 4: Design and Experimental Evaluation

4.1 Design of Proposed GaN ADPA $\ldots \ldots \ldots \ldots \ldots \ldots \ldots \ldots \ldots \ldots . \ldots \ldots$

4.1.1 Unit Stage Characteristics Investigation $\quad$............. 39

4.1.2 Cascode Gain Stage $\quad$...................... 49

4.1.3 First Tapered Line Asymmetric Distributed Power Amplifier .. 52

4.1.4 Nonlinear Capacitance Effect Research $\quad$................ 73

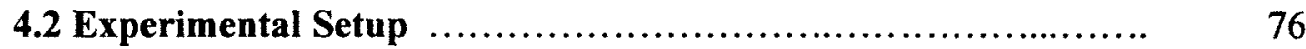

4.3 Measurement Results and Analysis of Fabricated Chip $\quad \ldots . . . . \quad 84$

4.4 Conclusion

Chapter 5: Investigation of Possible ADPA Performance

\section{Enhancements}

5.1 Improved Design with High Q Type Interconnections $\quad \ldots . . \quad 100$

5.2 Improved Tapered Line ADPA $\quad$........................ 104

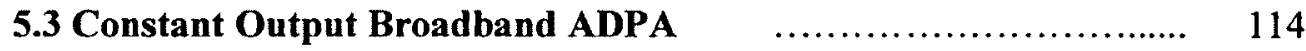

54 Cascode Tapered Line ADPA $\quad$.......................... 119

5.5 Stage-scaled ADPA $\quad$..................................... 121

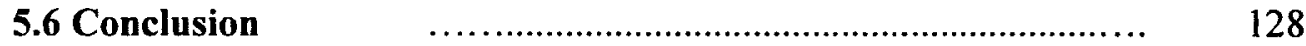

Chapter 6: Conclusion and Recommendations

6.1 Accomplishments

129

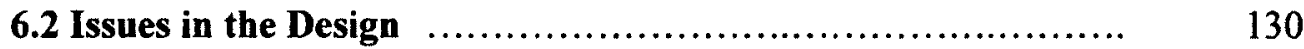

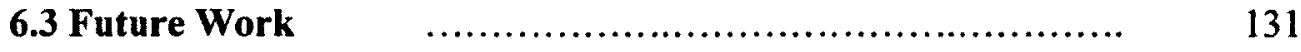


Bibliography 


\section{List of Tables}

Table 2.1. Summary of distortion products.

Table 2.2. Material properties of conventional and wide-bandgap

semiconductor bulk@300K (from [4] [12] [13] [14]).

Table 2.3. Power amplifier design using different technologies.

Table 4.1. Design Specification.

Table 4.2. Equipment list for small-signal s-parameter test.

Table 4.3. Equipment list for 1-tone power test.

Table 4.4. Equipment list for 2-tone measurement.

Table 4.5. Bias voltage difference between original and maximum PAE condition.

Table 6.1. Performance Comparison 


\section{List of Figures}

Figure 2.1. Relationship of Q-point and swing margin [1].

Figure 2.2. Drain current swing of different Class amplifier [3].

Figure 2.3. Output power of fundamental $\left(f_{1}\right)$ and IM3 $\left(2 f_{2}-f_{1}\right)$ versus input power [3].

Figure 2.4. Current dispersion because of trapping effect and thermal effect [4].

Figure 2.5. Trapping effects at the interface dielectric-semiconductor and impact on FET channel [4].

Figure 2.6. System view.

Figure 3.1. Distributed amplifier schematic [1].

Figure 3.2. Small-signal model of the transistor [1].

Figure 3.3. Equivalent Constant-K low-pass filter ladder network [1].

Figure 3.4. Constant-K section [4].

Figure 3.5. M-derived section [4].

Figure 3.6. Capacitive-coupled distributed amplifier [1].

Figure 3.7. Current distribution in a correctly tapered drain circuit [1].

Figure 3.8. Current combining for a three-cell distributed amplifier [1].

Figure 3.9. Stage-scaled distributed power amplifier [6].

Figure 4.1. Simulated $I_{D}$ versus Vds curve of $8 \times 50 \mu \mathrm{m}$ GaN500 HFET.

Figure 4.2. Simulated $\mathrm{I}_{\mathrm{D}}$ versus $\mathrm{V}_{\mathrm{gs}}$ curve of $8 \times 50 \mu \mathrm{m}$ GaN500 HFET biased at $15 \mathrm{~V}$. 
Figure 4.3. Load line of $8 \times 50 \mu \mathrm{m} \mathrm{GaN500} \mathrm{HFET.}$

Figure 4.4. Simulated HFET I-V curves for different transistor sizes biased at

$$
\mathrm{V}_{\mathrm{gs}}=-2.5 \mathrm{~V}, \mathrm{~V}_{\mathrm{ds}}=15 \mathrm{~V}
$$

Figure 4.5. $\quad f_{\mathrm{T}} / \mathrm{f}_{\max }$ simulation of $8 \times 50 \mu \mathrm{m}$ HFET biased at $\mathrm{V}_{\mathrm{DS}}=15 \mathrm{~V}$.

Figure 4.6. $\quad \mathrm{C}_{\mathrm{ds}}$ and $\mathrm{C}_{\mathrm{gs}}$ of $8 \times 50 \mu \mathrm{m}$ GaN500 HFET biased at $\mathrm{V}_{\mathrm{gs}}=-2.5 \mathrm{~V}$,

$\mathrm{V}_{\mathrm{ds}}=15 \mathrm{~V}$.

Figure 4.7. $\quad R_{i}$ and $R_{d s}$ of $8 \times 50 \mu \mathrm{m} \mathrm{GaN500} \mathrm{HFET} \mathrm{biased} \mathrm{at} V_{g s}=-2.5 \mathrm{~V}$,

$\mathrm{V}_{\mathrm{ds}}=15 \mathrm{~V}$

Figure 4.8. Input matching of single $8 \times 50 \mu \mathrm{m}$ HFET biased at $\mathrm{V}_{\mathrm{gs}}=-2.5 \mathrm{~V}$, $\mathrm{V}_{\mathrm{ds}}=15 \mathrm{~V}, 3.8 \mathrm{GHz}$.

Figure 4.9. Load Pull of $8 \times 50 \mu \mathrm{m}$ HFET biased $@ \mathrm{~V}_{\mathrm{gs}}=-2.5 \mathrm{~V}, \mathrm{~V}_{\mathrm{ds}}=15 \mathrm{~V}, 3.8$

GHz with $\left|\mathrm{S}_{11}\right|<-30 \mathrm{~dB}$.

Figure 4.10. Load Pull of $8 \times 50 \mu \mathrm{m}$ HFET biased $@ \mathrm{~V}_{\mathrm{gs}}=-2.5 \mathrm{~V}, \mathrm{~V}_{\mathrm{ds}}=15 \mathrm{~V}, 4$

GHz with $\left|\mathrm{S}_{11}\right| \leq-10 \mathrm{~dB}$.

Figure 4.11. DC bias cascode stage.

Figure 4.12. Maximum voltage gain comparison between cascode and single common-source in which common-source HFET is biased at $\mathrm{V}_{\mathrm{gs}}=-2.5 \mathrm{~V}, \mathrm{~V}_{\mathrm{ds}}=15 \mathrm{~V}$

Figure 4.13. $\quad S_{21}$ comparison between cascode and single common-source in which common-source HFET is biased at $\mathrm{V}_{\mathrm{gs}}=-2.5 \mathrm{~V}, \mathrm{~V}_{\mathrm{ds}}=15 \mathrm{~V}$.

Figure 4.14. Phase synchronization.

Figure 4.15. Maximum Gain (MaxGain) while sweeping middle drain line's 
inductance.

Figure 4.16. Three types of the available spiral inductor layouts.

Figure 4.17. Q comparison among three type layouts.

Figure 4.18. Substrate setup and first section drain line characteristics.

Figure 4.19. $\quad 2^{\text {nd }}$ section drain line characteristics.

Figure 4.20. $\quad 3^{\text {rd }}$ section drain line characteristics.

Figure 4.21. first and last section (side) gate line characteristics.

Figure 4.22. $\quad 2^{\text {nd }}$ and $3^{\text {rd }}$ stage (middle) gate line characteristics.

Figure 4.23. Schematic of the first ADPA design.

Figure 4.24. Final layout of the first design (transistors marked by the rectangle).

Figure 4.25. Stability factors, $\mathrm{K}$ is presented as $\log _{10}(\mathrm{~K})$.

Figure 4.26. Small signal s-parameter biased at $\mathrm{V}_{\mathrm{gs}}=-2.5 \mathrm{~V}, \mathrm{~V}_{\mathrm{dd}}=15 \mathrm{~V}$.

Figure 4.27. Large signal s-parameter biased at $\mathrm{V}_{\mathrm{gs}}=-2.5 \mathrm{~V}, \mathrm{~V}_{\mathrm{dd}}=15 \mathrm{~V}$.

Figure 4.28. Power gain, $\mathrm{P}_{\text {out }}$ and PAE.

Figure 4.29. Fundamental $\& 3^{\text {rd }}$ Harmonic versus $P_{\text {in }}$ at $3 \mathrm{GHz}$.

Figure 4.30. Linearity over $0.5 \mathrm{GHz}-6.5 \mathrm{GHz}$.

Figure 4.31. Harmonic distribution at $\mathrm{f}_{0}=6 \mathrm{GHz}$.

Figure 4.32. Harmonic distortion over $0.5 \mathrm{GHz}-6.5 \mathrm{GHz}$.

Figure 4.33. Time domain voltage/current input/output waveform at $3 \mathrm{GHz}$.

Figure 4.34. $\quad I_{d}$ through the HFET in the ADPA unit gain stage.

Figure 4.35. Load pull simulation at $1 \mathrm{GHz}$.

Figure 4.36. Load pull simulation at $4 \mathrm{GHz}$. 
Figure 4.37. Load pull simulation at $6 \mathrm{GHz}$.

Figure 4.38. Investigate of nonlinear capacitance effect on current.

Figure 4.39. Input voltage distortion in time domain and frequency domain.

Figure 4.40. $\quad \mathrm{C}_{\mathrm{gs}}$ versus $\mathrm{V}_{\mathrm{gs}}$ at $3 \mathrm{GHz}$.

Figure 4.41. Chip under test.

Figure 4.42. $2 \mathrm{~mm} \times 2 \mathrm{~mm}$ fabricated chip.

Figure 4.43. 1-tone power test and small signal s-parameter test set-up.

Figure 4.44. Small signal s-parameter test set-up diagram.

Figure 4.45. 1-tone Power test set-up diagram.

Figure 4.46. 2-tone measurement set-up diagram.

Figure 4.47. Measured and simulated DC Is $I_{d s}-V_{d s}$ curves (Vgs values are indicated for simulated curves).

Figure 4.48. Measured and simulated small-signal s-parameters versus for three samples (at nominal bias of $\mathrm{V}_{\mathrm{gs}}=-2.5 \mathrm{~V}, \mathrm{~V}_{\mathrm{dd}}=15 \mathrm{~V}$ ).

Figure 4.49. S-parameters of ISS Thru after network analyzer calibration.

Figure 4.50. Small-signal s-parameters of chip sample 1 while sweeping $\mathrm{V}_{\mathrm{gs}}$.

Figure 4.51. Measured and simulated $P_{\text {out }}$ of the ADPA for $P_{\text {in }}=20 \mathrm{dBm}$ at nominal DC bias.

Figure 4.52. Measured and simulated PAE of the ADPA for $P_{\text {in }}=20 \mathrm{dBm}$ at nominal DC bias.

Figure 4.53. Measured $\mathrm{P}_{\text {out }}$ at nominal bias, $2 \mathrm{GHz}$.

Figure 4.54. Measured and simulated $\mathrm{P}_{\text {sat }}$ at nominal bias. 
Figure 4.55. Measured and simulated $\mathrm{P}_{\mathrm{IdB}}$ at nominal bias.

Figure 4.56. Measured and simulated linearity at nominal bias.

Figure 4.57. Measured power results biased at $\mathrm{V}_{\mathrm{gs}}=-3.5 \mathrm{~V}, \mathrm{~V}_{\mathrm{ds}}=15 \mathrm{~V}, \mathrm{I}_{\mathrm{d}}=189$ $\mathrm{mA}, 3 \mathrm{GHz}$.

Figure 4.58. Measured power and linearity performances versus drain current (sweeping bias voltage and input power at $3 \mathrm{GHz}$ ).

Figure 4.59. Measured $\mathrm{P}_{\text {out }}$ comparison of the maximum PAE and the original operating condition.

Figure 4.60. Measured PAE comparison of the max. PAE and the original operating condition.

Figure 4.61. Measured: linearity comparison of the maximum PAE and the original operating condition.

Figure 5.1. Simulated Q comparison of three types of $L_{d 1}$

Figure 5.2. Simulated $\mathrm{Q}$ comparison of three types of $\mathrm{L}_{\mathrm{g} 1}$

Figure 5.3. Simulated $\mathrm{Q}$ comparison of three types of $\mathrm{L}_{\mathrm{g} 2}$ and $\mathrm{Lg}_{\mathrm{g}}$.

Figure 5.4. Simulated Q comparison of three types of $\mathrm{L}_{\mathrm{g}}$.

Figure 5.5. Simulated performance comparison of the ADPA implemented with the low Q type interconnections and the high Q type interconnections.

Figure 5.6. Simulated manual load pull at $6 \mathrm{GHz}$.

Figure 5.7. Simulated manual load pull at $4 \mathrm{GHz}$.

Figure 5.8. Simulated manual load pull at $2 \mathrm{GHz}$. 
Figure 5.9. The $2^{\text {nd }}$ drain line section characteristics of $2^{\text {nd }}$ design.

Figure 5.10. Phase matching of $2^{\text {nd }}$ stage of $2^{\text {nd }}$ design.

Figure 5,11. Load Pull simulation of the $2^{\text {nd }}$ ADPA Design at $2 \mathrm{GHz}, 4 \mathrm{GHz}$ and

$6 \mathrm{GHz}$.

Figure 5.12. Layout of the $2^{\text {nd }}$ ADPA Design (HFETs are indicated with the rectangle).

Figure 5.13. Stability.

Figure 5.14. Large signal s-parameters.

Figure 5.15. Power gain, delivered power, PAE.

Figure 5.16. Simulated linearity and power performance comparison between the first and $2^{\text {nd }}$ design over $0.5 \mathrm{GHz}$ to $6.5 \mathrm{GHz}$ frequency range.

Figure 5.17. Simulated harmonic distortion over $0.5 \mathrm{GHz}-7 \mathrm{GHz}$ bandwidth.

Figure 5.18. $\quad \mathrm{P}_{\text {out: }}$ sweeping $\mathrm{R}_{\text {load }}$ as a function of the frequency.

Figure 5.19. PAE: sweeping $R_{\text {load }}$ as a function of the frequency.

Figure 5.20. Power Gain: sweeping $R_{\text {load }}$ as a function of the frequency.

Figure 5.21. Tapered line broadband matching network.

Figure 5.22. S-parameter performance of tapered matching network.

Figure 5.23. Stability.

Figure 5.24. Large signal s-parameters.

Figure 5.25. Simulated power performance comparison between first and constant output design (first ADPA + broadband matching network).

Figure 5.26. Available power performance of cascode stage at $4 \mathrm{GHz}$. 
Figure 5.27. Characteristics of $\mathrm{L}_{\mathrm{d} 1}$ and $\mathrm{L}_{\mathrm{d} 2}$ in the stage-scaled ADPA design.

Figure 5.28. Phase synchronization in SSADPA design.

Figure 5.29. $2 \mathrm{~mm} \times 2 \mathrm{~mm}$ Stage-Scaled ADPA layout using original uniform principle which presented in [6] [43].

Figure 5.30. $2 \mathrm{~mm} \times 2 \mathrm{~mm}$ Stage-Scaled ADPA layout modified for maximum $P_{\text {out }}$ of each stage.

Figure 5.31. Load Pull simulation of the stage-scaled ADPA design using the original uniform SSDA principle.

Figure 5.32. EM simulated power performances comparison between the first SSADPA design (with output matching network) and the first ADPA design (fabricated).

Figure 5.33. EM simulated power performances comparison between the $2^{\text {nd }}$ SSADPA design (with output matching network) and the first ADPA design (fabricated). 


\section{List of Abbreviations}

ADPA

AM-PM

BW

CDMA

CPFC

DA

DPA

DRC

EDGE

EVM

GSM

GaN500

HFET

IM

IIP

IC

ISS

LTE

LPF

LVS
Asymmetric Distributed Power Amplifier

Amplitude Modulation-Phase Modulation

Bandwidth

Code Division Multiple Access

Canada Photonics Fabrication Center, belongs to NRC

Distributed Amplifier (same as TWDA)

Distributed Power Amplifier

Design Rule Check

Enhanced Data Rates for GSM Evolution

Error Vector Magnitude

Global System for Mobile Communications

Gallium Nitride, Transistor Gate Length is $500 \mathrm{~nm}$

Heterostructure Field-Effect Transistor

Intermodulation

Input Intercept Point

Integrated Circuit

Impedance Standard Substrates

$3^{\text {rd }}$ Generation Partnership Project Long Term Evolution

Low Pass Filter

Layout Versus Schematic 
MIC

MMIC

MIM

MOM

MTEE

NF

NRC

PA

PAE

$P_{l d B}$

SSADPA

TWDA

TDA

WiMAX
Microwave Integrated Circuit

Monolithic Microwave Integrated Circuit

Metal-Insulator-Metal

Metal-Oxide-Metal

Microstrip Transmission Line Tee

Noise Factor

National Research Council, Canada

Power Amplifier

Power Added Efficiency

Power Level of 1-dB Compression Point

Stage-Scaled asymmetric distributed power amplifier

Travelling Wave Distributed Amplifier (same as DA)

Tapered Distributed Amplifier

Worldwide Interoperability for Microwave Access 


\section{Chapter 1: Introduction}

This work describes the design and fabrication of a broadband Distributed Power Amplifier MMIC using GaN500 (CPFC) technology.

\subsection{Motivation and Overview}

As the demand for high-speed wireless data communication continues to grow, different standards are developed, and wider operating bandwidths are often needed. Depending on the application, different frequencies or bands are assigned. For consumer-end products like handhelds, this becomes a burden because the designers have to use different wireless devices to support different standards, such as CDMA, WiFi or Bluetooth. The more devices used in the system, the more power will be needed if several functions are used simultaneously, which could be a problem for the product's battery life and temperature constraints.

IC designers continue to develop consumer broadband devices which can support multiple standards and work over multi-octave bandwidth. Broadband systems have traditionally employed the Travelling Wave Distributed Amplifier (TWDA) architecture, as they have been extensively investigated and firmly established as being reliable and robust devices that can be realized in MIC and MMIC technology [1]. CMOS, the most popular technology, faces many challenges in trying to deliver large output power. The reason for this is that the breakdown voltage of the CMOS transistor is low, which limits the output voltage swing. In addition, supply voltages 
continue to decrease in advanced CMOS technologies, making it even more challenging to design a high power amplifier, which is often required in wireless communication applications such as CDMA and LTE base-stations. This weakness is even more obvious after considering the use of stacked devices and transformer topologies.

Further, in a conventional TWDA, the signals on the drain line are added in the forward direction as they arrive at the output. The waves traveling in the reverse direction are not in phase, and any un-canceled signal is absorbed by the drain-line termination [1]. While this eliminates reflections, it inevitably leads to some power loss which could be used at the amplifier's output.

To address these difficulties, an emerging microwave semiconductor technology, $0.5 \mu \mathrm{m}$ Gallium Nitride (GaN500), is adopted in this work. Compared to traditional and enhanced CMOS technologies, it has a much higher breakdown voltage; the gate-to-drain breakdown voltage (BVgdo) measured on the wafer having best performance could potentially go up to $100 \mathrm{~V}$. Meanwhile, a tapered line asymmetric distributed topology is used to maximize the output power and PAE as much as possible. The key point is removing the drain-line terminal in the reverse direction through drain line tapering, or in other words, adjusting the different sections of drain lines. Doing so eliminates reflected waves and increase the efficiency and output power of the amplifier. 


\subsection{Thesis Objectives}

This thesis focuses on the research of highly efficient, linear and broadband MMIC Power Amplifier design, which uses the GaN500 process developed and fabricated at the Canadian Photonics Fabrication Center (CPFC), which is a division of the National Research Council (NRC). First, this work starts with the study of GaN500 technology and an assessment of its suitability for broadband PAs. Then, the design of an Asymmetric Distributed Power Amplifier (ADPA) which delivers 1W output power based on this technology is demonstrated, in which the RF choke is not included on chip because of the large size of the inductors. Further, this PA design is fully validated through experimental characterization of fabricated prototypes. The bias points of maximum Power Added Efficiency (PAE) are examined as a function of frequency based on measurements, so as to allow a digital control block in future applications. Finally, possible enhancements to the implemented design that could lead to further increases in linearity, output power, PAE and bandwidth (BW) are investigated.

\subsection{Contributions}

The major research contribution of this thesis is the implementation of a low supply voltage, high output power, high PAE, wideband linear Class-AB Distributed Power Amplifier. This is the first implementation of a Tapered DPA MMIC using the $\mathrm{NRC/CPFC} \mathrm{GaN500} \mathrm{process.} \mathrm{In} \mathrm{this} \mathrm{work,} \mathrm{inductors} \mathrm{with} \mathrm{various} \mathrm{topologies} \mathrm{are}$ investigated, and compared so as to meet different applications. The tapered structure, 
stage-scale topology, and cascode stage are well analyzed in different designs. Some limitations of this process are reviewed. Finally, an attempt to flatten the output power variation with frequency is made in this work, challenging the boundaries of maximally flat output power.

\subsection{Thesis Organization}

Chapter 2 gives an overview of Power Amplifier concepts and key parameters and also, introduces the Gallium Nitride (GaN) technology used here.

Chapter 3 provides the operating principles and investigation of the different distributed amplifier structures such as Conventional DA, Tapered DA and Stage-Scale.

Chapter 4 gives a detailed presentation of the ADPA design and practical implementation, starting with design steps of the prototype chip, followed by extensive practical measured results. Differences between the simulations and measurements are explained.

Chapter 5 investigates via simulation several possible enhancements to the original ADPA design. These include, \#1 high Q interconnections, \#2 re-tapering of drain line sections, \#3 output matching circuit for constant output power, and \#4 stage-scaled ADPA.

Chapter 6 presents the conclusion and directions for future work. 


\section{Chapter 2: PA Concepts and GaN Technology}

Since the 1990s, modern cellular networks have expanded rapidly which gave rise to plenty of commercial applications starting with the second generation (2G) cellular systems. The interest in microwave techniques for communication systems has grown immensely over recent years, and the performance of microwave active and passive circuits for wireless systems technology has become well advanced [1]. Among all the blocks employed in wireless transceiver systems, one of the most critical active circuits is the power amplifier, which is typically used in the transmit side of RF or microwave systems to drive antennas. As a result, the PA has always been the first to benefit from developments in device and semiconductor technologies.

\subsection{Power Amplifier (PA)}

Recently, with the development of wireless communication, more and more emphasis is placed on the implementation of solid state power amplifiers in different bands. For instance, the WiMAX Forum has published three licensed spectrum profiles: $2.3 \mathrm{GHz}$, 2.5 GHz and $3.5 \mathrm{GHz}$. Furthermore, $5 \mathrm{GHz}$ is on the way. Analog and digital TV bands (700MHz, and perhaps others for HD digital TV signal) may become available for WiMAX usage. EU commissioner Viviane Reding has suggested re-allocation of the 500-800 MHz spectrum for wireless communication, including WiMAX [2].

In one handheld, multiple wireless communication strands might be used. For example, a state-of-the-art smart phone can have NFC, Wifi, and Bluetooth 
co-existing GSM, CDMA, EDGE or LTE. The RF portion always consumes the most power and generates most of the heat among all blocks. The demand of sizing the area and saving system power consumption, or in other words longer battery life, boosts the research of broadband power amplifier implementation from the hybrid (i.e. discrete-component) realm to the monolithic circuit arena by developing new semiconductor technologies.

In practical wireless applications, some of them require the need for linear power amplifiers, while the others do not. This requirement depends mainly on the modulation scheme of the communication system employed. For instance, a linear scheme is required for a linear power amplifier, while a nonlinear scheme can make use of a nonlinear power amplifier. There are also some special conditions, i.e. the non-linear power amplifier can be used in the system which uses a linear modulation scheme. For example, MSK, GMSK (also known as GSM, a well-known protocol used in $2 \mathrm{G}$ cell phone communication), and Offset-QPSK with pulse shaping, all have constant envelope characteristics because their constellation does not cross the origin, i.e. no zero crossing. And the information is embedded in the differential phase and not the amplitude change. Since there is no or only minimal amplitude change, the non-linear power amplifier does not generate a spectral regrowth phenomena further degrading channel performance. In other words, because the modulation envelope is constant, there is one single optimum point for each power level. Although the power amplifier is non-linear, the shape of the amplified signal never changes. Consequently, the information will not be lost. That is the reason why a non-linear, high efficiency 
power amplifier is attractive in wireless communications, especially in cell phone applications.

When moving to the next generation of wireless communication, non-linear modulation scheme such as QPSK and QAM are popularly used in systems such as 3G WCDMA and LTE. Then, a linear power amplifier is required to be used at the output terminal.

\section{PA Operating Categories}

Power amplifiers can be categorized into two groups. The first one is the LinearClass A, Non-linear Class AB, B, C. Then we have switching type amplifiers, Class E, F, etc. For narrow band amplifier design, a different class amplifier has its advantages and disadvantages, and they are normally trade-offs. For example, the Class A amplifier has the highest linearity among all the classes, at the expense of efficiency. And for switching amplifiers, linearity is traded for efficiency, which is very attractive for some applications which do not require high linearity. Based on the linearity and the efficiency requirements of the wireless communication system discussed before, Class $A B$ is the best choice for this work due to its higher efficiency compared to Class A, and good linearity compared to Class B, C.

\section{Quiescent Point}

When we start to design a power amplifier, the first step is to choose the DC bias point or quiescent point (Q-point). In deciding the value of bias voltages, $V_{D S}$ and $V_{G S}$, 
the swing margins of the input and output are determined. Meanwhile, the class of the amplifier is fixed. We can get a general idea by looking into the following graph, Figure 2.1. $\mathrm{V}_{\mathrm{th}}$ represents the threshold voltage, and $\mathrm{I}_{\mathrm{DSs}}$ is the maximum $\mathrm{DC}$ drain current the transistor can obtain. Normally, Class A quiescent point settles at the middle of the curve, where $I_{D}=\frac{I_{D S S}}{2}$. Then, because of its middle position, the transistor can swing with full margin, i.e. without reaching the limitation of $I_{D S s}$ and $\mathrm{V}_{\mathrm{th}}$. As can be seen from Figure 2.2, except Class A, the other two clip at negative swing due to reaching the $\mathrm{V}_{\mathrm{th}}$ limitation of the transistors.

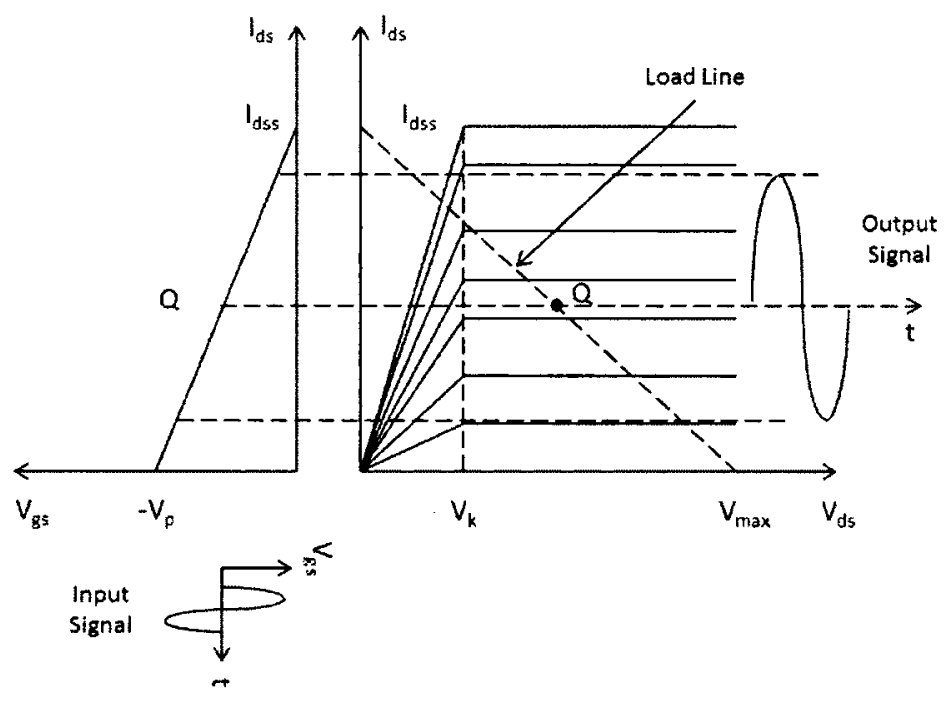

Figure 2.1. Relationship of Q-point and swing margin [1].

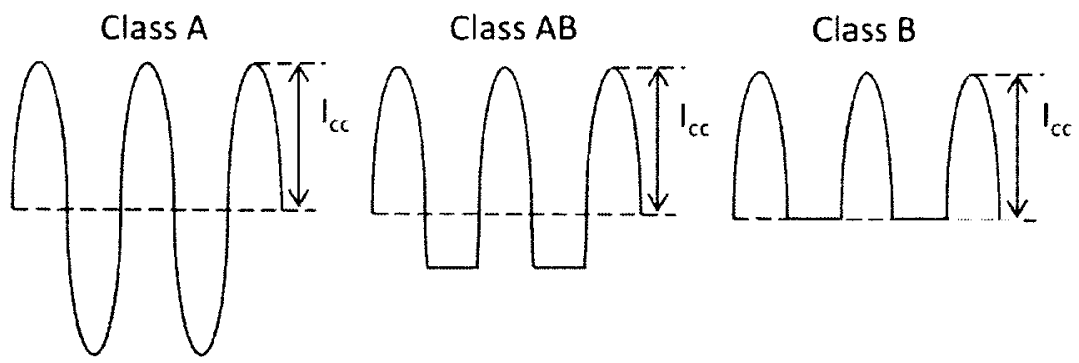

Figure 2.2.

Drain current swing of different Class amplifier [3]. 


\subsection{PAE and Linearity}

Among all the parameters of power amplifier characteristics, the three most important are output power $\left(\mathrm{P}_{\text {out }}\right), \mathrm{PAE}$, and Linearity. And for the low noise amplifier (LNA) normally used in the receiver, Noise Figure (NF) is always the first thumb parameter. We are familiar with drain efficiency, $\eta$, which describes how much power can be converted from DC supply to RF output. It is given by the equation of

$$
\eta=\frac{P_{\text {out }}}{P_{d c}}
$$

where

$$
P d c=\frac{1}{T} \int_{0}^{T} V_{c c} i_{d c} d t=V_{c c} I_{d c}
$$

Here, $\mathrm{P}_{\text {out }}$ is the RF output power, and Pdc corresponds to the DC power coming from the supply. Vcc and Idc are the supply DC voltage and current respectively.

Power-added efficiency (PAE) is another presentation of efficiency, which is given by the equation of

$$
P A E=\frac{P_{\mathrm{out}}-P_{\text {in }}}{P_{d c}}
$$

where $P_{\text {out }}$ and $P_{\text {in }}$ are the RF output power and input power respectively. If we introduce the parameter of power gain, $\mathrm{G}$, into the equation above, it can be rewritten as

$$
P A E=\frac{P_{\text {out }}-\frac{P_{\text {out }}}{G}}{P_{d c}}=\eta\left(1-\frac{1}{G}\right)
$$

PAE is an important parameter which is widely used in RF/MMIC device design, not only because of the low power tendency of custom chip design, but also due to the temperature control. For instance, in most RF/MMIC custom chips used in handheld devices, the un-converted power still contributes to heating. If the PAE is lower, more 
power coming from the DC supply is wasted, and the device heats up. Then, because of the thermal energy, the atoms and electrons could move around randomly, which leads to random current components in the circuit. These products are known as thermal noise, which is a white noise.

Ideally, the circuit operates linearly. In other words, the output of the circuit is linearly related to the input. Unfortunately, in practice, the transfer function of the circuit is complicated. A lot of products other than the fundamental are generated because of the nonlinearity of the active or passive devices, or due to clipping by the rail of the source. Further, recently developed wireless communication schemes such as QAM requires for linear operated electronic circuits. These issues are all important results for circuit linearity research; that is, to find out the region where the circuit can operate linearly. The representative parameter for this characteristic is the $1-\mathrm{dB}$ compression point, or $\mathrm{P}_{1 \mathrm{~dB}}$. And for different applications, this specification is replaced by others, such as 2-dB compression point $\left(\mathrm{P}_{2 \mathrm{~dB}}\right), 3-\mathrm{dB}$ compression point $\left(\mathrm{P}_{3 \mathrm{~dB}}\right)$, and saturation point (Psat). The choice of parameter is determined based on the different linearity requirements of modulation/demodulation schemes. Here, we only introduce the most commonly used concept, $1-d B$ compression point $\left(P_{1 d B}\right)$.

1-dB compression point $\left(P_{I d B}\right)$ is simply the power level, specified at both input and output, where the output power is $1 \mathrm{~dB}$ less than it would have been in an ideal linear device [3]. Normally, 1-dB compression point is measured or simulated with 1-tone. It is different with the other important parameter of linearity, IP3, which will be introduced in this chapter later. As shown in Figure 2.3, we can derive the equation of 
actual output voltage $v_{0}$ and the ideal linear output voltage $v_{0 i}$ as

$$
20 \log _{10}\left(\frac{v_{0}}{v_{o i}}\right)=-1 d B
$$

(Equation 2.7)

then we can have

$$
\frac{\mathrm{v}_{\mathrm{o}}}{\mathrm{v}_{\mathrm{oi}}} \approx 0.89125
$$

As we know, for an input voltage $v_{i}$, the actual output of 1-tone because of nonlinearity is

$$
v_{0}=k_{1} v_{i}+\frac{3}{4} k_{3} v_{i}^{3}
$$

Then, the ideal linear output voltage is

$$
\mathrm{v}_{\mathrm{o}}=\mathrm{k}_{1} \mathrm{v}_{\mathrm{i}}
$$

So, the input 1-dB compression point can be found by equation

$$
\frac{k_{1} v_{1 \mathrm{~dB}}+\frac{3}{4} k_{3} v_{1 \mathrm{~dB}}^{3}}{k_{1} v_{1 \mathrm{~dB}}}=0.89125
$$

Because nonlinearity causes compression rather than expansion, $\mathrm{k}_{3}$ must be negative, we have input $\mathrm{v}_{1 \mathrm{~dB}}$ as

$$
\mathrm{v}_{1 \mathrm{~dB}} \approx 0.38 \sqrt{\frac{\mathrm{k}_{1}}{-\mathrm{k}_{3}}}
$$

In addition to measuring the linearity, there is another important parameter, the third-order intercept point (IP3). The reason for research on the improvement of the IP3 is not only for the fundamental product's linearity, but also for the noise because of the nonlinear products such as IP3. In order to analyze it, we first review the Volterra series output voltage $v_{\text {out }}$ to input voltage $v_{\text {in }}$

$$
v_{\text {out }}=k_{o}+k_{1} v_{\text {in }}+k_{2} v_{\text {in }}^{2}+k_{3} v_{\text {in }}^{3}+\cdots
$$

The distortion and intermodulation products are generated because of the nonlinearity 
of the electronic system, which can be summarized as Table 2.1. In the table, HD represents the harmonic distortion, and IM represents the intermodulation.

Table 2.1. Summary of distortion products.

\begin{tabular}{|c|c|}
\hline Product & Frequency \\
\hline fundamental & $f_{1}$ \\
\hline fundamental & $\mathrm{f}_{2}$ \\
\hline $\mathrm{HD} 2$ & $2 f$ \\
\hline $\mathrm{HD} 2$ & $2 \mathrm{f}_{2}$ \\
\hline IND & $f_{2}+f_{z}$ \\
\hline $\mathrm{IND}$ & $f_{2}-f_{2}$ \\
\hline $\mathrm{HD} 3$ & $3 E_{=}$ \\
\hline $\mathrm{HD}_{3}$ & $3 f_{2}$ \\
\hline $\mathrm{INB}$ & $2 f_{1}-f_{2}$ \\
\hline $\mathrm{INB}$ & $2 f_{z}-f_{z}$ \\
\hline
\end{tabular}

It can be seen from Table 2.1 that the frequency of the intermodulation product IM3 is $2 f_{1}-f_{2}$ or $2 f_{2}-f_{1}$. Normally, multi-carrier or multi-frequency communication such as cell phone requires for a narrow band. In other words, the spacing between each fundamental is very small. For instance, W-CDMA only transmits on a pair of 5 $\mathrm{MHz}$-wide radio channels, while CDMA2000 transmits on one or several pairs of 1.25 $\mathrm{MHz}$ radio channels. As a result, it is impossible to filter out the IM3 products from the fundamentals, which could act as noise to adjacent channels.

The third-order intercept point (IP3) is a theoretical point where the amplitudes of third-order intermodulation tones at $2 f_{2}-f_{1}$ and $2 f_{1}-f_{2}$ are equal to the amplitudes 
of the fundamental tones at $f_{1}$ and $f_{2}[3]$. As shown in Figure 2.3, the slope of fundamental and IM3 products are $1 \mathrm{~dB}$ and $3 \mathrm{~dB}$ respectively. The input power of third-order intercept point (IP3) is called the input third-order intercept point (IIP3), and the output power of this point is known as the output third-order intercept point (OIP3). Those points cannot be practically measured directly, since then the amplifier will be heavily loaded. When performing the simulation and measurement, the space of the two fundamental tones should be taken care of. There are two rules for choosing the spacing. First, according to the customer chip application, it is better to take the channel space as the spacing of two-tone test. On that point, the measurement simulates exactly the real condition in the application. Second, we need to make sure the two fundamental tones and the IM3 tones are in the same gain bandwidth. Then, $f_{1}$ and $f_{2}, 2 f_{2}-f_{1}$ and $2 f_{1}-f_{2}$ components will not have any difference because of the different gain among different frequencies. With the setup described above, we estimate the worst condition which we could encounter with later in applications. Through optimization, the device performance could be improved.

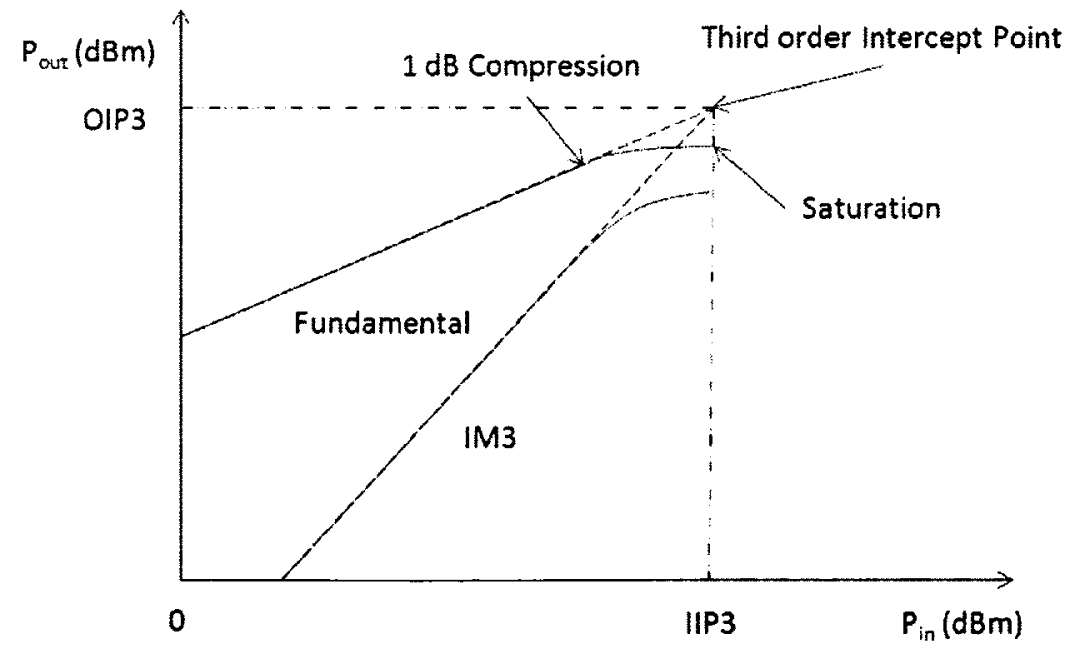

Figure 2.3. $\quad P_{\text {out }}$ of fundamental $\left(f_{1}\right)$ and IM3 $\left(2 f_{2}-f_{1}\right)$ as a function of $P_{\text {in }}[3]$. 


\subsection{Gallium Nitride Process and Device Characteristic}

Wide bandgap semiconductors have been introduced into power amplifiers design, which made the implementation of high output voltage swing amplifiers become possible. The materials' ability to operate at higher temperatures, higher power densities, higher voltages and higher frequencies make them highly interesting to be used in future electronic system applications [4]. Among all these materials, Gallium Nitride $(\mathrm{GaN})$ turns out to be the optimal choice for RF high power and high frequency applications. First, let us review the reasons that limit traditional silicon device power and frequency performance. CMOS devices have very low breakdown voltages, which means large RF (AC) and DC current must be applied to achieve high output power. However, high current operation is inefficient due to series losses coming from the components and interconnects. Also, from Equation 2.14, high capacitance and low impedance limit the maximum frequency which device can operate at.

$$
f_{T}=g_{m} / 2 \pi C_{g s}, f_{\max }=\frac{f_{T}}{2} \sqrt{R_{d s} / R_{g}}
$$

A comparison of different materials available for the implementation of power amplifiers is presented Table 2.2. 
Table 2.2. Material properties of CMOS and wide-bandgap semiconductor bulk @3 $300 \mathrm{~K}$ (from [4] [12] [13] [14]).

\begin{tabular}{|c|c|c|c|c|}
\hline Material & $\mathrm{E}_{\mathrm{g}}(\mathrm{eV})$ & $\varepsilon_{\mathrm{r}}$ & $\mathrm{K}\left(\mathrm{W} /{ }^{\circ} \mathrm{K} \cdot \mathrm{cm}\right)$ & $\mathrm{E}_{\mathrm{c}}(\mathrm{V} / \mathrm{m})$ \\
\hline $\mathrm{Si}$ & 1.12 & 11.9 & 1.5 & $3 \mathrm{e} 5$ \\
\hline $\mathrm{SiC}$ & 3.26 & 10.1 & $3.7-4.5$ & $3 \mathrm{e} 6$ \\
\hline $\mathrm{GaAs}$ & 1.43 & 12.8 & 0.54 & $4 \mathrm{e} 5$ \\
\hline $\mathrm{InP}$ & 1.35 & 12.5 & 0.67 & $4.5 \mathrm{e} 5$ \\
\hline $\mathrm{GaN}$ & 3.44 & 9.5 & $1.3-2.1$ & $3 \mathrm{e} 6$ \\
\hline
\end{tabular}

As seen in Table 2.2, Gallium Nitride has the largest Bandgap Energy $\left(E_{g}\right)$ which results in the highest Electric Breakdown Field $\left(\mathrm{E}_{\mathrm{c}}\right)$, yielding the highest breakdown voltage, or largest terminal peak voltage, translating into the highest $\mathrm{RF}$ output power. Next, the relative permittivity $\left(\varepsilon_{\mathrm{r}}\right)$ is an indication of the capacitance of a capacitor using the semiconductor material as a dielectric, and it also affects the device terminal impedances. Gallium Nitride has the lowest dielectric permittivity, which means it has the lowest capacitive loading since $C \propto \varepsilon_{\mathrm{r}} A$ (' $\mathrm{A}$ ' represents the area). On the other hand, for a given impedance, GaN will require the largest area among the four technologies studied; however, the highest current is obtained when the area is fixed. Finally, the thermal conductivity $(\mathrm{K})$ of a semiconductor material is extremely important since it is a measure of the ease of extracting the dissipated power from the device. Poor thermal conductivity results in degraded device performance at elevated temperatures. As demonstrated in Table 2.2, Gallium Nitride has the same thermal 
conductance as conventional Silicon, which is better than other wide-bandgap semiconductors such as GaAs and InP. Meanwhile, the thermal conductivity of Silicon Carbide (SiC) is normally $3.7-4.5 \mathrm{~W} /{ }^{\circ} \mathrm{K} \cdot \mathrm{cm}$, which is even higher than Silicon. Recent processes now grow $\mathrm{GaN}$ on $\mathrm{SiC}$ with much improved thermal capabilities. After considering all of the advantages that $\mathrm{GaN}$ has to offer compared to other available technologies for PA design, one might ponder the question if after all, there are any disadvantages of using GaN? Surprisingly, the answer is yes. There are two important effects, namely the trapping effect and thermal effect, which can cause current dispersion (collapse and rolling off) as shown in Figure 2.4.

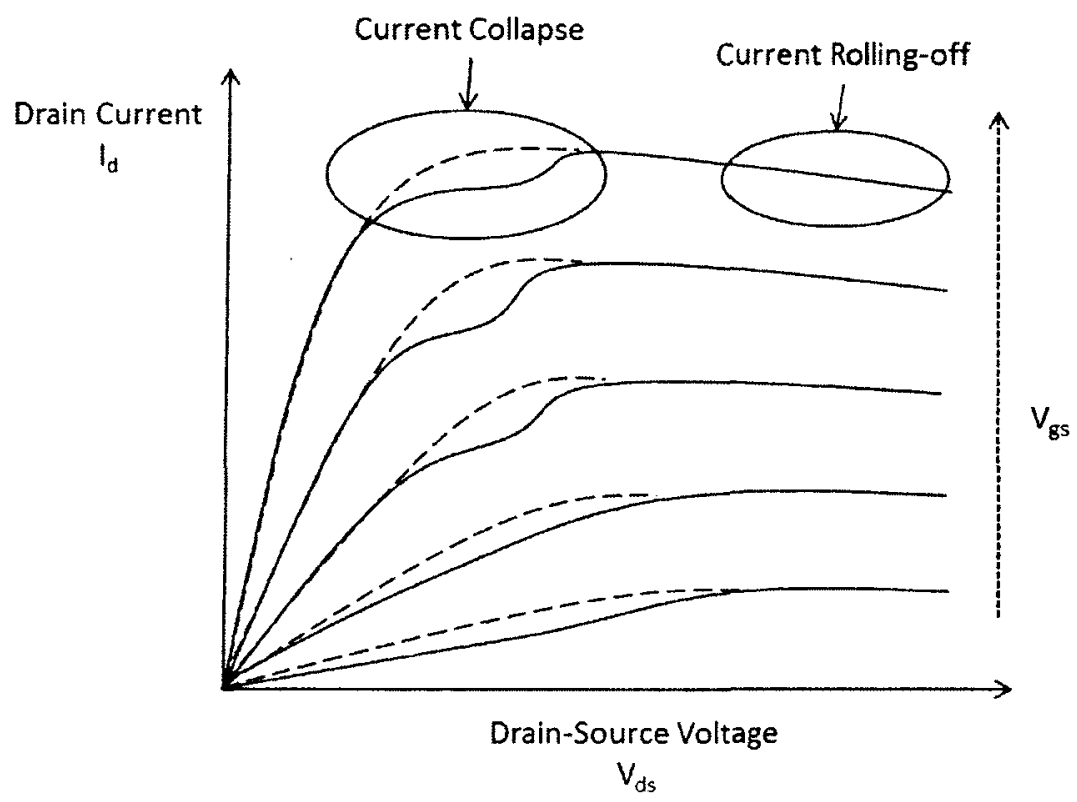

Figure 2.4. Current dispersion due to trapping effect and thermal effect [4].

During ideal operation, as shown in Figure 2.5 (I), the positive interface charge at the heterointerface results in the negative channel charge in an n-type FET, if we assume polarization doping only. Then, a negative surface charge at the top of the barrier is 
caused by the interface positive charge. The change of the surface charge during dynamic device operation will then directly interfere with the channel charge. In the second case, as shown in Figure 2.5 (II), the empty charges in the dielectric layer represent the de-trapping of the surface charges. As a result, the channel charge is modified. If the charge at the surface is not fully compensated statically and dynamically, some atoms will be trapped as empty charges in the channel shown in Figure 2.5 (II). So the electron carriers in the channel are trapped. This dynamic trapping and de-trapping is fundamentally connected to the static and dynamic leakage current at the semiconductor barrier/dielectric interface [4]. As a result, the current collapses. One other reason for the current collapse is due to the hot electron injection. When the temperature is high enough, fast random moving electrons can be injected into adjacent layers. Thanks to the research of process engineers, the trapping effect has been minimized. However, buffer traps in a Gallium Nitride (GaN) transistor may exhibit longer time than those encountered in GaAs. This greatly limits the performance of the device in a high power / high frequency system.
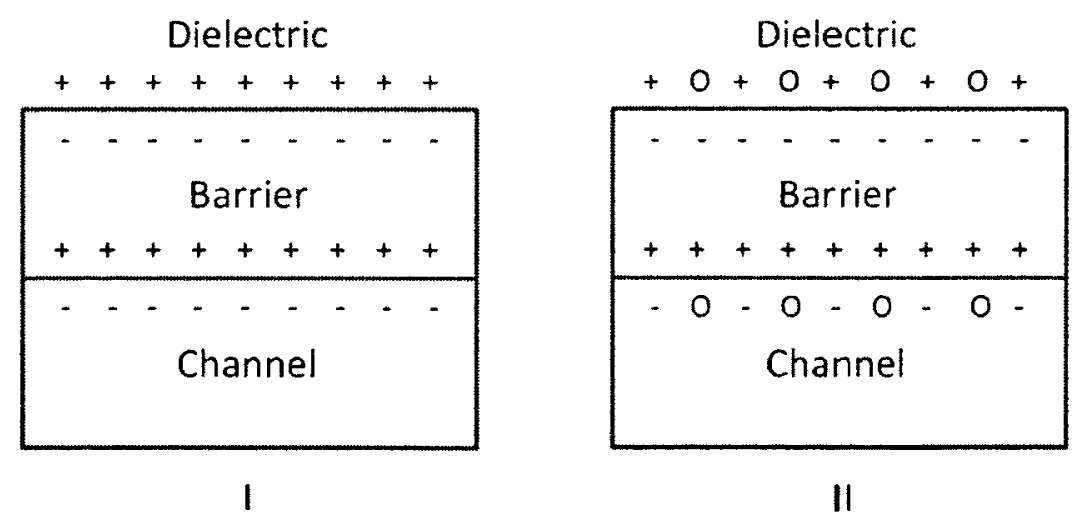

Figure 2.5. Trapping effects at the interface dielectric-semiconductor and impact on FET channel [4]. 
On the other hand, thermal and self-heating effects are presented in every power semiconductor device. Especially when the device is working in the high voltage and high power region, the self-heating causes electron carriers to accelerate in random directions instead of following the drain to source channel. Some of the electrons eject themselves out of the channel, causing significant roll off in the high voltage and high current region, which is observed in DC and RF current variations, as shown in Figure 2.4 .

Today, Gallium Nitride (GaN) High-Electron Mobility Transistors (HEMTs) or Heterojunction FETs (HFETs) are the most advanced electronic nitride devices. The heterostructures offers many advantages such as high breakdown and transport properties of undoped Gallium Nitride (GaN).

Gallium Nitride (GaN) Heterojunction FETs (HFETs) designed and modeled by the Canada National Research Center (NRC) were selected in our work. This GaN HFETs are processed on 3-inch diameter epitaxial layers grown on insulating silicon carbide wafers. Semi-insulating silicon carbide is one of the most attractive substrate materials for electronic applications, because of the favorable combination of lattice mismatch, isolation, and thermal conductivity [4]. The cutoff frequency and maximum oscillation frequency of the measured $2 \times 40 \mu \mathrm{m}$ device is $27 \mathrm{GHz}$ and 75 $\mathrm{GHz}$ respectively. Also, a $100 \mathrm{~V}$ device breakdown voltage is obtained with gate-drain spacing of $2 \mu \mathrm{m}$ or greater. For details of this process, please refer to the appendix. 


\subsection{Literature Review}

Amplifiers with extremely wide bandwidths and good RF performance have been successfully realized over the past 2 decades using both hybrid and monolithic technologies [1]. After the design specifications are fixed (output power $>1 \mathrm{~W}$, PAE $>$ $20 \%$ ), various technologies and topologies are reviewed. Commonly used CMOS technologies, including SiGe BiCMOS, can normally deliver lower than IW RF power. As reported in reference [15], TMSC $0.35 \mu \mathrm{m}$ SiGe BiCMOS is used in cascode structure; by biasing the $1 \mathrm{~mm} \times 0.8 \mathrm{~mm}$ device with $3.3 \mathrm{~V}$ DC voltage, 17 $\mathrm{dBm}$ output power is delivered in $0.6 \mathrm{GHz}-2.4 \mathrm{GHz}$ bandwidth with maximum $45 \%$ peak PAE. A commercial chip supplied by Hittite using a Dual SiGe HBT working in $\mathrm{DC}$ to $5 \mathrm{GHz}$ band has been reported delivering $20 \mathrm{dBm} \mathrm{RF}$ power with approximately $15.5 \%$ PAE. Usually, the only way for CMOS PAs to obtain more than IW output power is using a transformer or balun, as reported in reference [16] and [17]. However, including transformer or balun in the circuit would probably increase the device total size and introduce EM noise into other blocks of the circuit. When considering previous work reported in both GaN and GaAs, ultra-broadband PAs, which exhibit multi-octave bandwidth, have been reported by researchers starting in 2000. Output power larger than IW can be obtained with a simple structure by using such technologies as [18] - [26] which offer advantages when compared to CMOS. These designs are summarized in Table 2.3. In conclusion, CMOS material is limited by its bandgap which leads to low breakdown voltage. Without using a transformer or balun, the delivered output RF power is usually lower than $1 \mathrm{~W}$. On the other hand, 
III-V materials such as GaN and GaAs can easily obtain a high output voltage since they feature a wider bandgap. However, self-heating normally limits the performance of devices such as GaAs PAs due to GaAs' low thermal conductivity.

Table 2.3 Power amplifier design using different technologies

\begin{tabular}{|c|c|c|c|c|c|c|c|c|}
\hline Technolog & Topolog & $\mid \begin{array}{c}\text { DC vol tage } \\
(V)\end{array}$ & $\begin{array}{c}\text { Prequency } \\
\text { Bandwidth } \\
\text { (GHY) }\end{array}$ & $\mid \begin{array}{c}\text { Pe ak PAR } \\
(\boldsymbol{H})\end{array}$ & $\begin{array}{l}\text { Pout } \\
(\mathbb{B a})\end{array}$ & $\begin{array}{l}\text { OIP3 } \\
(\mathrm{dBn})\end{array}$ & $\begin{array}{l}\text { Sire } \\
\left(\operatorname{ma}^{\circ}\right)\end{array}$ & Ref \\
\hline 0. 35un Chos & $\begin{array}{c}\text { Distributed } \\
\text { active-tr unsformer }\end{array}$ & 2 & $\begin{array}{l}2.4 \text { (sinele } \\
\text { frequency) }\end{array}$ & 41 & 33 & - & $1.3 \times 2$ & 16 \\
\hline $0.35 \mathrm{~m}$ CMOS & $\begin{array}{c}\text { Single st age } \\
\text { sctive-tr unsfomer }\end{array}$ & 2.5 & $\begin{array}{l}2.4 \text { (single } \\
\text { frequency) }\end{array}$ & 31 & 33.4 & & $1.3 \times 2$ & 17 \\
\hline $\begin{array}{l}\text { ISUC 0.35um SiGe } \\
\text { BiCMOS }\end{array}$ & Cascode & 3.3 & $0.6-2.4$ & 45 & 17 & - & $1 \times 0.8$ & 15 \\
\hline Hittite SiGe FBT & - & 5 & $D C-4$ & 20.2 & 18 & 32 & - & Commercial Chip \\
\hline $\begin{array}{c}\text { Hittite Dual SiGe } \\
\text { HBI }\end{array}$ & - & 8 & $D C-5$ & 15.5 & 20 & 34 & 14.9 & Commerci al Chip \\
\hline Hittite InGaP hBI & - & 8 & $\mathrm{DC} 4.5$ & 17.9 & 22 & 35 & - & Comnercial Chip \\
\hline GaX HEHT & Cascade & 30 & $\begin{array}{c}3-4 / \\
9.5-12\end{array}$ & 28 & 37.5 & - & $\begin{array}{l}4 \times 2.8 / \\
3.5 \times 2.8\end{array}$ & 18 \\
\hline $0.20 \mathrm{GL}$ & Distributed & 10 & $2-18$ & 9 & 31 & - & $4 \times 2$ & 19 \\
\hline $0.2 \mathrm{un} \mathrm{Gal}$ & Darlington & 15 & $0.05-12.3$ & 20 & 30 & - & $1.7 \times 1.7$ & 20 \\
\hline $0.5 \mathrm{~m} G \mathrm{~d}$ & Distributed & 15 & $0.1-5$ & 30 & 30 & - & $\begin{array}{c}2.2 \times 4.2 \\
5 \\
\end{array}$ & 21 \\
\hline $0.7 \mathrm{um} G \mathrm{H}$ & $\begin{array}{c}\text { Cascode resistive } \\
\text { feedback }\end{array}$ & 19 & $0.2-7.5$ & 15 & 31.5 & - & - & 22 \\
\hline $0.2 \mathrm{um} \mathrm{GaH}$ & Cascode Darlington & 15 & $1-4$ & 20 & 31 & 41 & $1.7 \times 1.7$ & 23 \\
\hline $0.3 \mathrm{~m}$ Gali & \begin{tabular}{|c|} 
Cascode \\
Distributed \\
\end{tabular} & 25 & $\mathrm{DC}-8$ & $3 !$ & 37.8 & 43 & $2.5 \times 1.4$ & 24 \\
\hline Gahs & $\begin{array}{l}\text { Non-uniform } \\
\text { distributed }\end{array}$ & 10 & $2-18$ & 23 & 30.5 & - & $3.6 \times 1.7$ & 25 \\
\hline 0. 25un Gaks PYEHI & $\begin{array}{c}\text { Single staze } \\
\text { tr avelling wave } \\
\text { mplifier (SST/ } k \text { ) }\end{array}$ & - & $1-8$ & 50 & 30 & - & $\begin{array}{c}1.31 \times 2 \\
93\end{array}$ & 26 \\
\hline Hittite Gus MESPRT & Distributed & 12 & IC -6 & 16 & 29 & 41 & $\begin{array}{c}2.98 \times 2 \\
48\end{array}$ & Conmerci al Chip \\
\hline
\end{tabular}

\subsection{System Concept}

As introduced in Chapter 1, this work is built for multi-standard communications.

Because of the broad bandwidth of this work, multiple communication standards can be delivered with only one simple device instead of multiple narrowband solution chips; this means a smaller device size and lower total cost. Furthermore, we need a 
switchable matching network for different applications, as shown in Figure 2.6. The block of this work is marked with red rectangle.

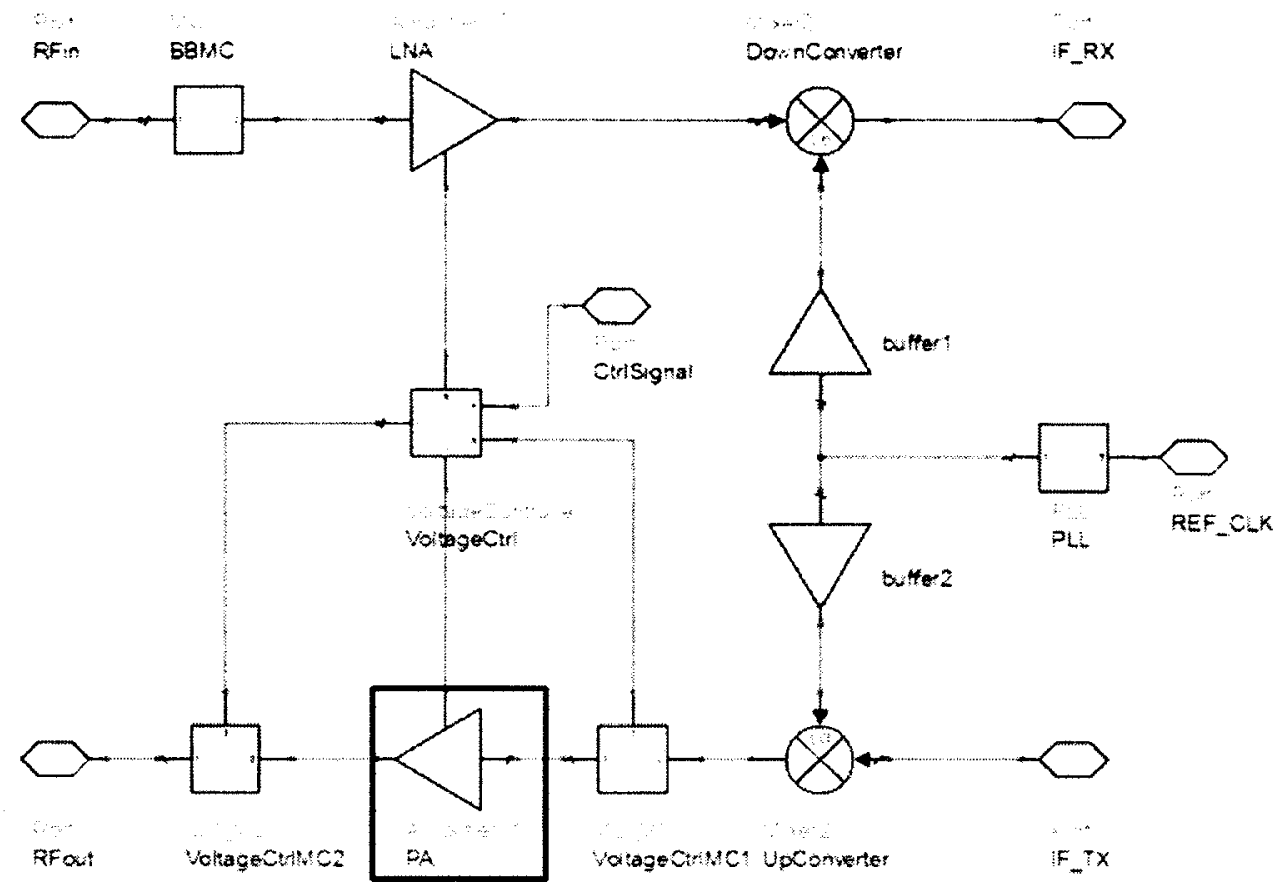

Figure 2.6 System View 


\section{Chapter 3: Principles of Distributed Power Amplifier}

In this chapter, we will focus on the investigation of the popular distributed structure used for ultra-broadband or multi-octave power amplifier design. 3 different types of distributed topologies, i.e. conventional Distributed Power Amplifier (DPA), and Asymmetric Distributed Power Amplifier (ADPA), will be demonstrated in their operating principles with design equations. Then, the advantages and disadvantages in the performance of these three will be presented in the following sections. Finally, some guidance will be concluded for our design in Chapter 4 .

\subsection{Conventional Distributed Power Amplifier (DPA)}

Based on the well-researched and established traveling wave concept, distributed (or traveling wave) amplifiers are immensely popular in the design of power amplifiers operating across ultra-broad bandwidths or multi-octave. In a conventional distributed amplifier, the input and output lines are two transmission lines with a number of transistors connected between them, as shown in Figure 3.1.

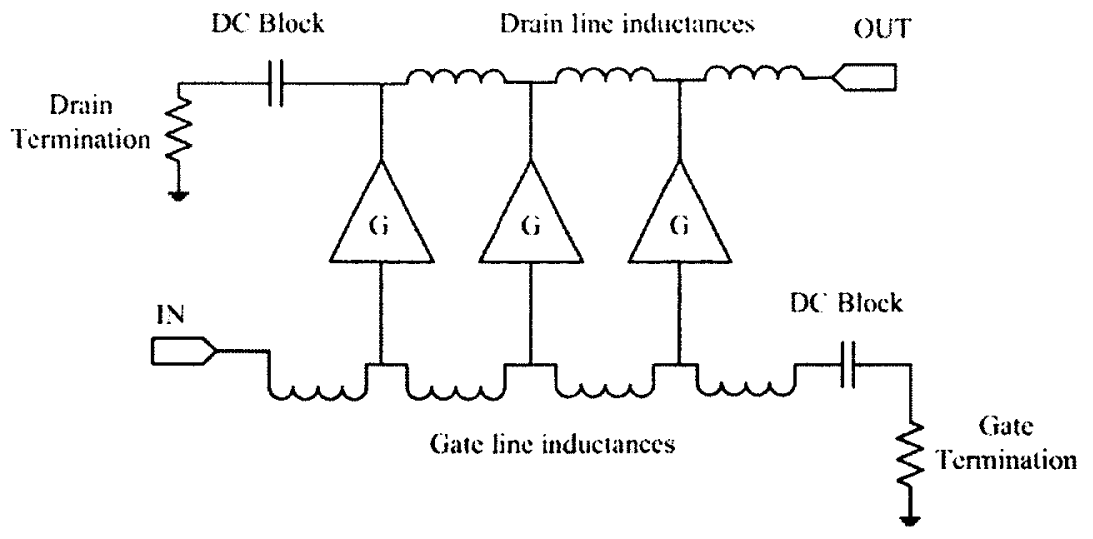

Figure 3.1. Distributed amplifier schematic [1]. 
The problem of achieving a broadband match to the transistor input and output impedances is overcome by incorporating the input and output capacitances of a number of transistors into artificial transmission-line structures [1]. The lossy input transmission line on the transistors' gate side absorbs the input capacitance, and simultaneously, the loss output transmission line on the transistors' drain side incorporates the output capacitance. The input and output capacitances are mainly supplied by transistors. As the signal travels down the gate transmission line, each transistor amplifies traveling voltage wave and transfers the signal to the drain transmission line through its transconductance. The output signals of each transistor are added in the forward direction as they arrive at the output node. At the same time, the waves traveling in the reverse direction are not in phase, and any un-canceled signal is absorbed by the drain line termination, or dummy end. In that, the reflection problem on the drain line is solved by the dummy termination. The same theory can be used in building gate-line dummy termination. In an ideal condition, adding more stages can increase gain. Unfortunately, the transmission lines, which we used as drain lines and gate lines, are heavily loaded by the transistor's resistance, and the transmission lines are actually lossy; therefore, the number of active device sections cannot be added indefinitely. This is because the attenuation of the transmission lines will offset the gain obtained by adding an additional transistor device.

In order to deliver maximum output power, it is essential that the drain currents generated by each transistor stage are added in phase as the signal traveling along the drain line toward the output terminal. Based on the above conclusion, in order to use 
the amplifier efficiently, the phase shift between transistor stages along the drain line must be exactly the same as the phase shift between transistor stages along the gate line grid. This is achieved by carefully sizing the lengths and widths of the gate and drain transmission lines in order to obtain the correct propagation constants for constructive phasing of the output signals.

Here, the concept is presented in a simple way. The phase shift of each stage is controlled by the artificial line's capacitance and inductance, essentially. The transistor is considered to be free of loss and has a gate capacitance $\mathrm{C}_{\mathrm{gs}}$ and a drain current generator $I_{n}$ with associated drain capacitance $C_{d s}$ as shown in Figure 3.2. After investigating the transistor small signal model of Figure 3.2, two capacitances are of interest in the equivalent circuit building. One is the drain-to-source capacitance $\mathrm{C}_{\mathrm{ds}}$, which is shunt-connected with the drain line forming a T-section low pass filter on the drain side; the other one is the gate-to-source capacitance $\mathrm{C}_{\mathrm{gs}}$, which is shunt-connected with the gate line forming a T-section low pass filter on the gate side. Then, the whole circuit could be represented as a constant-K low-pass filter ladder network as shown in Figure 3.3 based on constant-K model as shown in Figure 3.4. Other parasitic elements in the more general equivalent circuit are neglected to simplify the analysis.

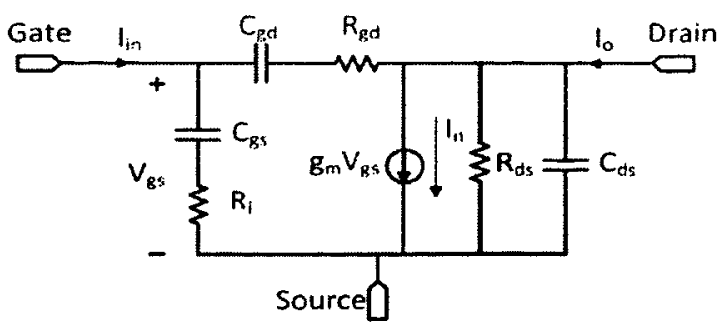

Figure 3.2. Small-signal model of the transistor [1]. 


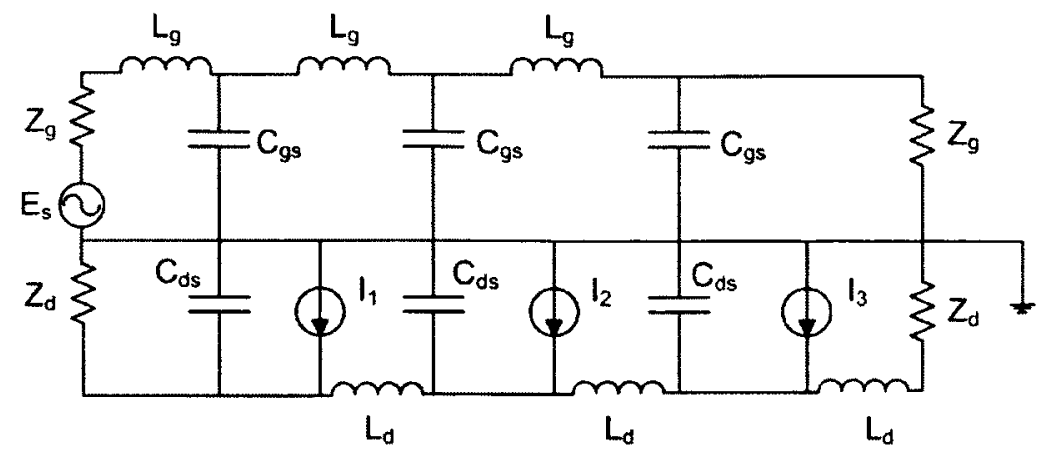

Figure 3.3. Equivalent Constant-K low-pass filter ladder network [1].

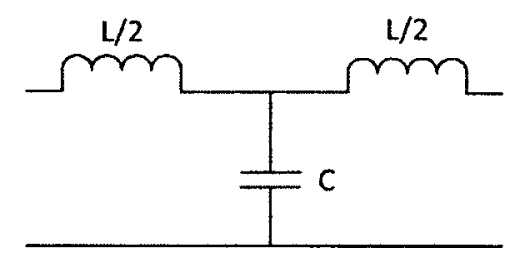

Figure 3.4. Constant-K section.

Similarly, the transmission lines, which form the input gate line inductance $\mathrm{L}_{\mathrm{g}}$ and the output drain line inductance $\mathrm{L}_{\mathrm{d}}$, are considered to be loss free lumped components. Then the gate and drain lines are terminated in their characteristic impedances $Z_{\mathrm{g}}$ and $Z_{d}$, respectively. According to low-pass filter theory, for each stage, the phase shift and cut-off frequency can be simply derived as follows [1]:

Phase Shift

$$
\varphi=-\arctan (2 \pi \mathrm{fZC})
$$

Cut-off frequency

$$
\mathrm{f}_{\mathrm{c}}=1 / 2 \pi \mathrm{ZC}
$$

where $Z$ represents the transmission line characteristic impedance $Z_{g}$ and $Z_{d}$ for different gate and drain section.

Using the above conclusion to obtain maximum output power, we need to match the phase shifts of the gate line and the drain line in order to add the signals at the output 
termination, i.e. for each stage $\varphi_{\mathrm{g}}=\varphi_{\mathrm{d}}$. We must also consider keeping the same cut-off frequency in gate and drain lines simultaneously, which can be derived as $f_{c \_g}$ $=f_{c_{\_} d}$. These equations can be concluded as

$$
\mathrm{Z}_{\mathrm{g}} \times \mathrm{C}_{\mathrm{g}}=\mathrm{Z}_{\mathrm{d}} \times \mathrm{C}_{\mathrm{d}}
$$

According to the conclusion explained above, if the phase velocities in the gate line and drain line of each section are roughly equal, which requires $Z_{g} \times C_{g}=Z_{d} \times C_{d}$, then the travelling signal from each transistor will add in phase at the output terminal. The characteristic impedance of the transmission line on gate or drain side is given by

$$
\mathrm{Z}=\sqrt{\mathrm{L} / \mathrm{C}}
$$

And compared to the parasitic capacitance of transmission line, transistor parasitic capacitance $C_{d s}$ and $C_{g s}$ is dominant. So the cut-off frequency is given by

$$
\mathrm{f}_{\mathrm{c}}=1 /(\pi \sqrt{\mathrm{LC}})
$$

Due to the impedance matching better than $-10 \mathrm{~dB}$ cannot be achieved for frequencies above approximately $86 \%$ of $f_{C}[44]$. We can calculate the inductance of the gate line and drain line roughly for transmission line design reference.

$$
\mathrm{f}_{\mathrm{H}} \approx 86 \% \mathrm{f}_{\mathrm{C}}
$$

In all the equations we derived above, we assume the transmission lines are ideal, which means they are lossless for a signal propagating along them. Furthermore, we can derive the n-section distributed amplifier power gain based on ideal lossless constant-K line [5].

For an $\mathrm{n}$ section distributed amplifier, the total current $I d$ in the load $Z_{0}$ is given by

$$
I_{d}=\left[I_{1} e^{-j n \beta d}+I_{2} e^{-j(n-1) \beta d}+\ldots+I_{n} e^{-j \beta d}\right] / 2
$$


where $\beta_{\mathrm{d}}$ represents the phase constant of each drain line section in the forward direction.

The voltage wave travelling down the gate line due to input voltage source Es produces voltages $V_{1}, V_{2}, \ldots, V_{n}$ across each input gate capacitor,

$$
V_{1}=V_{\text {in }} e^{-i \beta g}, V_{2}=V_{\text {in }} e^{-2 j \beta g}, \ldots, V_{n}=V_{\text {in }} e^{-j n \beta g}
$$

Where $\beta \mathrm{g}$ is the phase constant of each gate line section in the forward direction.

Then,

$$
I_{1}=g_{m} V_{1}, I_{2}=g_{m} V_{2}, \ldots, I_{n}=g_{m} V_{n}
$$

In order to simplify the analysis, if we assume the gate line and drain line to be lossless, then the following is achieved,

$$
\begin{gathered}
\left|V_{1}\right|=\left|V_{2}\right|=\ldots=\left|V_{n}\right|=\left|V_{\text {in }}\right|, \\
\left|I_{1}\right|=\left|I_{2}\right|=\ldots=\left|I_{n}\right|=\left|I_{\text {in }}\right|
\end{gathered}
$$

where $V_{\text {in }}$ is equal to Es/2 for a matched line.

Re-writing the expression for $I_{d}$ yields,

$$
I_{d}=V_{i n} G_{m}\left\{e^{-j(n \beta d+\beta g)}+I_{2} e^{-j[(n-1) \beta d+2 \beta g]}+\ldots+I_{n} e^{-j(\beta d+n \beta g}\right) / 2
$$

where current is converted to voltage via drain terminal or load resistance $Z_{0}$. The power dissipated in the load $\mathrm{Z}_{\mathrm{O}}$ is therefore given by,

$$
P_{\text {out }}=\frac{1}{16} E_{s}^{2} g_{m}^{2}\left[\sin \frac{\mathrm{n}}{2}(\beta \mathrm{d}-\beta \mathrm{g}) / \sin \frac{1}{2}(\beta \mathrm{d}-\beta \mathrm{g})\right]^{2} Z_{d}
$$

The input power is given by,

$$
P_{\text {in }}=E s^{2} /(4 Z s)
$$

The forward available gain is given by

$$
G=\frac{g^{2} Z_{d} Z_{g}}{4}\left[\frac{\sin \frac{n}{2}(\beta d-\beta g)}{\sin \frac{1}{2}(\beta d-\beta g)}\right]^{2}
$$


The function can be simplified in limiting case as $\beta \mathrm{g} \rightarrow \beta \mathrm{d}$. Then a sine function can be expressed by the following series,

$$
\sin x=x-\frac{x^{3}}{3 !}+\frac{x^{5}}{5 !}-\ldots
$$

so,

$$
\lim (\beta d-\beta g) \rightarrow 0\left\{\frac{\mathrm{n}-\frac{\mathrm{n}^{3}(\beta d-\beta g)^{2}}{4 \times 3 !}+\ldots}{1-\frac{(\beta d-\beta g)^{2}}{4 \times 3 !}+\ldots}\right\}^{2}=n^{2}
$$

Finally, we derive the available power gain expression,

$$
\mathrm{G}=\left(\mathrm{n}^{2} \mathrm{~g}_{\mathrm{m}}^{2} \mathrm{Z}_{\mathrm{d}} \mathrm{Z}_{\mathrm{g}}\right) / 4
$$

In practice, transmission lines are always lossy; that is the reason why there are limitations of the number of sections in a distributed amplifier. The result of the loss in the gate line is that the successive transistors along the gate line receive a decreasing level of input waveform. After a certain number of gate line sections the input signal becomes so weak, that there is no benefit in adding more transistor stages. Meanwhile, referring to the small signal model of the transistor as shown in Figure 3.2 , the resistance $R_{i}$ of each stage absorbs some of the signal travelling along the gate line, and simultaneously, the resistance $R_{d s}$ of each transistor will consume some of the signal travelling along the drain line. The gate line attenuation can be expressed as follows [5].

$$
\mathrm{Ag}=\frac{\omega \mathrm{c}}{\omega \mathrm{g}}(\omega / \omega \mathrm{c})^{2} / \sqrt{1-\left[1-\left(\frac{\omega c}{\omega g}\right)^{2}\right]\left(\frac{\omega}{\omega \mathrm{c}}\right)^{2}}
$$

Similarly, the drain line loss is given by

$$
\mathrm{Ad}=\frac{\omega \mathrm{d}}{\omega \mathrm{c}} / \sqrt{1-\left(\frac{\omega}{\omega c}\right)^{2}}
$$

where $\omega_{c}$ corresponds to the cut-off frequency of gate line and drain line, $\omega_{g}$ and $\omega_{d}$ represent the transistor intrinsic cut-off frequencies respectively, and are given by 


$$
\begin{aligned}
& \omega_{g}=1 /\left(R_{i} C_{g s}\right) \\
& \omega_{d}=1 /\left(R_{d s} C_{d s}\right)
\end{aligned}
$$

Then the gain equation given above, which assumed lossless transmission lines can be modified follows

$$
G=\frac{1}{4} g_{m}^{2} Z_{d} Z_{g}\left[\left(\mathrm{e}^{-\mathrm{nA} g}-\mathrm{e}^{-\mathrm{nA} d}\right) /\left(\mathrm{A}_{g}-\mathrm{A}_{d}\right)\right]^{2}
$$

And the optimum number of sections is given by

$$
N_{\text {opt }}=\ln \left(A_{g} / A_{d}\right) /\left(A_{g}-A_{d}\right)
$$

In the above demonstration, it has been assumed that the gate and drain lines have equal characteristic impedance for matching and equal phase velocities for maximum output power. In the constant-K ladder network, this can only be achieved if $\mathrm{C}_{\mathrm{gs}}$ equals to $C_{d s}$. Unfortunately, in practice, the capacitance $C_{g s}$ in the transistor is much bigger than $\mathrm{C}_{\mathrm{ds}}$, so more improvement must be taken to equalize the phase shift of gate line and drain line in order to get optimum output. Then, a m-derived section is introduced on the drain line for possible higher performance, by simply adding a series inductance $\alpha \mathrm{L}_{\mathrm{d}}$ connected between the drain node of transistor and drain line, as shown in Figure 3.5. In practice, this small inductance can be achieved by implementing a small section of transmission line. And the parameter $\alpha$ is adjusted based on performance.

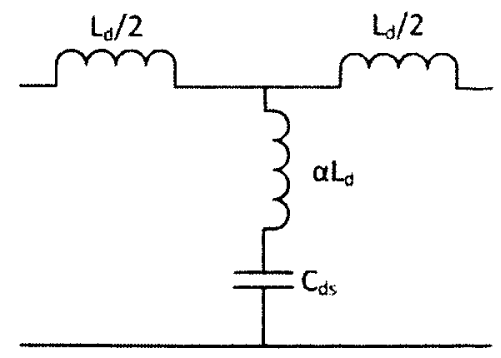

Figure 3.5. M-derived section. 
However, m-derived sections have limited bandwidths. The high capacitance $\mathrm{C}_{\mathrm{gs}}$ of the large gate width transistors leads to a reduction in the bandwidth. The capacitive-coupled distributed amplifier is introduced [5], as shown in Figure 3.6. This technology allows larger transistors to be employed without reducing the cut-off frequency of the gate line. With the capacitive coupling, the gain is reduced because of the potential divider action across $\mathrm{C}_{\mathrm{gs}}$ and the coupling capacitor. The shunted high value resistors are needed to supply the DC path for the transistor's gate. However, this imposes the restriction on the power performance, because the low input impedance is needed for maximum saturated power. Also, the shunt structure of the resistor and capacitor is difficult to implement in layout.

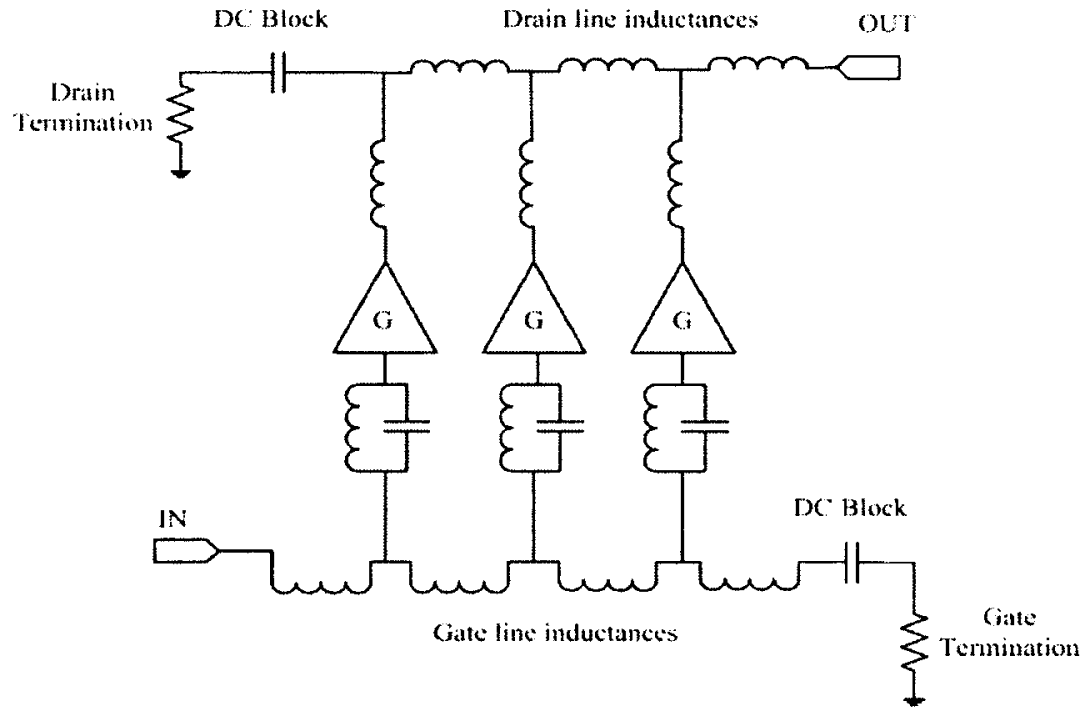

Figure 3.6. Capacitive-coupled distributed amplifier [1].

Compared to other topologies used in the implementation of broadband amplifiers such as feedback and Darlington amplifiers, the distributed topology has several advantages. A distributed amplifier provides ultra-wide bandwidth and a good input 
match, so gain modules can be easily be cascaded. Its isolation from output to input is good and this coupled with the non-resonant nature of the input and output impedance results in a stable amplifier configuration with no oscillatory tendency on module cascading. It supplies a higher power level than a single stage amplifier, as the current generated by each stage is added together at the output drain line. And because of the distributed topology, it is relatively insensitive to the tolerance of passive and active device characteristics and temperature. But the distributed amplifier is not perfect, it still has disadvantages. Phase velocity equalization is essential because the total output current is dependent on the phase coherence of the individual current generators. This may require extra capacitance to the drain line in parallel with $C_{d s}$ to compensate for the difference between $\mathrm{C}_{\mathrm{ds}}$ and $\mathrm{C}_{\mathrm{gs}}$. This adds complexity and may cause difficulties with realizing the amplifier. On the other hand, the prefect matched phase velocity between gate and drain lines will deteriorate the reverse isolation between input and output transmission lines and cause stability issues due to the feedback caused by the gate to drain parasitic capacitance $C_{g d}$. Normally, a staggering technique can be used by making the $\mathrm{f}_{\mathrm{C}}$ of the drain lines smaller than the counterpart of the gate lines [45] [46]. The amplifier's gain is limited by the gate line attenuation, which will eventually exceed the added gain obtained by increasing the number of transistor stages. Furthermore, because of using several active device stages and since all the transistors are working during amplifier operation, the total DC power consumption is high. In addition, the total layout size is large due to the transmission line section or inductor forming, as well as the large total required gate width. 


\subsection{Tapered Line Asymmetric Distributed Power Amplifier (ADPA)}

In the conventional distributed amplifier, the waveform propagating along the drain line travels in the forward and backward direction simultaneously. In the forward direction, with careful phase matching, the signal is added up at the output terminal. All the signal components travelling reversely are absorbed by the dummy drain terminal. This topology causes power loss and increases the whole chip temperature, because the current travelling reversely to the dummy drain terminal turns into thermal energy. In order to get higher power at the output terminal, the tapered drain line technique is introduced into the distributed amplifier topology, as shown in Figure 3.7. By eliminating the drain dummy termination, this technique attempts to force the total transistor output current travelling in the reverse direction along the drain line to zero, and ensure all the currents fed from the transistors are propagating in the forward direction only. And according to the load pull theory, we need to provide each transistor with its optimal load impedance for maximum output power or power added efficiency (PAE). This is accomplished by tapering the drain line impedance section by section. Without tapering transmission lines on the drain side of transistors, such as conventional distributed amplifier, each active device would see an impedance only half of the terminal impedance, which is $50 \Omega$ in most applications. By connecting the first transistor into a section of drain line in which the characteristic impedance is equal to the terminal impedance $Z_{O}$, all of the current will flow into the next stage in the forward direction. Then, if the next section line has characteristic impedance equivalent to half of $Z_{0}$, one third of the current fed from the second 
transistor will cancel the reflection coming from the first transistor at the boundary between the first and second drain line. The remaining two thirds of the current developed by the second transistor and four thirds of the current supplied by the first transistor will add and propagate along the drain line forward to the last transistor stage, as shown in Figure 3.7. The transmission line characteristic impedance of the third section should now be equal to one-third of $Z_{0}$. This will continue where each successive line section has characteristic impedance of $Z_{O} / n$, where $n$ is the number of the stages implemented.

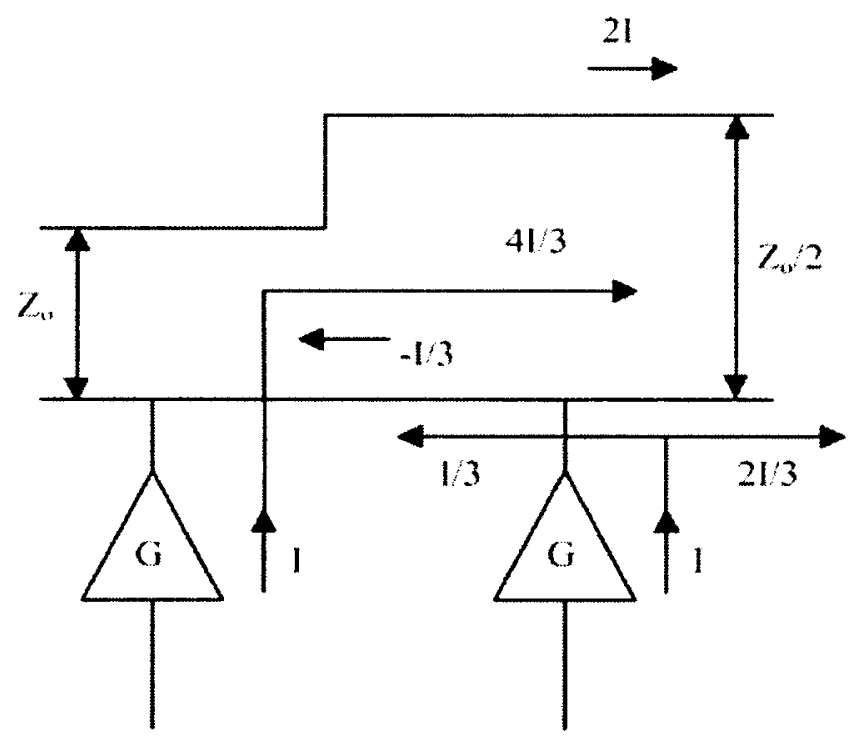

Figure 3.7. Current distribution in a correctly tapered drain circuit [1].

To illustrate the above explanation with an equivalent circuit, all the transistors can be placed as current sources in the network, and $\mathrm{R}_{\mathrm{L}}$ represents the optimum load impedance of a single stage, as shown in Figure 3.8. In the network, $R_{L}$ is a real value of the load impedance in order to simplify the design, and the termination is neglected. Then, each of the active devices will be operating under similar conditions, including 
the optimum load impedance. Hence, it implies that the last section of drain line must be scaled with a characteristic impedance of $R_{L} / n$ for an $n$ stage distributed amplifier. Similarly, the second last section should have a characteristic impedance of $R_{L} /(n-1)$ [1]. By tapering the drain line in this manner, the optimum load required for maximum output power can be synthesized. Therefore, this implies a load impedance of $R_{L}$ to each stage.

The condition of our design is not the same as introduced here. In our design, we have the last section of drain line which connects the last transistor with the output terminal. According to the theory introduced here, the characteristic impedance of last section drain line should be $Z_{\text {opt }} / n$, and terminal impedance should be $Z_{\text {opt. }}$ Then, each transistor is fed its optimal impedance and can obtain maximum output at each section. Further, each drain line needs to phase-shift match with the parallel gate line in the same direction, which guarantees that the output signal coming from each stage is added in phase; and whole PA delivers the maximum output power. This important conclusion will be used in Chapter 4 .

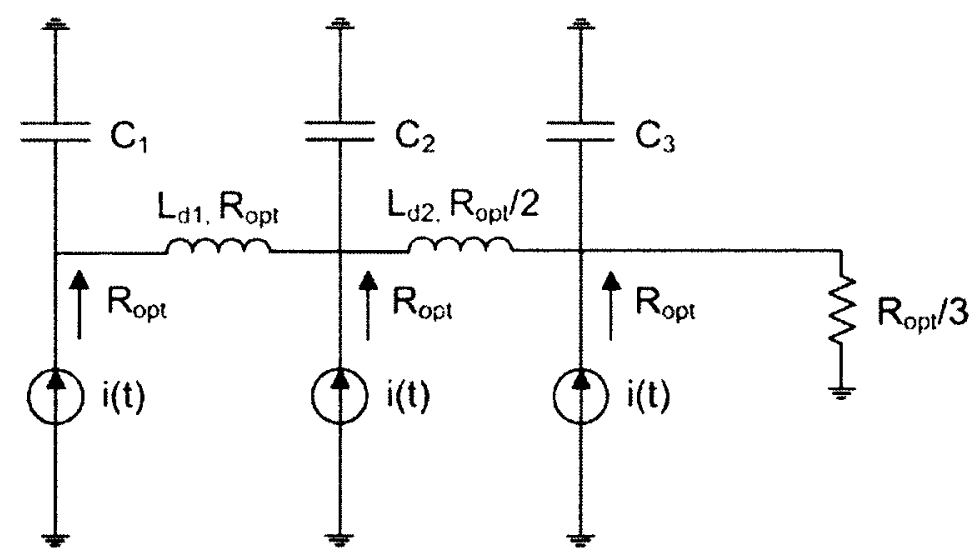

Figure 3.8. Current combining for a three-cell distributed amplifier [1]. 
We have made several assumptions in the above analysis which should be mentioned here.

First, we assumed that each active device or transistor is fed equal current. Unfortunately, due to unequal drive voltages along the lossy gate line, and the process variations, current equalization is difficult to achieve in practice. The gate and drain lines characteristics vary with frequency, which makes the tapering accurate only at a single frequency. There are also other practical considerations, such that the load impedance $R_{1} / n$ presented to the amplifier might be too low to be synthesized, and then transform to a nominal system terminal impedance of $50 \Omega$ in most applications. However, for our design in tapered line asymmetric topology, we have used a tapered drain line to make sure each transistor almost sees its optimal impedance. Or by tapering the drain line, each active device amplifies the signal to almost the maximum power it could deliver. But the tapering is not ideal, because the impedance of transmission line shifts along with the frequency. As a result, the output signal is not perfectly flat as a function of frequency.

\subsection{Stage-Scaled Distributed Power Amplifier}

Although the tapered line asymmetric distributed power amplifier has improved PAE and output power, by looking into the topology, we find that not all the transistors are working efficiently. This is because all active devices have the same size, and are biased at the same voltage in the above topology, which means that some transistors have been fully driven to work successfully, but the others are not. DC power is 
wasted in those transistors which are not fully driven; the current draw from the DC power source is not used properly. As a result of this defect, the value of the PAE as well as the efficiency we get from a tapered line asymmetric distributed power amplifier as introduced above is not the maximum value that can be achieved. In order to improve the amplifiers' efficiency as well as the power added efficiency, stage-scale technology is introduced into conventional distributed amplifier design.

Before presenting the stage-scale topology, we first review the conventional distributed amplifier to analyze the reason of total DC power loss. In the former chapter, we concluded that the current led from each active device should be added in phase in order to deliver maximum power to the output load. There are additional notes on this statement. Because of this distributed synthesis, the largest voltage swing only occurs at the last stage, and as a result, the active device in the last section is the only one that experiences maximum allowed voltage swing when output power saturates, while the other stages have sub-optimal voltage swings. As a result, the transistors have not experienced maximum allowed voltage swings and are not driven efficiently, which is the root cause of the DC power wastage in this condition. Therefore, if the voltage swing of the preceding sections can be increased, less current swing is needed to deliver the same power. Of course, DC power and bias current consumption can be done by directly adjusting the DC supply voltages and gate bias voltages of each transistor very carefully, although keeping each stage the same size. Unfortunately, this will complicate the amplifier physical layout and total cost, since each DC supply and bias requires a separate path and pad which will increase layout 
area. Each pad also requires an RF choke. These components will increase the total cost of the circuit.

To realize this concept, the stage-scale distributed amplifier topology is introduced. The drain line characteristic impedance and the active device size are scaled simultaneously from section to section to reduce the total DC power consumption without affecting the $\mathrm{AC}$ power delivered to the load [6]. In the topology shown as Figure 3.9 , the drain line characteristic impedance needs to scale up from the last section to the first section while the transistor size needs to scale down in the same direction to optimize the PAE. In order to reveal the crucial size scaling required, we assume the active device size scales by a factor of $\mathrm{K}$ in the reverse direction which traveling from output terminal to input, while the drain line impedances scales by factor of $Z$, in the same direction. For an n-section stage-scale distributed amplifier, in the scale direction, $\mathrm{i}_{\mathrm{D}}$ is scaled $\mathrm{K}$ and the impedance $\mathrm{Z}$ is scaled for each section, then the peak power generated by the $i_{t h}$ section is $\left(K^{2} Z\right)^{n-i} P_{\max }$, where $P_{\max }$ is the peak power delivered by each gain cell in a distributed amplifier, and $\mathbf{n}$ is the total number of the stages. In order to maintain the same maximum power, $\mathrm{K}^{2} \mathrm{Z}$ needs to be kept unity. Normally, $\mathrm{K}$ is chosen less than unity but close to " 1 " such as 0.96 in [6]. This gives us a starting point of how to scale the drain line impedance and the transistor size simultaneously without altering the total power delivered. However, the analysis above neglects reflections and transmission line losses when drain line scaling dominants.

Unfortunately, in a practical implementation of the amplifier, the modeling kit 
supplied by NRC is limited, which means the transistor size can only be adjusted in redefined steps making it impossible to compensate the impedance shift in drain line perfectly, reducing the ability to achieve higher and constant output power than tapered line technology.

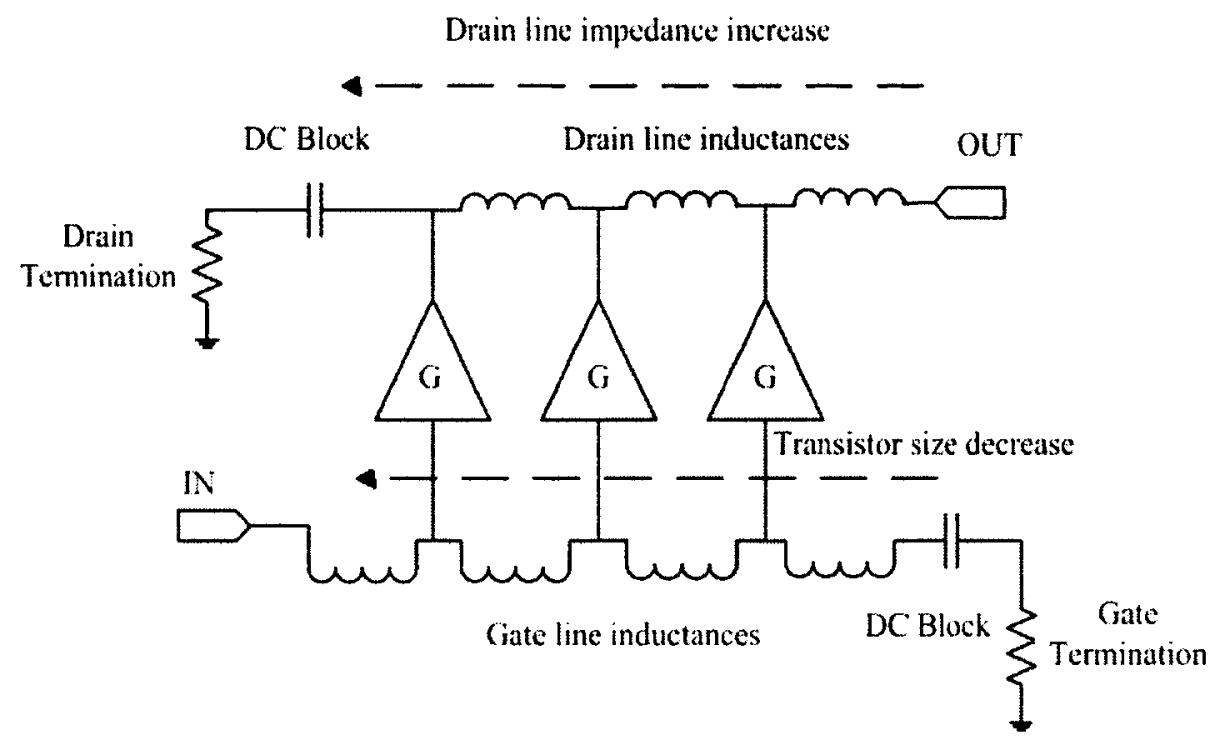

Figure 3.9. Stage-scaled distributed power amplifier [6]. 


\section{Chapter 4: Design and Experimental Evaluation}

Based on the analyses in the preview chapter, we have established so many basic guidelines for the design of the amplifier in this project. Next, design specifications of the amplifier are shown in Table 4.1. In this chapter, we begin with the selection of the transistor's steady-state operating point and the size, followed by the detailed experimental setup along with measurements and evaluation of the results. Finally, the design of the tapered line asymmetric distributed power amplifier (ADPA), improved tapered line ADPA, and also the stage-scale ADPA (SSADPA) will be introduced in this chapter.

Table 4.1. Design Specification.

\begin{tabular}{|c|c|c|c|}
\hline \multicolumn{2}{|c|}{ Technology } & \multicolumn{2}{c|}{$0.5 \mu \mathrm{m}$ GaN (CPFC) } \\
\hline Pout & $\geq 30 \mathrm{dBm}$ & PAE & $\geq 20 \%$ \\
\hline BW & $1 \mathrm{GHz}-6 \mathrm{GHz}$ & Gain & $\geq 10 \mathrm{~dB}$ \\
\hline Zo & 50 & Size & $\leq 2 \mathrm{~mm} \times 2 \mathrm{~mm}$ \\
\hline
\end{tabular}

\subsection{Design of Proposed GaN ADPA}

In this section, we will first present the single HFET characteristics, including static operating point (or $\mathrm{Q}$ point) selection, transistor size decision, and optimal output resistance simulation. Then the design procedure and all the simulation data of the design are reviewed. Finally, some conclusions are given based on the comparison of the designs.

\subsubsection{Single Transistor Characteristics Investigation}

Before we start the power amplifier design, we need to investigate the characteristics 
of the transistor which use CPFC GaN500 technology. Then based on the investigation, we decide the steady-stage operating point and the size of the transistor for our power amplifier's application.

For the purpose of applying the final design to common RF transmitter systems, we need to limit the DC supply voltage to $20 \mathrm{~V}$. Currently, the reported narrow-band $\mathrm{GaAs} / \mathrm{GaN}$ devices are commonly using $15-20 \mathrm{~V}$ DC supply, so we assume the device will be biased at $15 \mathrm{~V} \mathrm{DC}$ voltage in this work. Performing a DC simulation using the available GaN500 model in ADS, we obtain the I-V curve as shown in Figure 4.1 of an $8 \times 50 \mu \mathrm{m}$ transistor. The drain current is seen to vary between approximately $100 \mathrm{~mA}$ and $400 \mathrm{~mA}$ at $\mathrm{V}_{\mathrm{ds}}=15 \mathrm{~V}$. Current collapse is observed, which is attributed to hot electron injection and trapping in the buffer layer. Also after observing the I-V curve, it is noticed that the current keeps increasing in the saturation region; this is because the model of the HFET is built with consideration of channel-length modulation, which means the current in the saturation region is not constant as in the ideal model, but with a slope $1 / r_{0}$. But actually, the current will roll off after a particular voltage, which will be reviewed in Chapter 4 . Figure 4.2 shows the $I_{D}$ versus $V_{g s}$ characteristic, indicating a threshold voltage of $-4.3 \mathrm{~V}$, which will then be used to determine the steady-state operating point. Then, according to the design datasheet supplied by National Research Council Canada (NRC), together with the simulation, the transistor shut-down voltage is approximately $-4.2 \mathrm{~V}$. So, in order to make sure the power amplifier works in deep class-AB type while having high Power Added Efficiency (PAE), we need to bias the transistor close to $-4.2 \mathrm{~V}$. On the 
other hand, if we bias the transistor closer and closer to its shut-down voltage, the DC current decreases; which means the amplifier's output power cannot meet our targeted specification. Or in other words, low gate-source bias DC voltage could increase the device size.

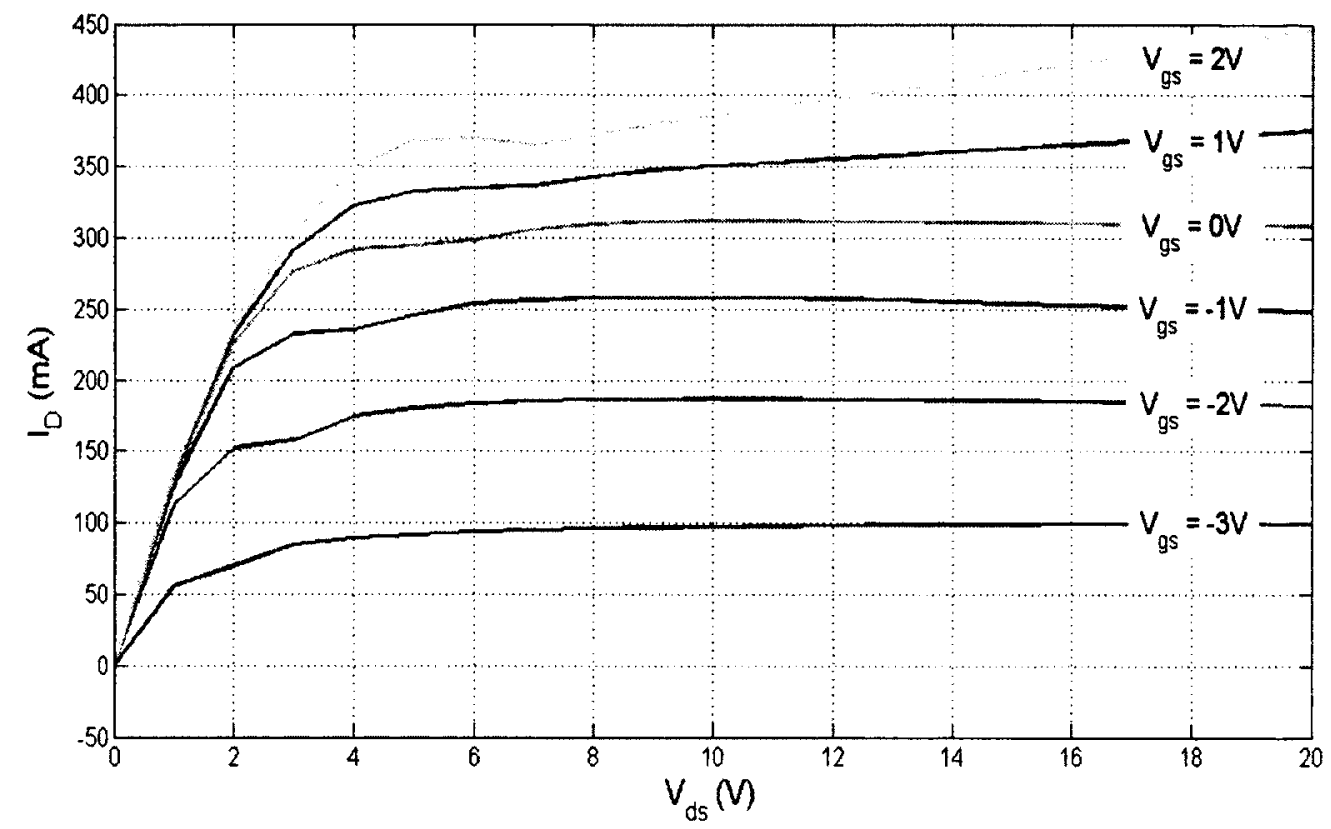

Figure 4.1.

Simulated $I_{D}$ versus $V_{d s}$ curve of $8 \times 50 \mu \mathrm{m}$ GaN500 HFET.

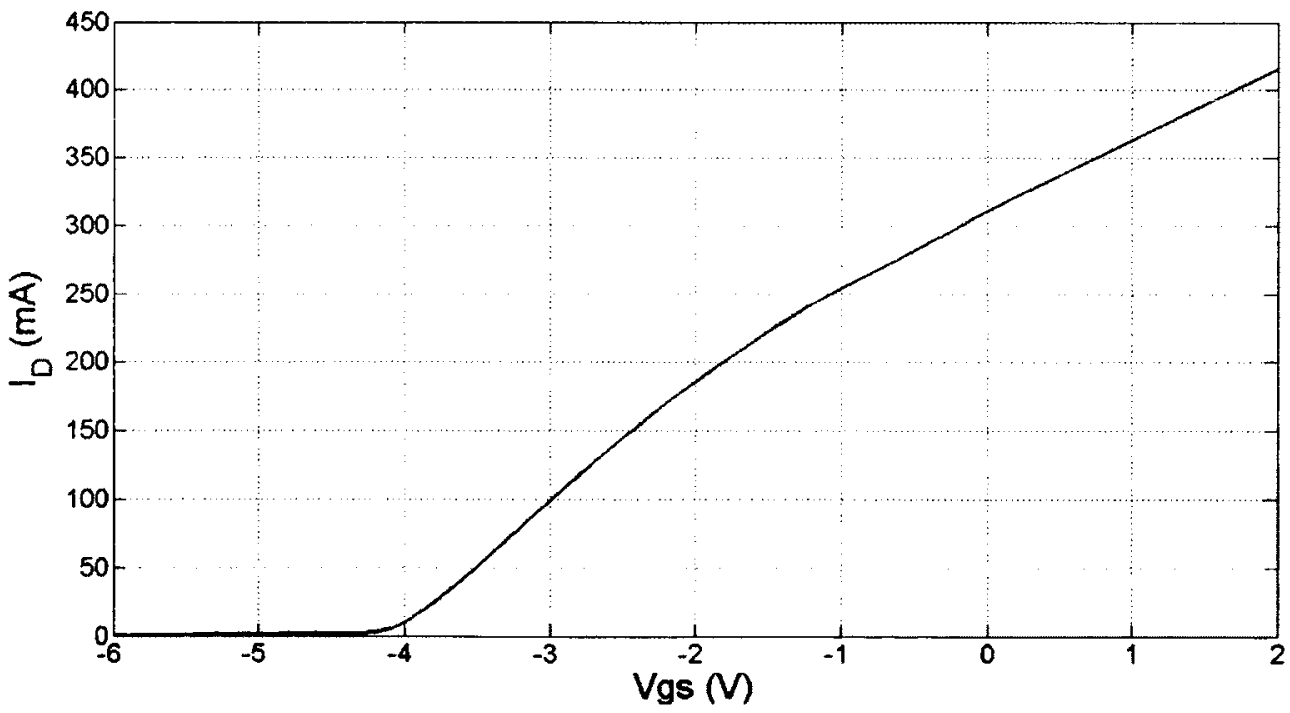

Figure 4.2.Simulated $\mathrm{I}_{\mathrm{D}}$ versus $\mathrm{V}_{\mathrm{gg}}$ curve of $8 \times 50 \mu \mathrm{m} \mathrm{GaN500} \mathrm{HFET} \mathrm{biased} \mathrm{at} 15 \mathrm{~V}$. 


\section{Operating Point and Transistor Sizing}

Based on our assumption of $10 \mathrm{~dB}$ power gain, if our amplifier delivers $1 \mathrm{~W}$ output with $50 \Omega$ input/output terminal impedance, we need have $V_{\mathrm{gs} \_ \text {peak }}$ such as $3.16 \mathrm{~V}$ given by the following calculation.

$$
\begin{gathered}
P_{\text {in }}=V_{p} I_{p} / 2=V_{p}^{2} /(2 R) \\
V_{g s_{-} \text {peak }}=\sqrt{2 P R}=\sqrt{2 \times 0.1 \times 50} \approx 3.16 \mathrm{~V}
\end{gathered}
$$

In order to support the full input swing, we need a positive $V_{g s}$ to peak up to approximately $2 \mathrm{~V}$, where the DC $\mathrm{I}_{d \text { _peak }}$ is about $410 \mathrm{~mA}$. After these conditions are met, we can draw the load line on the I-V curve to verify the Class-AB steady-state operating point (or $\mathrm{Q}$ point) chosen for this design. Class-A Q point is biased at $\mathrm{V}_{\mathrm{gs}} \approx$ $-1.5 \mathrm{~V}$, as shown in Figure 4.3. We can select the Class- $\mathrm{AB}$ operating point for $\mathrm{V}_{\mathrm{gs}}$ lower than $-1.5 \mathrm{~V}$ but higher than $-4.2 \mathrm{~V}$. Then we sweep the transistor width to find the size which can provide sufficient output power.

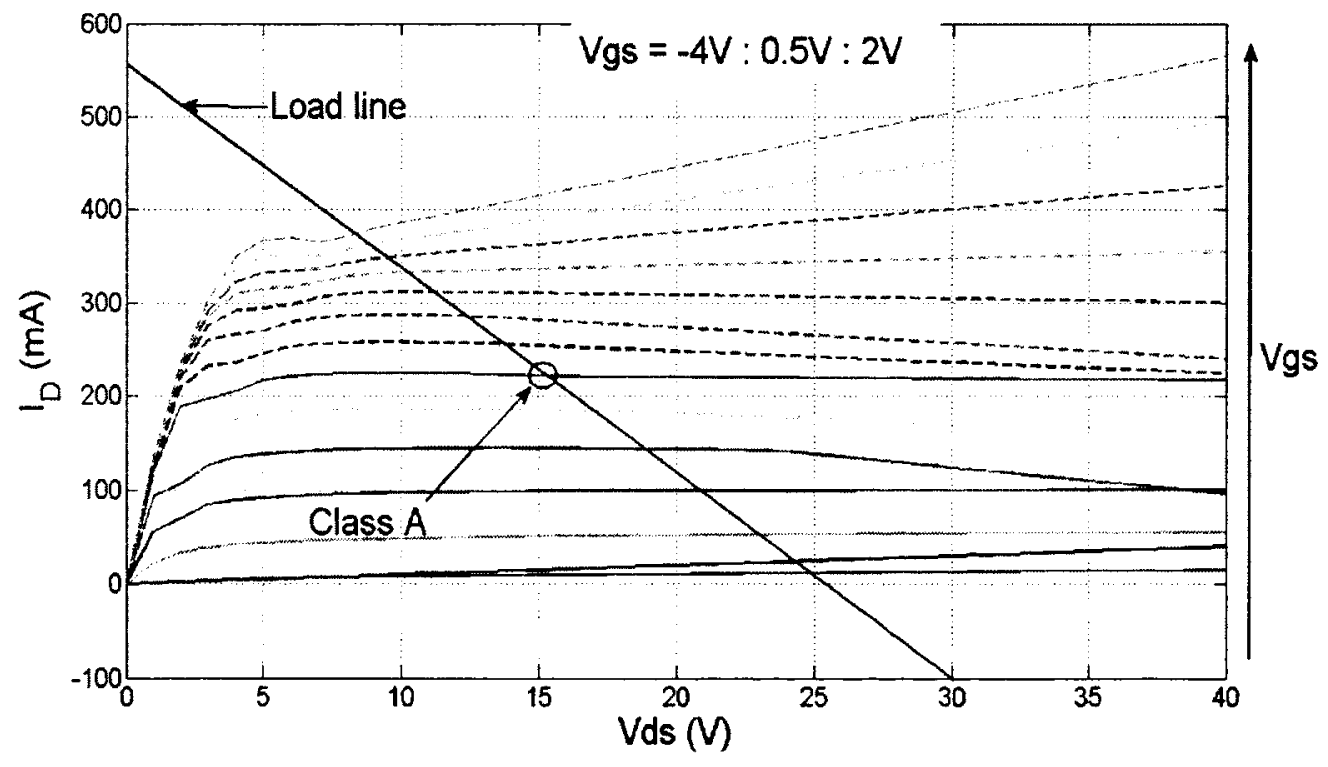

Figure 4.3. Load line of $8 \times 50 \mu \mathrm{m}$ GaN500 HFET. 
The transistor size is swept in DC simulation as shown in Figure 4.4. The transistor is biased at $\mathrm{V}_{\mathrm{ds}}=15 \mathrm{~V}, \mathrm{~V}_{\mathrm{gs}}=-2.5 \mathrm{~V}$. According to the target specification (output more than $1 \mathrm{~W}$ RF power, achieving at least $20 \%$ of PAE and $10 \mathrm{~dB}$ power gain), and using a 3-stage ADPA design (stage number will be explained in the following section), we assume $\mathrm{P}_{\text {out }}$ as $1.2 \mathrm{~W}$ for calculation simplification, i.e. each single stage transistor will deliver $0.4 \mathrm{~W}$. Then using the following equation,

$$
\begin{aligned}
\mathrm{PAE} & =\eta(1-1 / \mathrm{G}) \\
\eta & =\mathrm{P}_{\text {out }} / \mathrm{PDC}_{\mathrm{DC}}
\end{aligned}
$$

Since the gain $G=10 \mathrm{~dB}$,

$$
\begin{gathered}
\mathrm{P}_{\mathrm{DC}}=\mathrm{P}_{\text {out }} / \mathrm{\eta} \approx 0.4 / 0.2=2 \mathrm{~W}, \\
\mathrm{I}_{\mathrm{DC}}=\mathrm{P}_{\mathrm{DC}} / \mathrm{V}_{\mathrm{DC}}=2 / 15 \approx 0.13 \mathrm{~A}=130 \mathrm{~mA}
\end{gathered}
$$

With the calculation shown above, we need lightly more than $130 \mathrm{~mA}$ of DC current for each common-source transistor. Considering the smallest available size in this kit, an $8 \times 50 \mu \mathrm{m}$ transistor was selected.

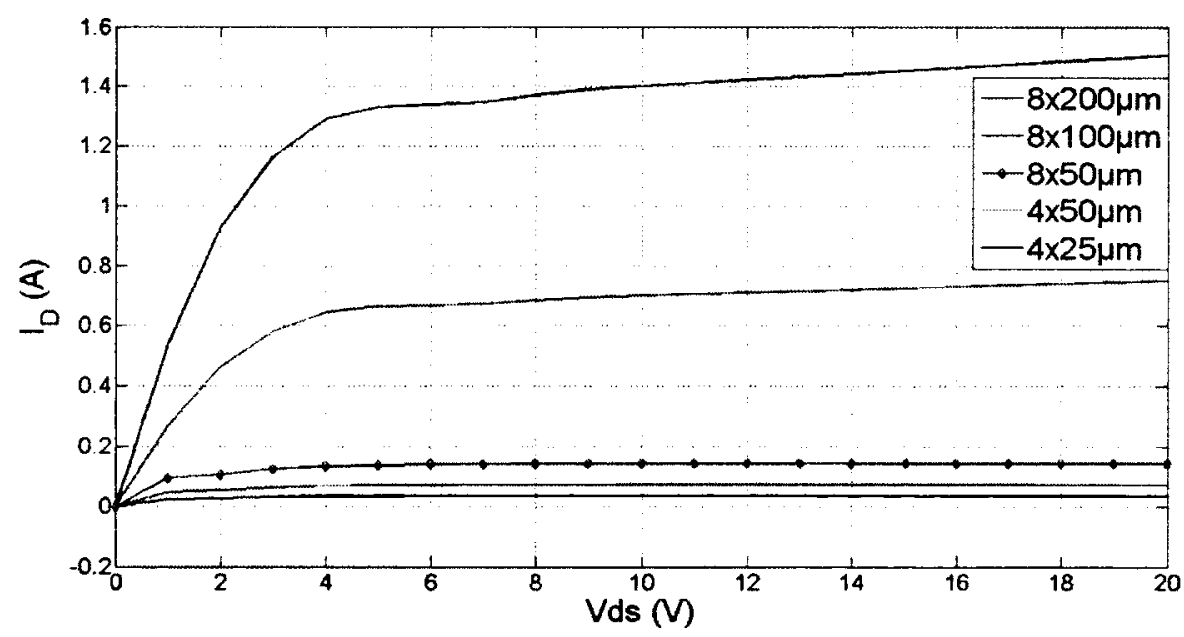

Figure 4.4. Simulated HFET I-V curves for different transistor sizes, biased at $\mathrm{V}_{\mathrm{gs}}=-2.5 \mathrm{~V}, \mathrm{~V}_{\mathrm{ds}}=15 \mathrm{~V}$ 
Next, the cut-off frequency or unity current gain frequency $f_{T}$ and the maximum oscillation frequency or unity voltage gain frequency $f_{\max }$ of the chosen transistor are checked to make sure it can support the application. The simulated $f_{T} / f_{\max }$ as a function of $I_{D}$ is shown as Figure 4.5 , in which the $8 \times 50 \mu \mathrm{m}$ transistor was biased at $V_{d s}=15 V$ while sweeping the $V_{g s}$ from $-4 V$ to $0 V$. At $V_{g s}=-2.5 V, I_{D}, f_{T}$ and $f_{\max }$ were observed approximately $144 \mathrm{~mA}, 35 \mathrm{GHz}$ and $90 \mathrm{GHz}$ respectively. With such an HFET, we can design a power amplifier which can be applied to a highest frequency of $10 \mathrm{GHz}$ without major issues. It should be noted that $f_{\mathrm{T}}$ is the parameter corresponding to the current gain into short circuit load, and $f_{\max }$ is used to evaluate the small signal power gain while the device is matched to optimum impedance. For these reasons, neither of these two boundaries $\left(f_{T}, f_{\max }\right)$ is the true indicator of maximum useful operating frequency of this power device; it will be at some frequency between the two curves.

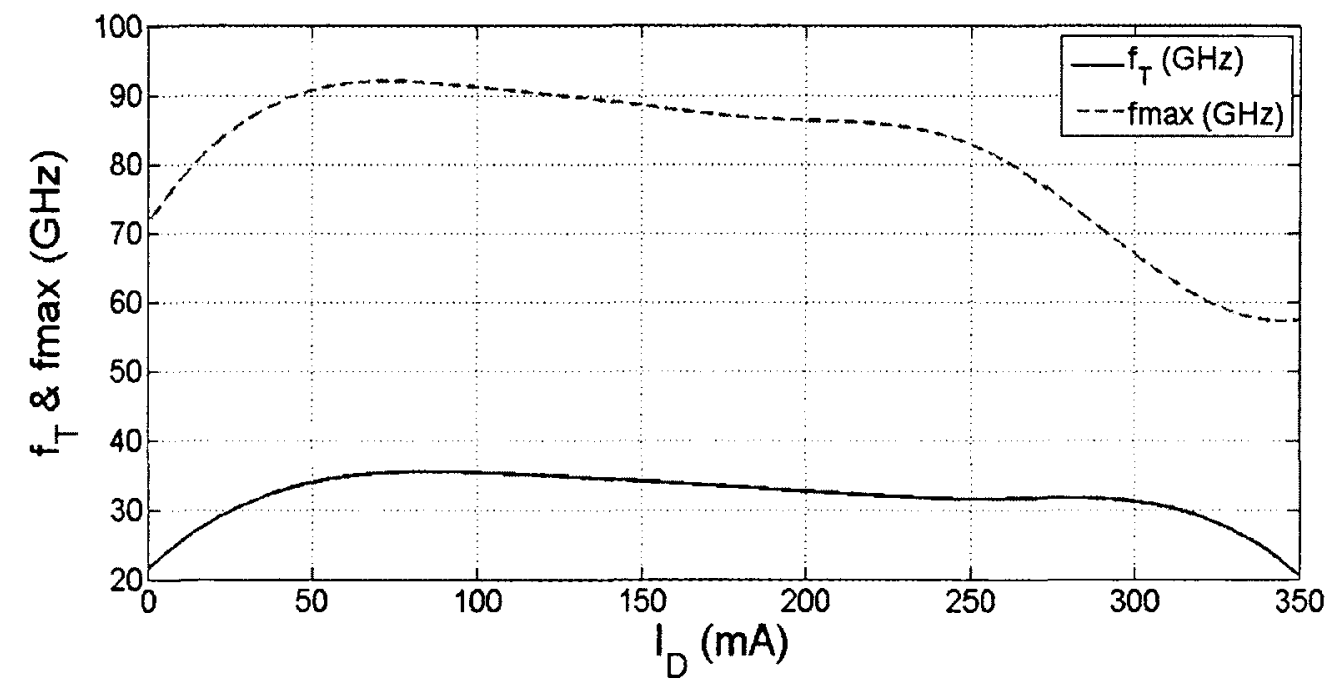

Figure 4.5.

$\mathrm{f}_{\mathrm{T}} \& \mathrm{f}_{\max }$ simulation of $8 \times 50 \mu \mathrm{m}$ HFET biased at $V_{\mathrm{DS}}=15 \mathrm{~V}$. 


\section{Transistor Simple Modeling}

Further, we modeled the $8 \times 50 \mu \mathrm{m} \mathrm{GaN500} \mathrm{HFET} \mathrm{biased} \mathrm{at} \mathrm{V}_{\mathrm{gs}}=-2.5 \mathrm{~V}, \mathrm{~V}_{\mathrm{ds}}=15$ $\mathrm{V}$ for the theoretical calculation in this section, in order to derive other important parameters such as $C_{g s}$ and $C_{d s}$. Using the flowing equations [7], we completed s-parameter simulation with fixed bias condition.

$$
\begin{gathered}
C_{d s}=\frac{\left(i m a g(Y(2,2))-\omega \times C_{g d}\right)}{\omega} \\
C_{g s}=\frac{\left(i m a g(Y(1,1))-C_{g d}\right)^{2}+(\operatorname{real}(Y(1,1)))^{2}}{\left(\operatorname{imag}(Y(1,1))-C_{g d}\right) \times \omega} \\
\mathrm{R}_{\mathrm{i}}=\frac{\operatorname{real}(\mathrm{Y}(1,1))}{\omega \times \operatorname{Cgs} \times\left(\operatorname{imag}(\mathrm{Y}(1,1))-\mathrm{C}_{g d}\right)} \\
\mathrm{R}_{\mathrm{ds}}=\frac{1}{\operatorname{real}(\mathrm{Y}(2,2))}
\end{gathered}
$$

where $\mathrm{C}_{\mathrm{gd}}=\frac{\operatorname{imag}(Y(1,2))}{\omega}, \omega=2 \times \pi \times$ frequency

It can be seen from the Figure 4.6 that for the $8 \times 50 \mu \mathrm{m}$ HFET biased at $\mathrm{V}_{\mathrm{gs}}=-2.5 \mathrm{~V}$, $\mathrm{V}_{\mathrm{ds}}=15 \mathrm{~V}, \mathrm{C}_{\mathrm{ds}}$ is stable along the frequency change up to $10 \mathrm{GHz}$, which is approximately $72 \mathrm{fF} ; \mathrm{C}_{\mathrm{gs}}$ fluctuates very rapidly when frequency changing, compared to $\mathrm{C}_{\mathrm{ds}}$, from about $473 \mathrm{fF}$ to $469 \mathrm{fF}$ in $1 \mathrm{GHz}-10 \mathrm{GHz}$ bandwidth. We assume the value of $\mathrm{C}_{\mathrm{gs}}$ is $470 \mathrm{fF}$ for hand calculations, because of its nearly constant behavior. Then from the plot of Figure 4.7, we extract $R_{i}$ and $R_{d s}$ of $4 \Omega$ and $370 \Omega$ respectively for manual calculation in chapter 4.1.3. 


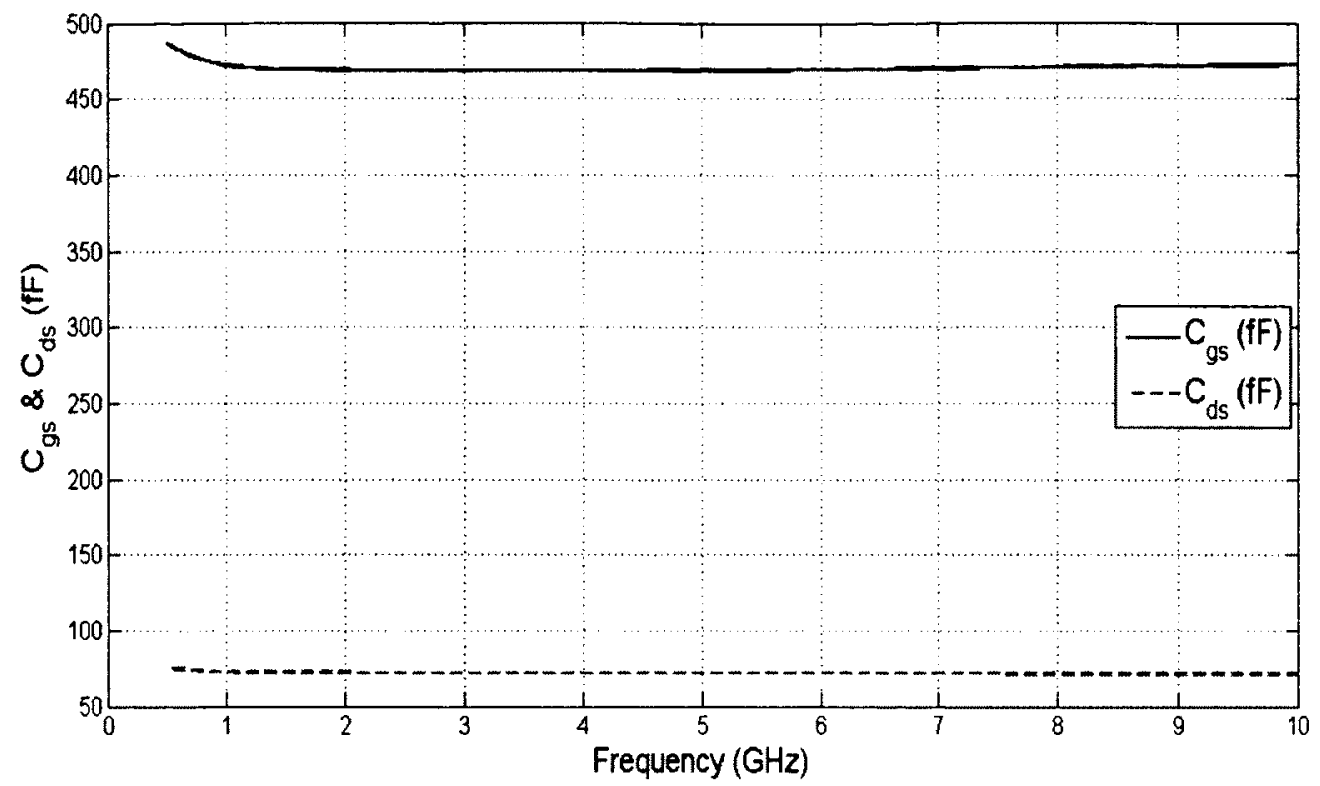

Figure 4.6. $\quad \mathrm{C}_{\mathrm{ds}}$ and $\mathrm{C}_{\mathrm{gs}}$ of $8 \times 50 \mu \mathrm{m}$ GaN500 HFET

(biased at $\mathrm{V}_{\mathrm{gs}}=-2.5 \mathrm{~V}, \mathrm{~V}_{\mathrm{ds}}=15 \mathrm{~V}$ ).

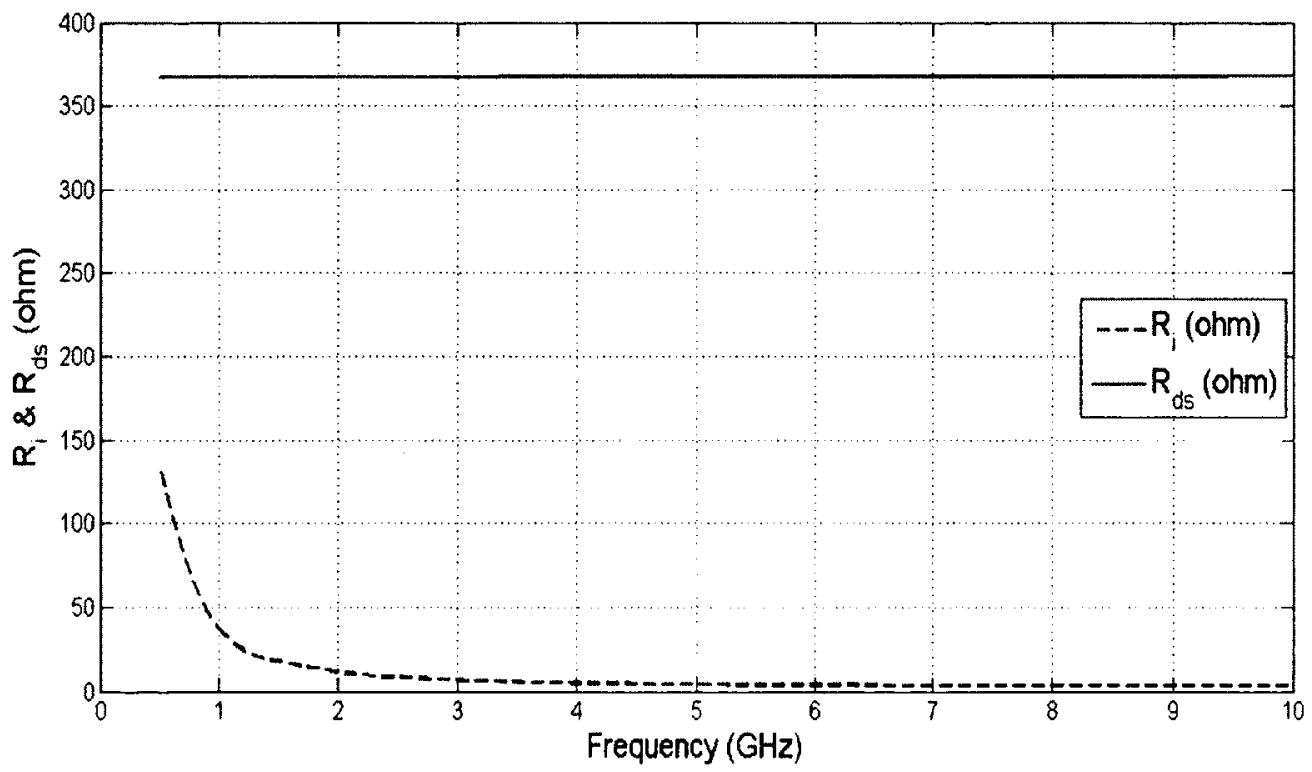

Figure 4.7. $R_{\mathrm{i}} \& \mathrm{R}_{\mathrm{ds}}$ of $8 \times 50 \mu \mathrm{m}$ GaN500 HFET biased at $\mathrm{V}_{\mathrm{gs}}=-2.5 \mathrm{~V}, \mathrm{~V}_{\mathrm{ds}}=15 \mathrm{~V}$. 


\section{$\underline{\text { Load Pull to obtain } \mathbf{R}_{\text {opt }}}$}

It is well known that for large signal transistor operation, maximum output power is obtained when optimum impedance $Z_{\mathrm{opt}}$ is presented to the output of the device. $A$ unit stage DA is formed by a common-source $8 \times 50 \mu \mathrm{m}$ HFET and investigated here. First, the stability was checked and input is matched with ideal elements at $3.8 \mathrm{GHz}$ within a $200 \mathrm{MHz}$ band as shown in Figure 4.8. Then, we performed a load pull for the $Z_{\mathrm{opt}}$ in the unit stage DA, which will be used as reference for drain line tapering in the following section. As expected, the $Z_{\mathrm{opt}}$ point should be close to the negative real axis in the smith chart for phase matching between the output voltage and current, in order to obtain maximum power. So, the optimum impedance $Z_{\text {opt }}$ can be represented by its real part $R_{\text {opt. }}$ It can be seen from the load pull results at different frequencies shown in Figure 4.9 and Figure 4.10 , that the optimal output impedance $\left(R_{o p t}\right)$ of a single HFET is approximately $13 \Omega$ if the input is perfectly matched $\left(\mathrm{S}_{11}<-30 \mathrm{~dB}\right)$, and $20 \Omega$ for $S_{11} \leq-10 \mathrm{~dB}$ which is normal in broadband matching.

In our design, a transmission line on the HFETs' drain and gate sides are mainly represented as inductors. Consider the model of an inductor, whose impedance is modeled as series resistance, $R_{S} . R_{S}=\omega L / Q$, where $\omega=2 \pi f$, and the $Q$ factors are normally between 4 and 20, depending on the losses present in the processes. After reviewing the possible impedance values of the inductors available in the GaN500 process, we assume $Q=10$ in our wideband design, and then $R_{\text {opt }}$ is approximately $20 \Omega$. 


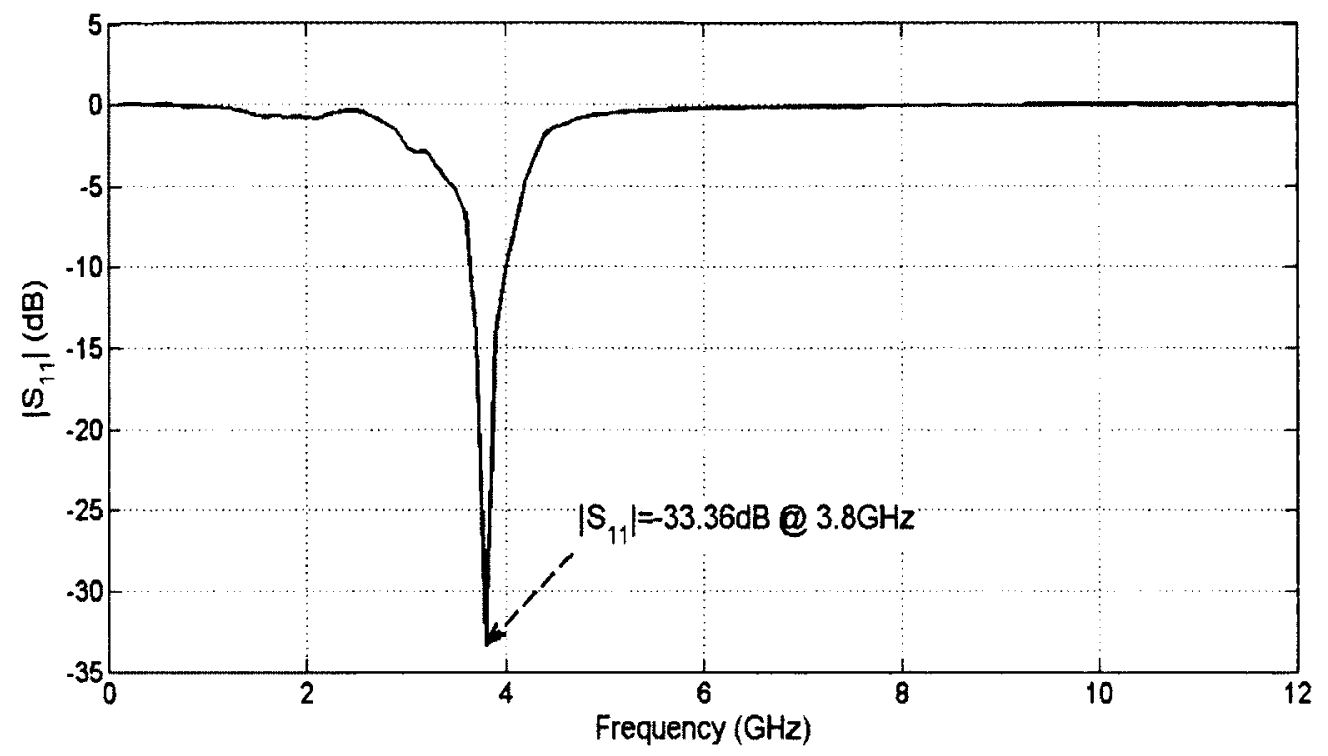

Figure 4.8. Return loss $S_{11}$ of single $8 \times 50 \mu \mathrm{m}$ HFET

(biased at $\mathrm{V}_{\mathrm{gs}}=-2.5 \mathrm{~V}, \mathrm{~V}_{\mathrm{ds}}=15 \mathrm{~V}, 3.8 \mathrm{GHz}$ ).

Peak Pout $(\mathrm{dBm})$ contour @ $3.8 \mathrm{GHz}$ with $\left|\mathrm{S}_{11}\right|<-30 \mathrm{~dB}$ Peak PAE (\%) contour @ $3.8 \mathrm{GHz}$ with $\left|\mathrm{S}_{11}\right|<30 \mathrm{~dB}$
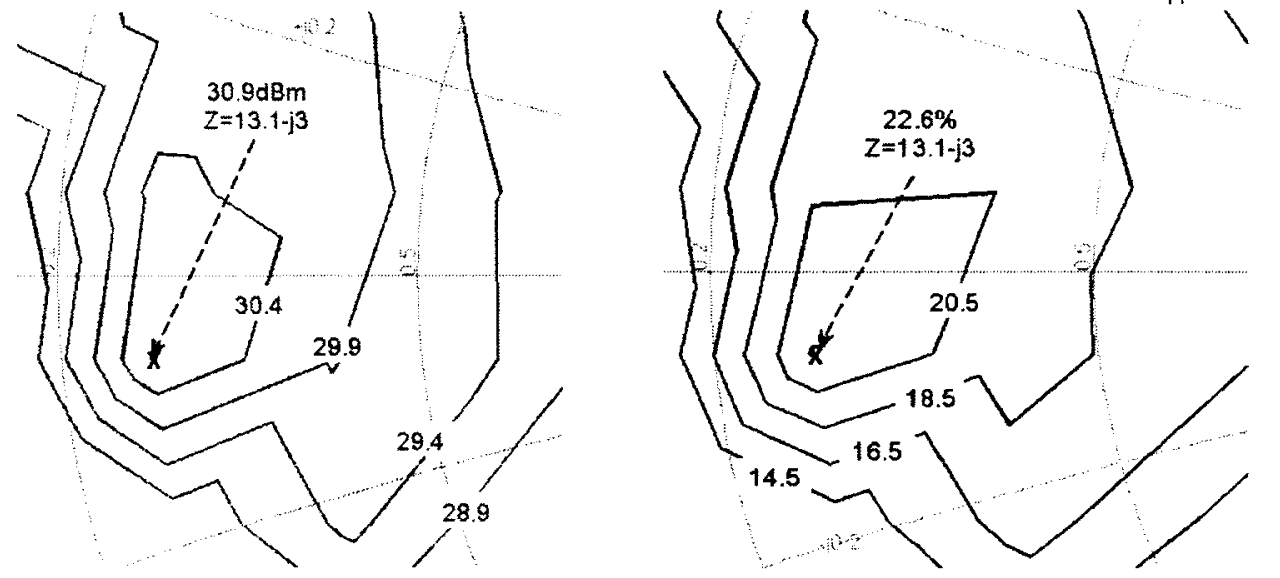

Figure 4.9 Load Pull of $8 \times 50 \mu \mathrm{m}$ HFET biased @ $\mathrm{V}_{\mathrm{gs}}=-2.5 \mathrm{~V}, \mathrm{~V}_{\mathrm{ds}}=15$

$\mathrm{V}, 3.8 \mathrm{GHz}$ with $\left|\mathrm{S}_{11}\right|<-30 \mathrm{~dB}$. 


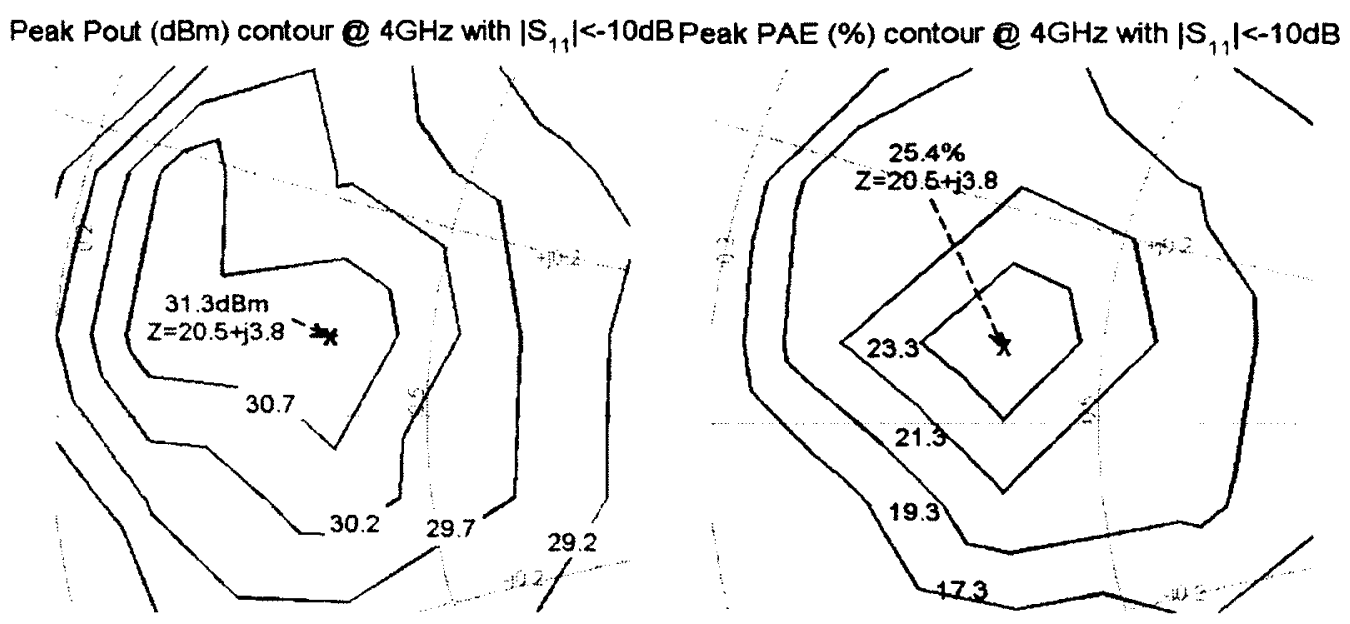

Figure 4.10. Load Pull of $8 \times 50 \mu \mathrm{m}$ HFET biased @ $\mathrm{V}_{\mathrm{gs}}=-2.5 \mathrm{~V}, \mathrm{~V}_{\mathrm{ds}}=15$

V, $4 \mathrm{GHz}$ with $\left|\mathrm{S}_{11}\right| \leq-10 \mathrm{~dB}$.

\subsubsection{Cascode Gain Stage}

In CMOS processes, such as CMOS $130 \mathrm{~nm}$ and CMOS $65 \mathrm{~nm}$, a cascode topology is used to obtain higher voltage swing or voltage gain compared to a single common source transistor structure. Then the question comes, can we use the same technology in the GaN500 process? Investigation is introduced here supported by simulation results, and we also did some analysis in theory.

We use 20V DC voltage as supply for the cascode circuit (all transistors have $8 \times 50$ $\mu \mathrm{m}$ width), and the common-source HFET should be biased at $\mathrm{V}_{\mathrm{gs}}=-2.5 \mathrm{~V}, \mathrm{~V}_{\mathrm{ds}}=15$ V. It can be seen from the simulation result as shown in Figure 4.11 , the gate of the cascode HFET should be biased at $12.6 \mathrm{~V}$. 


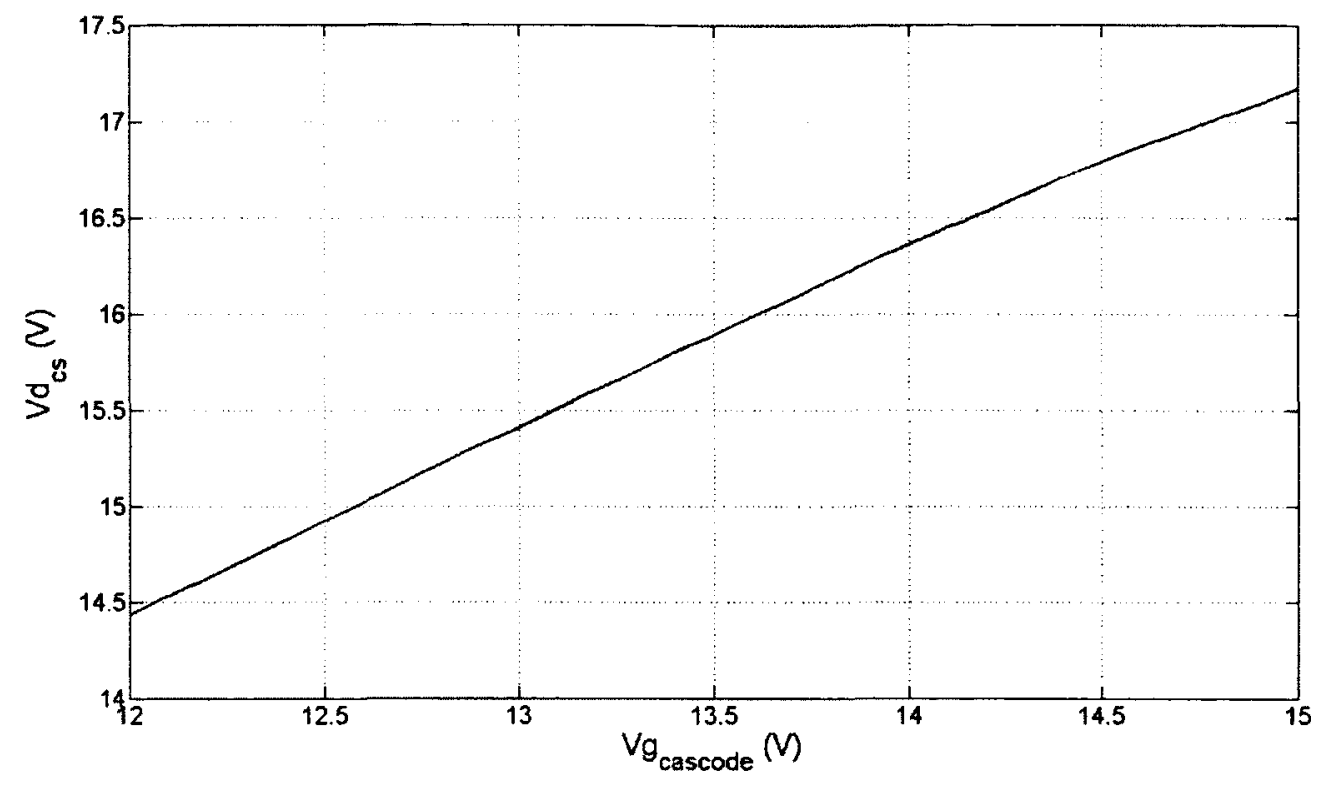

Figure 4.11. DC bias cascode stage.

By comparing the maximum gain and $S_{21}$ between single HFET amplifier and cascode topology as shown in Figure 4.12 and Figure 4.13, it can be seen that cascode stage has much more voltage gain than single common-source structure. In the simulation, ideal RF chocks and DC blocks were used, and a $Z_{22}$ of $77-\mathrm{j} 384 \Omega$ was observed in cascode PA at $2 \mathrm{GHz}$. This agrees with the theory, because cascode transistor contributes by increasing its load impedance.

All the parameters are evaluated by using Large Signal S-Parameter with $20 \mathrm{dBm}$ RF power. Based on the results we have obtained, it seems that using cascode topology in Asymmetric Distributed Power Amplifier is possible and much more powerful than the common-source stage. But we still need evidence that can prove the worth of complexity trading for better gain performance in ADPA. 


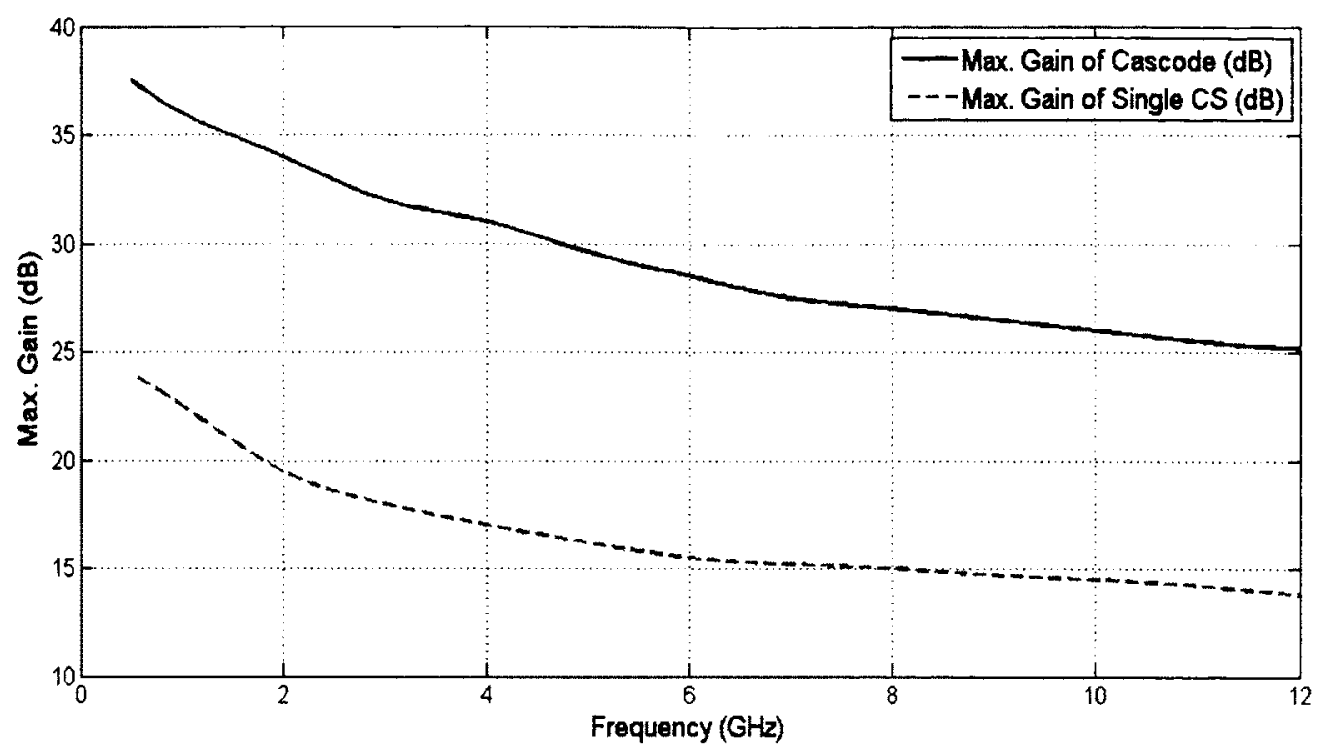

Figure 4.12. Maximum voltage gain comparison between cascode and single common-source in which common-source HFET is biased at $\mathrm{V}_{\mathrm{gs}}=-2.5 \mathrm{~V}, \mathrm{~V}_{\mathrm{ds}}=15 \mathrm{~V}$.

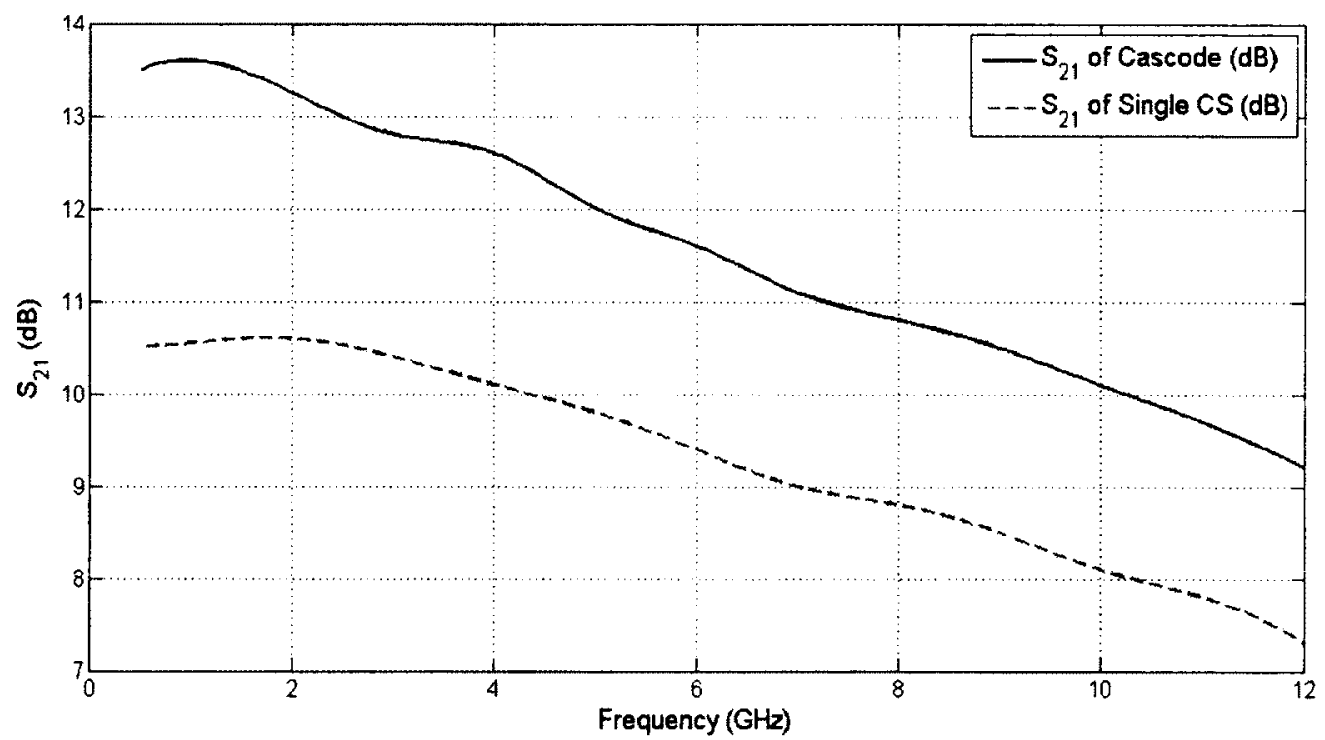

Figure 4.13. $\mathrm{S}_{21}$ comparison between cascode and single common-source in which common-source HFET is biased at $\mathrm{V}_{\mathrm{gs}}=-2.5 \mathrm{~V}, \mathrm{~V}_{\mathrm{ds}}=15 \mathrm{~V}$. 


\subsubsection{First Tapered Line Asymmetric Distributed Power Amplifier}

For the first design, we chose to use a single common-source HFET to form the unit stage of the asymmetric distributed power amplifier (ADPA), in order to focus on the analysis of the tapered line ADPA topology. The basic ADPA circuit schematic is given in Figure 4.14.

In the previous analysis of the single transistor, we have already fixed the HFET width as $8 \times 50 \mu \mathrm{m}$ and biased at $V_{\mathrm{gs}}=-2.5 \mathrm{~V}, \mathrm{~V}_{\mathrm{ds}}=15 \mathrm{~V}$, which corresponds to $\mathrm{I}_{\mathrm{D}}=$ $144 \mathrm{~mA}$, according to the design specifications. Now with all the available information, we first need to calculate gate and drain line inductance, and then determine the number of the stages of the ADPA, and finally optimized the tapering of the drain line based on simulation results and optimization. Simultaneously, we must take into account the DC current handling capability of all transistor interconnects especially on the drain side. Referring to Figure 4.14 , the DC current through $\mathrm{L}_{\mathrm{d} 1}, \mathrm{~L}_{\mathrm{d} 2}$ and $\mathrm{L}_{\mathrm{d} 3}$ is $144 \mathrm{~mA}, 288 \mathrm{~mA}$ and $432 \mathrm{~mA}$ respectively.

\section{Calculation}

Normally an artificial transmission line can be used up to approximately $86 \%$ of its cut-off frequency due to matching issues [44]. According to our application requirement, we assume the highest frequency is $\mathrm{f}_{\mathrm{H}}=8 \mathrm{GHz}$, well above the $6 \mathrm{GHz}$ operational upper frequency. Then $f_{c}=9.3 \mathrm{GHz}$, which means $\omega_{\mathrm{c}}=2 \pi \mathrm{f}_{\mathrm{c}}=58.4 \mathrm{Grad} / \mathrm{s}$. In theory, the characteristic impedance of transmission line is given by:

$$
Z_{o}=\sqrt{L / C}
$$


and its cut-off frequency is given by:

$$
f_{C}=1 /(\pi \sqrt{L C})
$$

Because the parasitic capacitance of HFET is considerably higher than the one of transmission line, and $C_{d s}$ or $C g s$ is parallel with $C_{T L}$, the cut-off frequency of the transmission line is mainly determined by $C_{d s}$ or $C_{g s}$ and the inductance of the drain/gate line. The following equation can be derived based on conventional distributed amplifier single section and using a constant-K ladder model,

$$
\omega_{C_{-} g}=2 / \sqrt{L_{g} C_{g s}}, \quad \omega_{C_{-} d}=2 / \sqrt{L_{d} C_{d s}}
$$

where $L_{g}$ and $L_{d}$ represents gate and drain line impedance respectively. With the simulated results of Section 4.1.1, each $8 \times 50 \mu \mathrm{m}$, each single transistor has $\mathrm{C}_{\mathrm{gs}} \approx$ $470 \mathrm{fF}, \mathrm{C}_{\mathrm{ds}} \approx 72 \mathrm{fF}$ in the $0.5 \mathrm{GHz}-10 \mathrm{GHz}$ bandwidth, and every drain/gate line section, except those next to the input and output ports, are connected to $C_{d s}$ and $C_{g s}$ on both sides; then we can calculate an $\mathrm{L}_{\mathrm{g}} \approx 1.07 \mathrm{nH}$. We can directly use $\mathrm{L}_{\mathrm{g}}=1.07$ $\mathrm{nH}$ as the inductance of the gate line in our asymmetric distributed power amplifier, but the drain line or $L_{d}$ needs to be tapered for each section; the $L_{d}$ value will guarantee the cut-off frequency of the drain line will be higher than $10 \mathrm{GHz}$.

Furthermore, in order to maximize the output power, phase synchronization for each stage has to be ensured as follows,

$$
\theta_{g}=\beta_{g} l_{g}=\theta_{d}=\beta_{d} l_{d}
$$

where $\beta=\omega \sqrt{\mathrm{LC}}$, and $\lg$ and $\mathrm{ld}$ are the length of the gate/drain lines.

Then Eq. 4.12 can be re-written as,

$$
\omega \sqrt{L_{g} C_{g s}} \times l_{g}=\omega \sqrt{L_{d} C_{d s}} \times l_{d}
$$




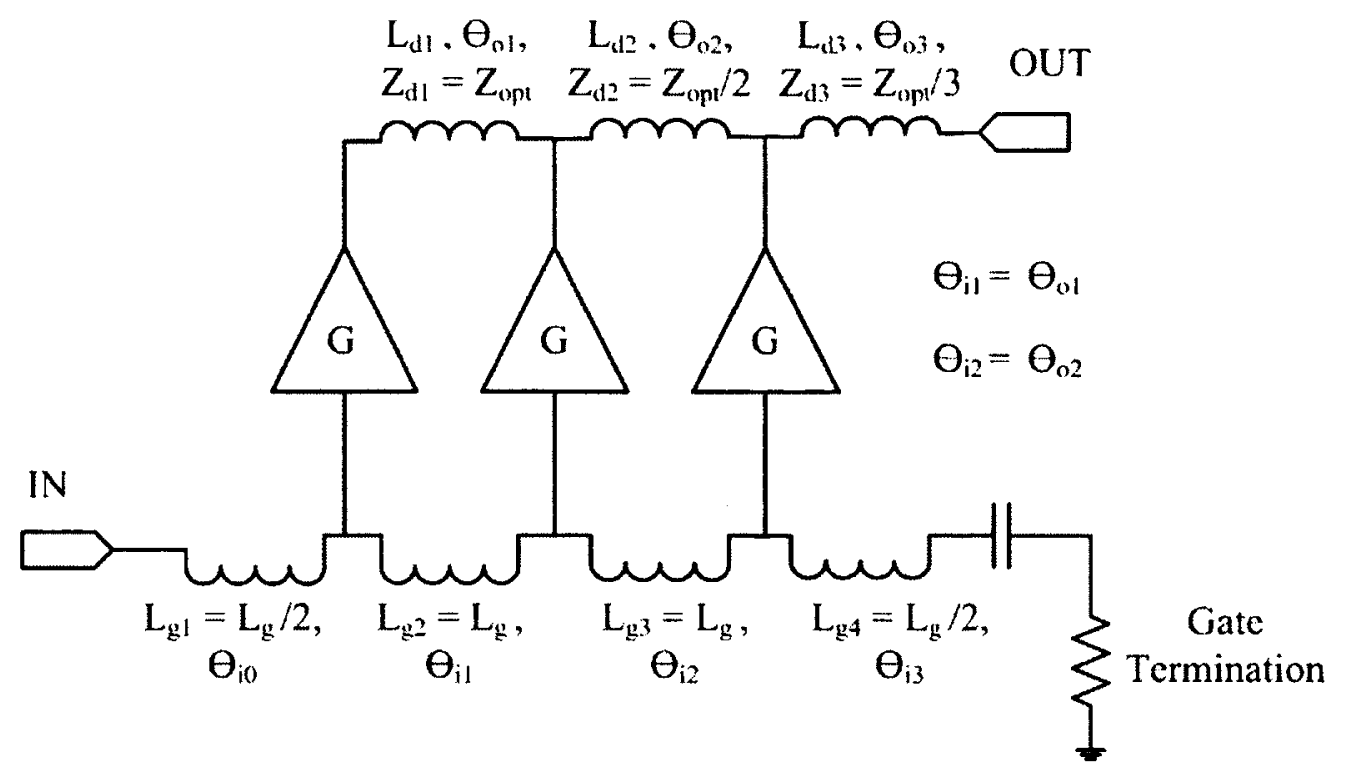

Figure 4.14. Phase synchronization.

For the first section, we have $L_{d 1}=2.25 \mathrm{nH}$ with the assumption that $L_{\mathrm{g} 2}=1.1 \mathrm{nH}$. Next, we will estimate the tapering required for the artificial line in each stage. In Chapter 3, we have already analyzed and introduced the basic idea of tapering. For an n-section line, we need to obtain the drain line's characteristic impedance of $Z_{0} / n$. With the assumption that all the transistors have the same size and neglecting process variation, $C_{d s}$ will remain constant for all sections. Assuming the inductance of the first section drain line on the left corresponds to $L_{d 1}$, then $L_{d 2}, L_{d 3}, \ldots L_{d n}$, we can derive the following relationship:

$$
L_{d n}=L_{d 1} / n^{2}
$$

So, we can simply calculate that $L_{d 2}$ and $L_{d 3}$ are approximately $0.6 \mathrm{nH}$ and $0.2 \mathrm{nH}$ respectively for the 3-stage tapered line distributed amplifier. Meanwhile, this relationship can only be taken as a design reference, since the impedance of a spiral inductor is affected by other parameters such as line width. 
After calculating all the inductances of the drain and gate lines, we can finally derive the optimal number of stages which is obtained for maximum gain in the asymmetric power amplifier.

From the simulation plotted as Figure 4.7, we know over the bandwidth of interest, the parameters $R_{i}$ and $R_{d s}$ of HFET, biased at $V_{g s}=-2.5 \mathrm{~V}, V_{d s}=15 \mathrm{~V}, 6 \mathrm{GHz}$ are approximately $4 \Omega$ and $370 \Omega$, respectively. We can then calculate the drain/gate line attenuation with the equations given as follows,

$$
\begin{gathered}
A_{g}=\left(\frac{\omega c}{\omega g}\right)\left(\frac{\omega}{\omega c}\right)^{2} / \sqrt{1-\left[1-\left(\frac{\omega c}{\omega g}\right)^{2}\right]\left(\frac{\omega}{\omega c}\right)^{2}} \\
A_{d}=\frac{\omega d}{\omega c} / \sqrt{1-\left(\frac{\omega}{\omega c}\right)^{2}}
\end{gathered}
$$

where HFET's intrinsic cut-off frequencies $\omega_{\mathrm{g}}$ and $\omega_{\mathrm{d}}$, cut-off frequency of gate/drain line are given by

$$
\begin{aligned}
& \omega_{g}=1 / R_{i} C_{g s} \\
& \omega_{d}=1 / R_{d s} C_{d s}
\end{aligned}
$$

With the attenuation value calculated and assuming a working frequency of $8 \mathrm{GHz}$, we can calculate that $\omega_{\mathrm{g}} \approx 5.32 \times 10^{11}, \omega_{\mathrm{d}} \approx 3.75 \times 10^{10}$, resulting in $\mathrm{A}_{\mathrm{g}} \approx 0.06$, and $\mathrm{A}_{\mathrm{d}} \approx$ 0.84 . Finally, the optimum number of sections $\mathrm{N}_{\mathrm{opt}}$ is given by

$$
N_{\text {opt }}=\frac{\ln \left(\frac{A g}{A d}\right)}{A g-A d} \approx 3
$$

Over $10 \mathrm{~dB}$ of gain is obtained by using Eq. 4.20 while $\mathrm{g}_{\mathrm{m}}, Z_{\mathrm{d}}, Z_{\mathrm{g}}$ is approximately $0.1 \mathrm{~S}, 20 \Omega$ and $50 \Omega$ respectively.

$$
G=n^{2} g_{m}^{2} Z_{d} Z_{g} / 4
$$

By sweeping drain line $\mathrm{L}_{\mathrm{d} 2}$ while fixing the other $\mathrm{L}_{\mathrm{d} 1}$ and $\mathrm{L}_{\mathrm{d} 3}$ as $2.25 \mathrm{nH}$ and $0.2 \mathrm{nH}$ respectively (as shown in Figure 4.15), the maximum gain is plotted at different frequencies. Other $L_{\text {Dmid }}$ values are desirable, but $0.5 \mathrm{nH}$ is preferred due to its small 
size and easier implementation. So, as a starting point, we choose the tapered lines' inductance as $2.25 \mathrm{nH}, 0.5 \mathrm{nH}, 0.2 \mathrm{nH}$ from the first to the last stage, the $\mathrm{Q}$ of which is assumed to be about 10 for broadband design.

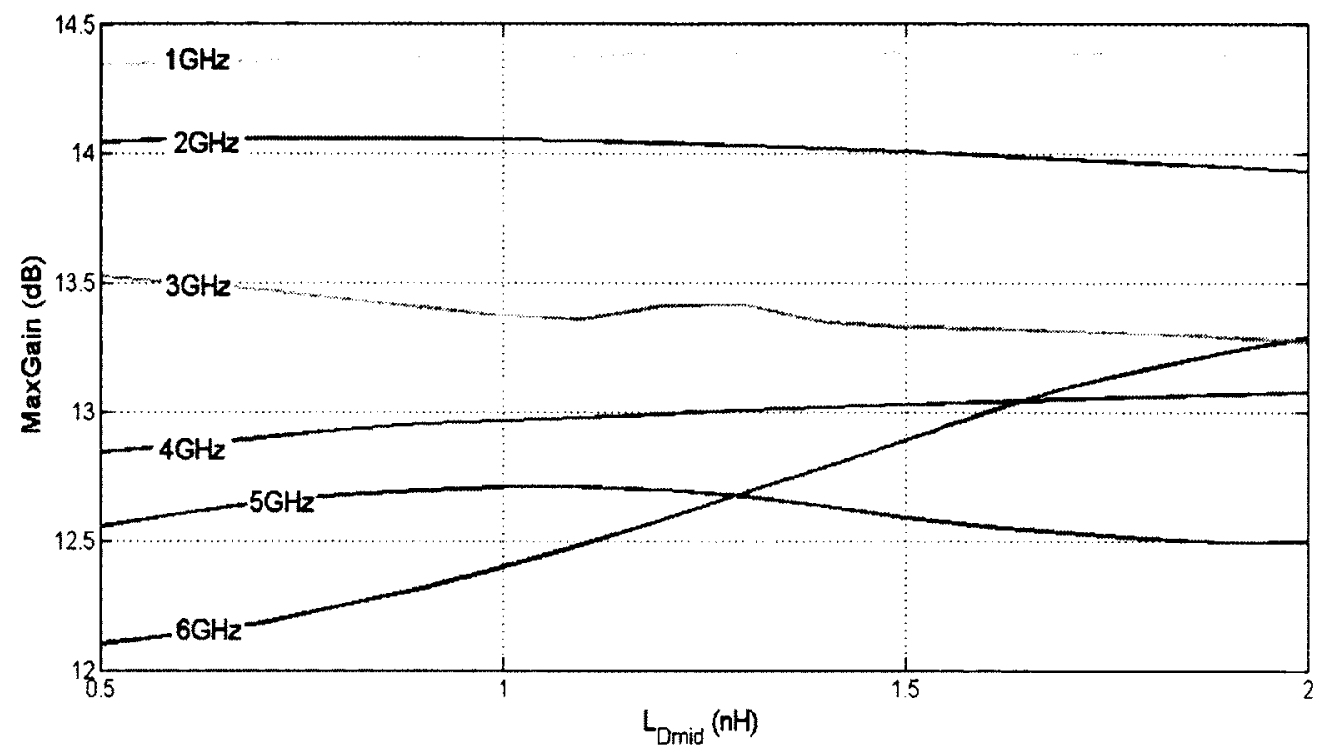

Figure 4.15. Maximum Gain (MaxGain) while sweeping middle drain line's inductance.

After an initial study using lumped elements, we begin to migrate to using real kit components, taking into account the current density limitation of the metal layer, which is $6 \mathrm{~mA} / \mathrm{um}$ as stated in design manual.

Recall that we have analyzed the tapered line distributed amplifier in Chapter 3. In order to obtain the maximum output power, we need to feed each transistor its optimal impedance, which means the drain line's impedance represented to each stage should be $Z_{\text {opt }}, Z_{\text {opt }} / 2$ and $Z_{\text {opt }} / 3$ respectively. After the load-pull of each unit stage was completed in section 4.1 .1 at $4 \mathrm{GHz}$ (with return loss at input port $S_{11} \leq 10 \mathrm{~dB}$ ), the $Z_{\text {opt }}$ is determined to be $20 \Omega$. Then the first section of drain line is chosen to be a 
spiral inductor due to the large required inductance that arises from $\mathrm{Z}_{\text {opt }}=$ $\sqrt{L_{d 1} / C_{d r a i n \_t o t a l}}$, where the $C_{\text {drain_total }}$ of $5.6 \mathrm{pF}$ is the total capacitance presented at the drain side of the first stage. The impedance of the other sections of drain lines are adjusted according to Fig. 4.14 for maximum output power. Furthermore, each drain line section phase shift matches with the parallel gate line on the input side $\left(C_{g s}\right.$ and $\mathrm{C}_{\mathrm{ds}}$ are included in the phase shift evaluation). Hence, the impedances for maximum output power presented by the drain lines from the first to last stage are approximately $20 \Omega, 10 \Omega$ and $6 \Omega$, respectively.

\section{Line Tapering}

As, we start to size the tapered drain lines, another question comes about. According to the GaN500 design manual, there are 3 different spiral inductor layouts that can be chosen, as shown in Figure 4.16. Type 1 uses $1 \mathrm{ME}$ (for the layer table, refer to the Appendix of this thesis) to build all the internal turns, with a bridge connecting out the terminal on one side. Type 2 uses bridges for internal turns when the sections cross the outlet terminal line. Type 3 is different from the above two, which uses landed metal. As shown in Figure 4.17, the $Q$ factor is investigated among these three inductors; type 1 design has the highest $\mathrm{Q}$, while type 2 has the lowest simulated $\mathrm{Q}$. While it would be desirable to employ the highest $Q$ type of inductor to minimize losses, the low Q type 3 is chosen for the application due to its larger current carrying capability. It will be shown in Section 4.4.1 that the difference in achievable PAE and output power between highest $Q$ type and type 3 inductors is minimal. 


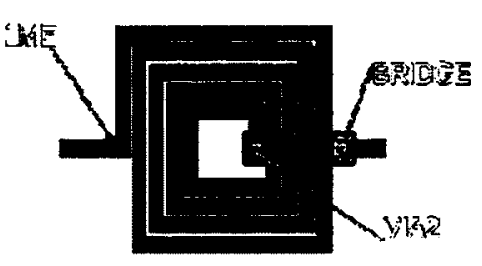

Type 1

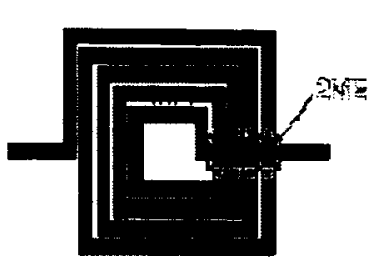

Type 2

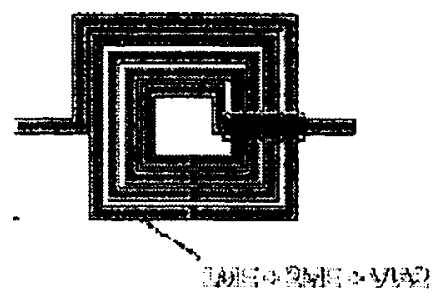

Type 3

Figure 4.16.

Three types of allowed spiral inductor layouts.

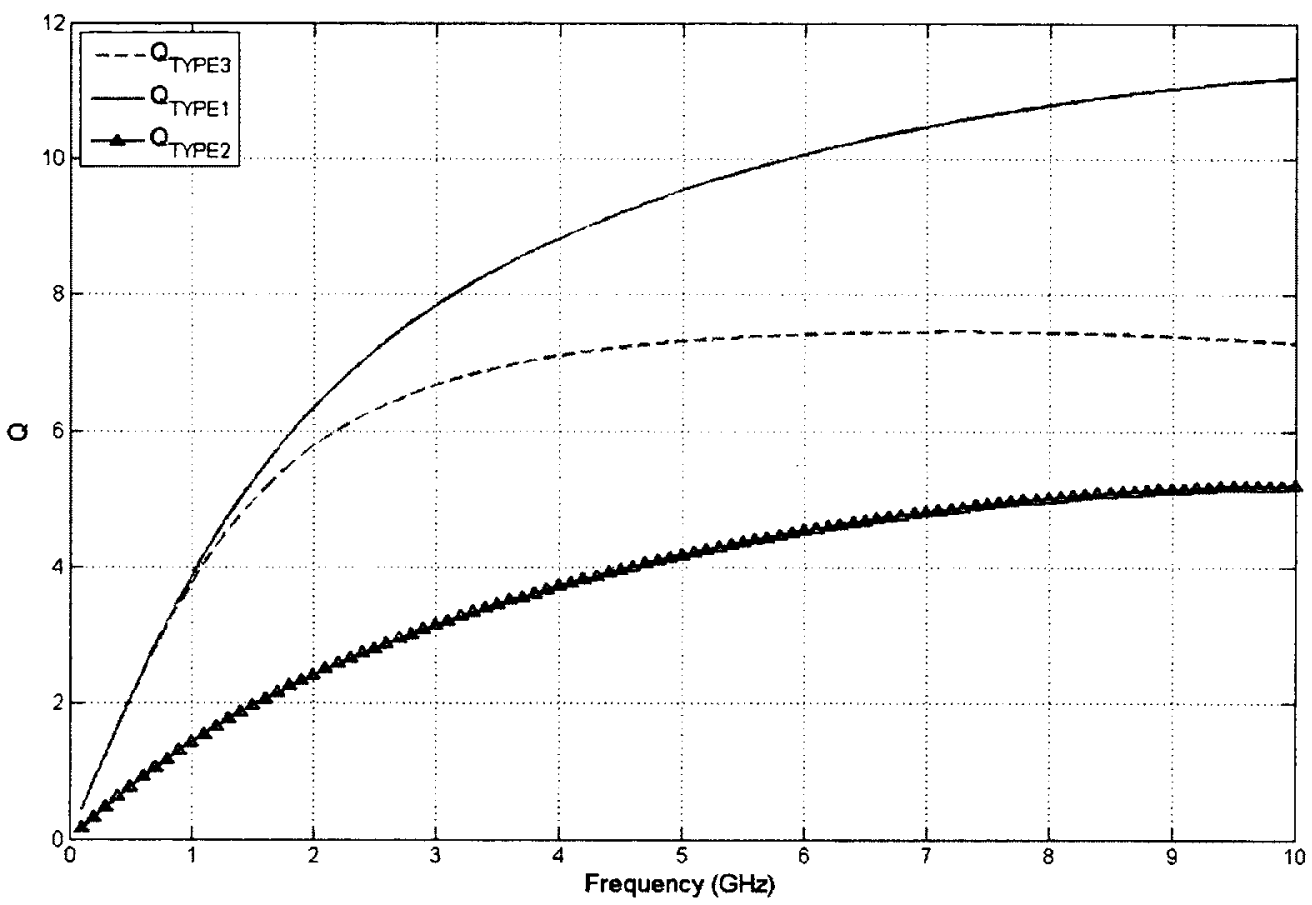

Figure 4.17. Q comparison among three type layouts (1 $\mathrm{nH}$ implemented inductor).

After all of the investigation presented above, the coplanar waveguide at drain line sections were sized accordingly, and the final values are as follows: $30 \mu \mathrm{m}, 54 \mu \mathrm{m}$, and $78 \mu \mathrm{m}$, the length as $2.58 \mathrm{~mm}, 0.67 \mathrm{~mm}$, and $0.28 \mathrm{~mm}$, from left first section to right last section; as a result, they can sustain $144 \mathrm{~mA}, 288 \mathrm{~mA}$ and $432 \mathrm{~mA} \mathrm{DC}$ current required, respectively. 
Figures $4.18-4.22$ show the inductance values and $Q$ factors, of the drain and gate lines' implementations. The low $Q$ type spiral inductor design was chosen for broadband matching due to the application of the device. Figure 4.18 confirms that the first inductor implementation has $\mathrm{L}_{\mathrm{d} 1}=2.5 \mathrm{nH}$, as required, and self-resonates well beyond $6 \mathrm{GHz}$. In addition, its maximum $\mathrm{Q}$ is 4.5 .

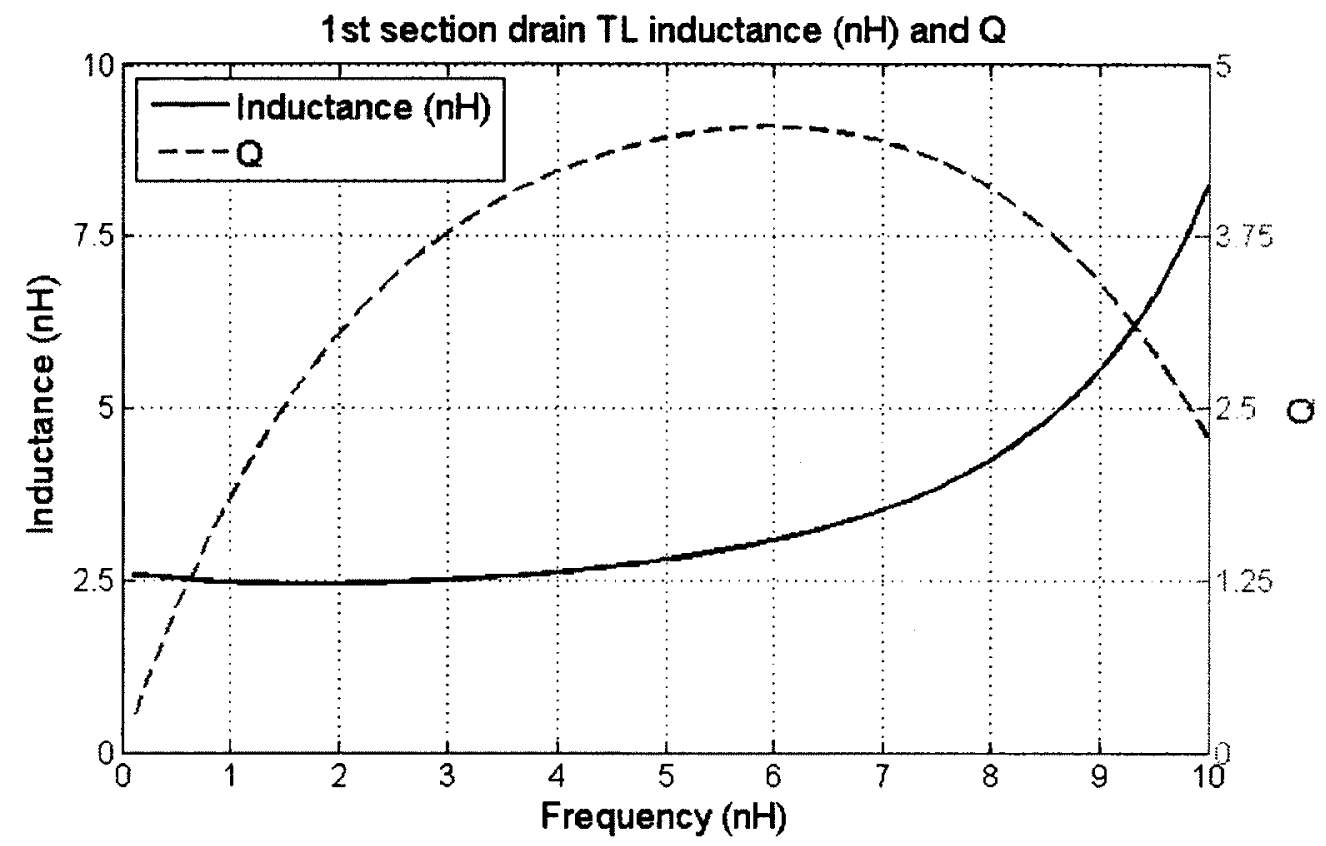

Figure 4.18. Substrate setup and first section drain line characteristics.

Figure 4.19 shows that the implementation of $\mathrm{L}_{\mathrm{d} 2}$ yields an inductance of $0.48 \mathrm{nH}$ as required and a maximum $Q$ of 17 , with no indication of self-resonate effects up to 10GHz. Figure 4.20 illustrates the third inductor implementation has $\mathrm{L}_{\mathrm{d} 3}$ of $0.18 \mathrm{nH}$, as required, and self-resonates well beyond $10 \mathrm{GHz}$. The maximum observed $\mathrm{Q}$ is approximately 14.5 . 


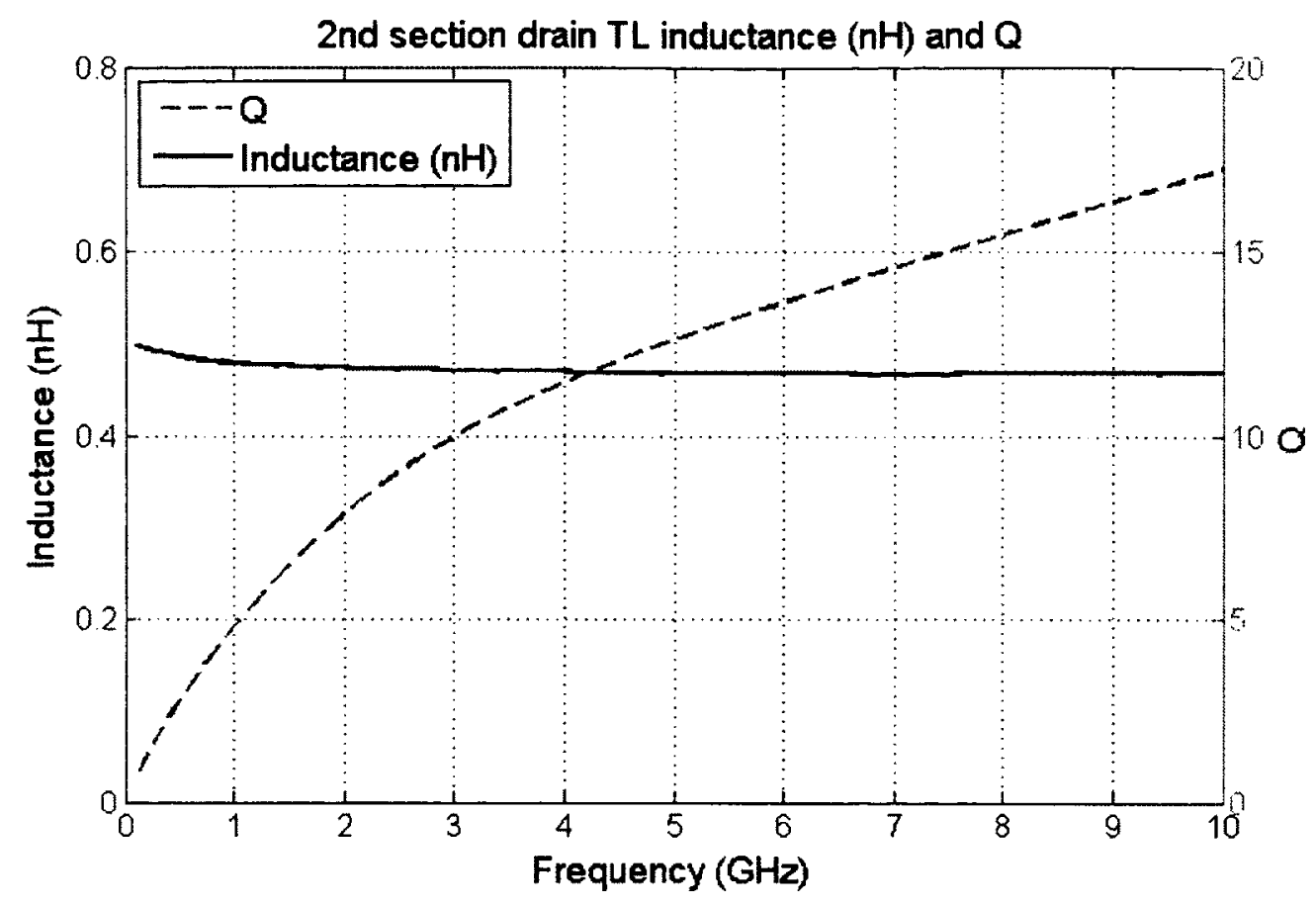

Figure 4.19. $\quad 2^{\text {nd }}$ section drain line characteristics.

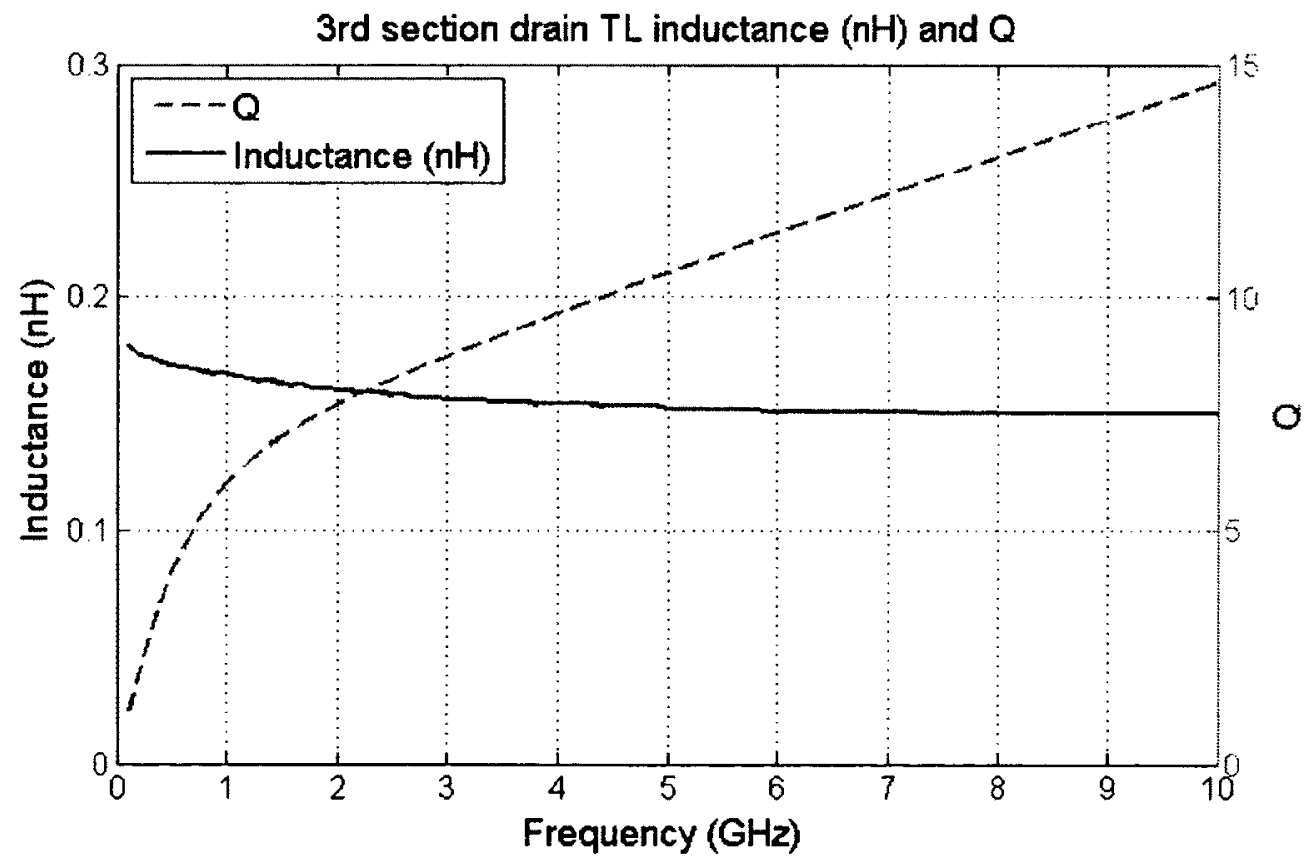

Figure 4.20. $\quad 3^{\text {rd }}$ section drain line characteristics. 

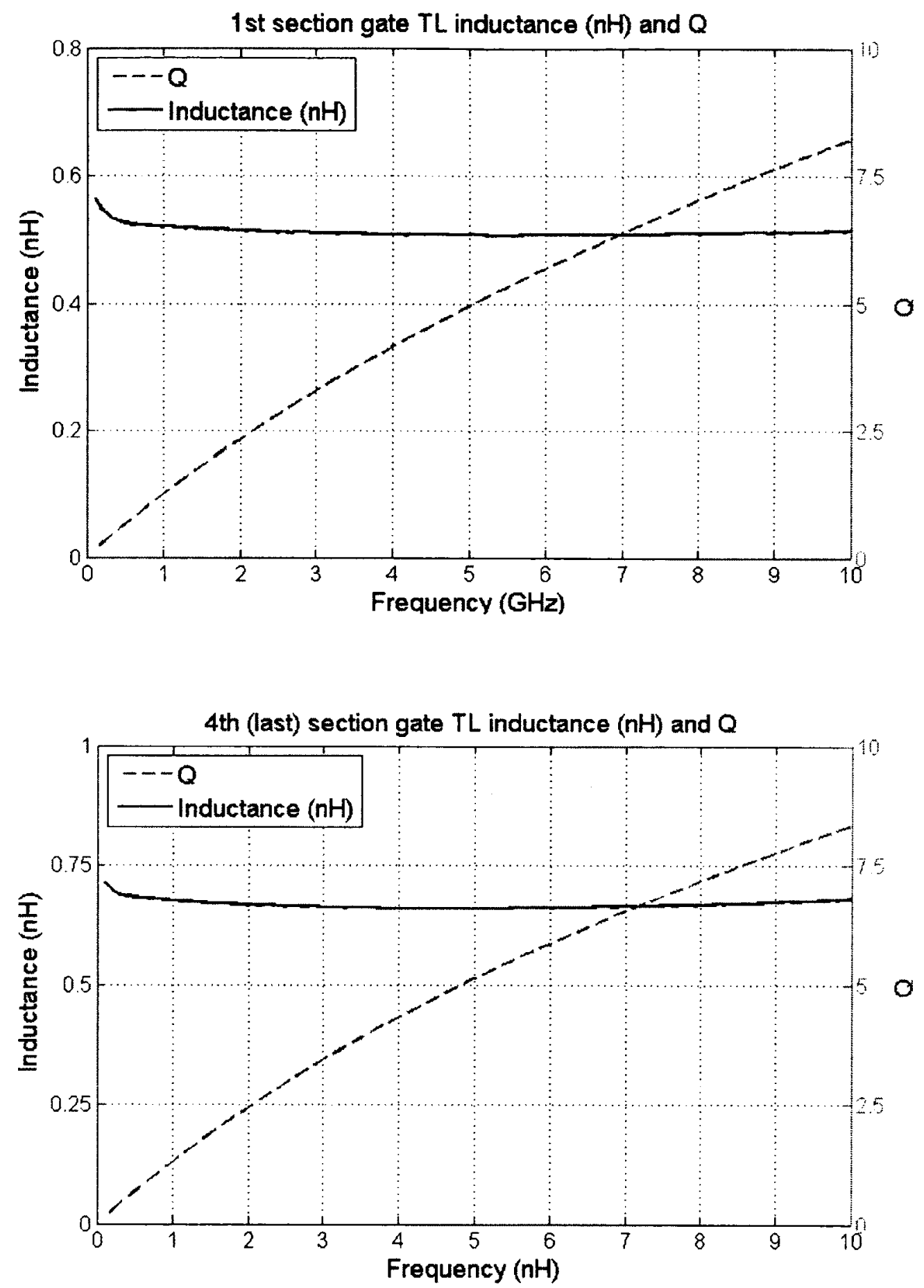

Figure 4.21 .

first and last section (side) gate line characteristics. 


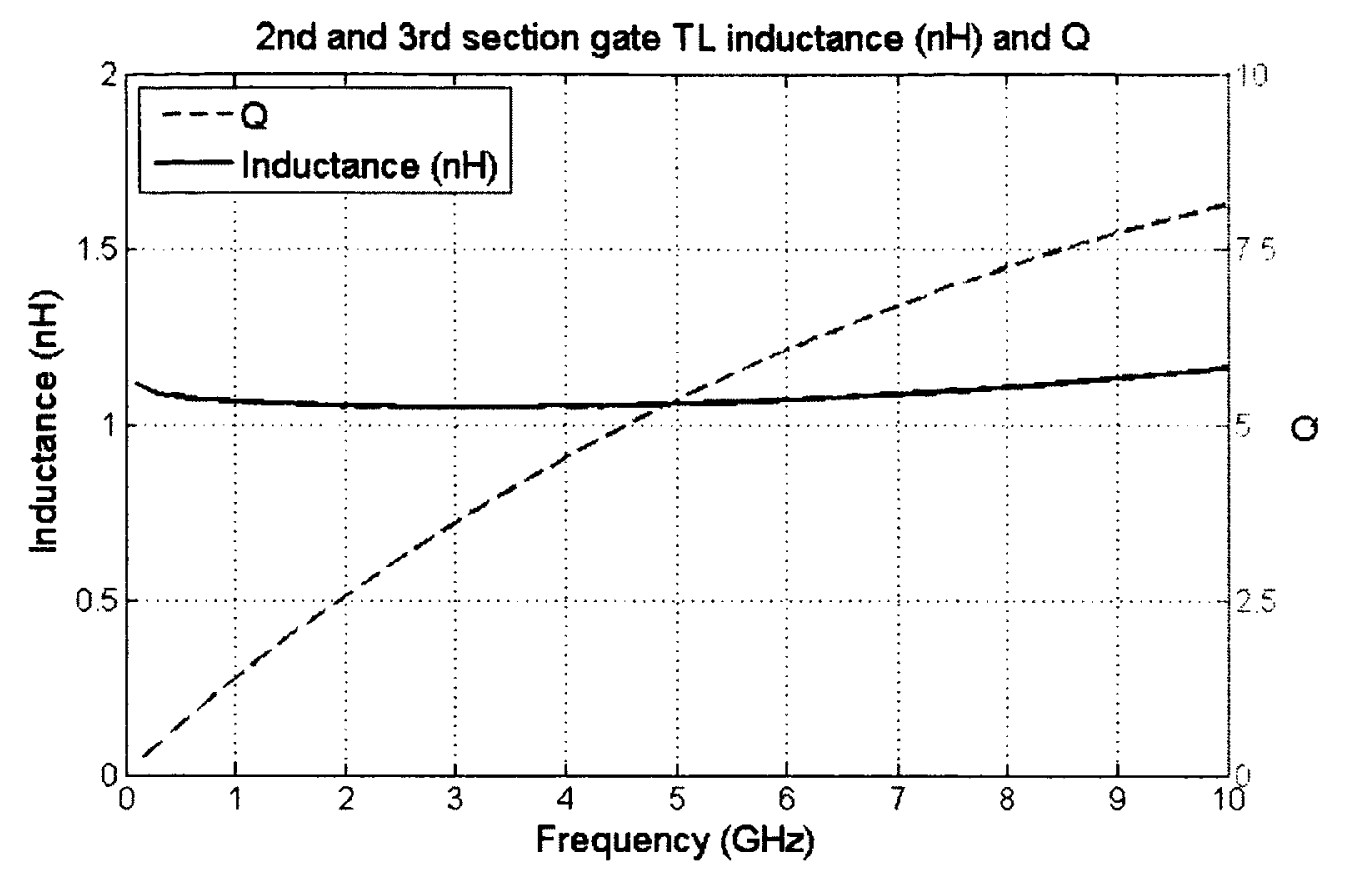

Figure 4.22. $\quad 2^{\text {nd }}$ and $3^{\text {rd }}$ stage (middle) gate line characteristics.

Figure 4.21 confirms that the implementations of $\mathrm{L}_{\mathrm{gl}}$ and $\mathrm{L}_{\mathrm{g} 4}$ present inductances of $0.51 \mathrm{nH}$ and $0.66 \mathrm{nH}$ as expected and maximum Quality Factors of approximately 8.1 and 8 respectively, with self-resonances beyond $10 \mathrm{GHz}$. Figure 4.22 shows the inductance $\mathrm{L}_{\mathrm{g} 2}$ and $\mathrm{L}_{\mathrm{g} 3}$ of the implemented $2^{\text {nd }}$ and $3^{\text {rd }}$ gate lines yield to $1.06 \mathrm{nH}$ as required, and self-resonates well beyond $8 \mathrm{GHz}$. In addition, its maximum $Q$ is approximately 8 .

From the above plots, it can be concluded that, the inductor implementations are providing the desired $\mathrm{Zg}, Z_{\mathrm{opt}}, Z_{\mathrm{opt}} / 2$ and $Z_{\mathrm{opt}} / 3$ values at the appropriate stage of the ADPA as expected. Detailed phase matching will be presented in Section 4.4. 1.

All of the elements of this first design are indicated in the final circuit schematic of Figure 4.23. The corresponding layout that results from this schematic is shown in Figure 4.24. 


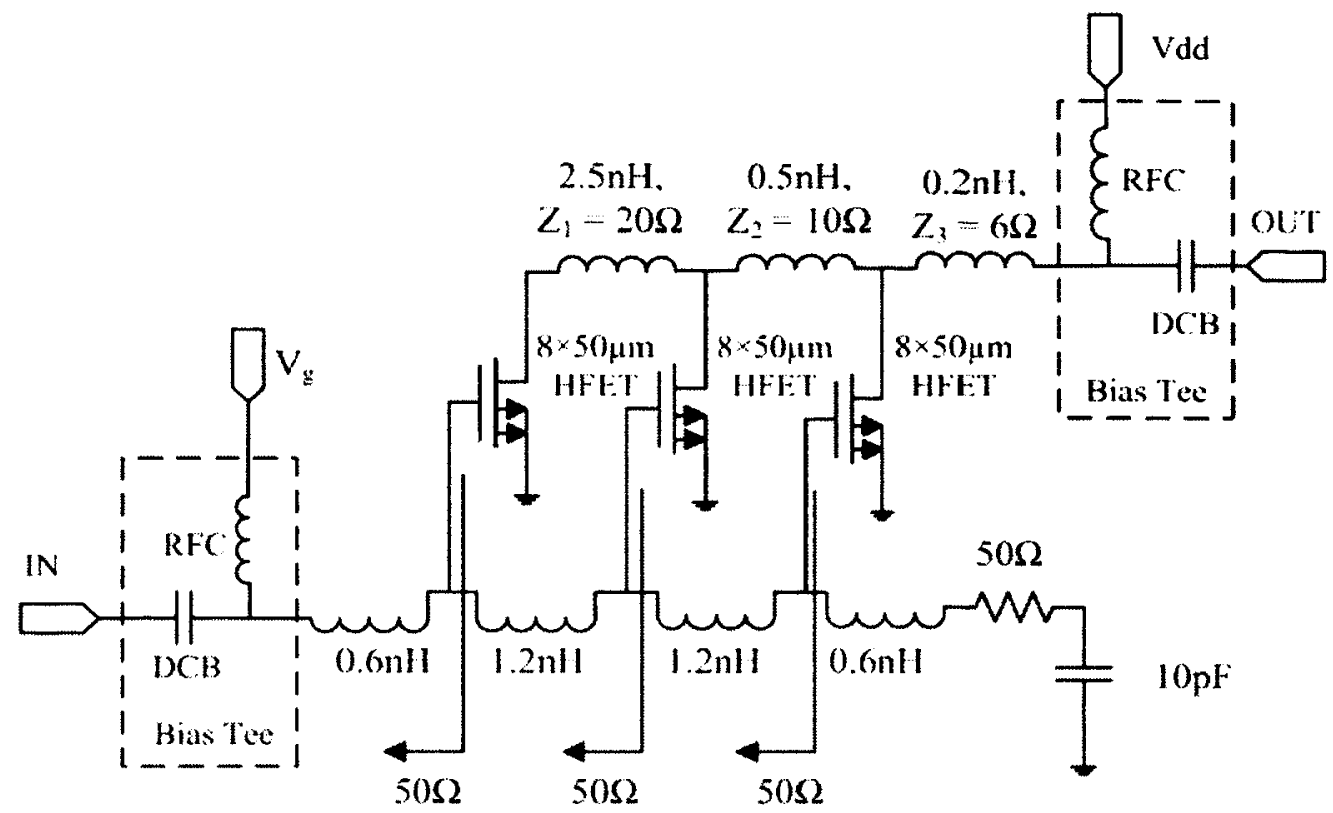

Figure 4.23

Schematic of the first ADPA design

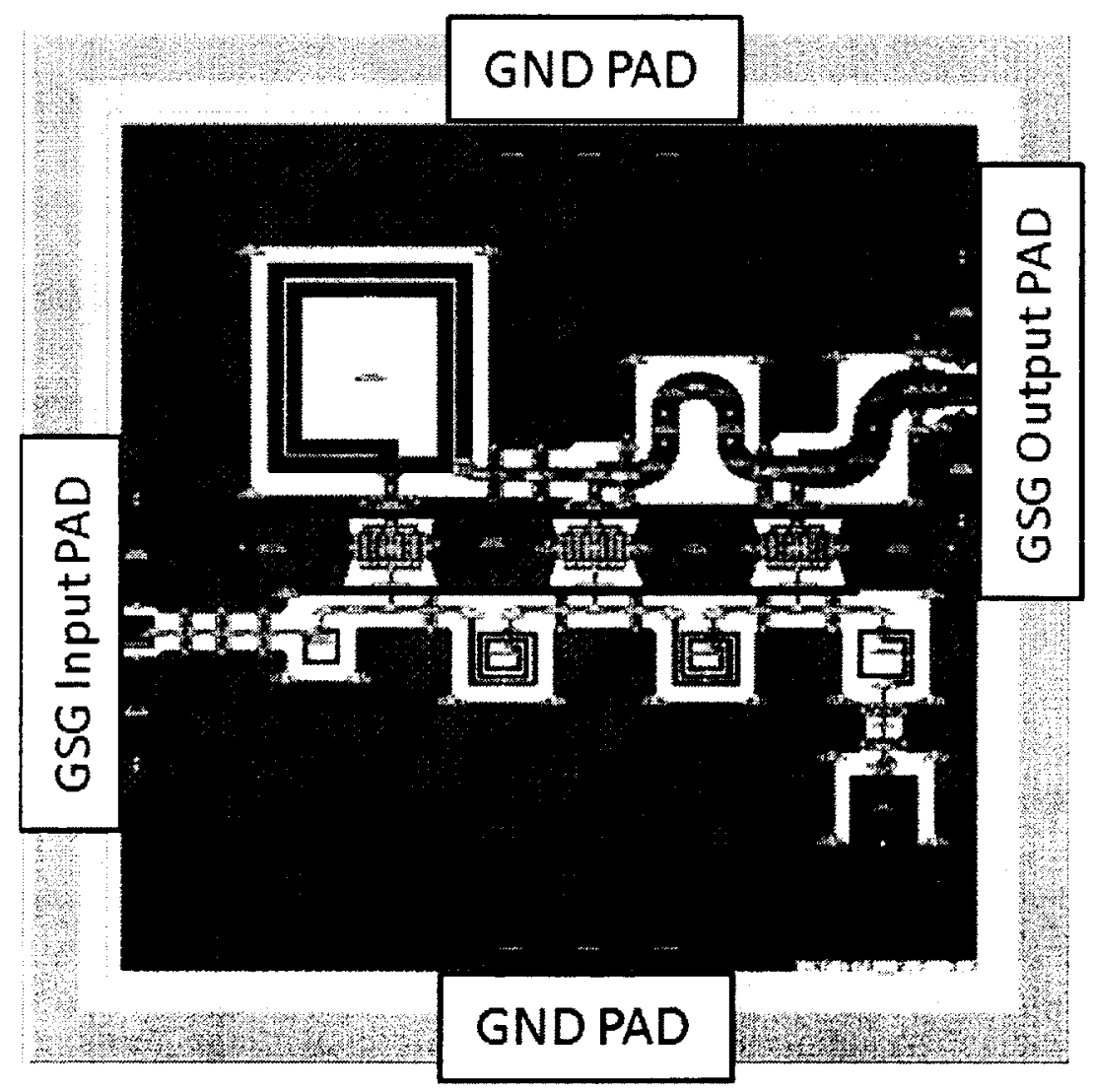

Figure 4.24. Final layout of the first design (HFETs marked by the rectangle). 
The last drain line section is directly connected to the $50 \Omega$ ground-signal-ground (GSG) pads required for probe measurements. The GSG pads are designed to obtain $50 \Omega$ impedance with $150 \mu \mathrm{m}$ pitch. The performance (small and large signal S-parameter, stability, power gain, delivered power, PAE, linearity, harmonic distortion) of this first design is now presented, as captured from post-layout simulation. Each device is biased at $\mathrm{V}_{\mathrm{gs}}=-2.5 \mathrm{~V}$ and, $\mathrm{V}_{\mathrm{ds}}=15 \mathrm{~V}$. The stability of the ADPA is checked in Figure 4.25. $\mathrm{K}$ factor is presented using a logarithmic scale; it can be seen that $\mathrm{B} 1$ factor is in the range of 0 and 1 , and $\mathrm{K}$ is higher than 1 , which presents the ADPA is stable over $0.1 \mathrm{GHz}-10 \mathrm{GHz}$ frequency range.

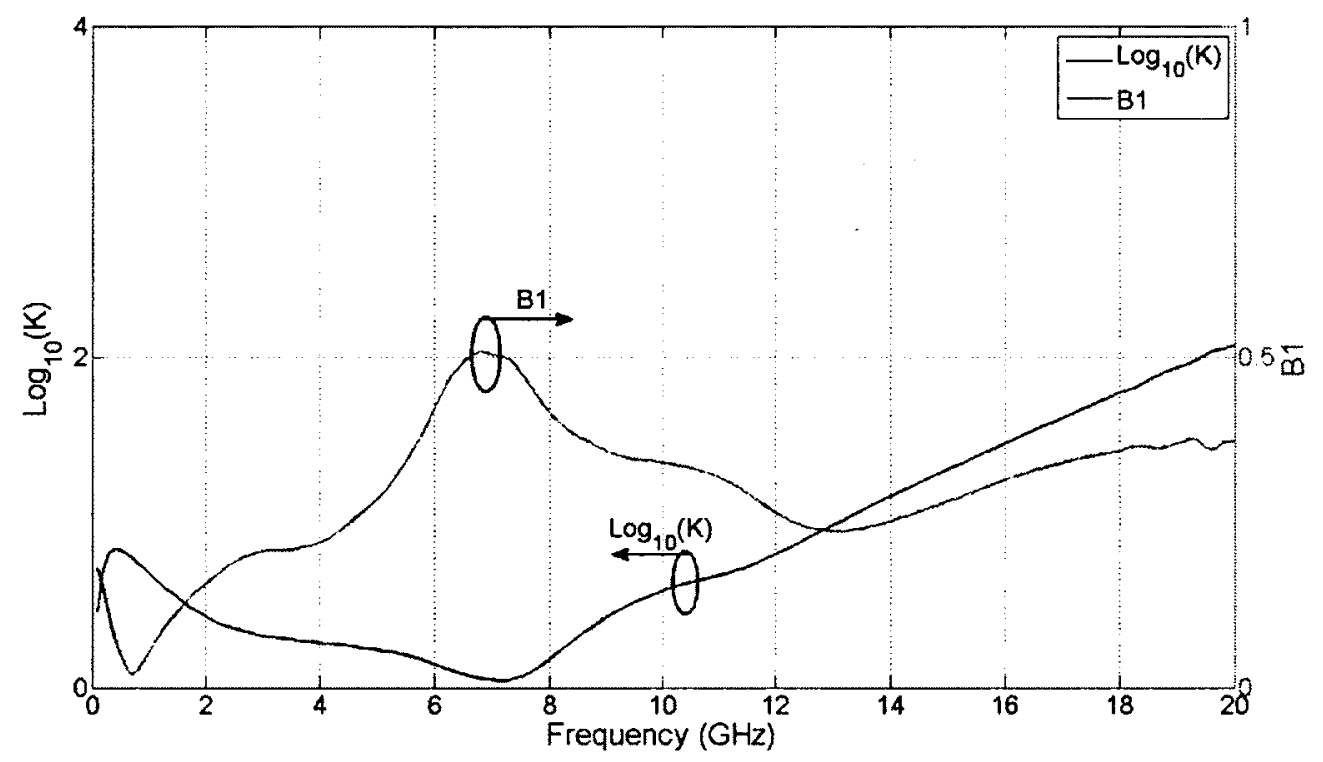

Figure 4.25. Stability factors, $K$ is presented as $\log _{10}(K)$.

The small-signal s-parameter results over the $0.1 \mathrm{GHz}$ to $10 \mathrm{GHz}$ range are presented in Figure 4.26. As expected, the gain is above $10 \mathrm{~dB}$ over the operating bandwidth of the artificial transmission line, which is approximately $8 \mathrm{GHz}$. The low frequency gain is $13 \mathrm{~dB}$ and the upper $3 \mathrm{~dB}$ corner frequency is approximately $8 \mathrm{GHz}$ as expected in 
calculation. Looking at $S_{11}$, the ADPA is seen to be well matched $\left(S_{11}<-10 \mathrm{~dB}\right)$ from $0.5 \mathrm{GHz}$ to $6.5 \mathrm{GHz}$. As seen from the $S_{22}$ curve, the output is not as well matched to $50 \Omega$ but this is not required as the amplifier is designed for maximum power to the load. The low values of $S_{12}$ below approximately $-20 \mathrm{~dB}$ across the band confirm the good isolation between input and output lines, as assumed in the design methodology. The large-signal s-parameter performance is shown in Figure 4.27 for an input power, $P_{\text {in }}=20 \mathrm{dBm}$ (the design specification). Very little change is observed compared to the small-signal results of Figure 4.26. $\mathrm{S}_{11}$ remains below $-10 \mathrm{~dB}$ over a broader bandwidth extending from $0.5 \mathrm{GHz}$ to $7.5 \mathrm{GHz}$.

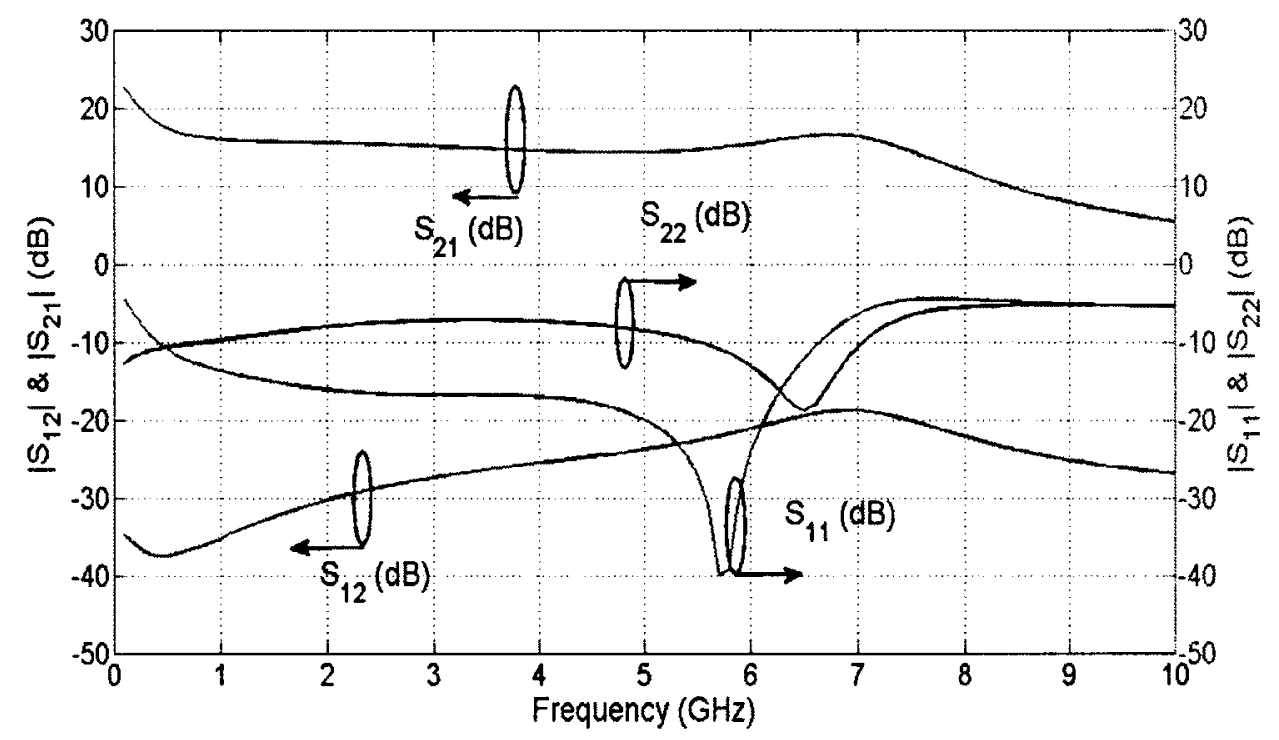

Figure 4.26. Small signal s-parameter biased at $\mathrm{V}_{\mathrm{gs}}=-2.5 \mathrm{~V}, \mathrm{~V}_{\mathrm{dd}}=15 \mathrm{~V}$. 


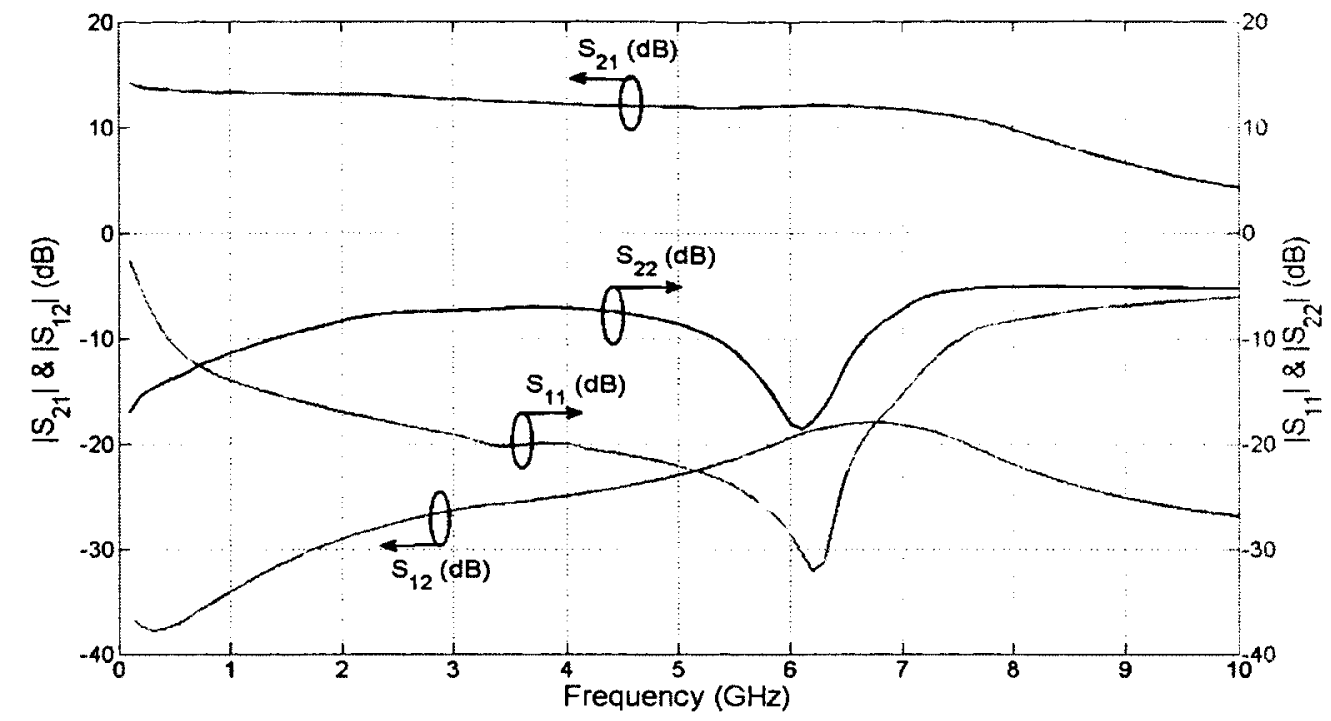

Figure 4.27. Large signal s-parameter biased at $\mathrm{V}_{\mathrm{gs}}=-2.5 \mathrm{~V}, \mathrm{~V}_{\mathrm{dd}}=15 \mathrm{~V}$.

The amplifier achieved a gain greater than $10 \mathrm{~dB}$ over the $0.1 \mathrm{GHz}-8 \mathrm{GHz}$ bandwidth, and has obtained a PAE higher than $20 \%$ over the $0.1 \mathrm{GHz}-7 \mathrm{GHz}$ frequency range as shown in Figure 4.28. The amplifier delivers a peak RF power of approximately $33.2 \mathrm{dBm}$ to the output load, with $33.8 \%$ peak PAE at $0.9 \mathrm{GHz}$ while consuming 6.4 W peak DC power (15 V DC supply, $427 \mathrm{~mA}$ total simulated DC current). 


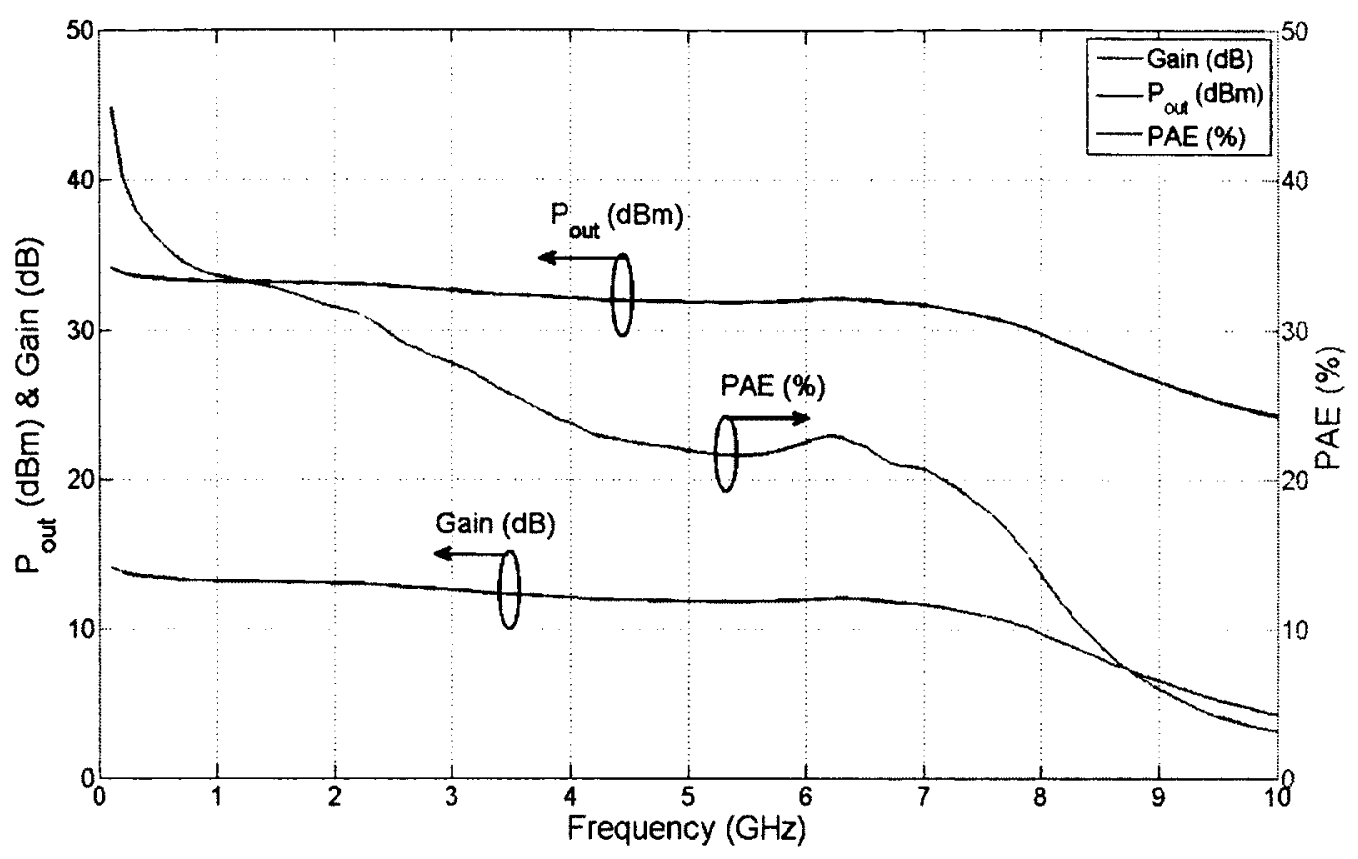

Figure 4.28. Power gain, $P_{\text {out, }}$ and PAE.

Figure 4.29 illustrates the methodology used for the OIP3 and IIP3 calculation. It can be seen from Figure 4.30 that the OIP3 and IIP3 are above $45 \mathrm{dBm}$ and $31 \mathrm{dBm}$ respectively over the entire bandwidth of interest, which means the ADPA is operating linearly while in band. Figure 4.31 presents the spectrum waveform of the harmonic distribution at $\mathrm{f}_{\mathrm{o}}=6 \mathrm{GHz}$. The fundamental has approximately $32 \mathrm{dBm}$ while the $2^{\text {nd }}$ and $3^{\text {rd }}$ harmonic presents $5.9 \mathrm{dBm}$ and $2.7 \mathrm{dBm}$ respectively, which are over $25 \mathrm{~dB}$ below the fundamental. Figure 4.32 shows the output signal distortion as a function of frequency. The fundamental is above $30 \mathrm{dBm}$ over the entire bandwidth, while the harmonics are almost $20 \mathrm{~dB}$ below the fundamental across the band. 


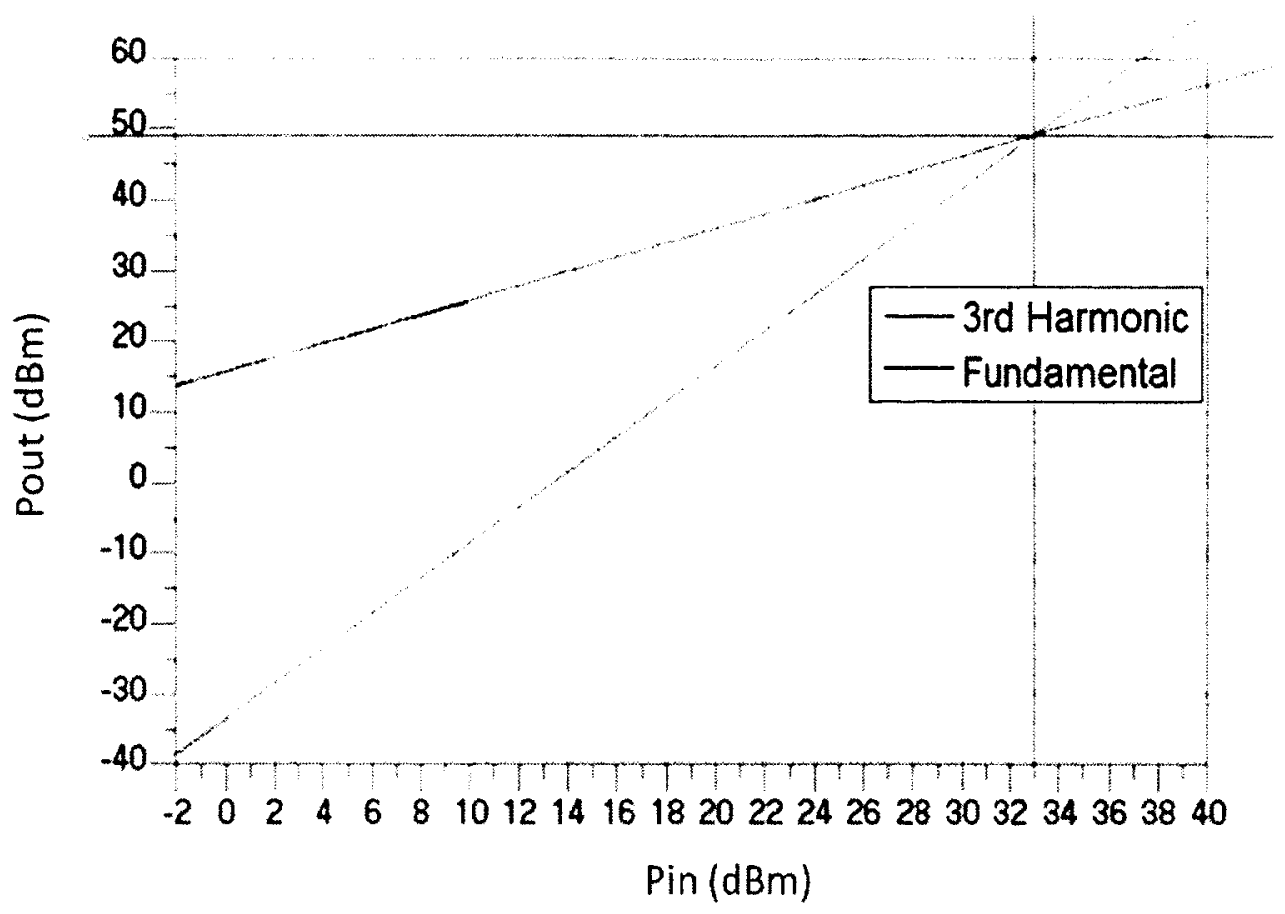

Figure 4.29. Fundamental \& $3^{\text {rd }}$ Harmonic versus $P_{\text {in }}$ at $3 \mathrm{GHz}$.

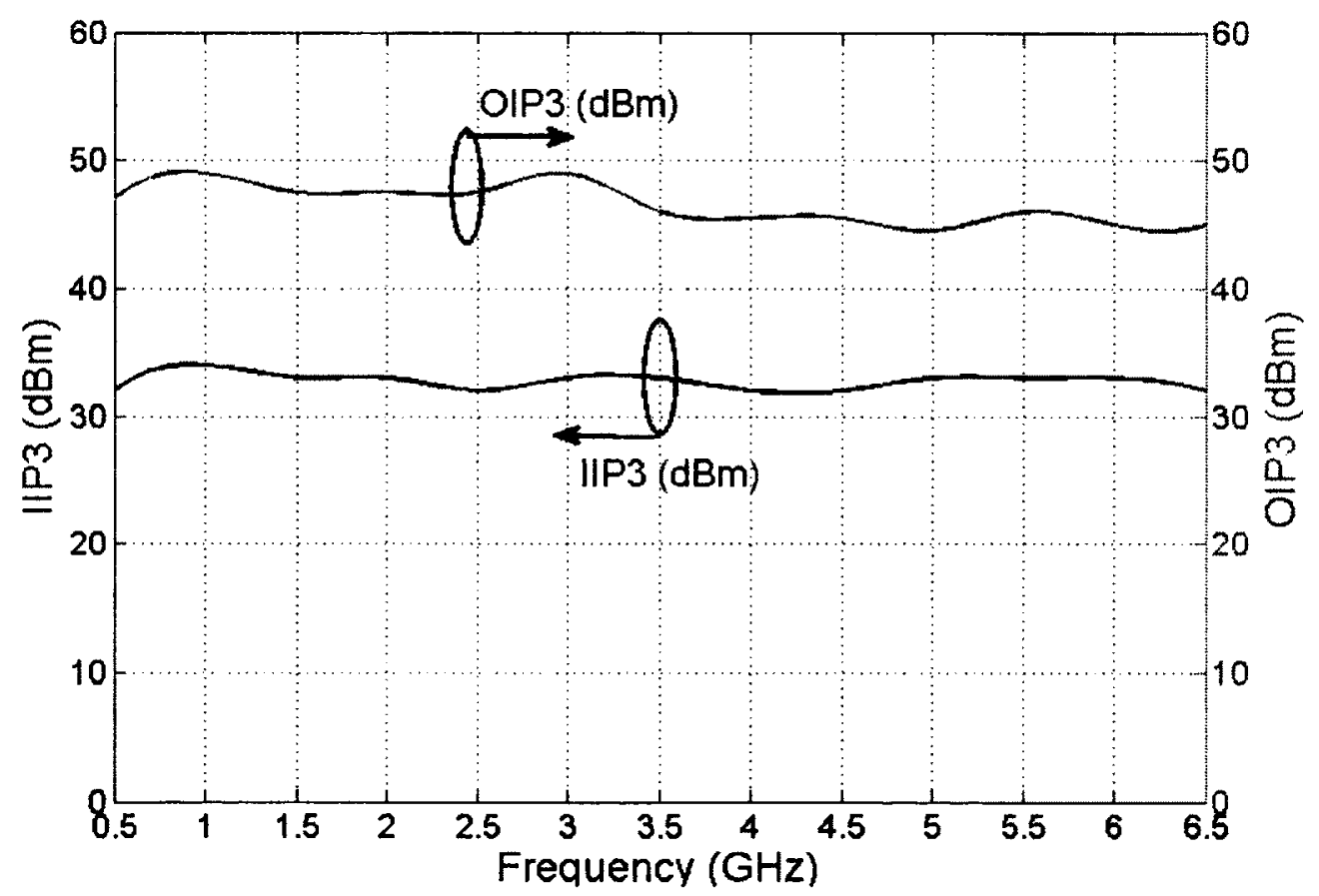

Figure 4.30. Linearity over $0.5 \mathrm{GHz}-6.5 \mathrm{GHz}$. 


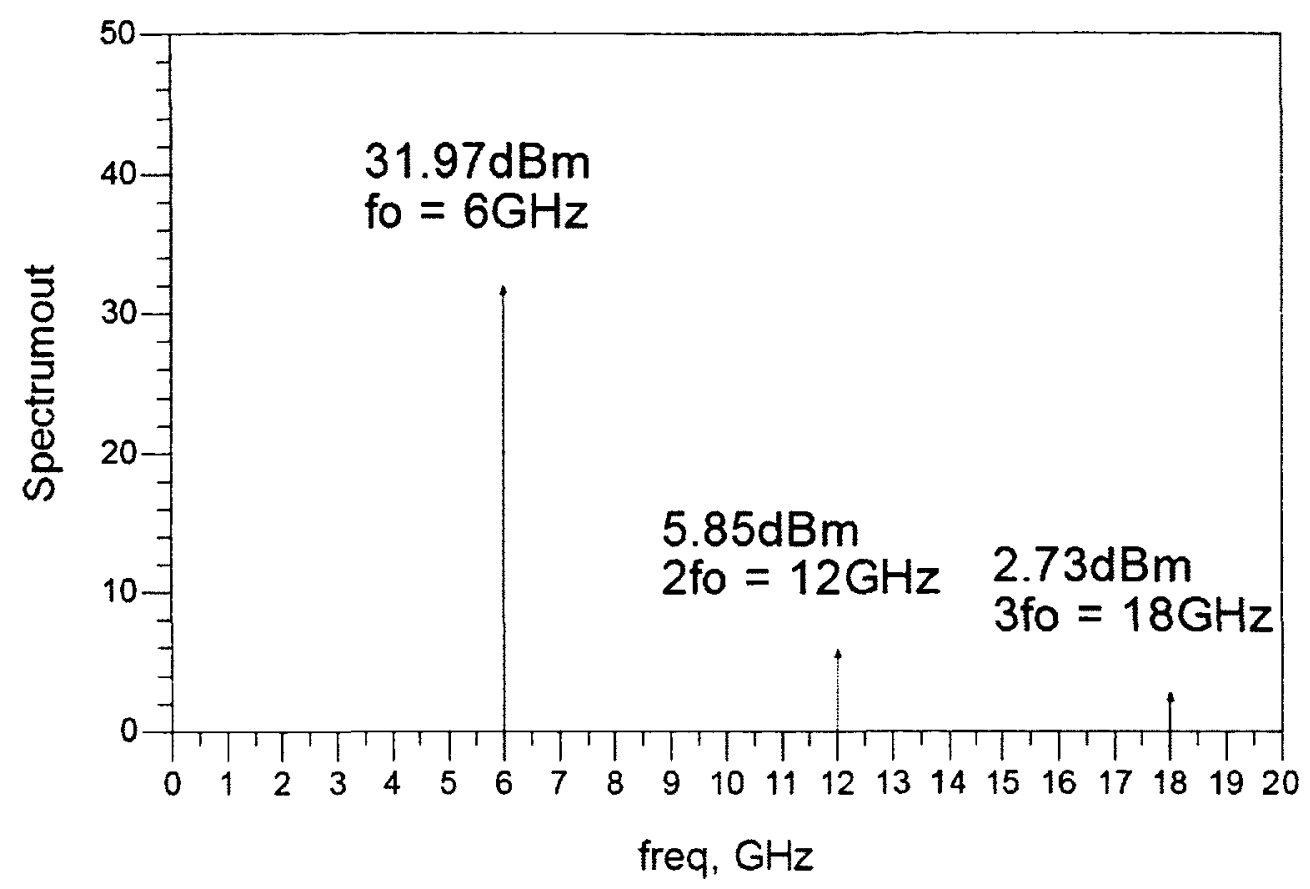

Figure 4.31. Harmonic distribution at $\mathrm{f}_{\mathrm{o}}=6 \mathrm{GHz}$.

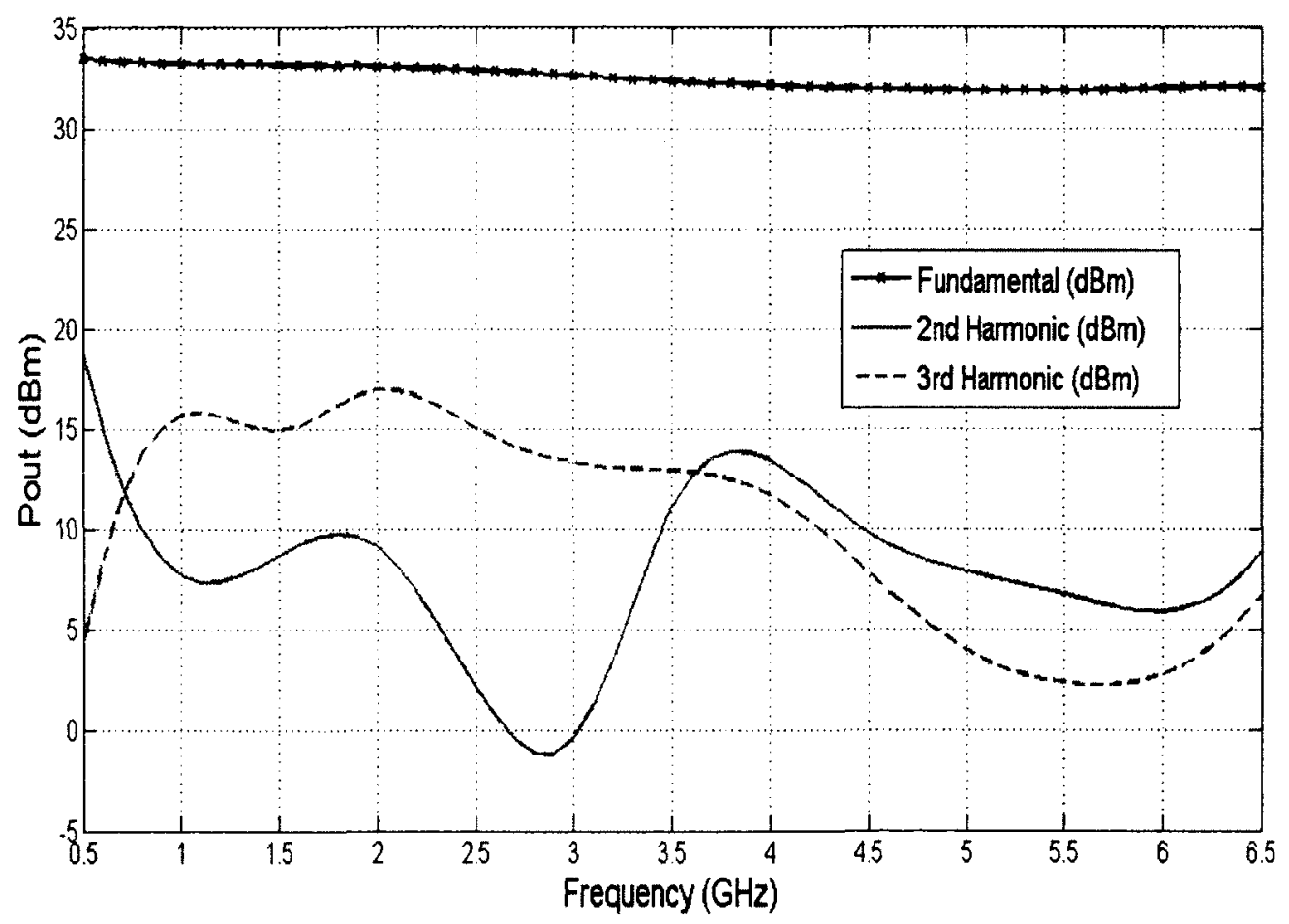

Figure 4.32. Harmonic distortion over $0.5 \mathrm{GHz}-6.5 \mathrm{GHz}$. 

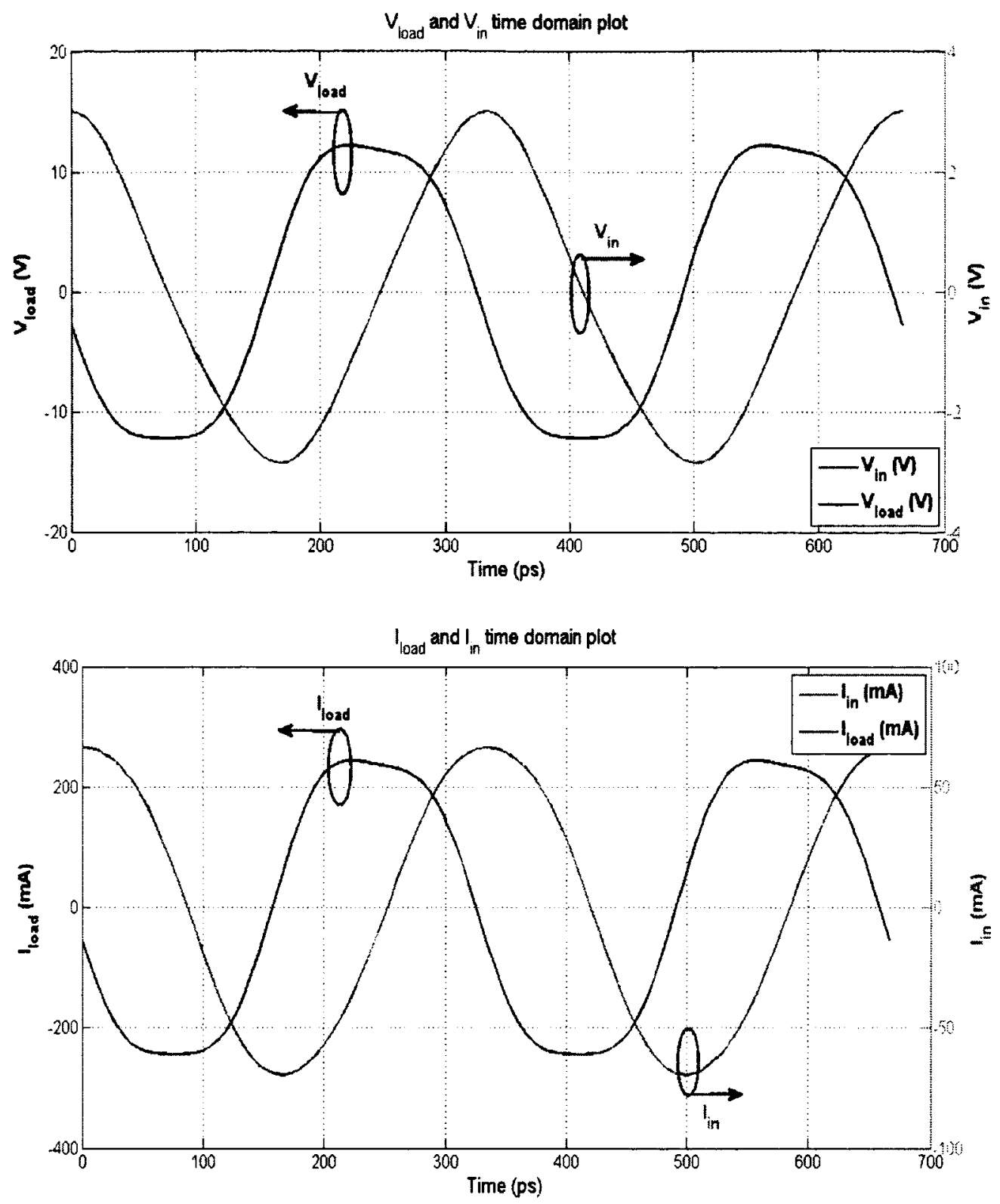

Figure 4.33. Time domain voltage/current input/output waveform at $3 \mathrm{GHz}$.

From Figure 4.31 and Figure 4.32, it can be seen that, since no harmonic shorting circuitry is included in the APDA, contribution from the harmonics have resulted in the distortion of output waveform in time domain as shown in Figure 4.33. This performance could be improved for a specific narrow-band application, in which a 
reconfigurable network could be added to successfully eliminate the harmonics at arbitrary frequencies. Also, it can be seen from Figure 4.34 that all the gain HFETs in the ADPA are operating as Class-AB amplifiers.

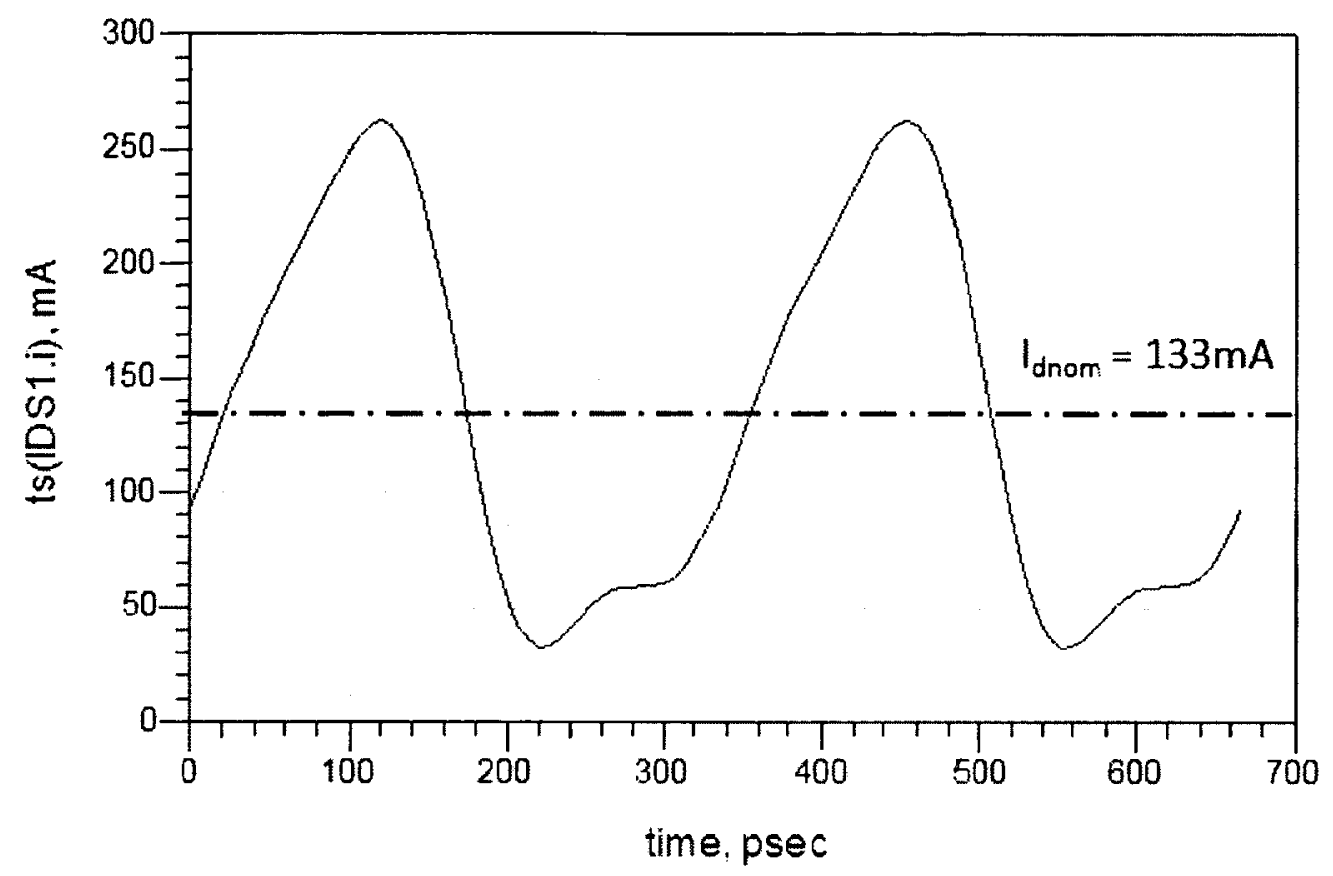

Figure 4.34. $I_{d}$ through the common-source HFET in the ADPA unit gain stage.

It is interesting to now consider how optimal the fixed $50 \Omega$ load impedance is over the broad operating range of frequencies of this amplifier. We conducted a load pull analysis at the amplifier's output port at various frequencies: $1 \mathrm{GHz}, 4 \mathrm{GHz}$, and 6 $\mathrm{GHz}$, to obtain the $\mathrm{R}_{\mathrm{opt}}$ required for delivering maximum output power. This is shown in Figures $4.35-4.37$. It can be seen from the simulation results, that the $\mathrm{R}_{\mathrm{opt}}$ is not constant as a function of the frequency. If we need to obtain maximum output power at low frequencies, typical for a cell-phone band at $1 \mathrm{GHz}$, we would need to match to the optimum load, which is approximately $55 \Omega$, close to $50 \Omega$. Or, we need to use the PA in high frequency applications such as WiFi and WiMAX, where the PA would be 
better to match to approximately $30 \Omega$ optimum load in order to deliver maximum power. It is ideal to build a reconfigurable matching circuit for each application at a specific frequency; however, in this work we focus on the research of asymmetric distributed topology, so a reconfigurable network is not included. However, it will be recommended for future work.
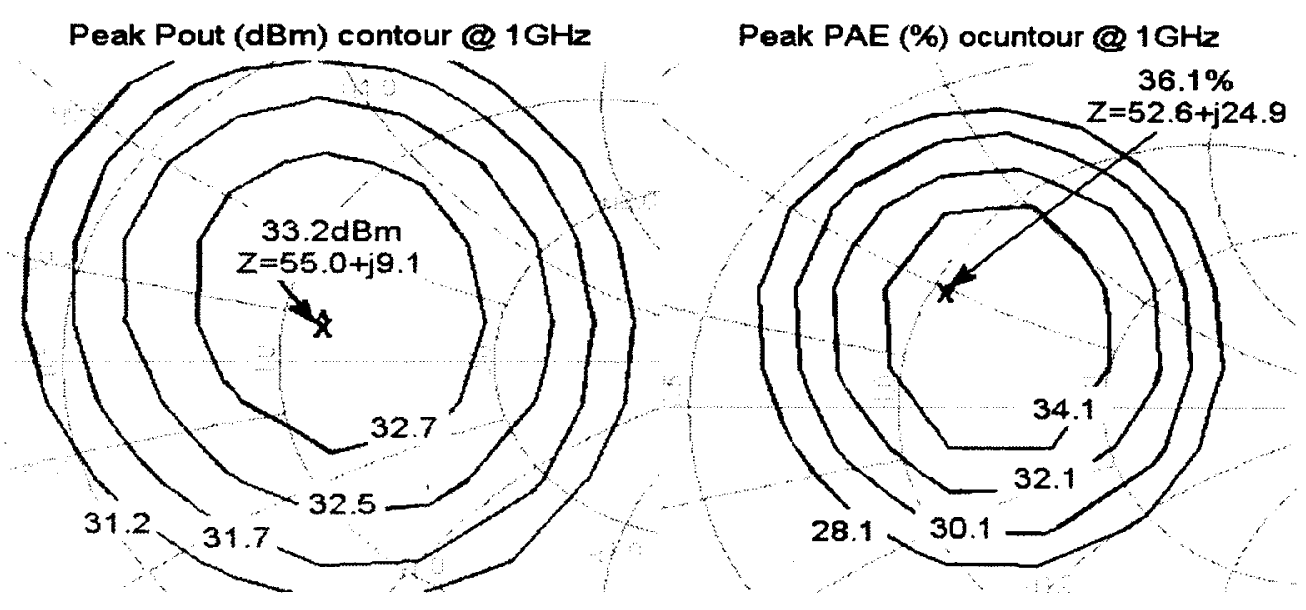

Figure 4.35.

Load pull simulation at $1 \mathrm{GHz}$.

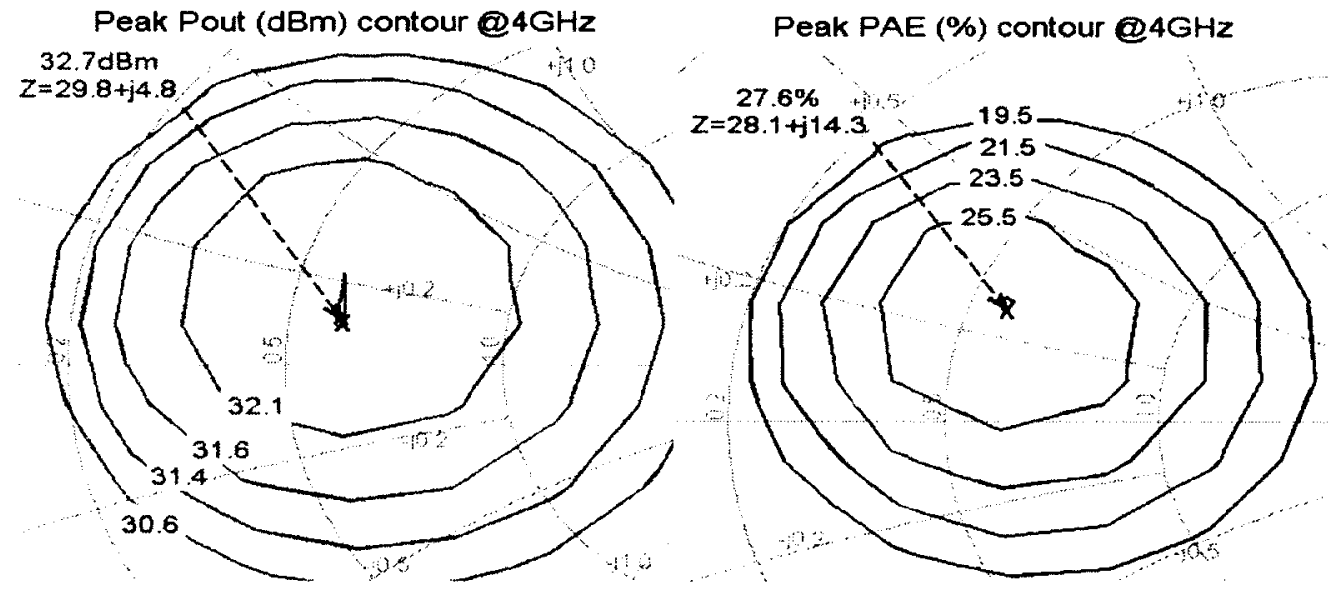

Figure 4.36.

Load pull simulation at $4 \mathrm{GHz}$. 


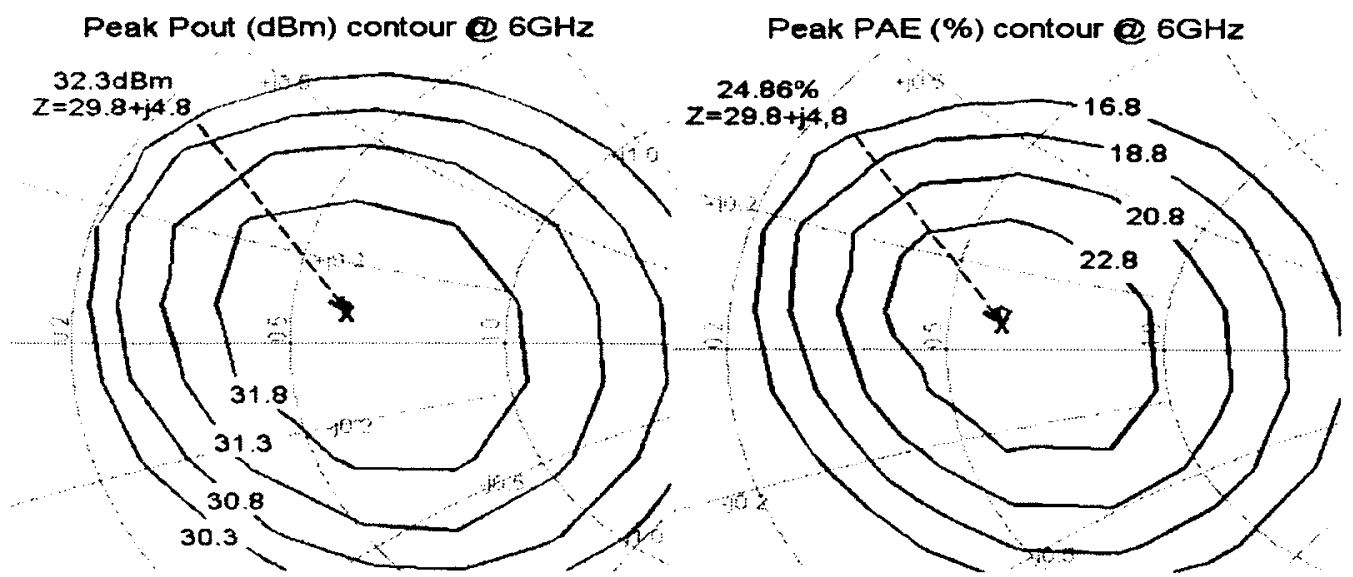

Figure 4.37.

Load pull simulation at $6 \mathrm{GHz}$.

There is another phenomenon that attracts our attention in Figure 4.33. The input waveform is also distorted, not an ideal sinusoidal wave which is supplied by an ideal signal source in ADS. The reason for this will be explained in the next section.

\subsubsection{Nonlinear Capacitance Effect Research}

In this section, we will discuss the nonlinear effect due to the gate-to-source parasitic element inside the HFET, $\mathrm{C}_{\mathrm{gg}}$, as this mechanism is responsible for a part of the signal distortion observed in the previous section.

The analysis of nonlinear properties of voltage-dependent capacitors has a long history, reaching as far back as the 1960 s when varactor multipliers were the only means of generating significant power levels at $\mathrm{GHz}$ frequencies using solid state components [8]. First, we will review the basic equation of current to voltage in a circuit which has nonlinear capacitance at input terminal, as shown in Figure 4.38. 


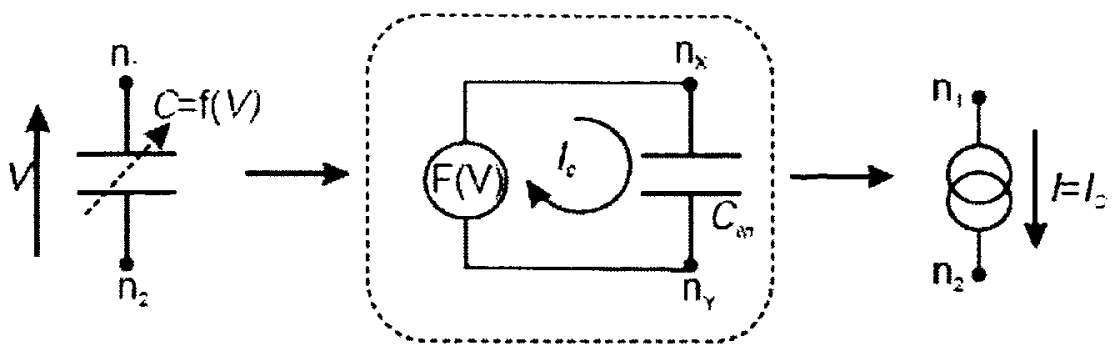

Figure 4.38. Investigate of nonlinear capacitance effect on current.

The linear and nonlinear capacitance is named as $C_{\text {lin }}$ and $C_{\text {nonlin }}$ respectively. The nonlinear function describing the differential capacitance variation along with the voltage is given as,

$$
C_{\text {nonlin }}=f(V)
$$

where the output voltage is equal to the voltage integral of the capacitance,

$$
F(V)=\int f(V) d V
$$

Then, the total current passing through the circuit is proportional to the sum effect coming from both the linear and nonlinear capacitance part, which is given as

$$
I=C_{\text {lin }} \frac{d V}{d t}=C_{l i n} \frac{d F(V)}{d V} \frac{d V}{d t}=C_{\text {lin }} f(V) \frac{d V}{d t}
$$

In the time domain simulation, the device input voltage is distorted from its original sinusoidal form because of the exit of $\mathrm{C}_{\mathrm{gs}}$ as shown in Figure 4.39. If the bias point is changed, the change of conduction angle of the output is observed. The reason of that is because of the varactor distortion; in other words, it is caused by the voltage distortion of $\mathrm{C}_{\mathrm{gg}}$. Further, the voltage distortion appearing across parasitic capacitance $\mathrm{C}_{\mathrm{gs}}$ will cause significant changes in the output voltage harmonic products.

Single transistor model and characteristics were investigated in Section 4.1, from which it can be concluded that the parasitic capacitance $C_{g s}$ does not change 
significantly over frequency. We use the same methodology here to have a look at the varactor effect of $\mathrm{C}_{\mathrm{gs}}$ versus variations in its gate voltage. A frequency of $3 \mathrm{GHz}$ is chosen for an $8 \times 50 \mu \mathrm{m}$ HFET with gate voltage $V_{g s}$ varying from $-3 \mathrm{~V}$ to $+3 \mathrm{~V}$.
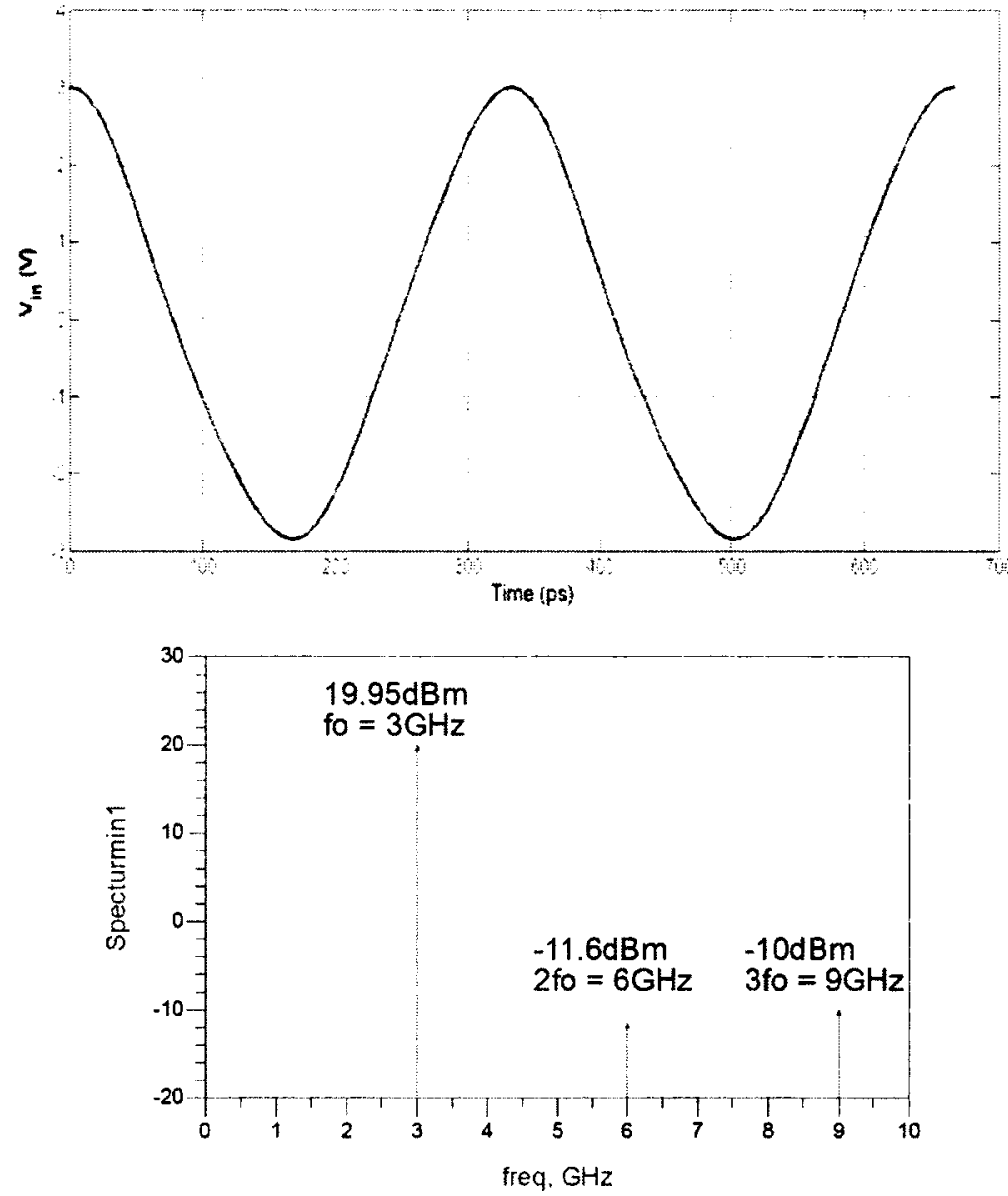

Figure 4.39. Input voltage distortion in time domain and frequency domain.

The gate-to-source capacitance, $C_{g s}$, is observed to change when $V_{g s}$ is swept, and the margin is approximately $487 \mathrm{fF}$ to $245 \mathrm{fF}$ as shown in Figure 4.40.

Now it becomes clear after this brief inspection that the input varactor capacitance $C_{g s}$ can have a major impact on voltage and current distortion in the ADPA's operation. As a possible solution to the harmonic distortion caused by the varactor effect of $\mathrm{C}_{\mathrm{gs}}$, 
a harmonic short circuit could be used at the input side of the transistor device. This would be similar to harmonic short circuits placed at the output of the device in narrow band PA design. While the $2^{\text {nd }}$ harmonic is normally shorted via $\lambda / 4$ short circuited shunt stub (SCSS) at the transistor device's output in MMIC design, it would seem that minimal distortion on the input side is due to both $2^{\text {nd }}$ and $3^{\text {rd }}$ harmonics (see frequency domain plot in Figure 4.39).

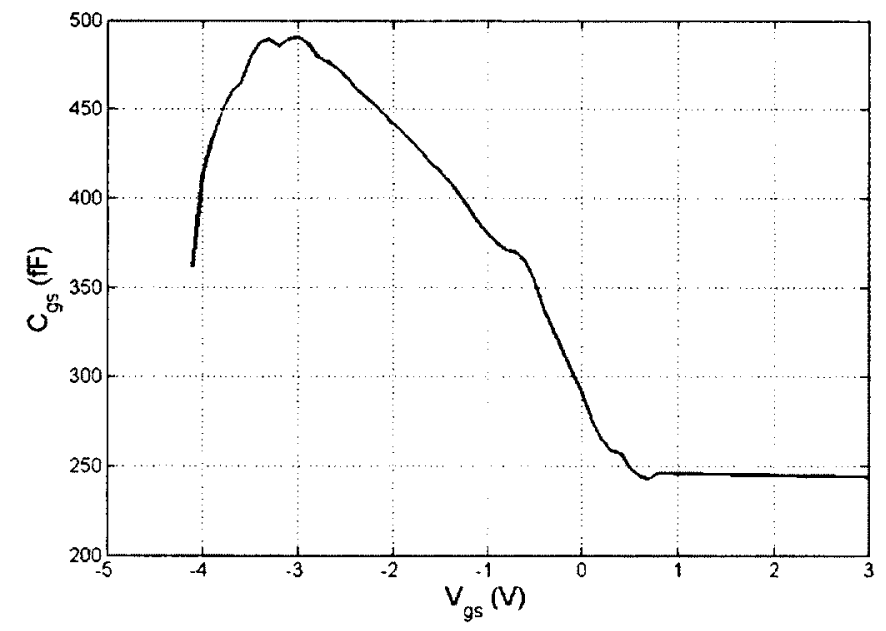

Figure 4.40. $\quad \mathrm{C}_{\mathrm{gs}}$ as a function of $\mathrm{V}_{\mathrm{gs}}$ at $3 \mathrm{GHz}$.

\subsection{Experimental Setup}

The high efficient linear broadband ADPA chips were fabricated at the NRC using the CPFC GaN500 technology. The fabricated chip is shown in Figure 4.40. In this section we describe the experimental set up intended to measure the following PA performance parameters: DC I-V curve; small-signal s-parameters; full power $\mathrm{P}_{\text {out }}$ (while input $20 \mathrm{dBm}$ RF power); 1-dB compression point $\left(\mathrm{P}_{1 \mathrm{~dB}}\right)$; saturated output power $\left(\mathrm{P}_{\text {sat }}\right)$. From the measured data, PAE and linearity (IIP3/OIP3) will be derived. Because of the limitation of available apparatuses, Bit Error Rate (BER) and Error 
Vector Magnitude (EVM) will not be experimentally measured.

\section{Chip Grounding and Heat-sinking}

Test samples were mounted on a metal heat-sink as shown in Figure 4.41 in order to, first, spread the thermal dissipation, and second, create a ground plane which exists in the simulation layer set-up but not included in the implemented substrate. Once the chip/heat-sink assembly is placed on the probe station, the ground will exist for both the probes and the PA chip via the test station's metal chuck. Six DC bias pads are connected to GND (three pads on the top and three pads on the bottom as shown in Figure 4.42) using wire bonding to the metal plate. Therefore, the test samples are well grounded not only through the GSG (Ground-Signal-Ground) probe, but also via the ground metal chuck of the probe station.

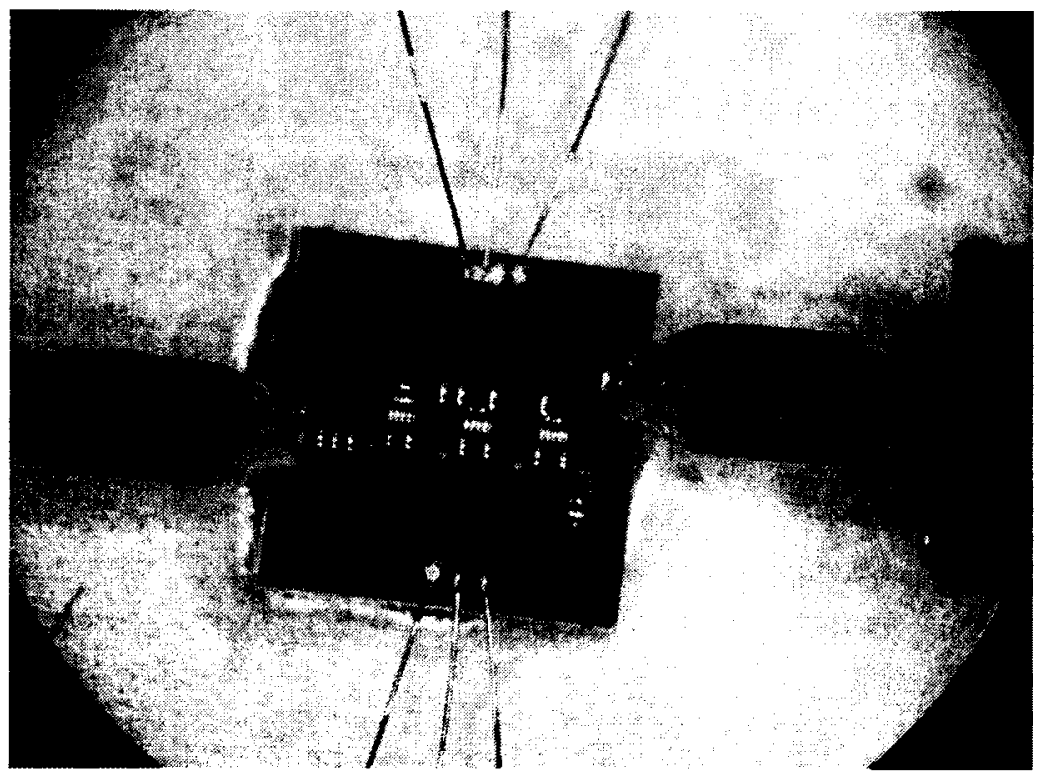

Figure 4.41.

Chip under test. 


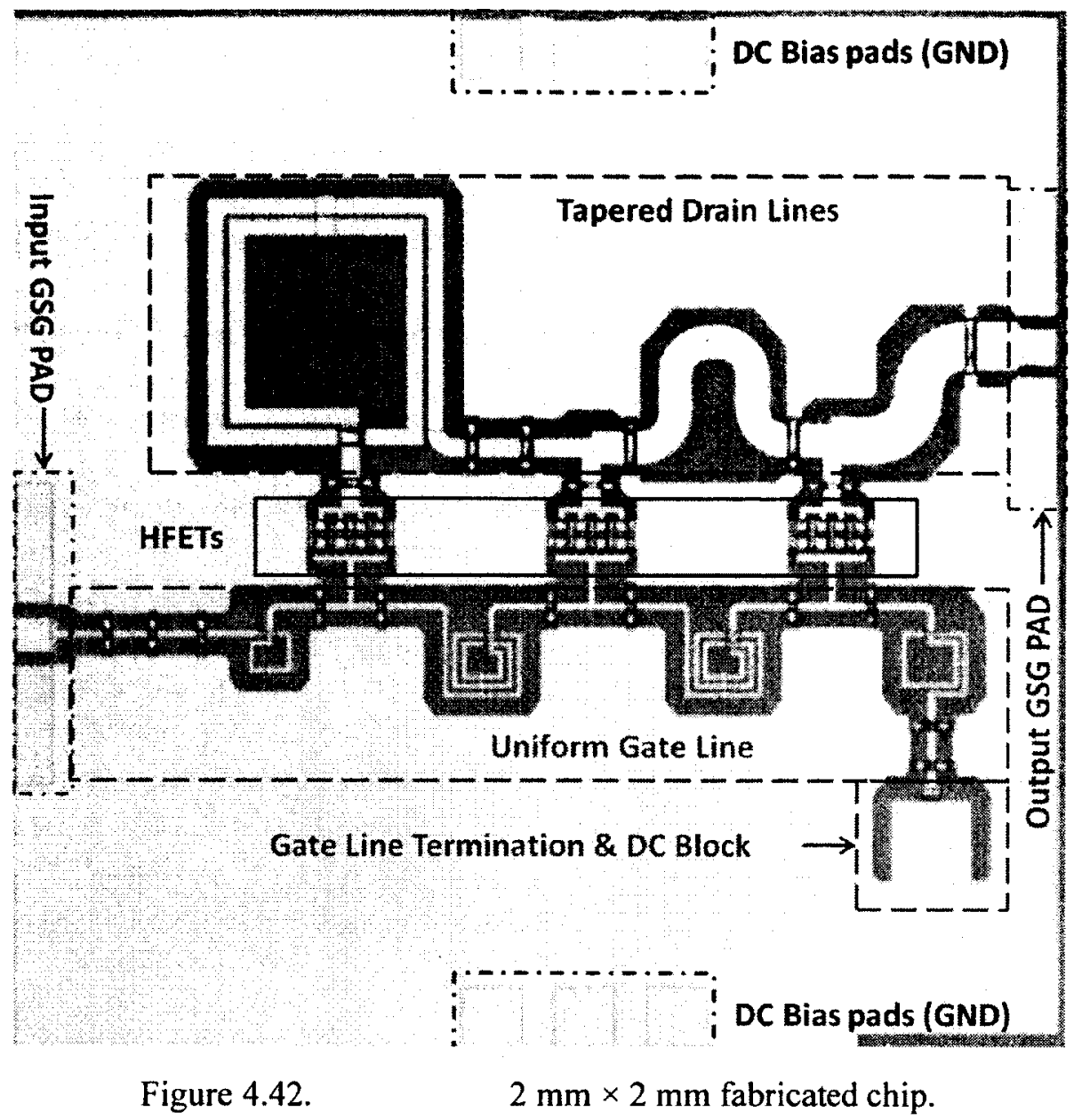

\section{DC \& RF Measurement Apparatus}

The test components used can be categorized as DC and RF in nature; several test benches were set up using different pieces of equipment available in the Department of Electronics at Carleton University. All required instruments were carefully selected based on the ADPA simulated performance. All the test benches' set-up and equipment brief specifications are presented, and the ICs were tested on a Cascade Microtech 9000TM Analytical Probe Station. As an example, a photograph of the DC test and 1-tone RF measurement (1-tone power test and small signal s-parameter measurement) set-up is shown as Figure 4.43. 


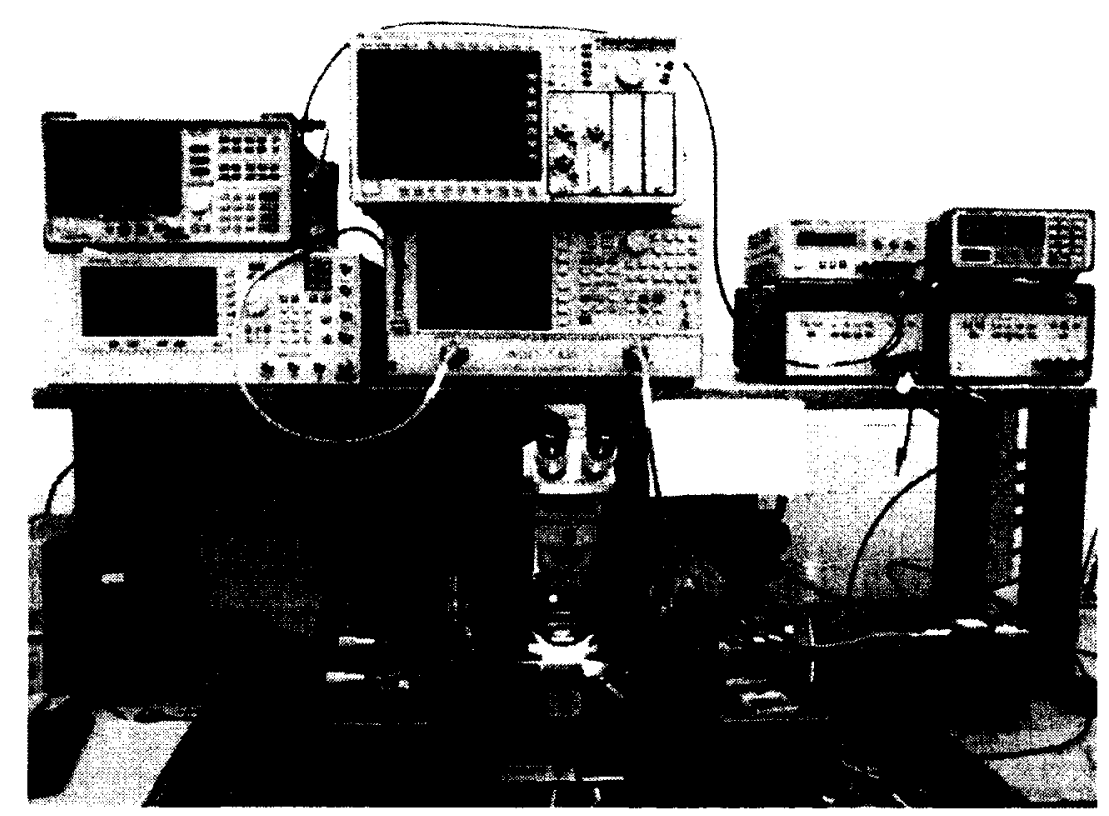

Figure 4.43 .

1-tone power test and small signal s-parameter test set-up.

First, the DC test is presented. Before starting any RF test, an oscillation test was performed to check whether the ADPA would have any unwanted instability and oscillation. This was done by biasing the PA with the DC supply but no RF signal applied to the input, with the output connected to an oscilloscope via the probes. When DC sources were turned on, no oscillation waveform was observed at the output of the power amplifier. This means that the noise injected by the DC supply does not cause the power amplifier to oscillate. After the oscillation check, a DC I-V (current-voltage) curve was measured. By biasing the device with the DC voltage supply, the current levels were recorded.

Then, the RF measurements are introduced. Due to the limitation of the s-parameter Network Analyzer which is opt001, instead of the high power test option such as opt085, the large-signal s-parameter measurement cannot be performed. In our 
measurement, only the small-signal s-parameters were obtained. The set-up diagram is shown as Figure 4.44, and the apparatuses are listed in Table 4.2, where 'BT' represents the bias tee and 'DUT' represents the device under test. In the diagram, probes are included in paths instead of being represented by a separate block. This rule of not illustrating the probes in the diagram will also be applied to all subsequent figures.

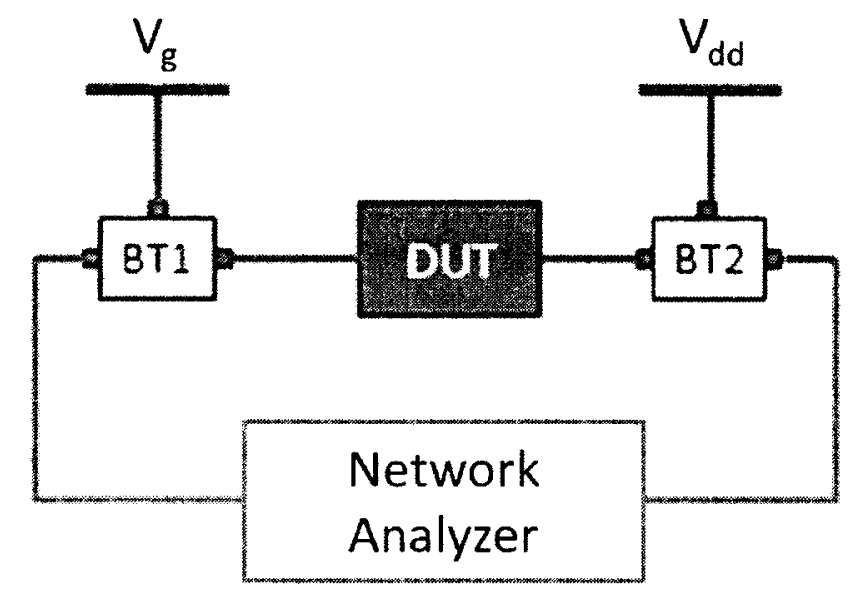

Figure 4.44. Small signal s-parameter test set-up diagram.

Table 4.2. $\quad$ Equipment list for small-signal s-parameter test.

\begin{tabular}{|c|c|c|c|c|}
\hline Fintor & 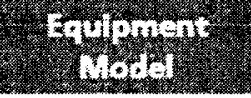 & 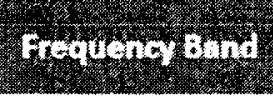 & hating & gathing \\
\hline $\begin{array}{c}V_{g} \\
\text { Supply }\end{array}$ & HP E3630A & DC & N/A & $\begin{array}{c}0 \mathrm{~V}-6 \mathrm{~V}, 2.5 \mathrm{~A} \\
10 \mathrm{~V}- \pm 20 \mathrm{~V}, 1.5 \mathrm{~A}\end{array}$ \\
\hline $\begin{array}{l}\text { Vdd } \\
\text { Supply }\end{array}$ & Agilent E3646A & DC & N/A & $\begin{array}{c}0 \mathrm{~V}-8 \mathrm{~V}, 3 \mathrm{~A} \\
10 \mathrm{~V}-20 \mathrm{~V}, 1.5 \mathrm{~A}\end{array}$ \\
\hline $\begin{array}{c}\text { BT1 } \\
\text { Bias Tee }\end{array}$ & $\begin{array}{l}\text { Picosecond } \\
5541 A-104\end{array}$ & $80 \mathrm{KHz}-26 \mathrm{GHz}$ & $1 \mathrm{~W} \max$. & $\begin{array}{c}50 \mathrm{~V}, 100 \mathrm{~mA} \\
\max .\end{array}$ \\
\hline $\begin{array}{c}\text { BT2 } \\
\text { Bias Tee }\end{array}$ & $\begin{array}{l}\text { HP 11590A } \\
\text { OPT1001 }\end{array}$ & $1 \mathrm{GHz}-18 \mathrm{GHz}$ & $\begin{array}{l}24 \mathrm{dBm} \\
\text { max. }\end{array}$ & $\begin{array}{c}100 \mathrm{~V}, 500 \mathrm{~mA} \\
\max .\end{array}$ \\
\hline $\begin{array}{c}\text { RF } \\
\text { Probes }\end{array}$ & $\begin{array}{c}\text { GGB Model } \\
\text { 40A-GSG-150P }\end{array}$ & $\mathrm{DC}-40 \mathrm{GHz}$ & N/A & N/A \\
\hline $\begin{array}{l}\text { Network } \\
\text { Analyzer }\end{array}$ & HP 8722ES & $\begin{array}{c}50 \mathrm{MHz}-40 \mathrm{GHz} \\
80\end{array}$ & $\begin{array}{l}30 \mathrm{dBm} \\
\max .\end{array}$ & $40 \vee \max$. \\
\hline
\end{tabular}


Single-tone power measurements such as power gain, output power, and PAE (Power-Added-Efficiency) were performed by using the test diagram and the equipment shown in Figure 4.45 and Table 4.3 respectively. Two different models of bias tee were used for BT2 (Bias Tee 2) depending on the frequency band. For measurements in the $0.5 \mathrm{GHz}-4 \mathrm{GHz}$ range, the Mini-Circuit bias tee was used as the maximum output levels are in excess of $24 \mathrm{dBm}$, which is the maximum RF power specification of the Agilent bias tee. Due to the limited available RF power of the signal generator and the loss of input cables, a pre-amplifier was used to obtain the required $20 \mathrm{dBm} R$ R input power. This pre-amp was used for measurements at $2 \mathrm{GHz}$ and higher.

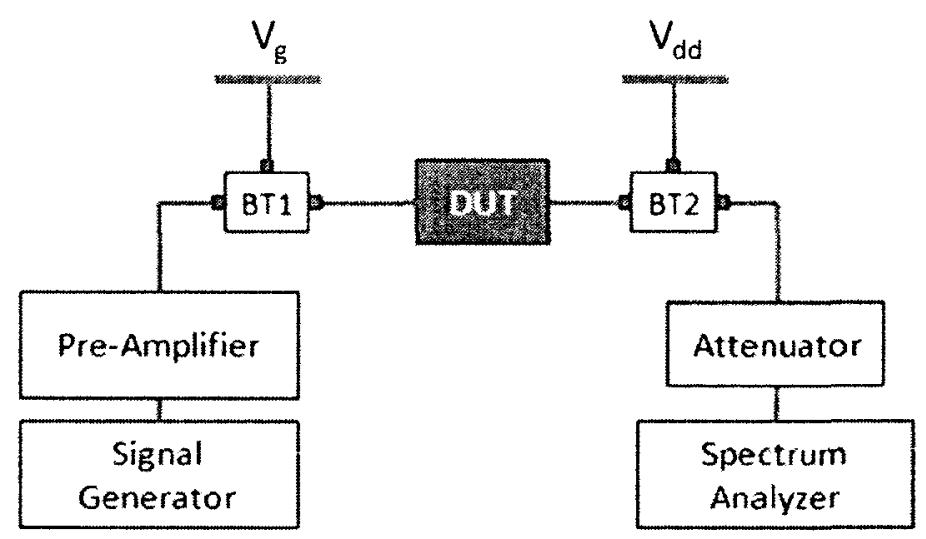

Figure 4.45. 1-tone power test set-up diagram 
Table 4.3. Equipment list for 1-tone power test.

\begin{tabular}{|c|c|c|c|c|}
\hline $\begin{array}{l}\text { Function } \\
\text { Pame }\end{array}$ & $\begin{array}{l}\text { Equipment } \\
\text { Model }\end{array}$ & Frequenoy Band & $\begin{array}{l}\text { Bf Power } \\
\text { Rating }\end{array}$ & DCPating \\
\hline $\begin{array}{c}V_{\mathbf{g}} \\
\text { Supply }\end{array}$ & HP E3630A & $D C$ & N/A & $\begin{array}{c}0 \mathrm{~V}-6 \mathrm{~V}, 2.5 \mathrm{~A} \\
10 \mathrm{~V}- \pm 20 \mathrm{~V}, 1.5 \mathrm{~A}\end{array}$ \\
\hline $\begin{array}{l}\text { Vdd } \\
\text { Supply }\end{array}$ & Agilent E3646A & $D C$ & N/A & $\begin{array}{c}0 V-8 V, 3 \mathrm{~A} \\
10 \mathrm{~V}-20 \mathrm{~V}, 1.5 \mathrm{~A}\end{array}$ \\
\hline $\begin{array}{c}\text { BT1 } \\
\text { Bias Tee }\end{array}$ & $\begin{array}{l}\text { Picosecond } \\
5541 A-104\end{array}$ & $80 \mathrm{KHz}-26 \mathrm{GHz}$ & $1 W_{\max }$ & $\begin{array}{c}50 \mathrm{~V}, 100 \mathrm{~mA} \\
\max .\end{array}$ \\
\hline \multirow{2}{*}{$\begin{array}{c}\text { BT2 } \\
\text { Bias Tee }\end{array}$} & $\begin{array}{l}\text { Mini-Circuit } \\
15542 \text { ZFBT- } \\
\text { 4R2GW }\end{array}$ & $0.1 \mathrm{MHz}-4.2 \mathrm{GHz}$ & $\begin{array}{l}30 \mathrm{dBm} \\
\max .\end{array}$ & $\begin{array}{c}30 \mathrm{~V}, 500 \mathrm{~mA} \\
\max .\end{array}$ \\
\hline & $\begin{array}{l}\text { HP 11590A } \\
\text { OPT1001 }\end{array}$ & $1 \mathrm{GHz}-18 \mathrm{GHz}$ & $\begin{array}{l}24 \mathrm{dBm} \\
\max .\end{array}$ & $\begin{array}{c}100 \mathrm{~V}, 500 \mathrm{~mA} \\
\max .\end{array}$ \\
\hline $\begin{array}{c}\mathrm{RF} \\
\text { Probes }\end{array}$ & $\begin{array}{c}\text { GGB Model } \\
\text { 40A-GSG-150P }\end{array}$ & $\mathrm{DC}-40 \mathrm{GHz}$ & N/A & N/A \\
\hline Attenuator & $\begin{array}{c}\text { Mini-Circuits } \\
15542 \text { VAT-6 } \\
6 \mathrm{~dB} \text { Attenuator }\end{array}$ & $\mathrm{DC}-6 \mathrm{GHz}$ & $1 \mathrm{~W}$ Rating & No DC Feeding \\
\hline Pre-Amp & HP 8349B & $2 \mathrm{GHz}-20 \mathrm{GHz}$ & $\begin{array}{l}38 \mathrm{dBm} \\
\max .\end{array}$ & N/A \\
\hline $\begin{array}{l}\text { Signal } \\
\text { Generator }\end{array}$ & $\begin{array}{c}\text { Agilent E8257C } \\
\text { PSG }\end{array}$ & $250 \mathrm{KHz}-40 \mathrm{GHz}$ & $\begin{array}{l}23 \mathrm{dBm} \\
\text { Rating }\end{array}$ & $N / A$ \\
\hline $\begin{array}{l}\text { Spectrum } \\
\text { Analyzer }\end{array}$ & HP $8593 E$ & $9 \mathrm{KHz}-26.5 \mathrm{GHz}$ & $\begin{array}{l}30 \mathrm{dBm} \\
\max .\end{array}$ & OV \\
\hline
\end{tabular}

Then, 2-tone measurement, which is used for the linearity evaluation of the IIP3 and OIP3, is presented. The set-up diagram and the equipment list are shown in Figure 4.46 and Table 4.4 respectively. 


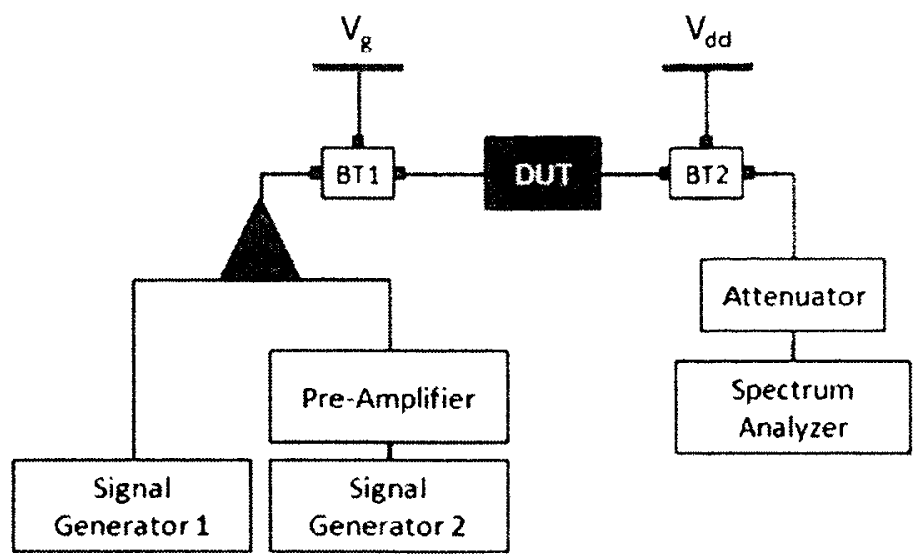

Figure 4.46.

2-tone measurement set-up diagram.

Table 4.4.

Equipment list for 2-tone measurement.

\begin{tabular}{|c|c|c|c|c|}
\hline Futsion & 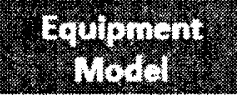 & Freprenor Bond & 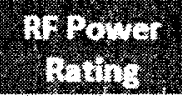 & Expoting \\
\hline $\begin{array}{c}V_{B} \\
\text { Supply }\end{array}$ & HP E3630A & $\mathrm{DC}$ & N/A & $\begin{array}{c}0 \mathrm{~V}-6 \mathrm{~V}, 2.5 \mathrm{~A} \\
10 \mathrm{~V}- \pm 20 \mathrm{~V}, 1.5 \mathrm{~A}\end{array}$ \\
\hline $\begin{array}{l}\text { Vdd } \\
\text { Supply }\end{array}$ & Agilent E3646A & DC & N/A & $\begin{array}{c}0 V-8 V, 3 \mathrm{~A} \\
10 \mathrm{~V}-20 \mathrm{~V}, 1.5 \mathrm{~A}\end{array}$ \\
\hline $\begin{array}{c}\text { BT1 } \\
\text { Bias Tee }\end{array}$ & $\begin{array}{l}\text { Picosecond } \\
5541 A-104\end{array}$ & $80 \mathrm{KHz}-26 \mathrm{GHz}$ & $1 \mathrm{~W} \max$. & $\begin{array}{c}50 \mathrm{~V}, 100 \mathrm{~mA} \\
\text { max. }\end{array}$ \\
\hline \multirow{2}{*}{$\begin{array}{c}\mathrm{BT} 2 \\
\text { Bias Tee }\end{array}$} & $\begin{array}{c}\text { Mini-Circuit } \\
\text { 15542 ZFBT- } \\
\text { 4R2GW }\end{array}$ & $0.1 \mathrm{MHz}-4.2 \mathrm{GHz}$ & $\begin{array}{l}30 \mathrm{dBm} \\
\max .\end{array}$ & $\begin{array}{c}30 \mathrm{~V}, 500 \mathrm{~mA} \\
\max .\end{array}$ \\
\hline & $\begin{array}{l}\text { HP 11590A } \\
\text { OPT1001 }\end{array}$ & $1 \mathrm{GHz}-18 \mathrm{GHz}$ & $\begin{array}{l}24 \mathrm{dBm} \\
\max .\end{array}$ & $\begin{array}{c}100 \mathrm{~V}, 500 \mathrm{~mA} \\
\text { max. }\end{array}$ \\
\hline $\begin{array}{c}\mathrm{RF} \\
\text { Probes }\end{array}$ & $\begin{array}{c}\text { GGB Model } \\
\text { 40A-GSG-150P }\end{array}$ & $\mathrm{DC}-40 \mathrm{GHz}$ & $N / A$ & N/A \\
\hline Attenuator & $\begin{array}{l}\text { Mini-Circuits } \\
15542 \text { VAT-6 } \\
\text { 6dB Attenuator }\end{array}$ & $\mathrm{DC}-6 \mathrm{GHz}$ & 1. W Rating & No DC Feeding \\
\hline Pre-Amp & HP 83498 & $2 \mathrm{GHz}-20 \mathrm{GHz}$ & $\begin{array}{l}38 \mathrm{dBm} \\
\max .\end{array}$ & N/A \\
\hline $\begin{array}{c}\text { Signal } \\
\text { Generator1 } \\
\text { Signal } \\
\text { Generator2 }\end{array}$ & $\begin{array}{c}\text { Agilent E8257C } \\
\text { PSG }\end{array}$ & $250 \mathrm{KHz}-40 \mathrm{GHz}$ & $\begin{array}{l}23 \mathrm{dBm} \\
\text { Rating }\end{array}$ & N/A \\
\hline $\begin{array}{l}\text { Spectrum } \\
\text { Analyzer }\end{array}$ & HP 8593E & $9 \mathrm{KHz}-26.5 \mathrm{GHz}$ & $\begin{array}{l}30 \mathrm{dBm} \\
\max .\end{array}$ & OV \\
\hline
\end{tabular}




\subsection{Measurement Results and Analysis of the Fabricated Chip}

As introduced in the above section, practical measurements are conducted at DC and at RF separately. The available DC supply does not allow pulsed-mode measurements for the I-V curves. The RF performance is obtained without any signal modulation (i.e. CW mode only).

The measured $I_{d}-V_{d s}$ curves are shown in Figure 4.47, along with the corresponding simulated curves of the 3 parallel connected transistors. As can be seen, the measured curves show a roll-off in the saturated region which is not found in simulations. This is believed to be due to the trapping effect and mainly the thermal effect as explained

in detail in Chapter 2. The thermal effect is present because of the high temperature obtained through DC power dissipation within the device. With reference to Figure 4.47, when the ADPA is biased at $\mathrm{V}_{\mathrm{gs}}=-2.5 \mathrm{~V}$, and $\mathrm{V}_{\mathrm{ds}}=15 \mathrm{~V}$ (nominal bias conditions), the total drain current is approximately $300 \mathrm{~mA}$, which results in $4.5 \mathrm{~W}$ of internal power dissipation; compared to simulation, the measured current is approximately $100 \mathrm{~mA}$ down from the simulated curve in the saturated region. It should be noted that, the gate length of the GaN HFET is $500 \mathrm{~nm}$, which is a short gate device. When such a device operates at high temperature, its electron mobility and saturation velocity are reduced from their corresponding low temperature values. While such an effect might be detrimental to RF performance, it is believed that the RF simulation model takes heating into account and the result is satisfactory (as seen in the following RF measurements). 


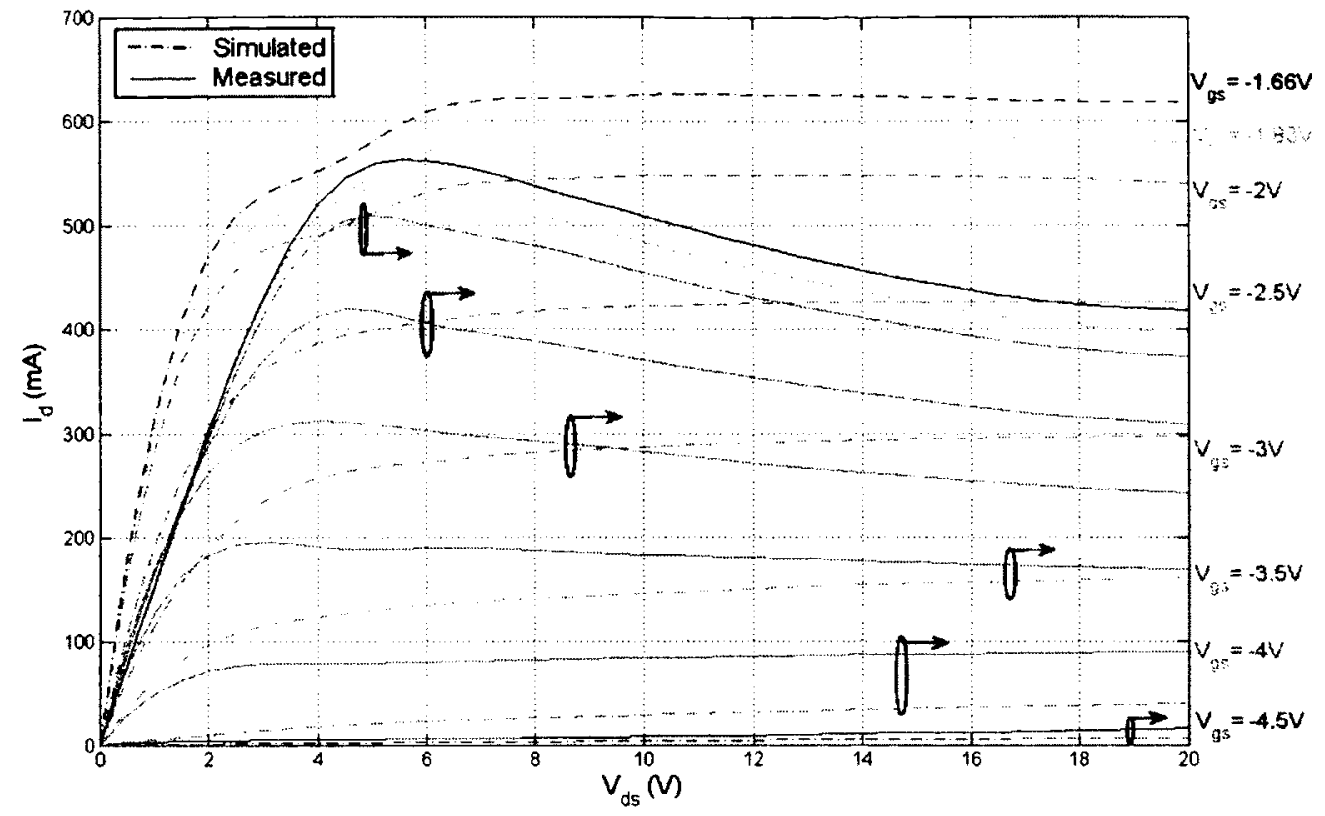

Figure 4.47.

Measured and simulated DC $I_{d s}-V_{d s}$ curves

(Vgs values are indicated for simulated curves).

Now the measured RF performance is presented. Small-signal s-parameters are measured by using an s-parameter network analyzer, as introduced in the above section. Figure 4.48 presents the measured and simulated small-signal s-parameter results. The measured gain $\left(\mathrm{S}_{21}\right)$ is approximately $13 \mathrm{~dB}$ over the operating band of $0.5 \mathrm{GHz}-6.5 \mathrm{GHz}$. It is also approximately $2.8 \mathrm{~dB}$ lower than the simulation data over the entire $0.1 \mathrm{GHz}-10 \mathrm{GHz}$ range, which is believed to be due to the self-heating effect that is not taken into account during small-signal simulations. None the less, the measured gain is above the $10 \mathrm{~dB}$ specification over the operating frequency range of the ADPA. From the remaining $S_{11}$ and $S_{22}$ curves shown in Figure 4.48 , it can be seen that, the measured performance matches well with the simulation data. The ADPA is found to be well matched at the input port $(\mathrm{S} 11<-10 \mathrm{~dB})$ from $0.5 \mathrm{GHz}-$ 
$6.5 \mathrm{GHz}$, and the shifts in $S_{11}$ and $S_{22}$ minima are likely due to some parasitic components of the ADPA which are not fully captured during simulation (such as grounding through bond-wires, probe to pad parasitic, etc.). Also, some jitter in the small signal plots exist at the frequencies above the $0.1 \mathrm{GHz}-6.5 \mathrm{GHz}$ bandwidth, which is due to the high frequency limitations of the cables used in the test system. For instance, the available cables employed in the test set up are limited to testing at frequencies below $6 \mathrm{GHz}$.

To support the investigation of the jittery behavior, the s-parameters of Thru on the Impedance Standard Substrates (ISS) were measured after the network analyzer was calibrated. The results are shown in Figure 4.49. The small jitter shows up, and the return loss $S_{11}$ and $S_{22}$ are above $-40 \mathrm{~dB}$ from $6 \mathrm{GHz}$ to $10 \mathrm{GHz}$, which would not be expected with perfect cables. Meanwhile, there exists a difference between $S_{11}$ and $S_{22}$ as a function of the frequency, which is another indication of the imperfection in the cables. All these phenomena related to the performance of the cables used in the test system confirm that the accuracy is limited beyond $6 \mathrm{GHz}$. 


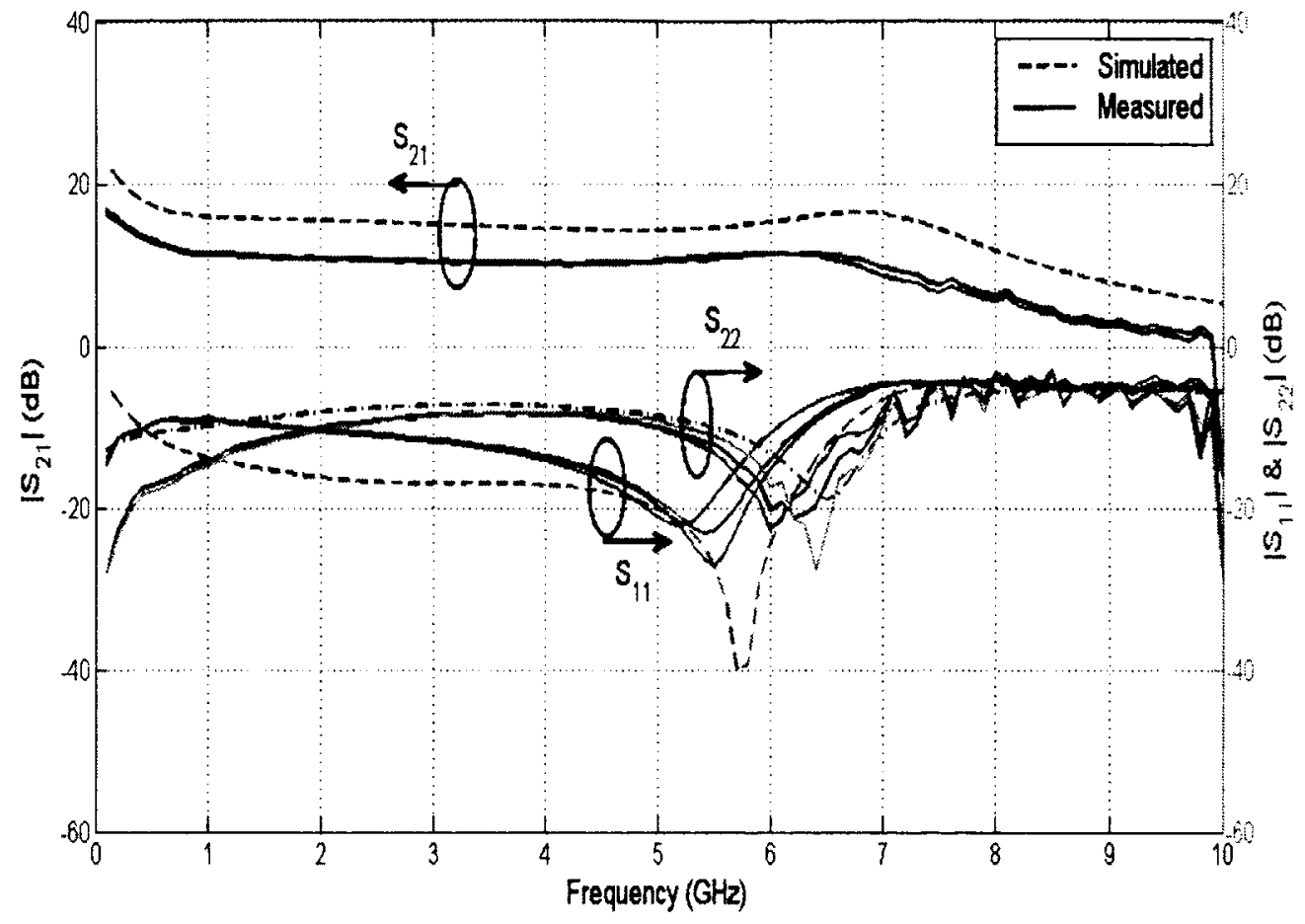

Figure 4.48. Measured and simulated small-signal s-parameters for three samples

(at nominal bias condition of $\mathrm{V}_{\mathrm{gs}}=-2.5 \mathrm{~V}, \mathrm{~V}_{\mathrm{dd}}=15 \mathrm{~V}$ ).

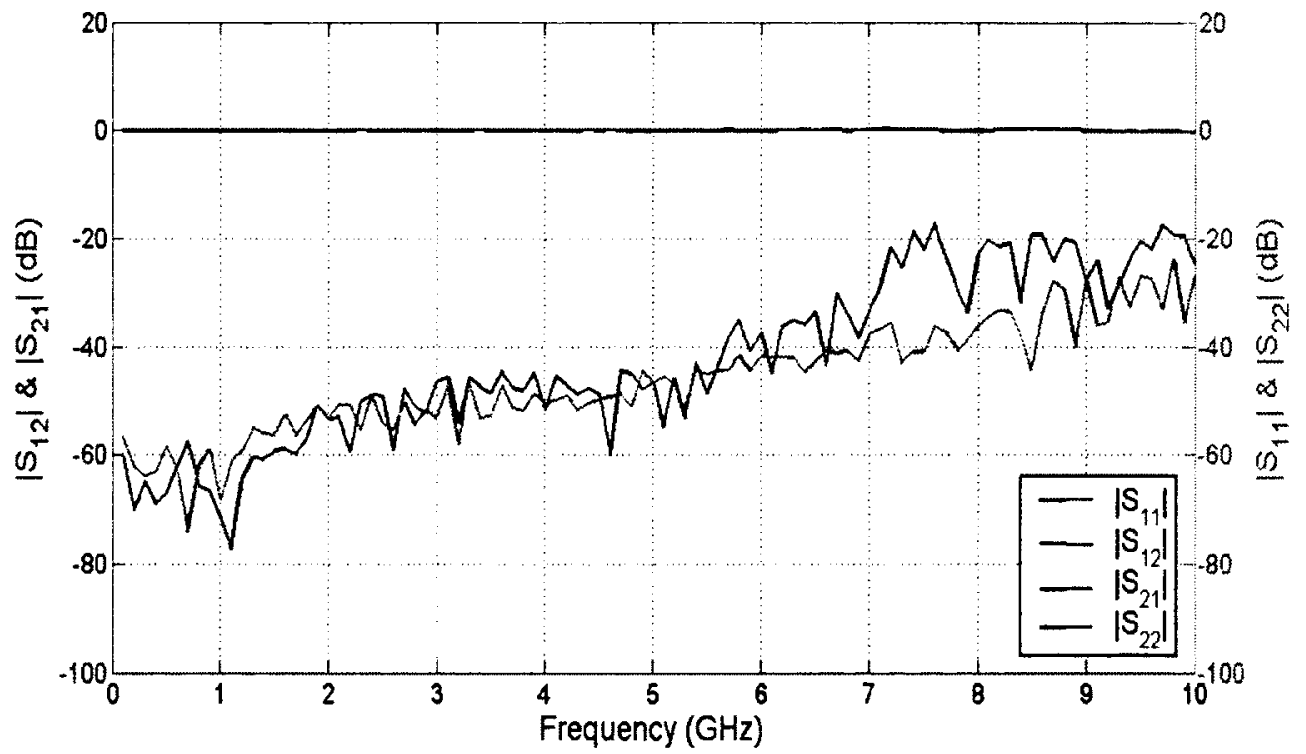

Figure 4.49. S-parameters of ISS Thru after the network analyzer calibrated. 
Further characterization of the ADPA consisted of sweeping $V_{g s}$ while keeping $V_{d d}$ at $15 \mathrm{~V}$ to investigate the relationship between the small signal voltage gain $\left(\mathrm{S}_{21}\right)$ and $V_{\mathrm{gs}}$. The measured results of one sample are shown in Figure 4.50 (the results from two other samples were virtually identical and are not shown). The maximum gain is obtained when the device is biased at $\mathrm{V}_{\mathrm{gs}}=-3.5 \mathrm{~V}, \mathrm{~V}_{\mathrm{ds}}=15 \mathrm{~V}$ in simulation, but at $\mathrm{V}_{\mathrm{gs}}$ $=-3 \mathrm{~V}, \mathrm{~V}_{\mathrm{ds}}=15 \mathrm{~V}$ in measurement. The input and output return loss $S_{11}$ and $S_{22}$ present no big difference among various bias conditions over the operating frequency range, and the best matching is obtained while the maximum gain is achieved. The difference between optimum simulated and optimum measured $V_{\mathrm{gs}}$ values is due to the DC modeling limitation of the HFETs, and is confirmed by the results in Figure 4.47.

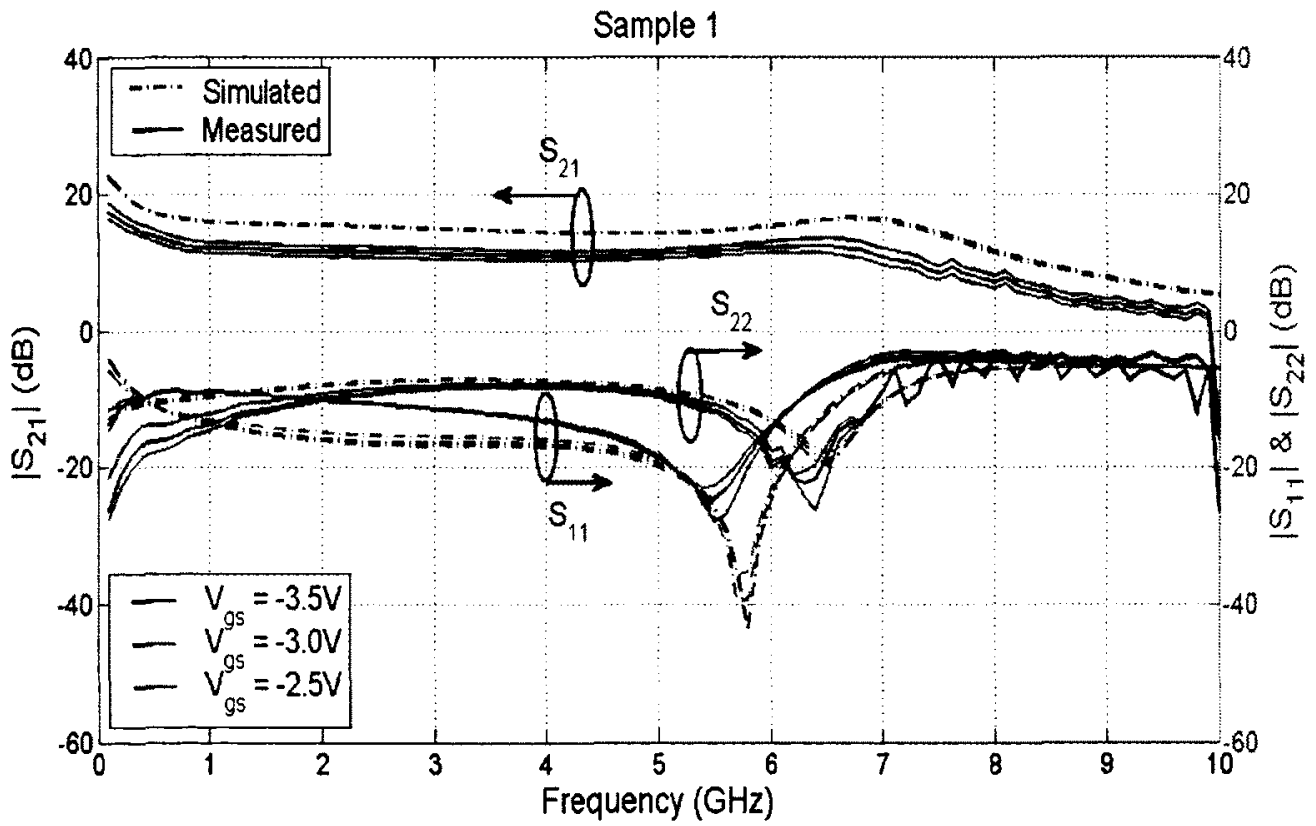

Figure 4.50. Small-signal s-parameters of chip sample 1 while sweeping $\mathrm{V}_{\mathrm{gs}}$. 
According to the comparison of measured and simulated s-parameters as shown above, cable characterization and power compensation should be done in the following power test, where the apparatus has no test system calibration function. The power meter was used in the cable loss data collection. By comparing the power level of the signal generator direct output and at the end of the cables, the power loss of the cables were derived and recorded as the reference of the ADPA output power correction.

Then, the RF power measurements such as $\mathrm{P}_{\text {out }}$ PAE, $\mathrm{P}_{1 \mathrm{~dB}}$, and linearity are presented while input power $P_{\text {in }}=20 \mathrm{dBm}$ at $V_{\mathrm{gs}}=-2.5 \mathrm{~V}$ and $V_{\mathrm{ds}}=15 \mathrm{~V}$.

Figure 4.51 shows the simulated and measured output power as a function of frequency over the $0.5 \mathrm{GHz}-7 \mathrm{GHz}$ frequency range. As expected, the measured $P_{\text {out }}$ is above $30 \mathrm{dBm}$ over the entire $0.5 \mathrm{GHz}-6.5 \mathrm{GHz}$ operating bandwidth, and the peak output power of approximately $33 \mathrm{dBm}$ is achieved. Meanwhile, a slight difference (minimum $0.5 \mathrm{dBm}$ ) between the measured results and simulated data is observed, and it is changing as a function of frequency. The larger difference exists at frequencies higher than $5 \mathrm{GHz}$; this could be due to the self-heating effect and unaccounted for measurement error (e.g. random losses of cables). 


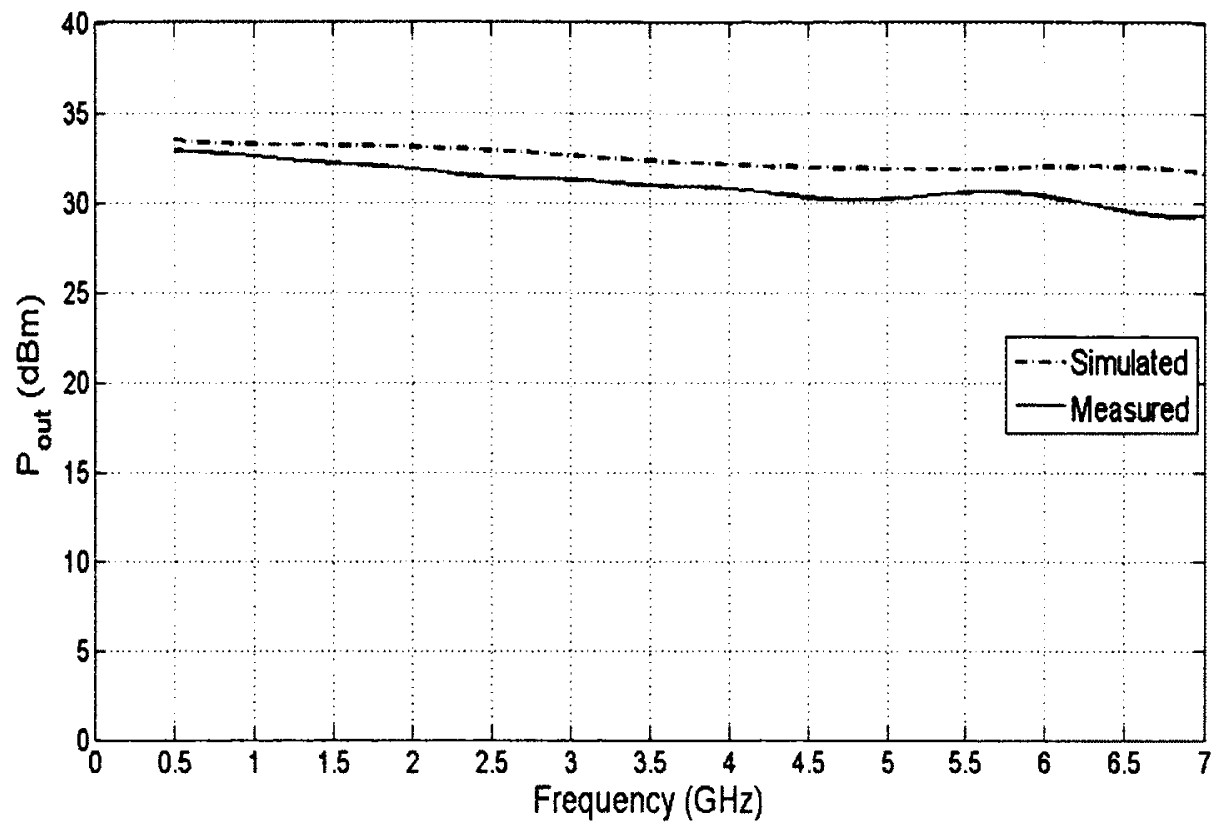

Figure 4.51. Measured and simulated $P_{\text {out }}$ of the ADPA for $P_{\text {in }}=20 \mathrm{dBm}$ at nominal DC bias.

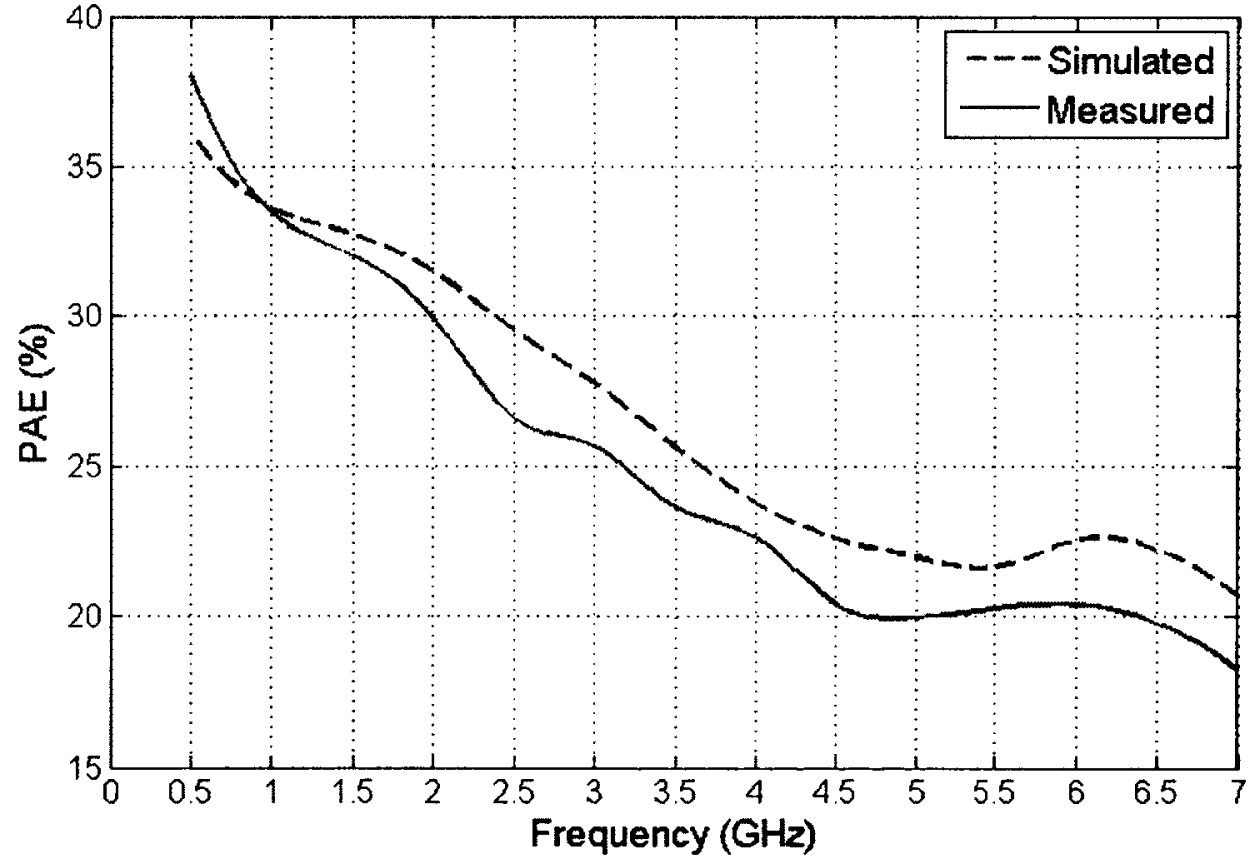

Figure 4.52. Measured and simulated PAE of the ADPA for $P_{\text {in }}=20 \mathrm{dBm}$ at nominal DC bias. 
Figure 4.52 presents the PAE performance comparison between the simulation and measurement. Due to the fact that the measured current consumption is lower than the value simulated, the measured PAE is above the simulation results at frequencies lower than $1 \mathrm{GHz}$, but beneath over $1 \mathrm{GHz}-7 \mathrm{GHz}$. A peak PAE of $38.1 \%$ is achieved at $0.5 \mathrm{GHz}$, while greater than $20 \%$ PAE is obtained over $0.5 \mathrm{GHz}-6.5$ GHz operating frequency of the ADPA. As described in Chapter 2, PAE is calculated as $\mathrm{PAE}=\left(\mathrm{P}_{\text {out }}-\mathrm{P}_{\mathrm{in}}\right)_{\mathrm{RF}} / \mathrm{P}_{\mathrm{DC}}$. For example at $2 \mathrm{GHz}$, Pout $=32 \mathrm{dBm}, \mathrm{Vds}=15 \mathrm{~V}$, Id $=331 \mathrm{~mA}$, Pin $=20 \mathrm{dBm}$ to yield $\mathrm{PAE}=30 \%$.

In Figure 4.53, measured output power is given as a function of input power at nominal bias, $2 \mathrm{GHz}$. 1-dB compression point $P_{1 \mathrm{~dB}}$ and saturated power $P_{\text {sat }}$ of approximately $31.3 \mathrm{dBm}$ and $32.2 \mathrm{dBm}$ are indicated in the plot respectively, according to the concept introduced in Chapter 2. As shown in Figure 4.54, a peak saturated output power of approximately $34 \mathrm{dBm}$ is measured at about $0.7 \mathrm{GHz}$, while a saturated power $P_{\text {sat }}$ above $30 \mathrm{dBm}$ is obtained over the $0.5 \mathrm{GHz}-6.5 \mathrm{GHz}$ frequency range. The measured $P_{\text {sat }}$ is approximately $1 \mathrm{dBm}$ down from the simulation, and the difference is observed as a function of frequency, which could be due to the self-heating effect and the error introduced in the measurement.

Figure 4.55 illustrates the comparison between measured 1-dB output power and simulated $P_{1 \mathrm{~dB}}$ as a function of frequency over $0.5 \mathrm{GHz}-7 \mathrm{GHz}$ range. A peak measured $\mathrm{P}_{1 \mathrm{~dB}}$ of approximately $32.6 \mathrm{dBm}$ is obtained at $0.5 \mathrm{GHz}$, while more than 30 $\mathrm{dBm}$ is measured over $0.5 \mathrm{GHz}-6.5 \mathrm{GHz}$ bandwidth. The two curves match each other very well, and the simulated curve shows a higher $P_{1 \mathrm{~dB}}$ over the measured one at 
most frequencies. A maximum difference of only approximately $1 \mathrm{~dB}$ is observed.

The measured OIP3 and IIP3 are given in Figure 4.56 for the two input tones separated by $10 \mathrm{MHz}$ from the design center frequency. The definitions of OIP3 and IIP3 are given in Chapter 2. The measured OIP3 and IIP3 are above $40 \mathrm{dBm}$ and 25 $\mathrm{dBm}$ respectively over the entire $2 \mathrm{GHz}-6.5 \mathrm{GHz}$ frequency range, which indicates that the ADPA is operating in the linear region with a nominal input of $20 \mathrm{dBm} R F$ power over the operating frequency bandwidth. The simulation results are in reasonable agreement.

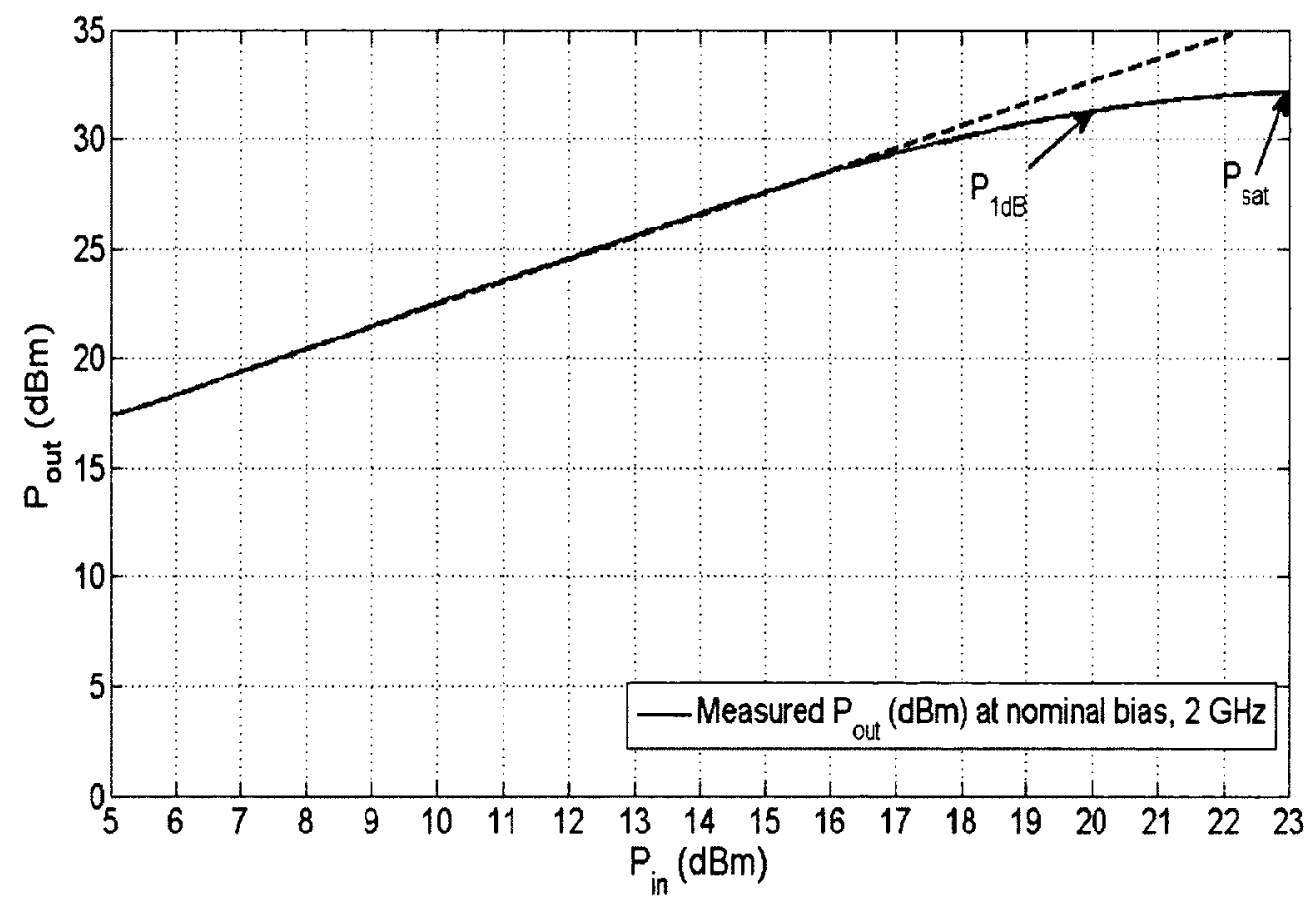

Figure 4.53.

Measured $\mathrm{P}_{\text {out }}$ at nominal bias, $2 \mathrm{GHz}$ 


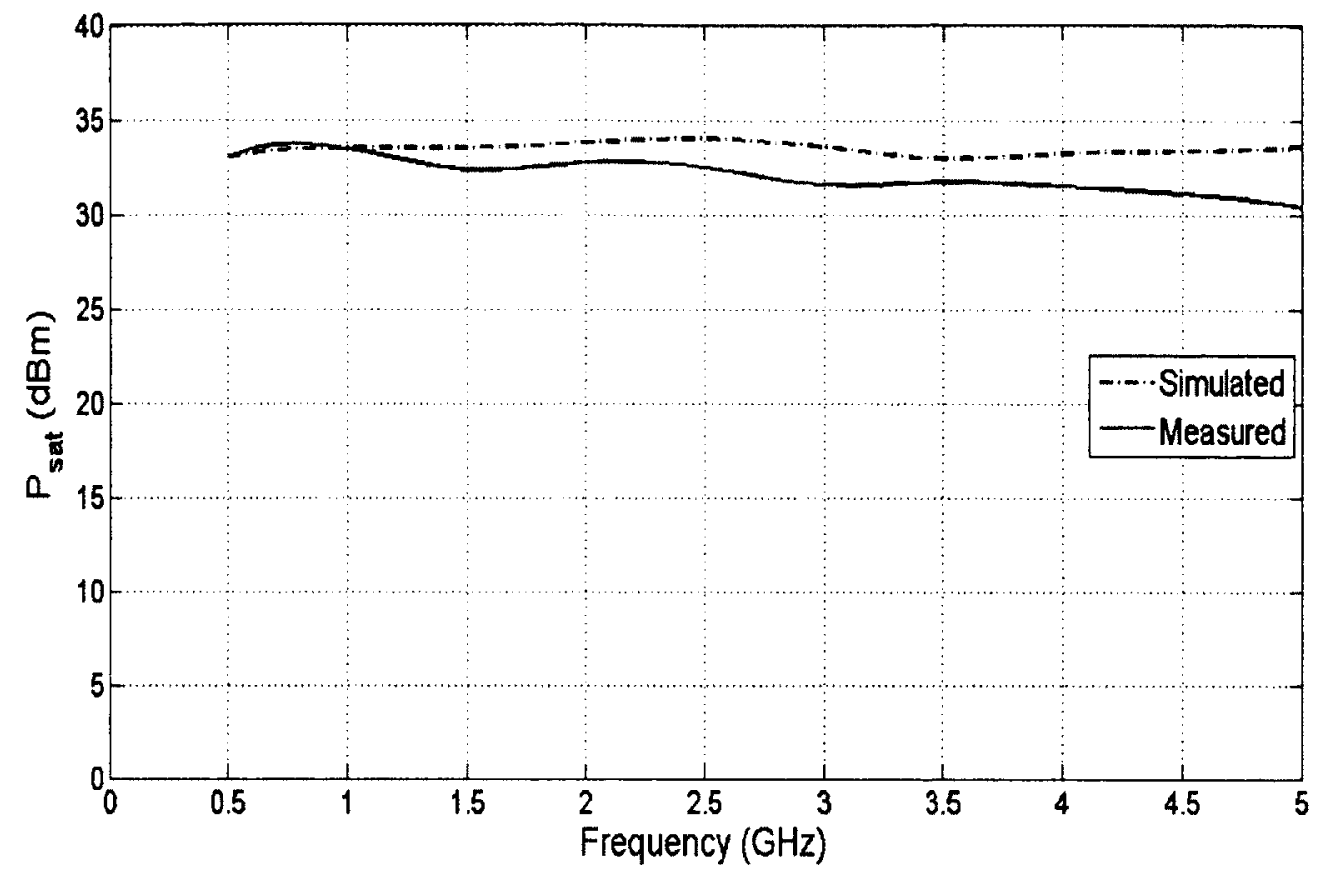

Figure 4.54. Measured and simulated $P_{\text {sat }}$ at nominal bias.

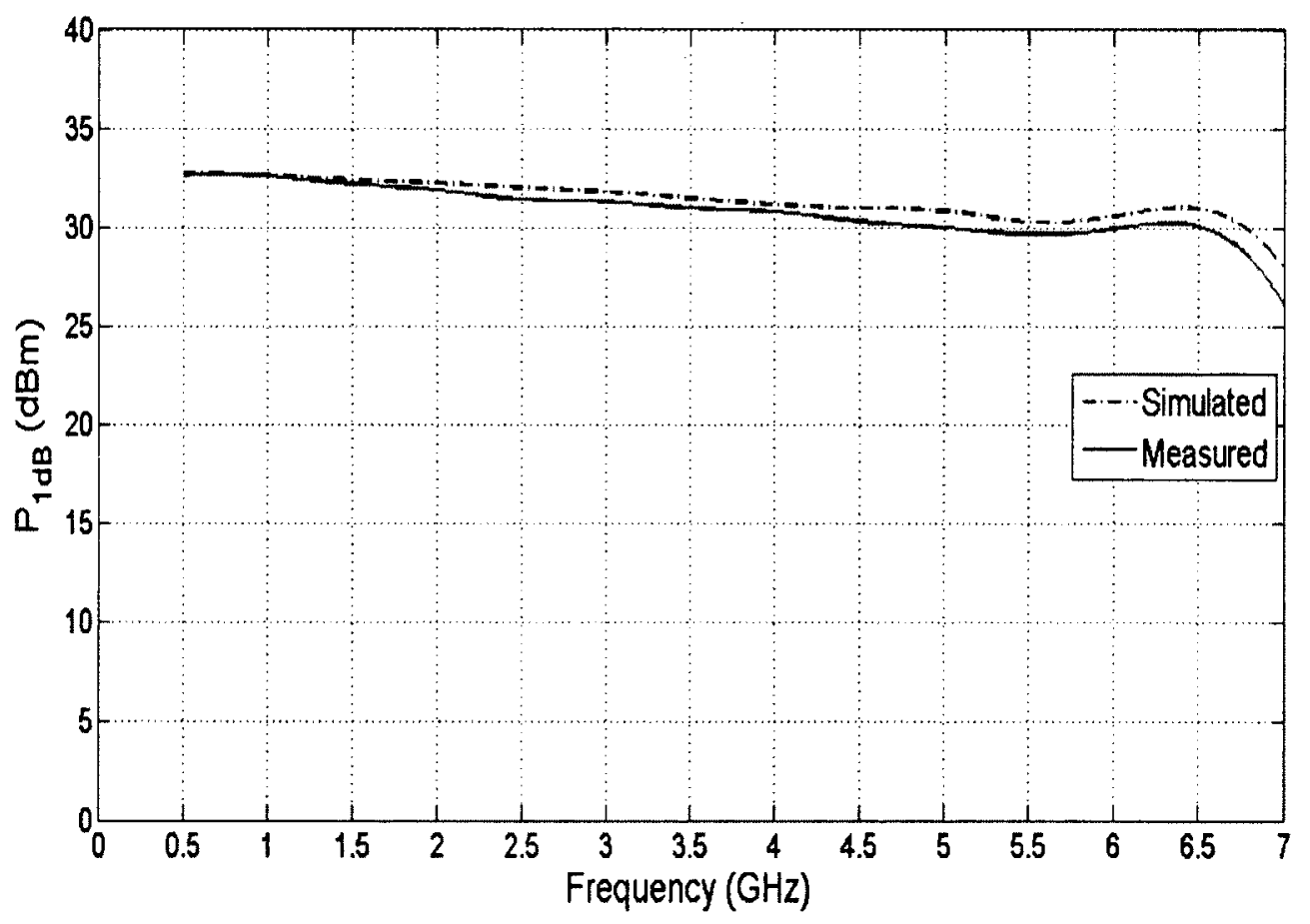

Figure 4.55.

Measured and simulated $P_{1 \mathrm{~dB}}$ at nominal bias. 


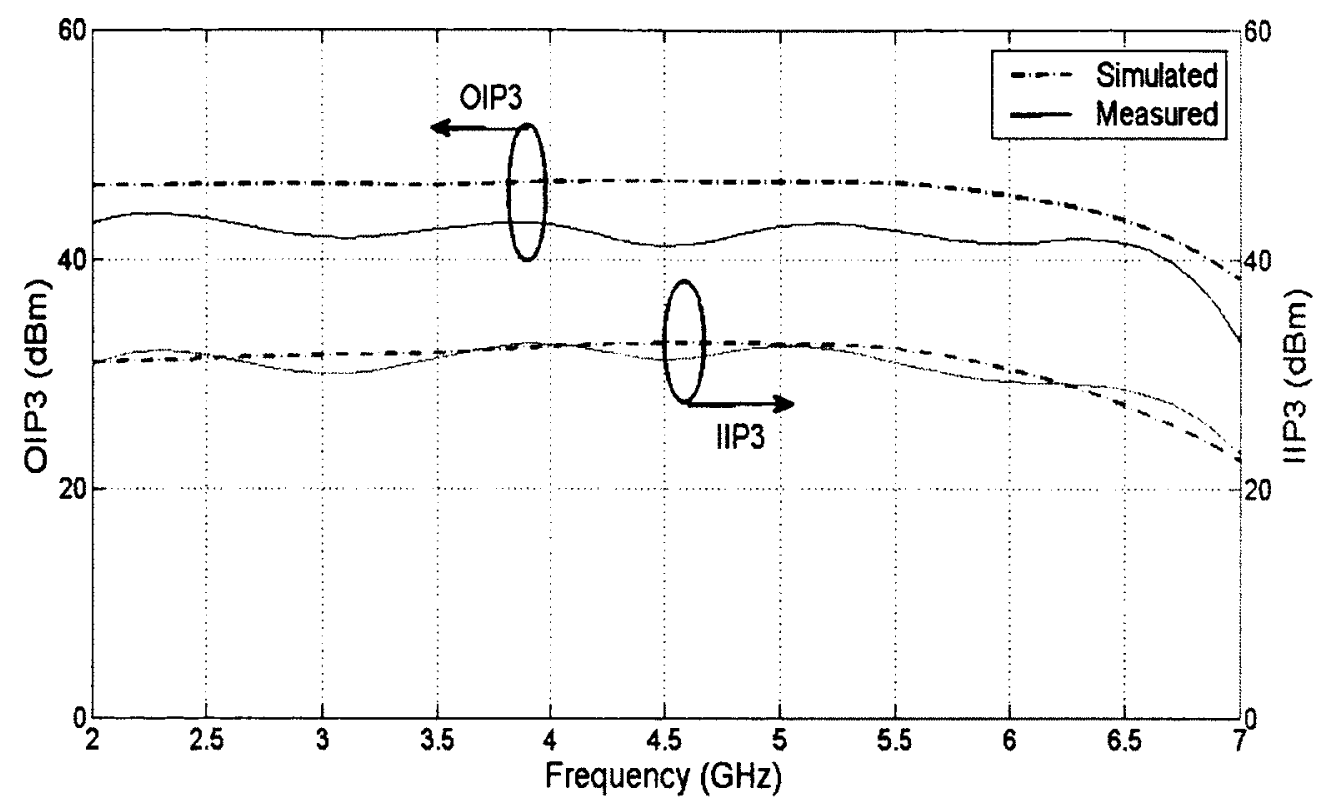

Figure 4.56.

Measured and simulated linearity at nominal bias.

As can be seen from the above plots, although there are some differences between the measurement results and the simulation data which are caused by self-heating and systematic errors during testing, the measured data successfully matches the simulated results.

To further, characterize the ADPA and determine the highest possible PAE, the bias point is swept together with input power. For instance, power performance is plotted at $\mathrm{V}_{\mathrm{gs}}=-3.5 \mathrm{~V}, \mathrm{~V}_{\mathrm{ds}}=15 \mathrm{~V}$, when sweeping the input power at $3 \mathrm{GHz}$, as shown in Figure 4.57; the maximum PAE is obtained at approximately $20.5 \mathrm{dBm}$ of input power, just before reaching the peak $\mathrm{P}_{\text {out }}$. When biasing the device into deeper saturation, lower PAE would be expected. At the operating condition of the peak PAE, more than $10 \mathrm{~dB}$ gain and $30 \mathrm{dBm} \mathrm{P}_{\text {out }}$ are obtained. 


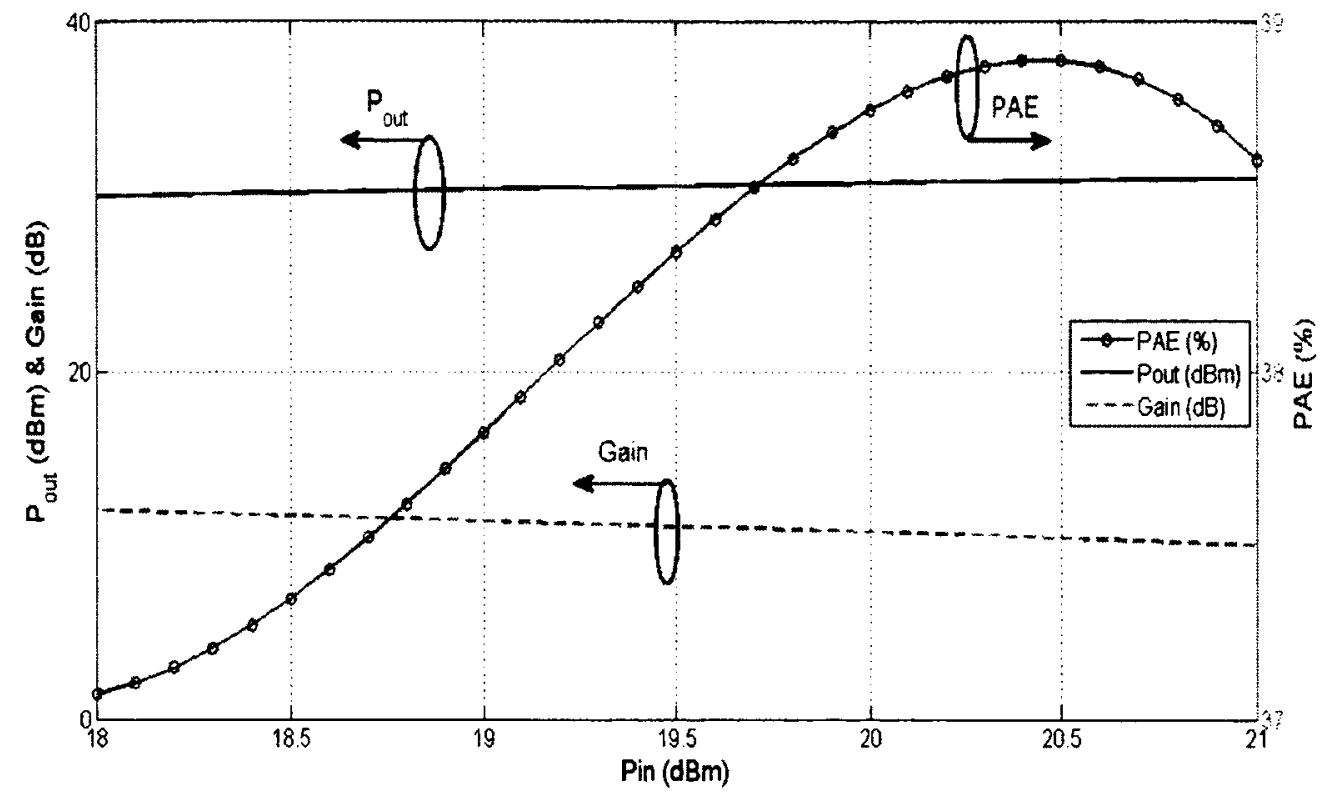

Figure 4.57. Measured power results biased at $\mathrm{V}_{\mathrm{gs}}=-3.5 \mathrm{~V}, \mathrm{~V}_{\mathrm{ds}}=15 \mathrm{~V}, \mathrm{I}_{\mathrm{d}}=$ $189 \mathrm{~mA}, 3 \mathrm{GHz}$.

Figure 4.58 shows the power and linearity performances while sweeping bias voltages (both $V_{g s}$ and $V_{d s}$ ) along with the input power $\left(P_{i n}\right)$ at $3 \mathrm{GHz}$. Since multiple combinations of bias and input power are driven by different drain DC currents, the various power levels are plotted versus drain DC current. A maximum PAE of approximately $40 \%$ is achieved when $20 \mathrm{dBm}$ of input power is supplied to the ADPA which draws about $190 \mathrm{~mA}$ DC current from the voltage source at $V_{\mathrm{gs}}=-3.5$ $\mathrm{V}, \mathrm{V}_{\mathrm{ds}}=15 \mathrm{~V}$ (point 1). Also, a gain of $10 \mathrm{~dB}$, more than $30 \mathrm{dBm} \mathrm{P}_{\text {out }}$ and about 38 $\mathrm{dBm}$ OIP3 are obtained at this operating condition. A peak gain of $12.9 \mathrm{~dB}$ is obtained when the ADPA is biased at $\mathrm{Vgs}=-2.5 \mathrm{~V}, \mathrm{Vds}=20 \mathrm{~V}(\mathrm{Id}=270 \mathrm{~mA})$, with $P_{\text {in }}=18 \mathrm{dBm}$ (point 2). The maximum output power of $32.5 \mathrm{dBm}$ is achieved at Vgs $=-3 \mathrm{~V}, \mathrm{Vds}=20 \mathrm{~V}(\mathrm{Id}=245 \mathrm{~mA}), P_{\text {in }}=21 \mathrm{dBm}$, indicated as point 3 in Figure 4.57. 


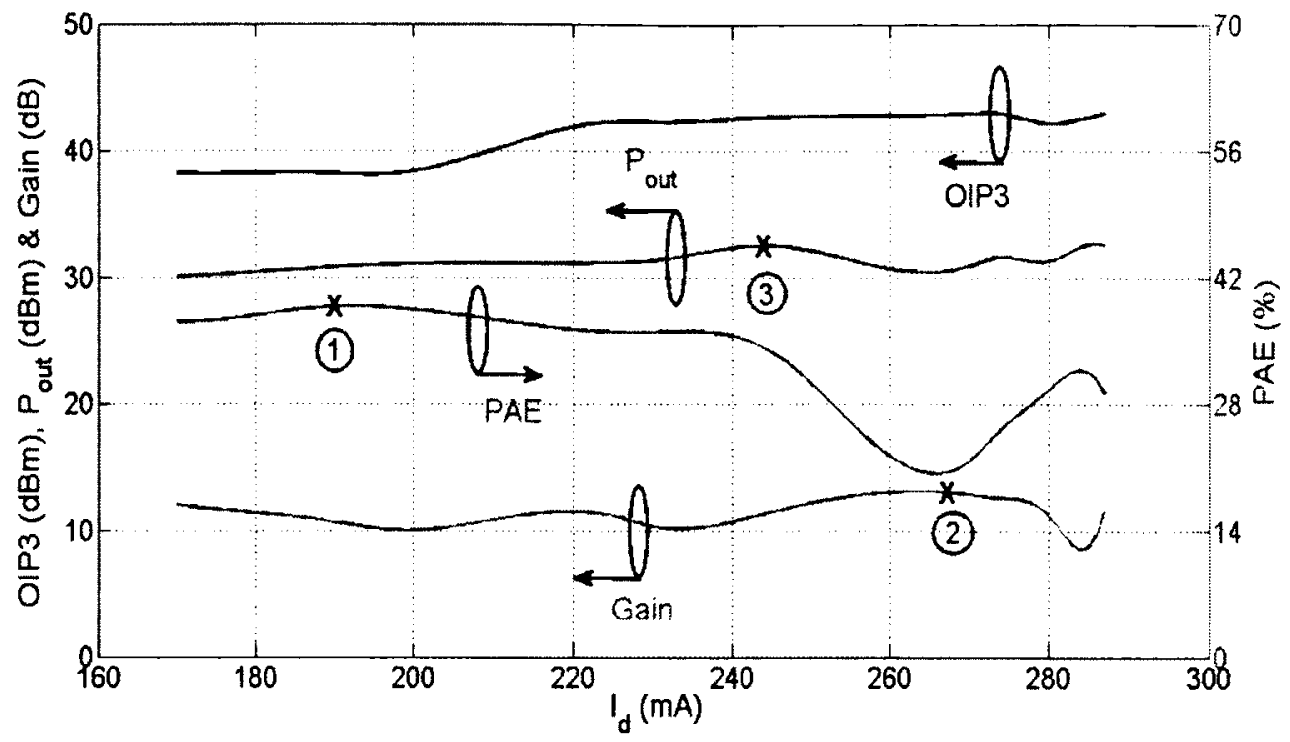

Figure 4.58. Measured: power and linearity performances versus drain current (sweeping bias voltage and input power at $3 \mathrm{GHz}$ ).

Figure 4.59 to Figure 4.61 illustrates the performance comparison between the original operating condition and the maximum PAE operating condition. The 'operating condition' mentioned does not only adjust the gate and drain bias voltages, but also the input power level. It can be seen that the output power for the two conditions (nominal and maximum PAE) described is almost the same over $0.5 \mathrm{GHz}-$ $5 \mathrm{GHz}$ range, and the $\mathrm{P}_{\text {out }}$ of the ADPA when working at maximum PAE is above 30 $\mathrm{dBm}$ over the entire $0.5 \mathrm{GHz}-6.5 \mathrm{GHz}$ bandwidth. From Figure 4.60, a maximum PAE of approximately $52.7 \%$ is obtained at $0.5 \mathrm{GHz}$. The PAE is higher than $40 \%$ up to $2 \mathrm{GHz}$, and larger than $30 \%$ up to $3.5 \mathrm{GHz}$, while the PAE curve is above $20 \%$ over $0.5 \mathrm{GHz}-6.5 \mathrm{GHz}$ bandwidth. The bias voltage comparison between the original and maximum PAE condition is illustrated in Table 4.5.

The gain and linearity of these two operating conditions are checked as shown in 
Figure 4.61. A higher gain of approximately $1 \mathrm{~dB}$ above the gain of the ADPA working at the original operating condition is obtained, when the ADPA is operating at the maximum PAE condition over the entire $0.5 \mathrm{GHz}-6.5 \mathrm{GHz}$ bandwidth, while linearity is decreased as a trade-off. However, the IIP3 and OIP3 of the ADPA working at the maximum PAE condition is higher than $20 \mathrm{dBm}$ and $30 \mathrm{dBm}$ respectively over $0.5 \mathrm{GHz}-6.5 \mathrm{GHz}$ frequency range, which means the ADPA will operate in linear mode in applications requiring high PAE.

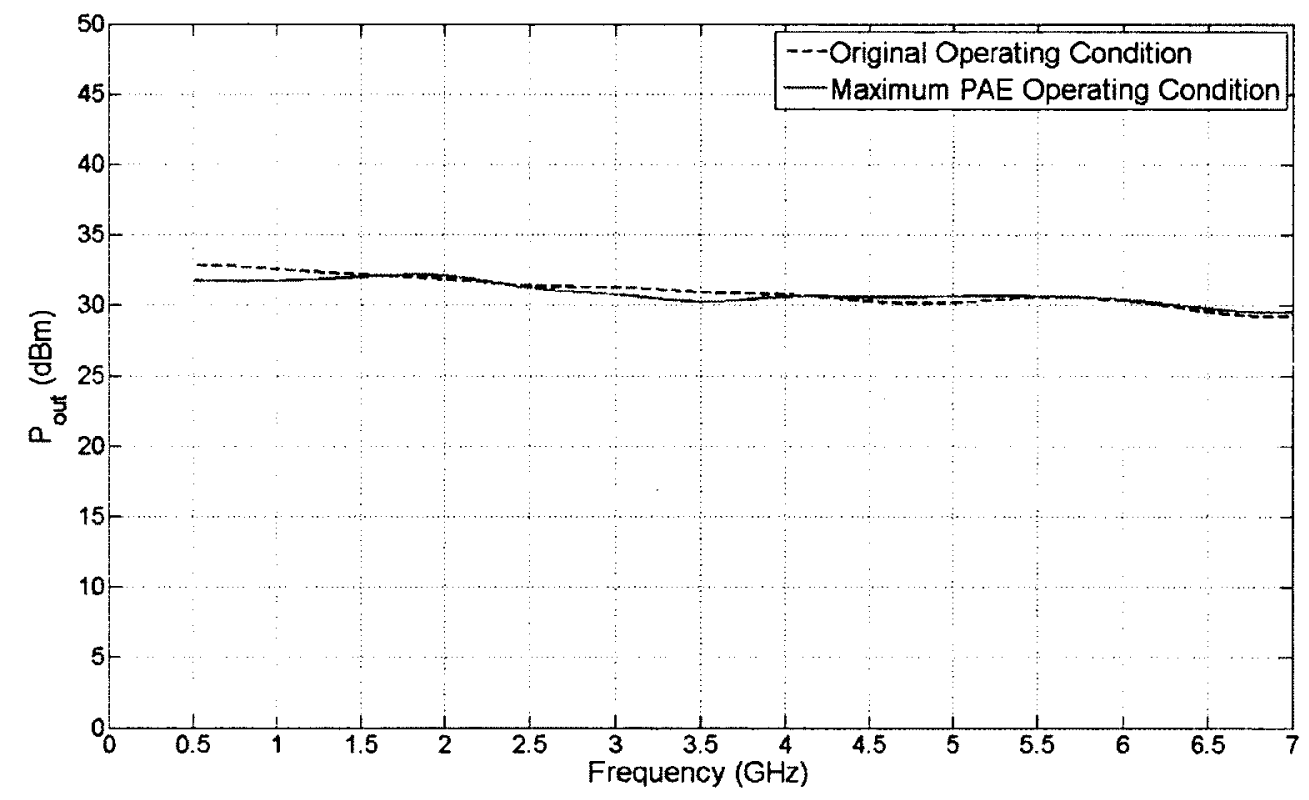

Figure 4.59. Measured $\mathrm{P}_{\text {out }}$ comparison of the maximum PAE and the original operating condition. 


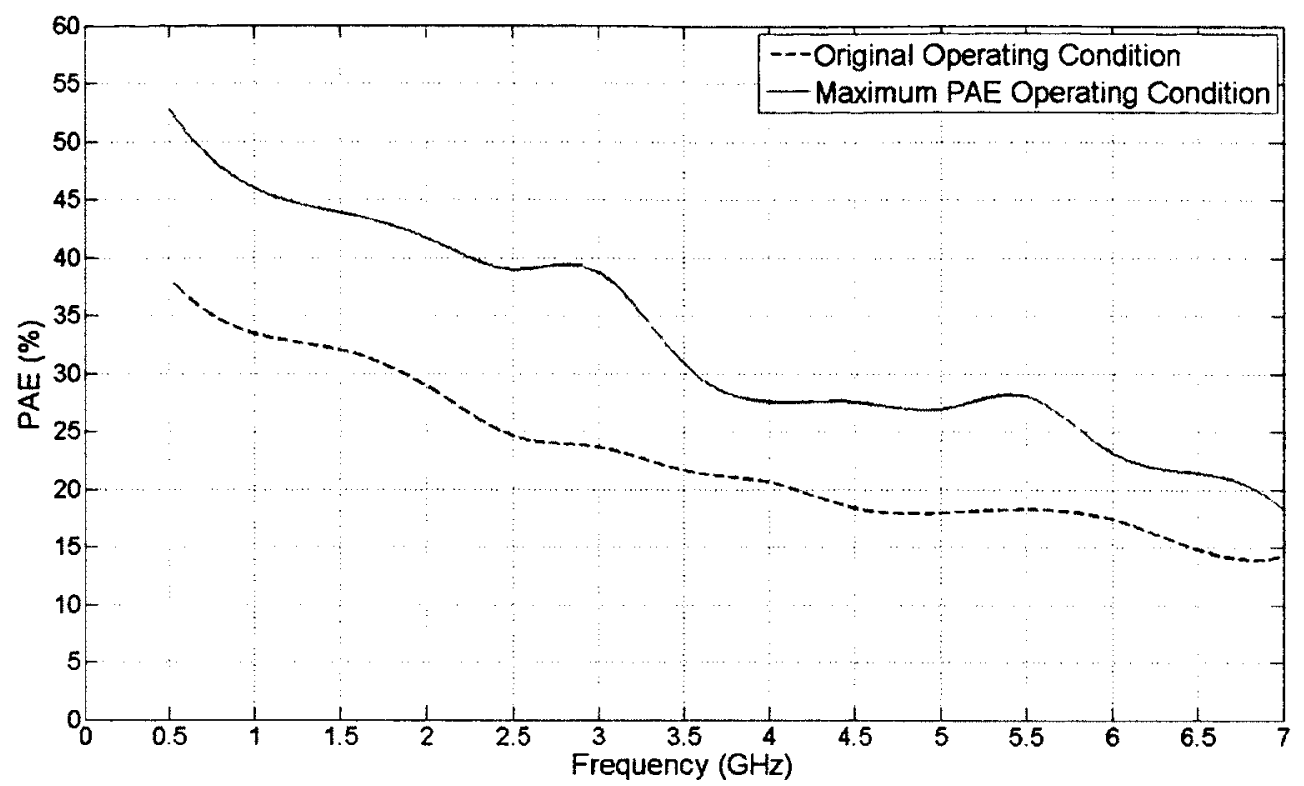

Figure 4.60. Measured PAE comparison of the max. PAE and the original operating condition.

Table 4.5. Measured bias voltage difference between original and maximum PAE operating condition.

\begin{tabular}{|c|c|c|c|c|}
\hline \multirow{2}{*}{ Frequency $(\mathrm{GHz})$} & \multicolumn{2}{|c|}{ Max. PAE condition } & \multicolumn{2}{|c|}{ Original condition } \\
\hline & $V_{g s}(V)$ & $V_{d s}(V)$ & $V_{g s}(V)$ & $V_{d s}(V)$ \\
\hline 0.5 & -3.5 & 15 & -2.5 & 15 \\
\hline 1 & -3.5 & 15 & -2.5 & 15 \\
\hline 1.5 & -3.5 & 15 & -2.5 & 15 \\
\hline 2 & -3 & 15 & -2.5 & 15 \\
\hline 2.5 & -3.5 & 15 & -2.5 & 15 \\
\hline 3 & -3.5 & 15 & -2.5 & 15 \\
\hline 3.5 & -3.5 & 15 & -2.5 & 15 \\
\hline 4 & -3 & 15 & -2.5 & 15 \\
\hline 4.5 & -3 & 15 & -2.5 & 15 \\
\hline 5 & -3 & 15 & -2.5 & 15 \\
\hline 5.5 & -3.5 & 15 & -2.5 & 15 \\
\hline 6 & -2.5 & 15 & -2.5 & 15 \\
\hline 6.5 & -3 & 15 & -2.5 & 15 \\
\hline 7 & -2.5 & 20 & -2.5 & 15 \\
\hline
\end{tabular}




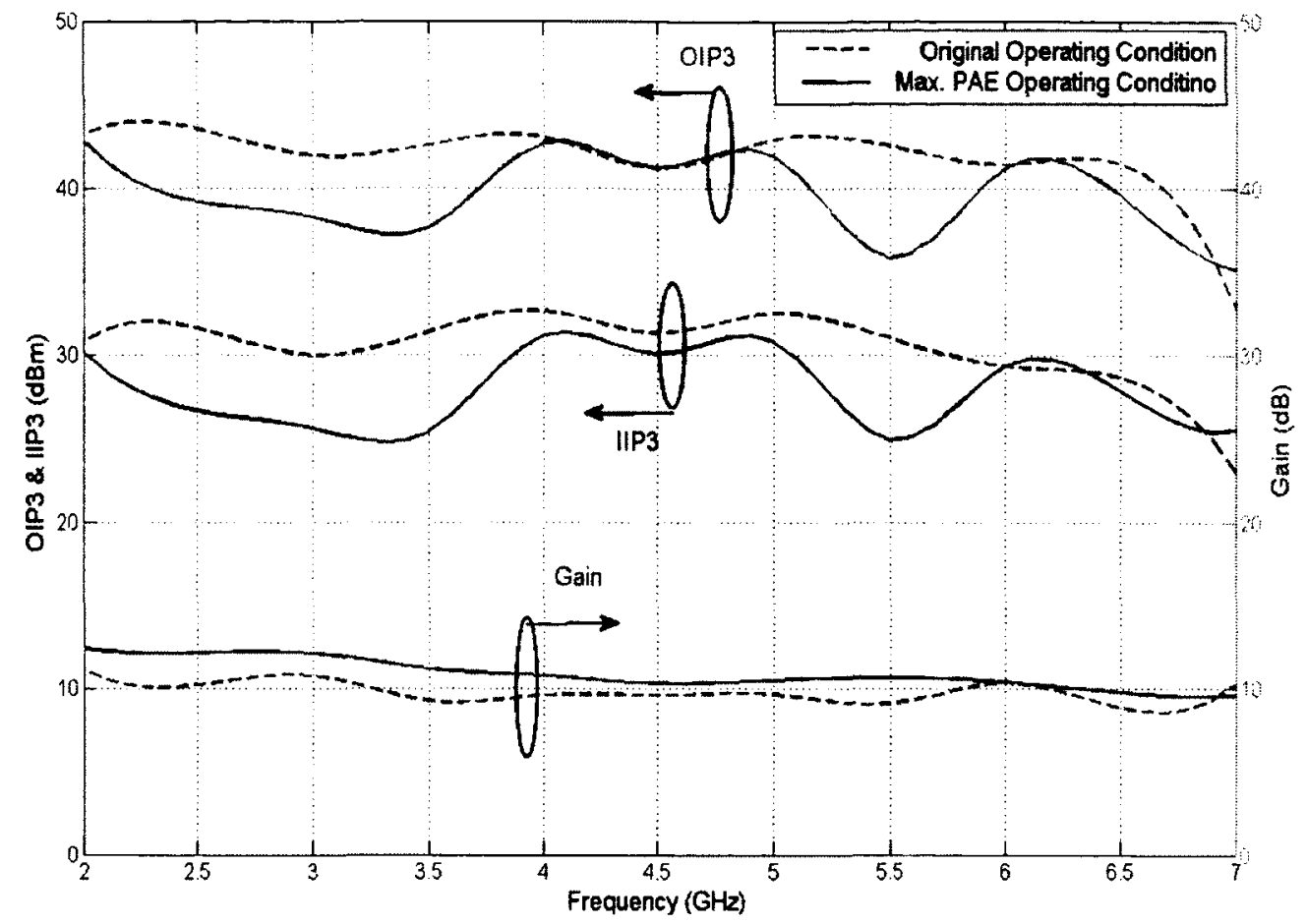

Figure 4.61. Measured: linearity comparison of the maximum PAE and the original operating condition.

\subsection{Conclusion}

In this chapter, an asymmetric distributed power amplifier has been successfully designed and measured using the $0.5 \mu \mathrm{m} \mathrm{GaN}$ process and results presented in detail. A maximum PAE of $52.7 \%$ is obtained at $0.5 \mathrm{GHz}$ with an output power of $31.8 \mathrm{dBm}$ in peak PAE bias condition. Meanwhile, more than $10 \mathrm{~dB}$ of gain, a $\mathrm{P}_{\text {out }}$ of $30 \mathrm{dBm}$ and a PAE better than $20 \%$ are achieved over the $0.5 \mathrm{GHz}-6.5 \mathrm{GHz}$ bandwidth. Also the PAE is higher than $40 \%$ for frequencies up to $2 \mathrm{GHz}$, and higher than $30 \%$ for frequencies up to $3.5 \mathrm{GHz}$. By comparing the measurement and simulated data, the models are found to be reliable. Some of the findings can be followed up in the future, such as reconfigurable matching network for specific multi-band applications. 


\section{Chapter 5: Investigation of Possible ADPA Performance}

\section{Enhancements}

The proposed ADPA was fabricated and successfully measured, and then, some prototype of possible ADPA performance enhancements will be investigated in this chapter. Only simulated results will be presented here.

\subsection{Improved Design with High Q Type Interconnections}

As discussed in Section 4.1.3, type 3 inductor design of interconnects was chosen because of its larger current carrying capacity, although it is not the highest $Q$ option. The limitation of its $Q$ factor would cause power losses when current passes though the lossy interconnections. The effect of using inductors with higher $Q$ is studied here while keeping the circuitry and parameter values the same as the first tapered ASPA design presented above.

As shown from Figure 5.1 to Figure 5.4, type 1 implementation is proven with simulation to obtain the highest $\mathrm{Q}$ among the three layout implementations for the chosen inductances of the different gate and drain sections. 


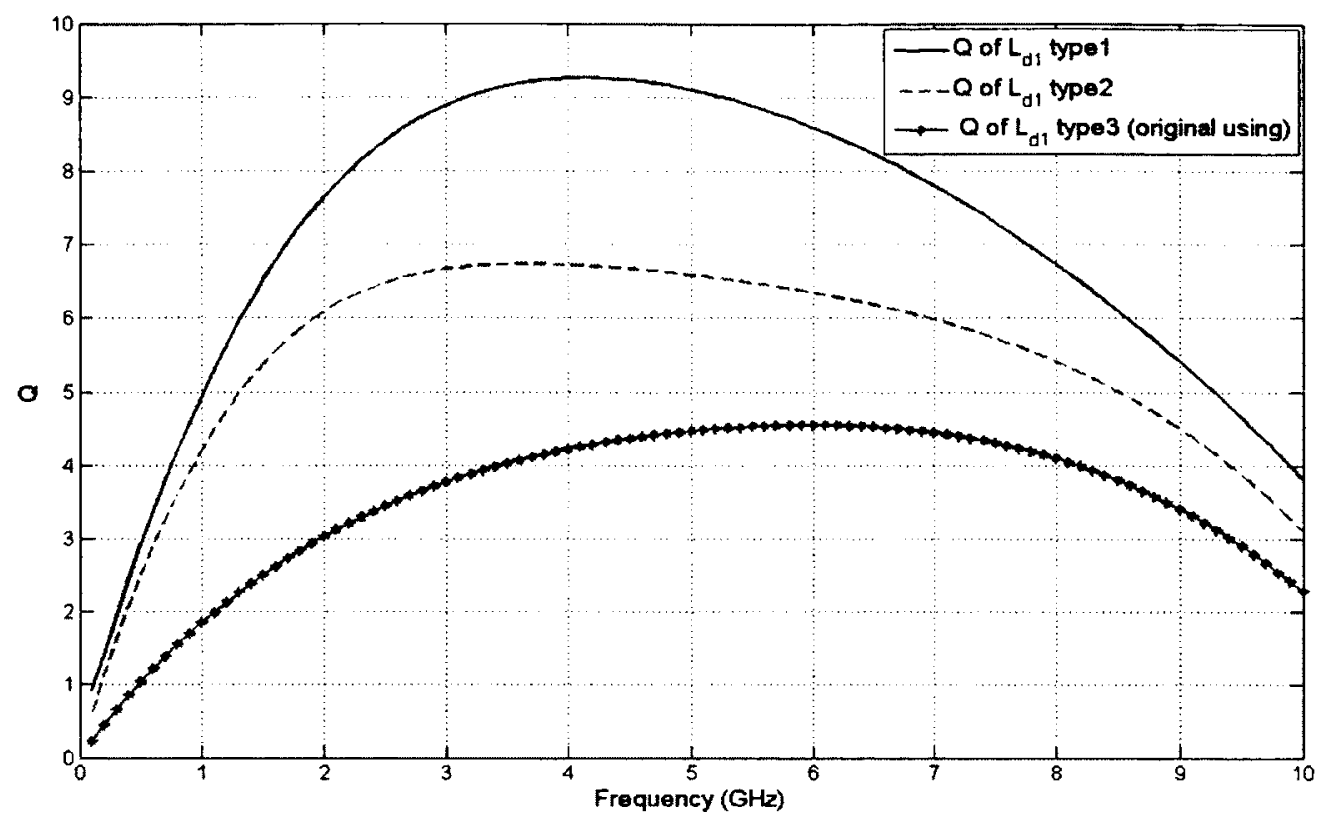

Figure 5.1. Simulated Q comparison of three types of $L_{d 1}$.

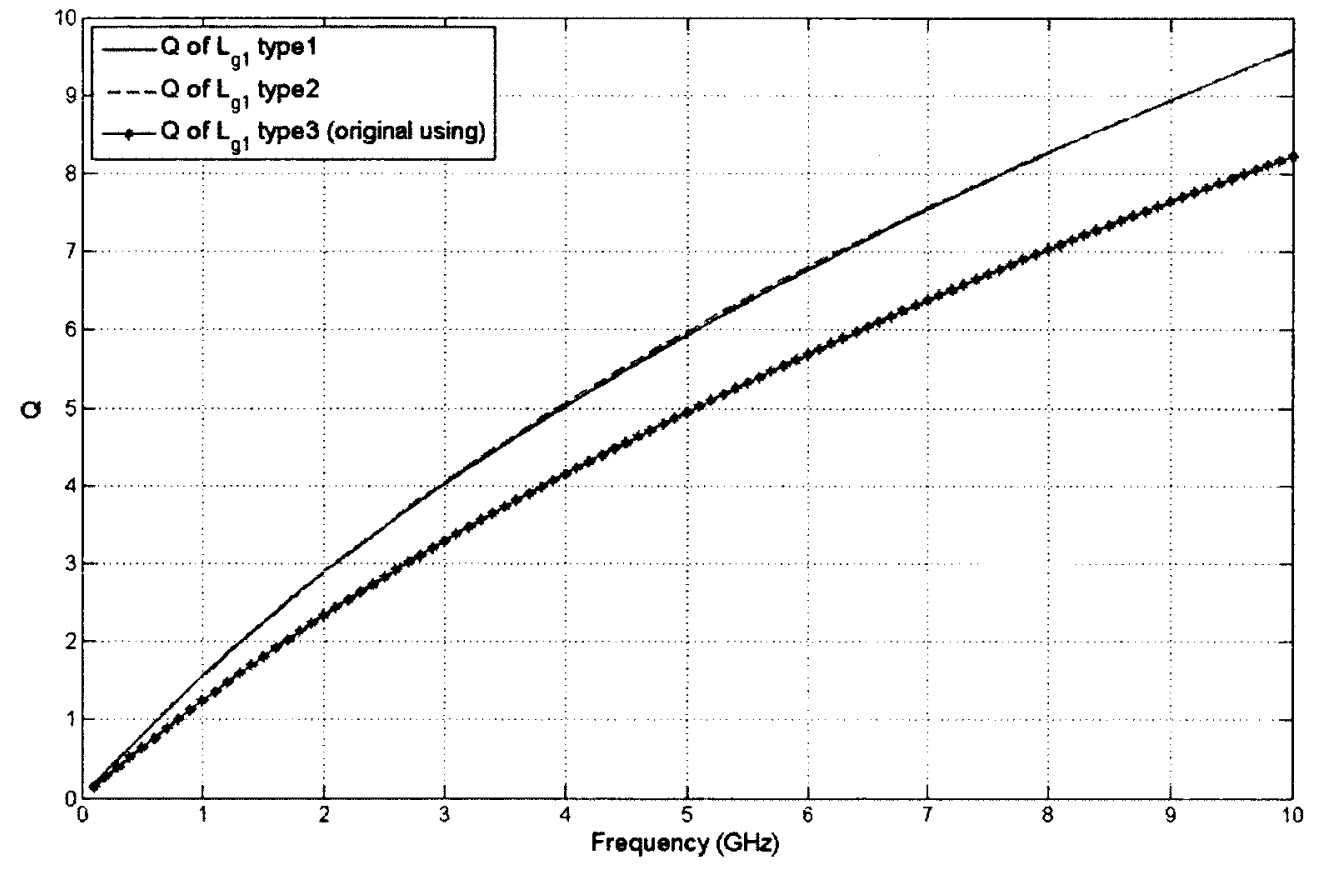

Figure 5.2.

Simulated Q comparison of three types of $\mathrm{L}_{\mathrm{gl}}$. 


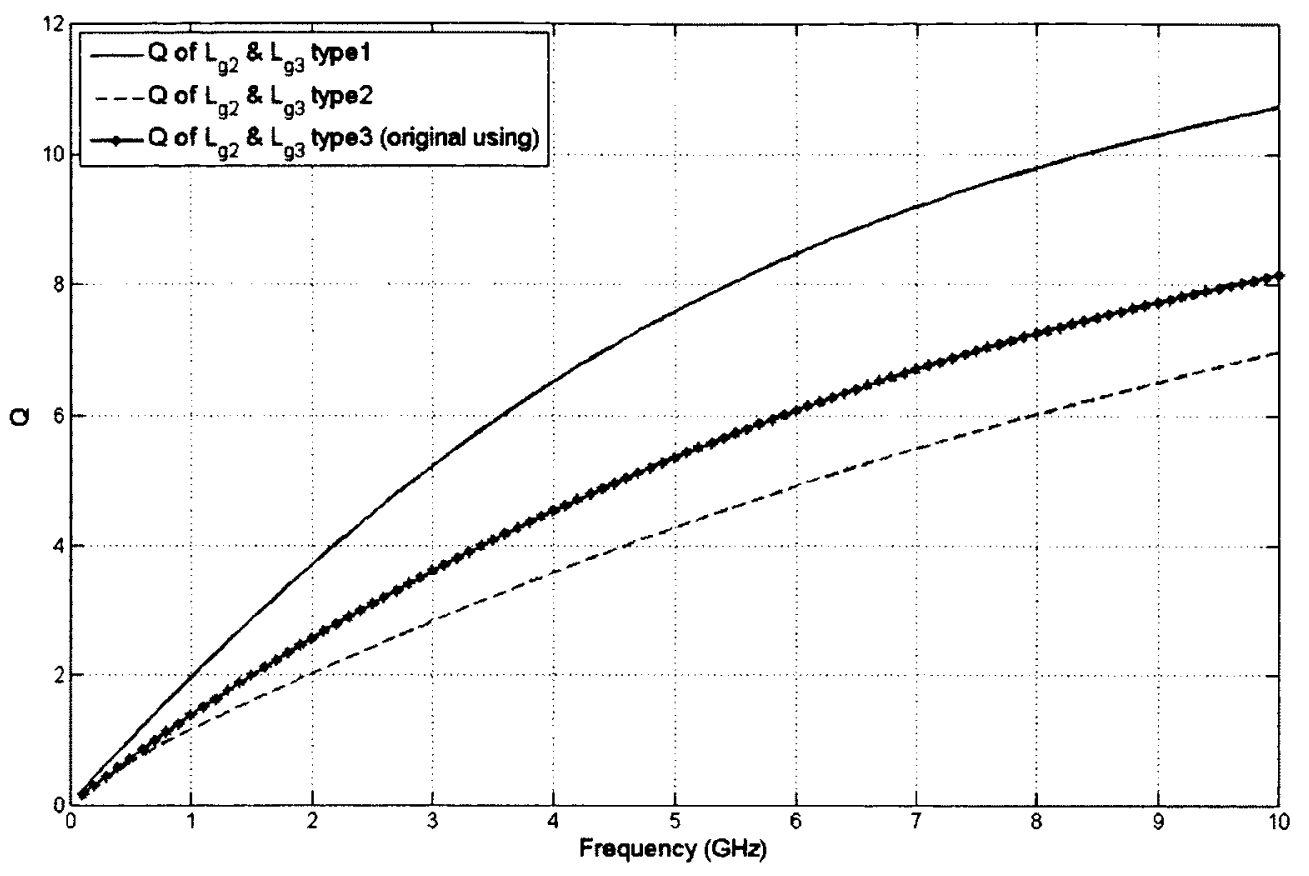

Figure 5.3. Simulated $\mathrm{Q}$ comparison of three types of $\mathrm{L}_{\mathrm{g} 2}$ and $\mathrm{L}_{\mathrm{g} 3}$.

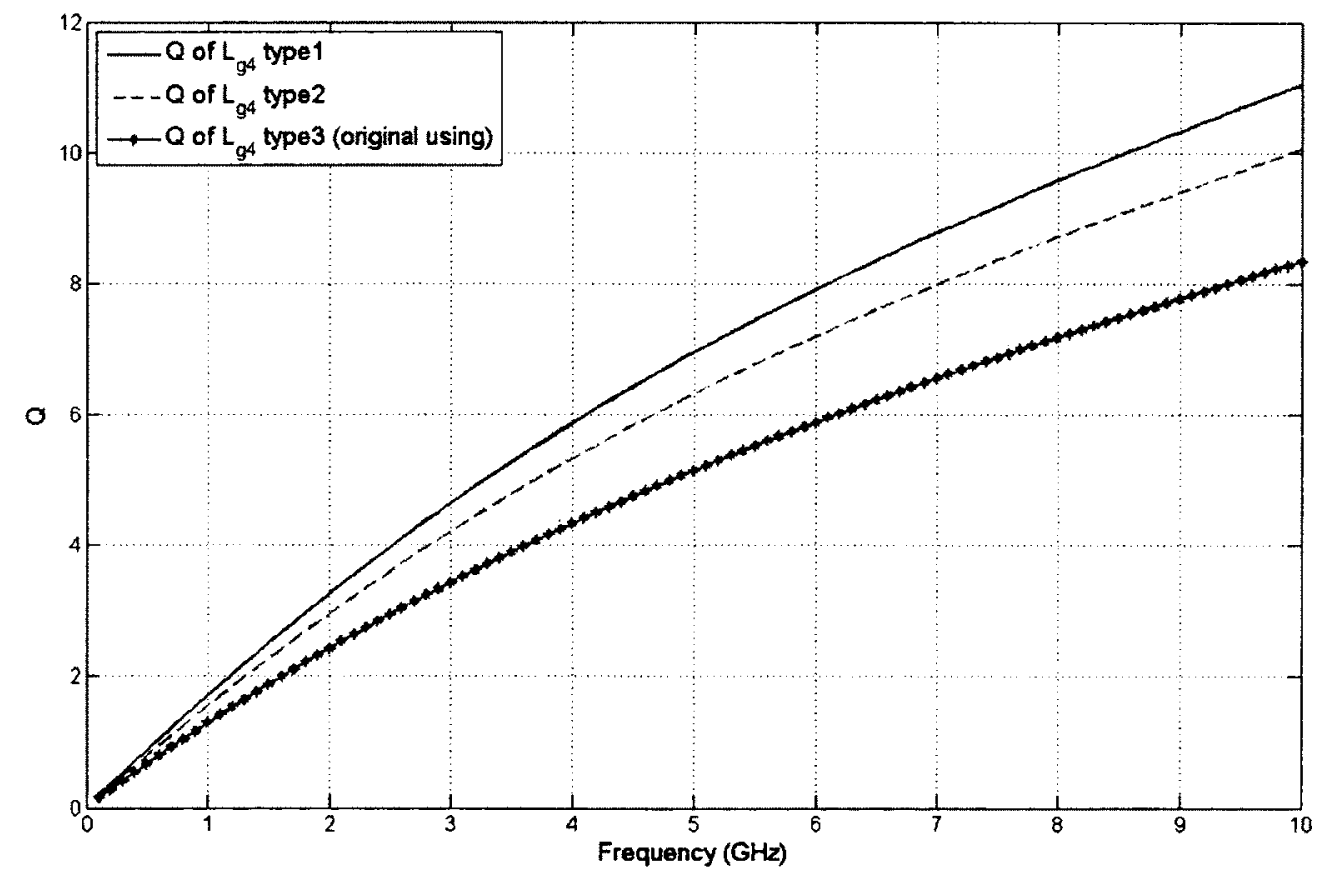

Figure 5.4.

Simulated $\mathrm{Q}$ comparison of three types of $\mathrm{L}_{\mathrm{g} 4}$. 


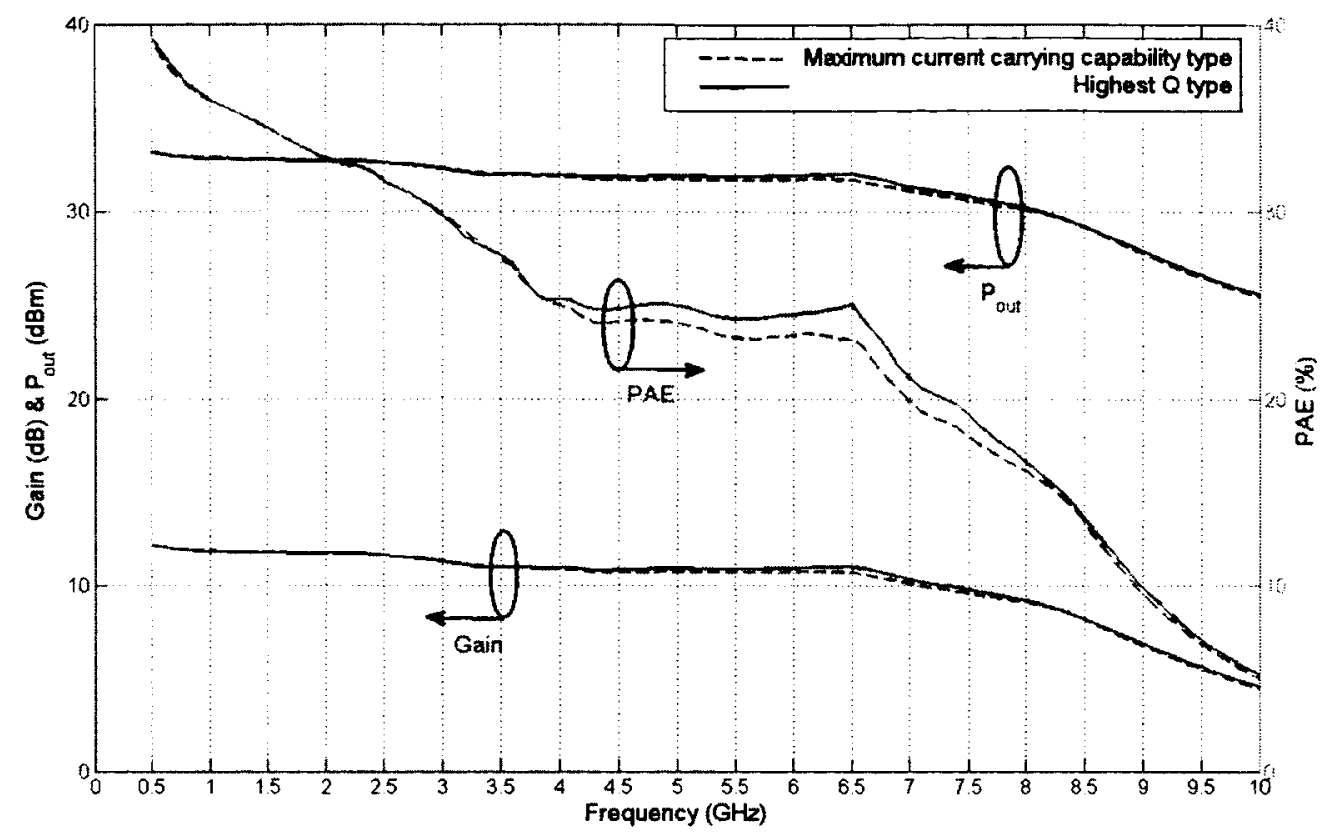

Figure 5.5. Simulated performance comparison of the ADPA implemented with the low $Q$ type interconnections and the high $Q$ type interconnections.

Figure 5.5 presents the difference of the power performance between the original ADPA using the low $Q$ but the largest current carrying capacity type interconnections, and the improved one which uses the highest $Q$ type interconnections. The difference in the gain and output power performance is minimal, while PAE is improved largely from $4 \mathrm{GHz}$ to $8 \mathrm{GHz}$. A maximum improvement in the PAE of $1 \%$ is observed at 6.5 $\mathrm{GHz}$, and a maximum PAE of approximately $25 \%$ is obtained at $6.5 \mathrm{GHz}$. 


\subsection{Improved Tapered Line Asymmetric Distributed Power Amplifier}

The initial tapered lines, based on calculation results in the first ADPA design, caused power loss, as the HFET in the $2^{\text {nd }}$ gain stage has not seen its optimum load of the maximum power (see Section 4.1). In this section, we optimize the drain line sections in the $2^{\text {nd }}$ ADPA design for higher output power.

First, we go back to the lumped element circuit simulation. The load pull simulation set-up used (ADS) can only change the load impedance $\left(\mathrm{R}_{\text {load }}\right)$, but has nothing to do with the drain line tapering. Based on the load pull theory, a manual load pull was performed by sweeping the inductances of the three drain line sections together with the $\mathrm{R}_{\text {load }}$ at three different frequencies, $6 \mathrm{GHz}, 4 \mathrm{GHz}$ and $2 \mathrm{GHz}$, as shown in Figure 5.6-5.8. Following the simulation results, the values of the drain line sections and $\mathrm{R}_{\text {load }}$ should be $\mathrm{L}_{\mathrm{d} 1}=2.25 \mathrm{nH}, \mathrm{L}_{\mathrm{d} 2}=1.5 \mathrm{nH}, \mathrm{L}_{\mathrm{d} 3}=0.2 \mathrm{nH}$, and $\mathrm{R}_{\text {load_opt }}=50 \Omega$ respectively for the maximum output power.

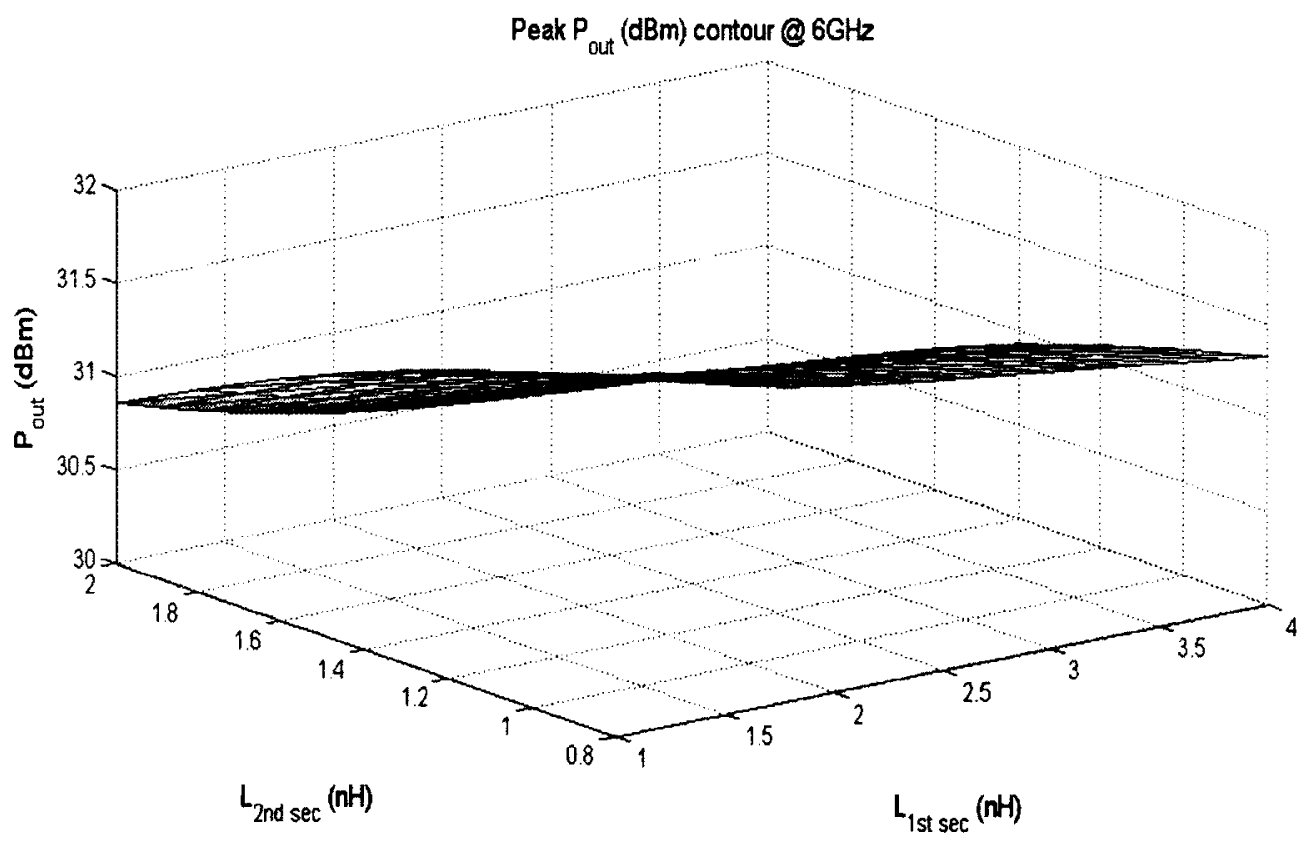

Figure 5.6. Simulated manual load pull at $6 \mathrm{GHz}$. (a) Peak $\mathrm{P}_{\text {out }}$ contour. 


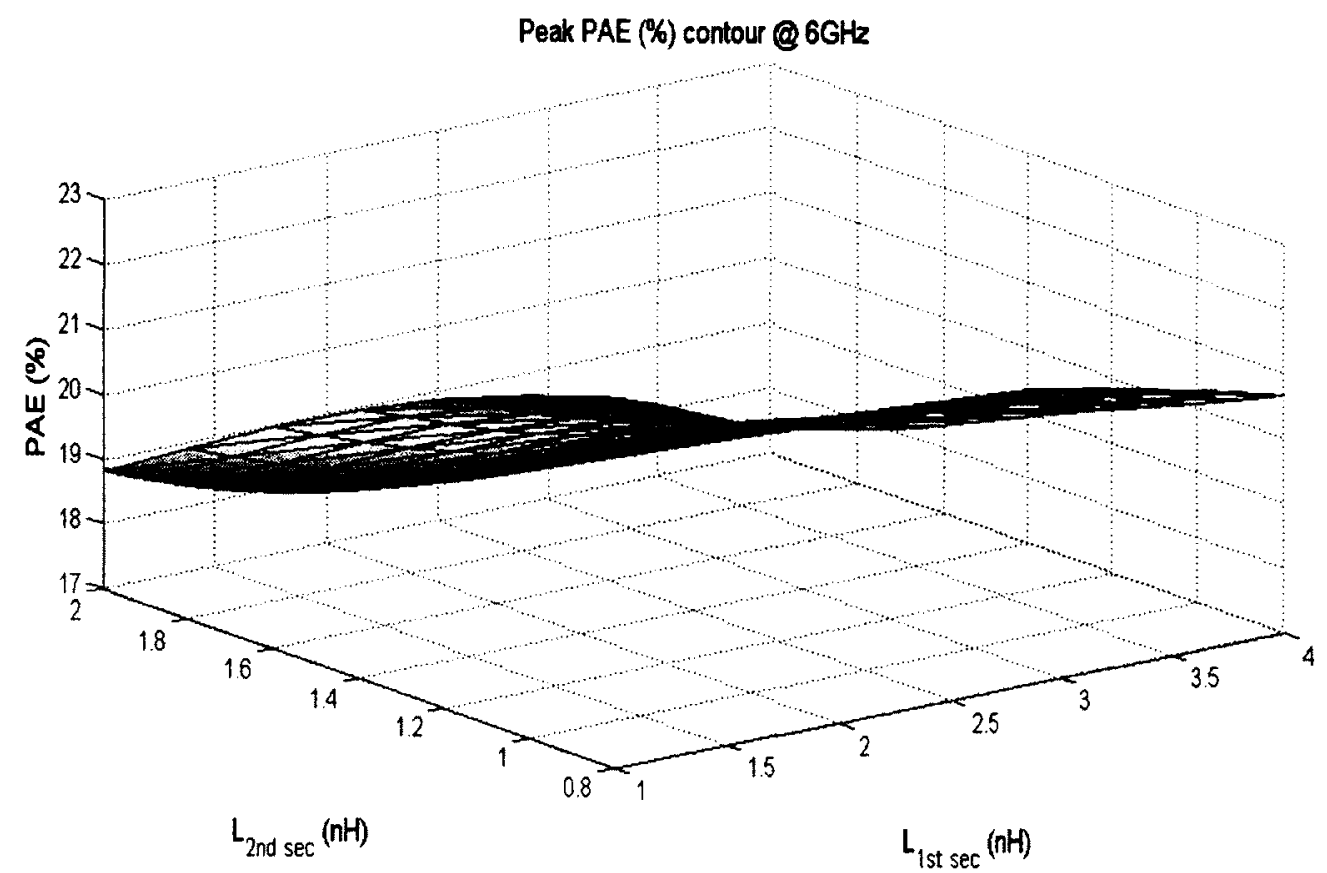

Figure 5.6.(continue) $\quad$ Simulated manual load pull at $6 \mathrm{GHz}$.

(b) peak PAE contour.

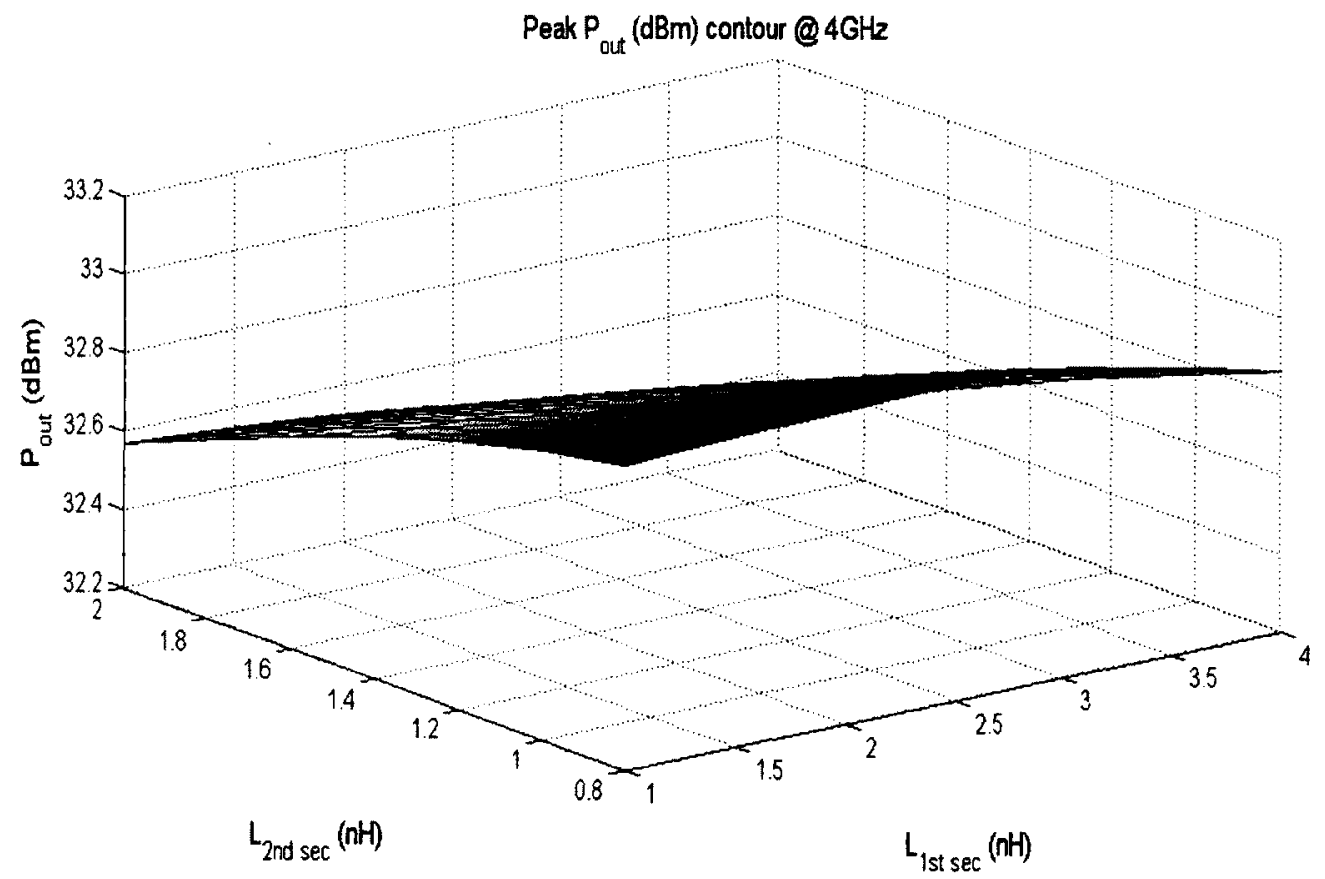

Figure 5.7.

Simulated manual load pull at $4 \mathrm{GHz}$.

(a) Peak $\mathrm{P}_{\text {out }}$ contour. 


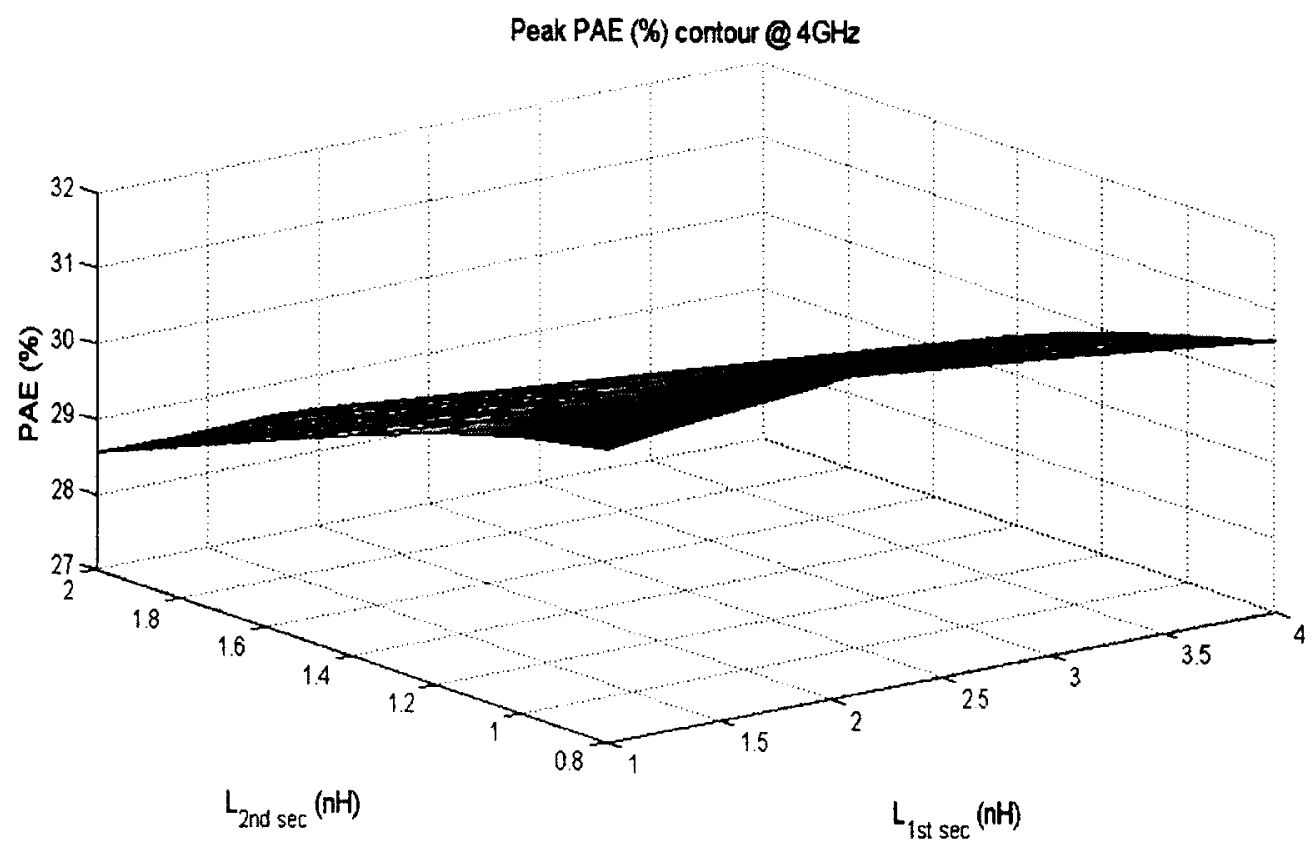

Figure 5.7.(continue)

Simulated manual load pull at $4 \mathrm{GHz}$.

(b) peak PAE contour.

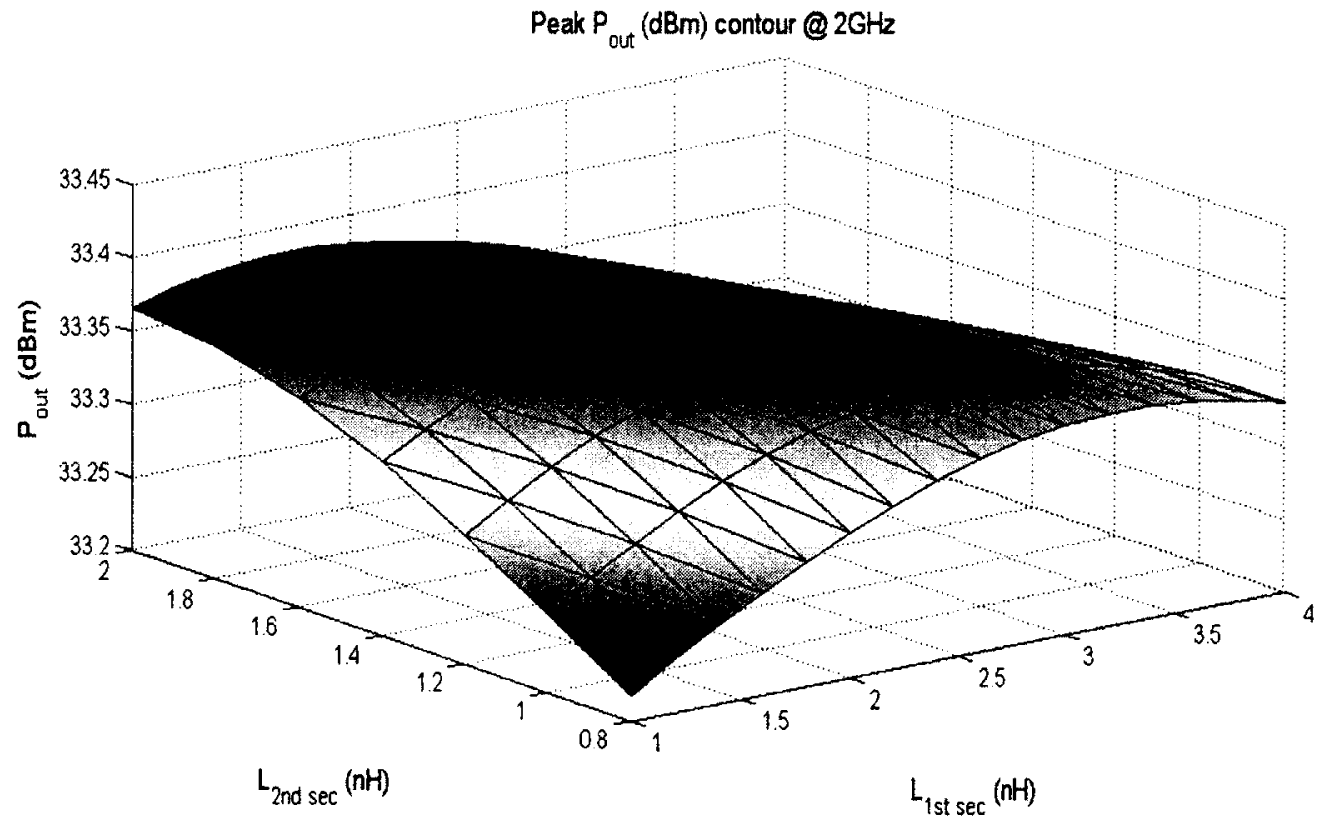

Figure 5.8.

Simulated manual load pull at $2 \mathrm{GHz}$.

(a) Peak $\mathrm{P}_{\text {out }}$ contour. 


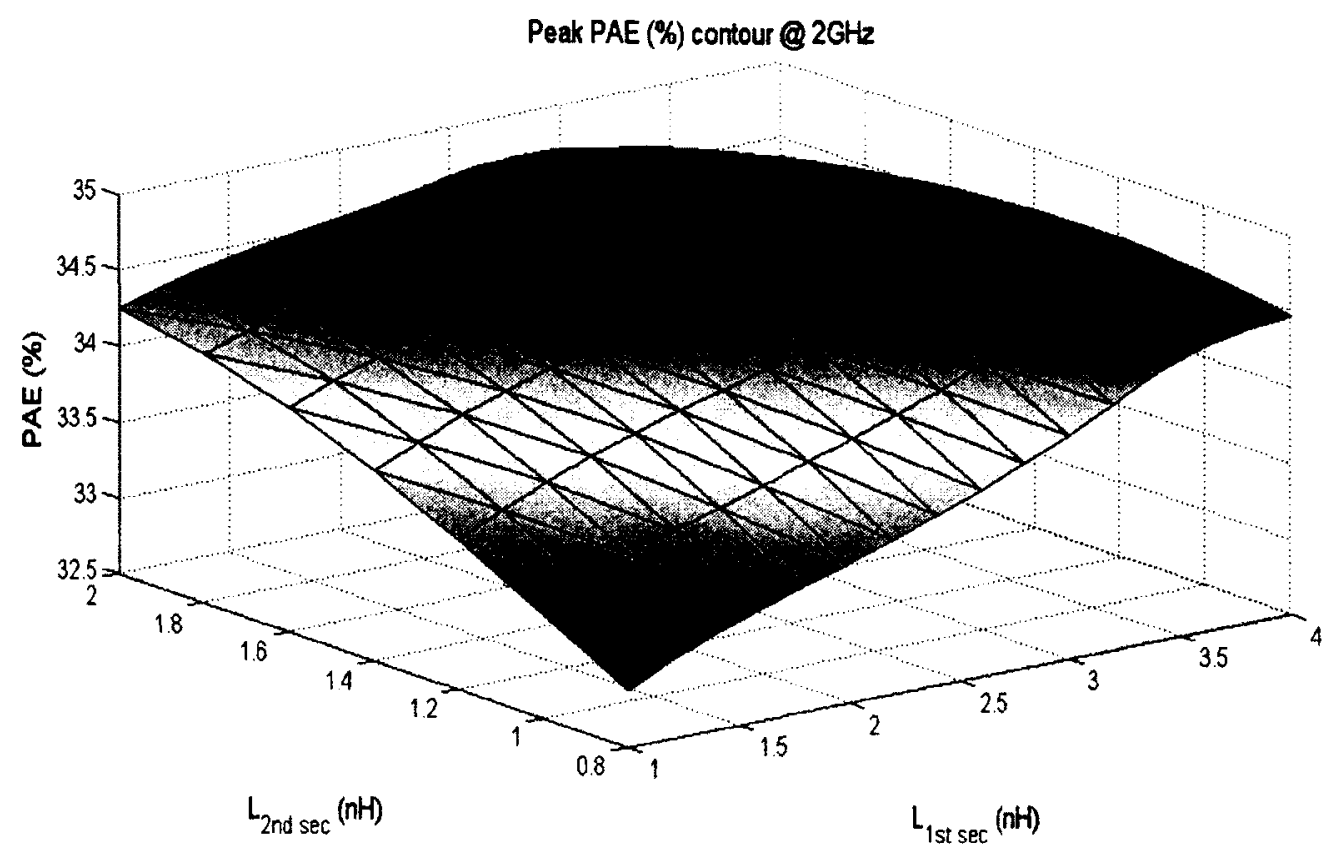

Figure 5.8.(continue)

Simulated manual load pull at $2 \mathrm{GHz}$.

(b) Peak PAE contour

Then, the $L_{d 2}$ drain line's estimated inductance of $1.5 \mathrm{nH}$ is chosen as the start point of re-sizing. As shown in Figure 5.9, this new implemented $\mathrm{L}_{\mathrm{d} 2}$ drain section has an inductance of $1.5 \mathrm{nH}$ as expected, and a maximum $\mathrm{Q}$ of approximately 13 , with no indication of self-resonating effects below $6 \mathrm{GHz}$. The drain line presents approximately $10 \Omega$ impedance to the HFET's drain side as expected.

Figure 5.10 shows the phase shift comparison between the implemented $L_{g 3}$ and $L_{d 2}$ (according to Figure 4.14 ) in the $2^{\text {nd }}$ ADPA design. A maximum phase shift difference of approximately $14^{\circ}$ at $6.5 \mathrm{GHz}$ is observed, and a phase shift difference lower than $10^{\circ}$ is obtained over $0.1 \mathrm{GHz}-4 \mathrm{GHz}$ frequency range. 


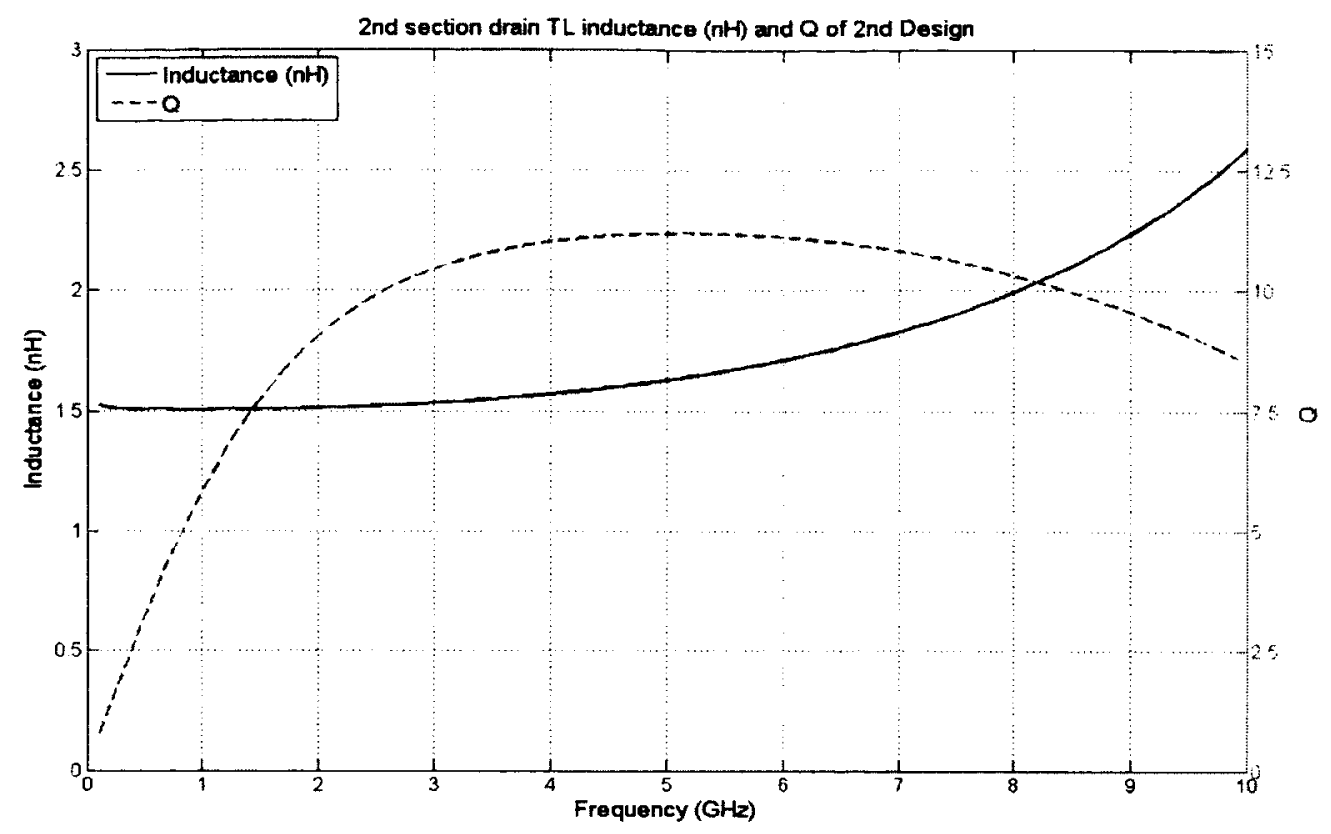

Figure 5.9 .

The $2^{\text {nd }}$ drain line section characteristics of $2^{\text {nd }}$ design.

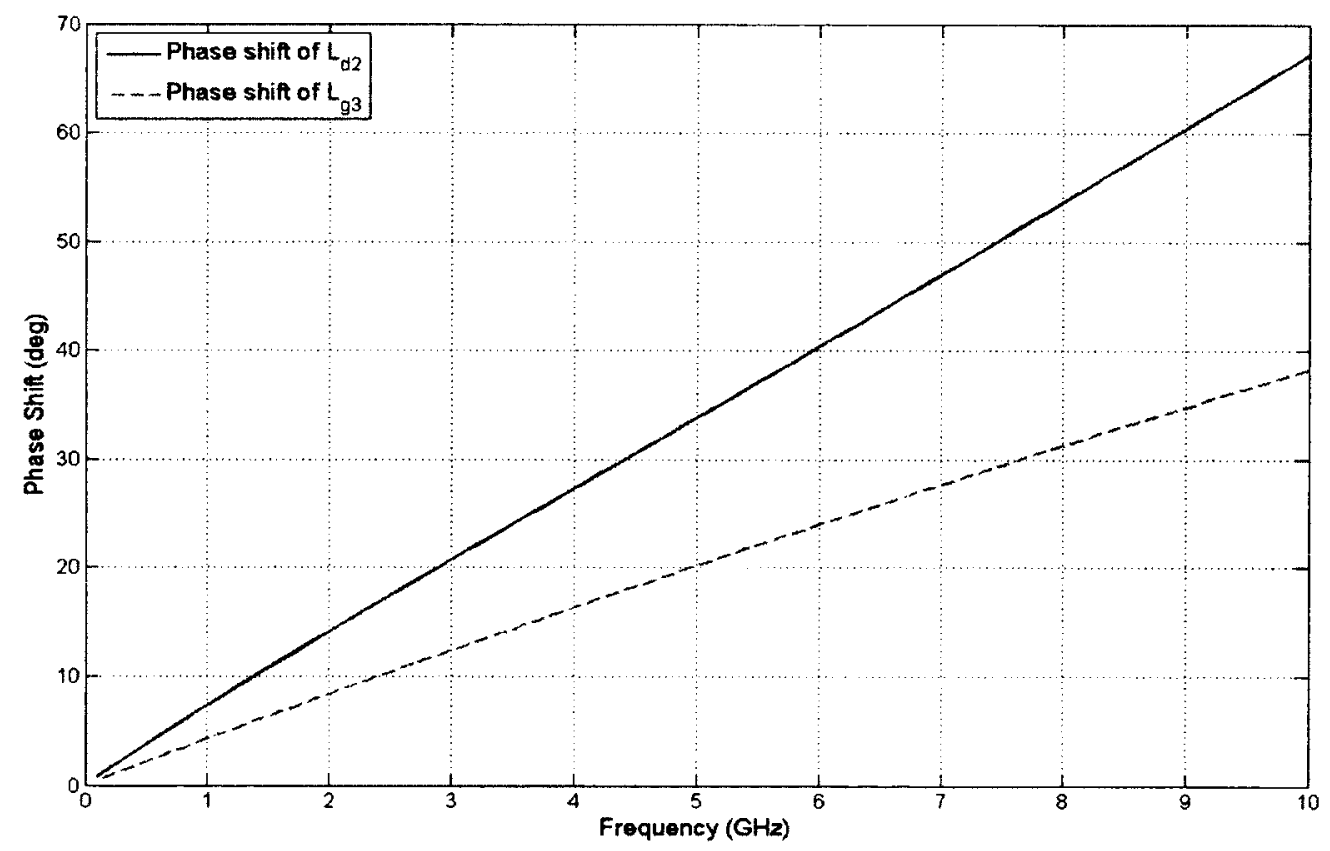

Figure 5.10.

Phase matching of $2^{\text {nd }}$ stage of $2^{\text {nd }}$ design. 

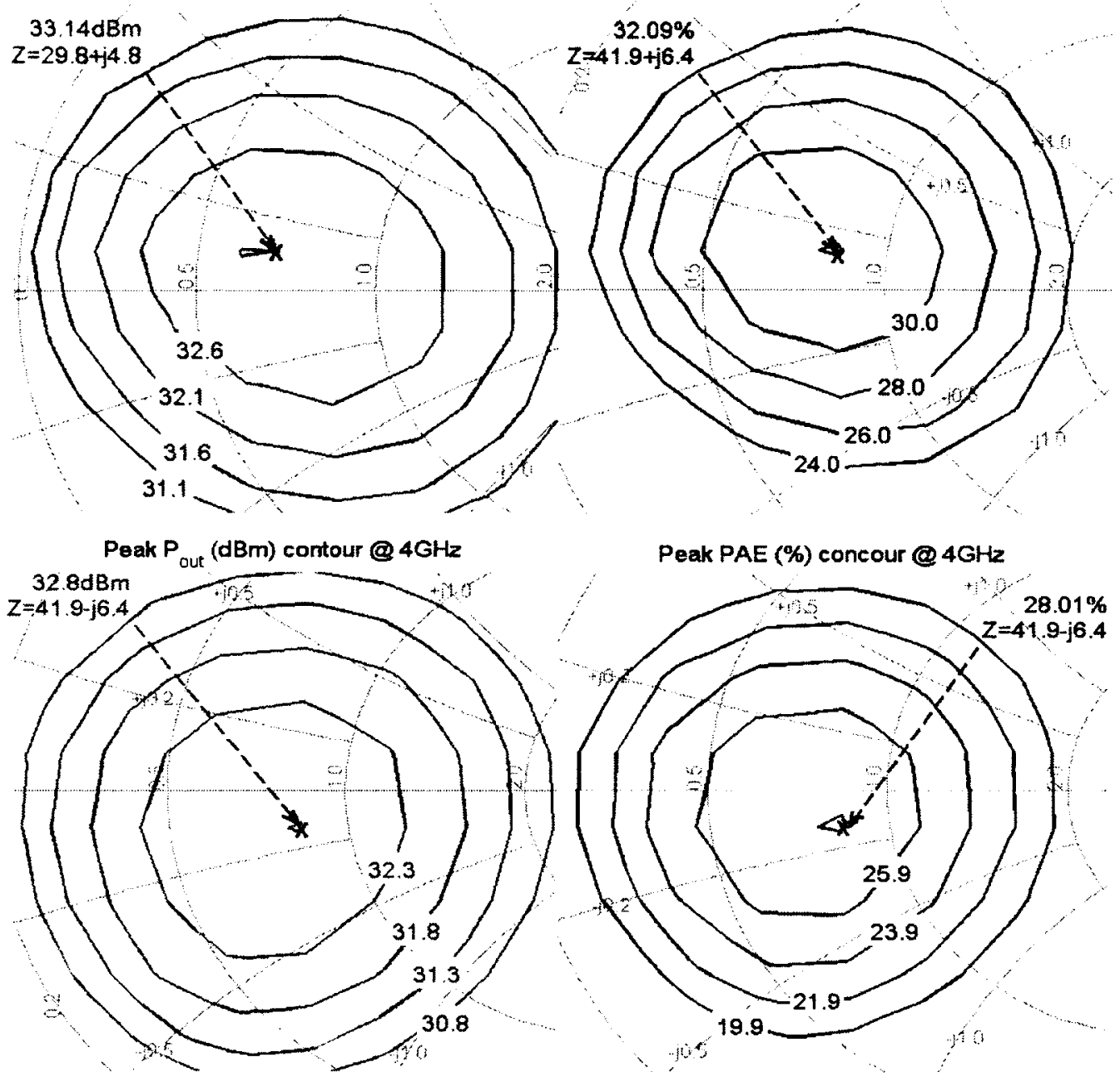

Peak P out $(\mathrm{dBm})$ contour @ 6GHz

Peak PAE (\%) contour @ 6GHz
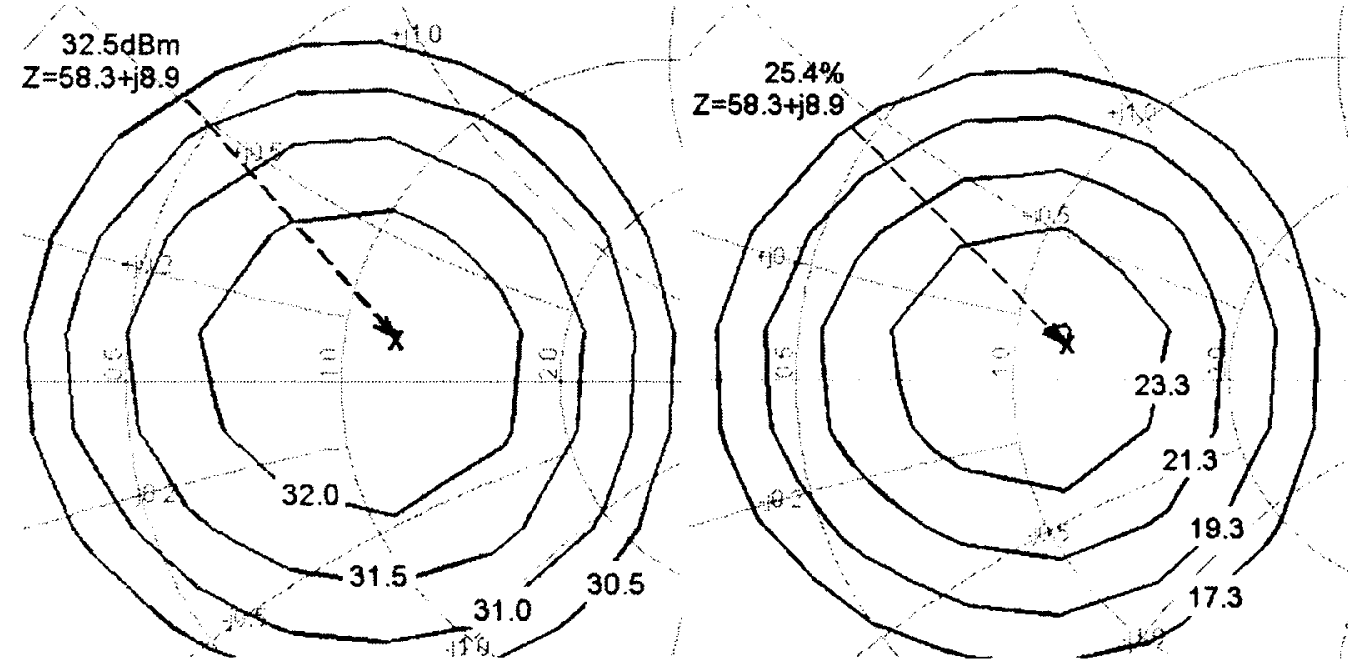

Figure 5.11. Load Pull simulation of the $2^{\text {nd }}$ ADPA Design at $2 \mathrm{GHz}, 4 \mathrm{GHz}$ and $6 \mathrm{GHz}$. 
Next, a load pull analysis is performed as shown in Figure 5.11, in order to optimize both the peak $P_{\text {out }}$ and the peak PAE. A $50 \Omega$ load can be used for the maximum output power over the frequency range we want to improve. Figure 5.12 presents a layout of $2^{\text {nd }} A D P A$ design.

Stability is first checked as shown in Figure 5.13, where B1 values are in the range of 0 to 1 , and $\mathrm{K}$ is higher than 1 , to ensure unconditional stability, meaning the $2^{\text {nd }}$ ADPA design will not oscillate.

Figure 5.14 shows the large-signal s-parameters simulation results over $0.1 \mathrm{GHz}-10$ $\mathrm{GHz}$ range. The voltage gain $\left(S_{21}\right)$ is above $10 \mathrm{~dB}$ up to $8 \mathrm{GHz}$, while return loss $S_{11}$ at the input port is beneath $-10 \mathrm{~dB}$ over $0.5 \mathrm{GHz}-10 \mathrm{GHz}$. The $S_{12}$ is lower than -20 $\mathrm{dB}$ over the entire $0.1 \mathrm{GHz}-10 \mathrm{GHz}$ band which shows great isolation between the input and output of the ADPA. As seen from the $S_{22}$ curve, the output is not well matched to $50 \Omega$ but this is not required as the PA is designed for maximum output power delivery.

Figure 5.15 illustrates the simulated power performance of the $2^{\text {nd }}$ ADPA design. It can be seen from the curves that the specification of Pout $>30 \mathrm{dBm}, \mathrm{PAE}>20 \%$, and gain $>10 \mathrm{~dB}$ are achieved over the entire $0.5 \mathrm{GHz}-6.5 \mathrm{GHz}$ operating bandwidth. The PAE at frequencies above $5 \mathrm{GHz}$ is increased compared to the first ADPA design. In order to investigate the details, the first and $2^{\text {nd }}$ ADPA simulated performance is compared in Figure 5.16. 


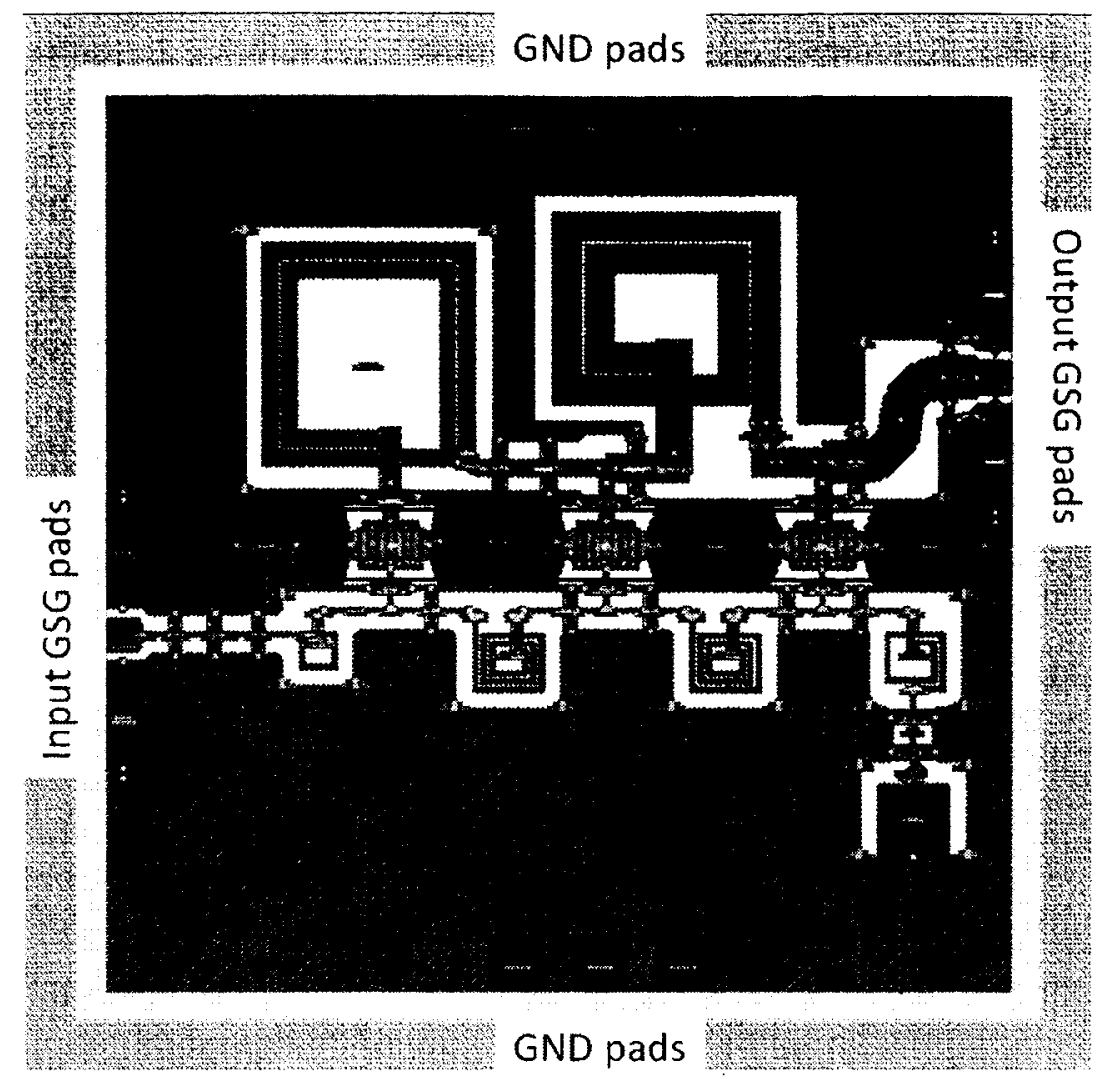

Figure 5.12.

Layout of the $2^{\text {nd }}$ ADPA Design

(HFETs are indicated with the rectangle).

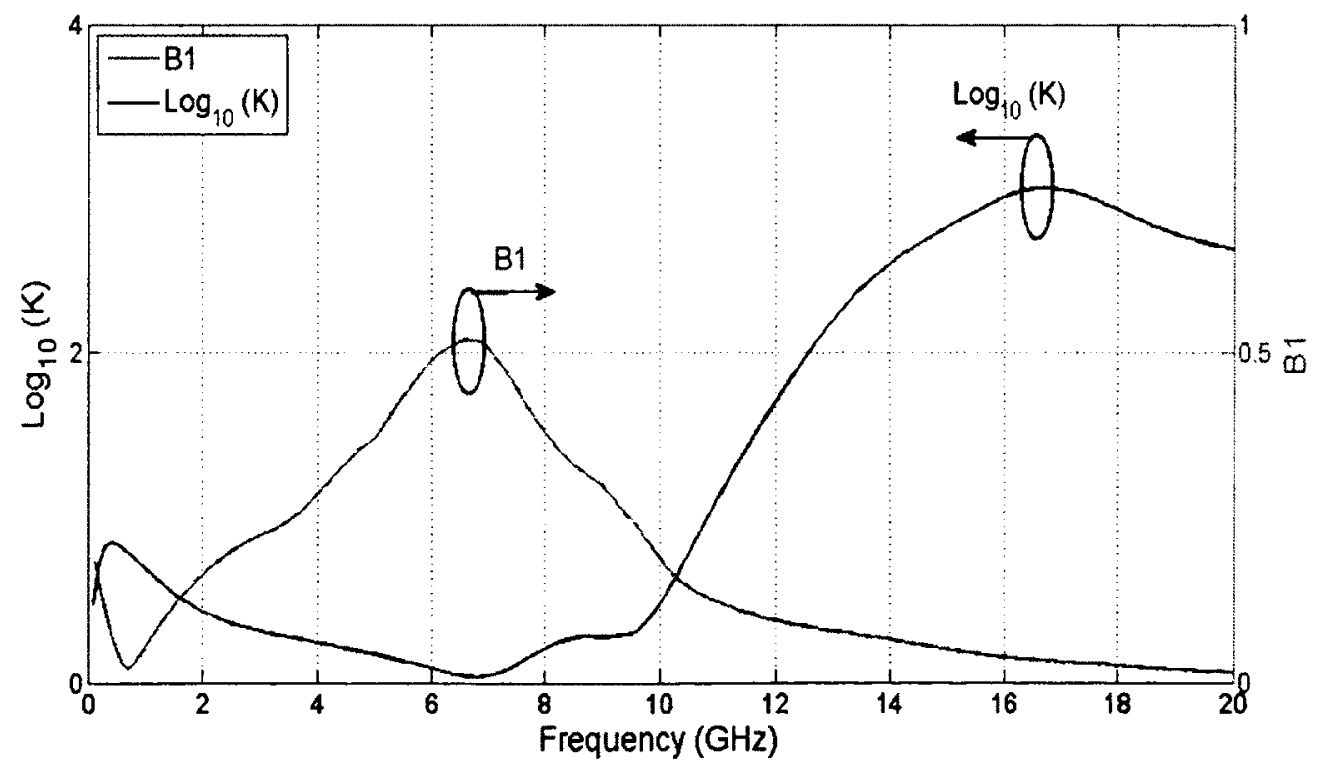

Figure 5.13. Stability. 


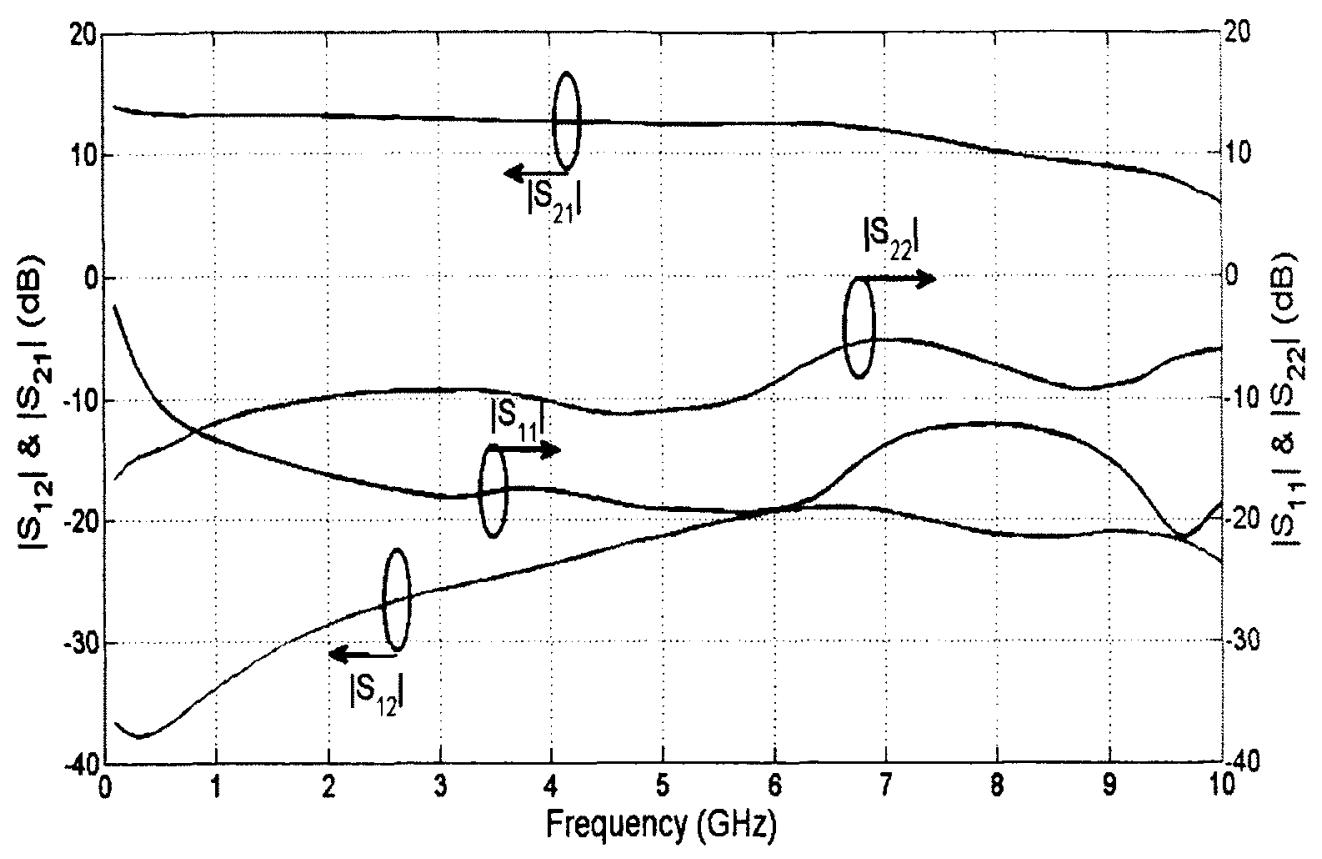

Figure 5.14. Large signal s-parameters.

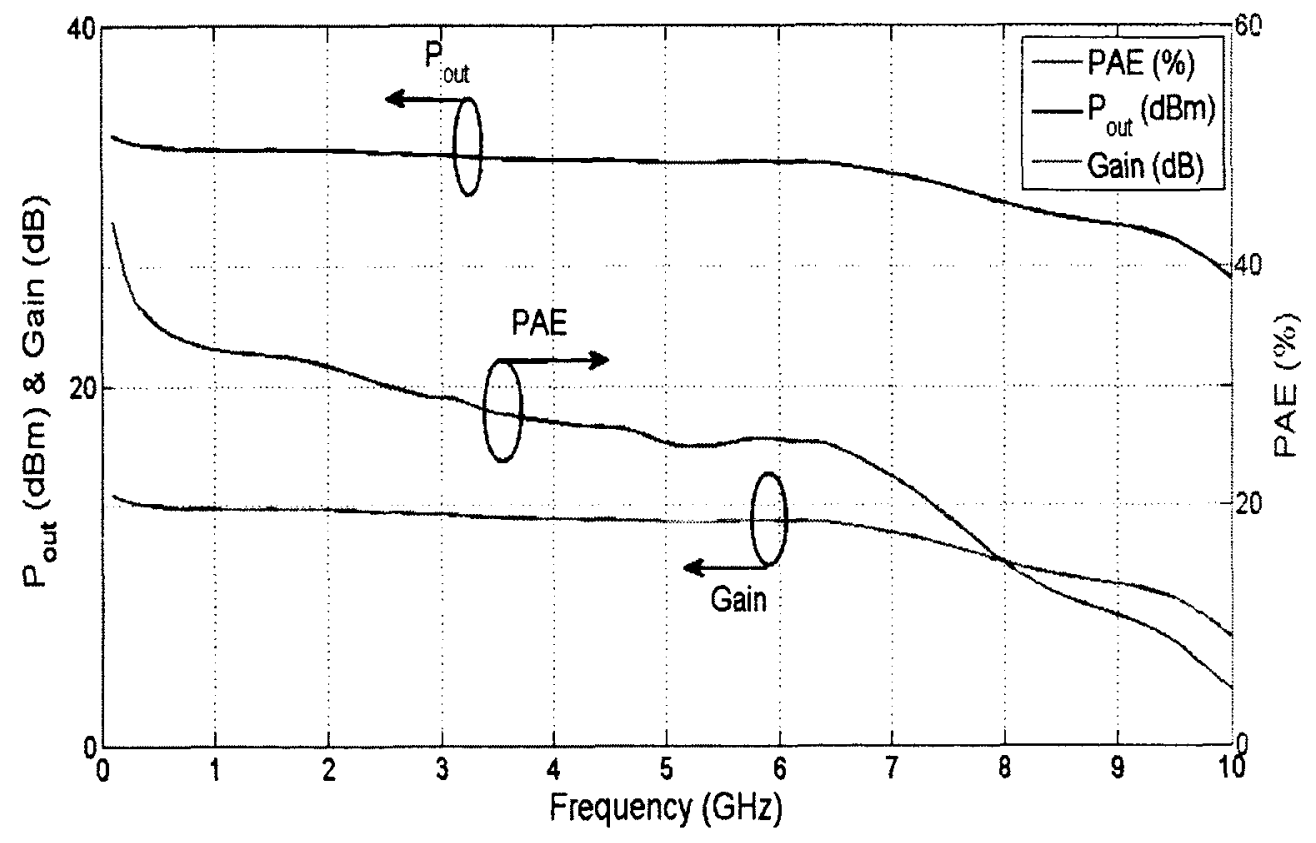

Figure 5.15.

Power gain, delivered power, PAE. 
Figure 4.76 presents the comparison of the simulated power performance between the first ADPA design and the $2^{\text {nd }}$ one over $0.5 \mathrm{GHz}-6.5 \mathrm{GHz}$ bandwidth. It can be seen that at $3 \mathrm{GHz}$, the $2^{\text {nd }}$ ADPA design obtains higher gain and output power, and especially greater PAE than the first design at frequencies above approximately 2.5 GHz. The $P_{\text {out }}$ increases approximately by $0.6 \mathrm{dBm}$, and a maximum PAE improvement of $4 \%$ is obtained in the $2^{\text {nd }}$ ADPA design at frequencies higher than $2.5 \mathrm{GHz}$, while the performance at lower frequencies has minimal differences. Such a performance improvement acquired at high frequencies is in the trade-off of the linearity.

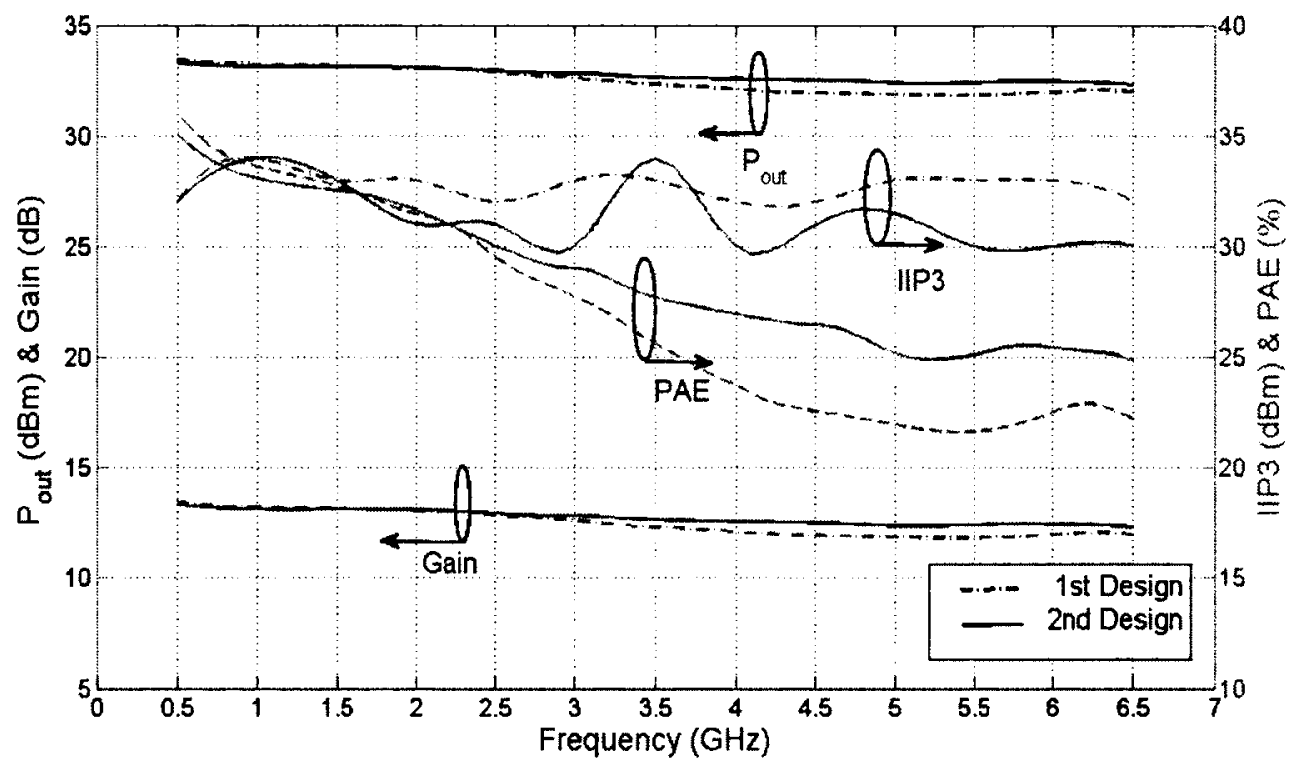

Figure 5.16. Simulated linearity and power performance comparison between first and $2^{\text {nd }}$ design over $0.5 \mathrm{GHz}$ to $6.5 \mathrm{GHz}$ frequency range.

As shown in Figure 5.17, the fundamental element of the output power is above 30 $\mathrm{dBm}$ over the entire $0.5 \mathrm{GHz}-7 \mathrm{GHz}$ frequency range as expected. Meanwhile, the 
$2^{\text {nd }}$ and $3^{\text {rd }}$ harmonics are approximately $18 \mathrm{~dB}$ down from the fundamental. The need for harmonic shorting circuitry would depend on the application.

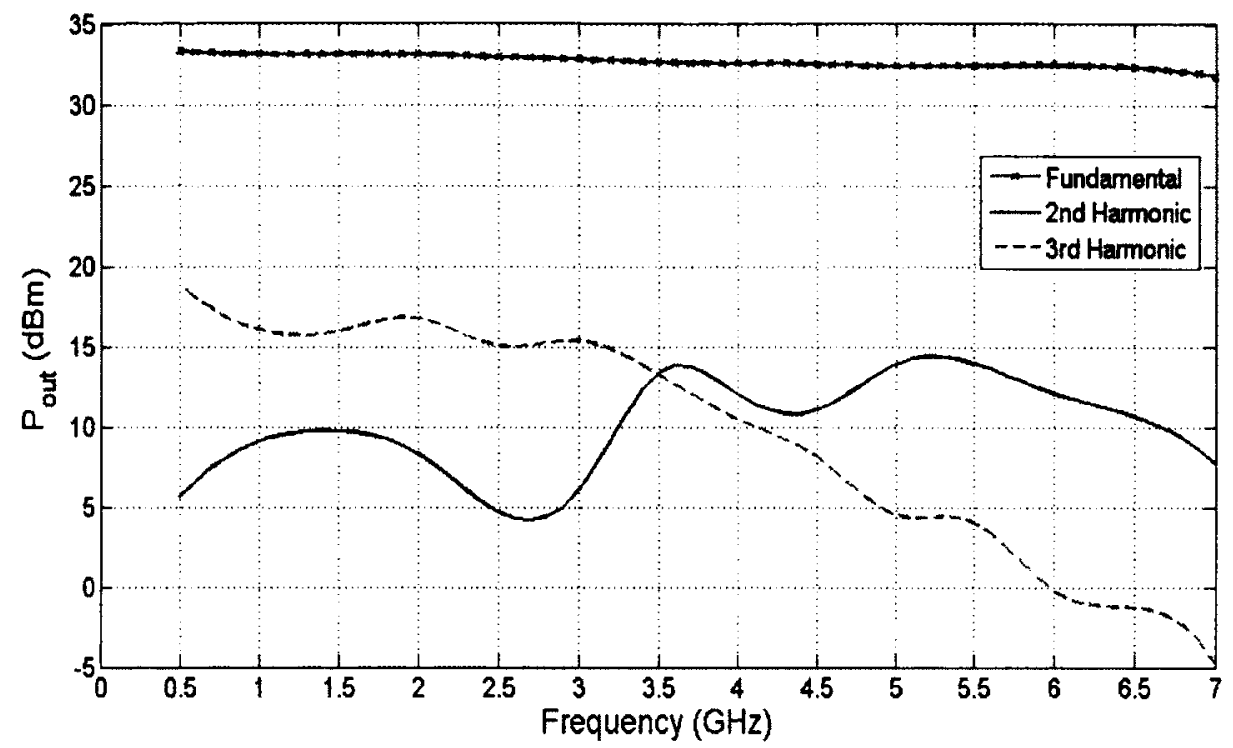

Figure 5.17. Simulated harmonic distortion over $0.5 \mathrm{GHz}-7 \mathrm{GHz}$ bandwidth.

\subsection{Constant Output Broadband ADPA}

In the preceding sections, we have reviewed the first ADPA, high $\mathrm{Q}$ interconnection effect, and the $2^{\text {nd }}$ (improved) ADPA design. The drain lines are tapered for maximum output power, and all optimizations are based on the $\mathrm{Z}_{\mathrm{opt}}$ data obtained from simulation of the unit gain stage at $4 \mathrm{GHz}$, which is the middle of the bandwidth.

In the optimization of the first design section, load pull simulations at 3 different frequencies were carried out (i.e. $2 \mathrm{GHz}, 4 \mathrm{GHz}$ and $6 \mathrm{GHz}$ ), and $\mathrm{R}_{\mathrm{opt}}$ was measured as a function of frequency. If we terminate the output of the ADPA to the optimum impedance $R_{o p t}$, which can balance the performances at low and high frequencies in the entire $0.5 \mathrm{GHz}-6.5 \mathrm{GHz}$ bandwidth, a constant output power and PAE could be implemented. 
In this section, a design based on constant output and implemented using the first ADPA circuitry is presented. As shown from Figure 5.18 to Figure 5.20, the $R_{\text {load }}$ value is swept as a function of the frequency while checking the power amplifier performance in terms of its $P_{\text {out }}, \mathrm{PAE}$ and power gain. The load value of $20 \Omega$ is indicated for the constant output power performance, and the output power, PAE and gain are above $32 \mathrm{dBm}, 20 \%$ and $10 \mathrm{~dB}$ respectively over the $0.5 \mathrm{GHz}-7 \mathrm{GHz}$ frequency range.

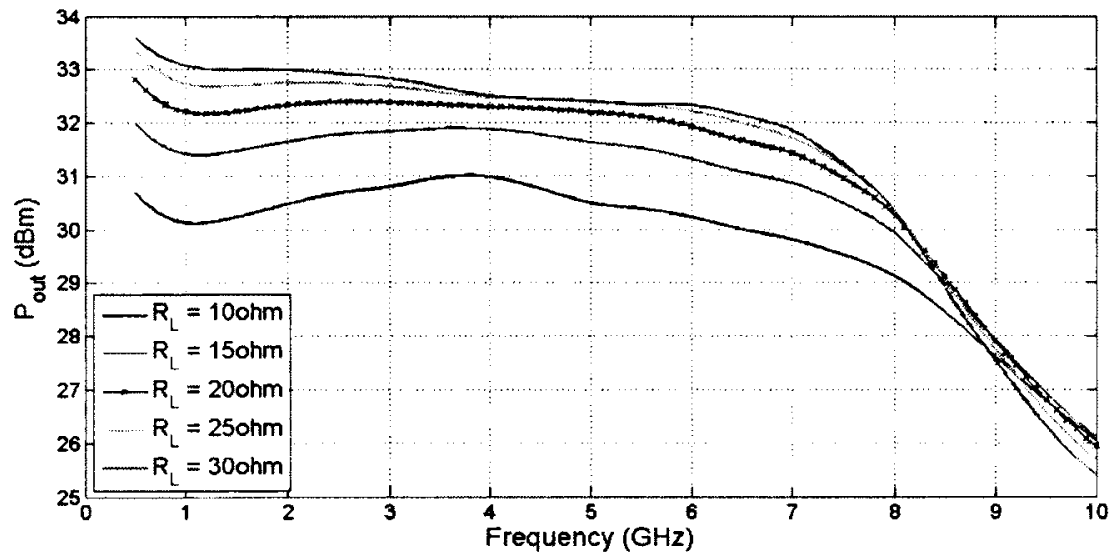

Figure 5.18. $\quad \mathrm{P}_{\text {out }}$ sweeping $\mathrm{R}_{\text {load }}$ as a function of the frequency.

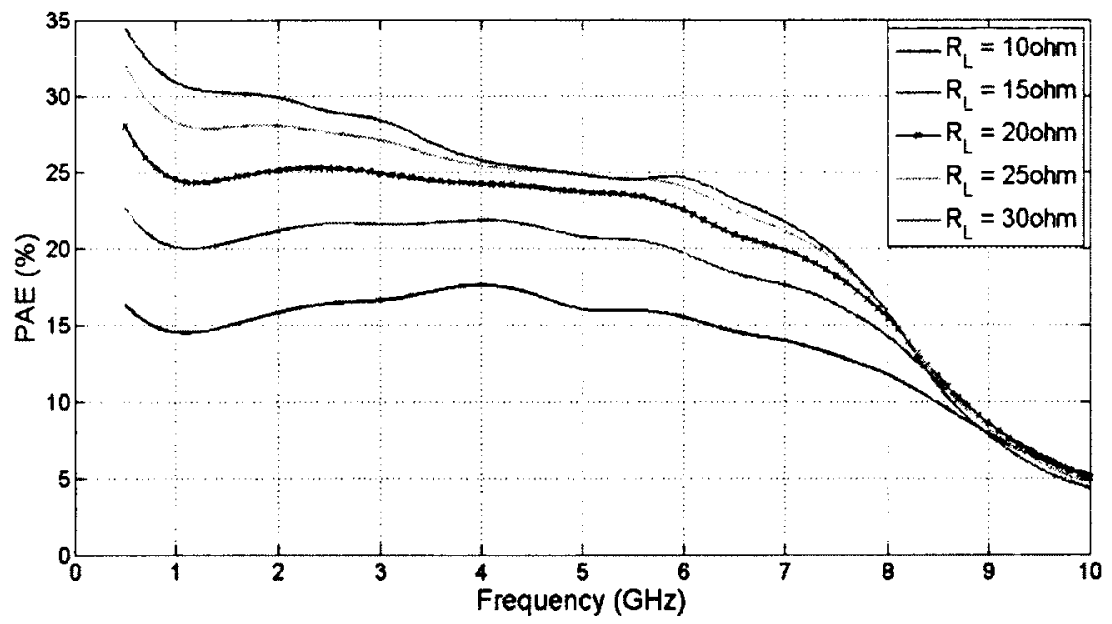

Figure 5.19.

PAE: sweeping $R_{\text {load }}$ as a function of the frequency. 


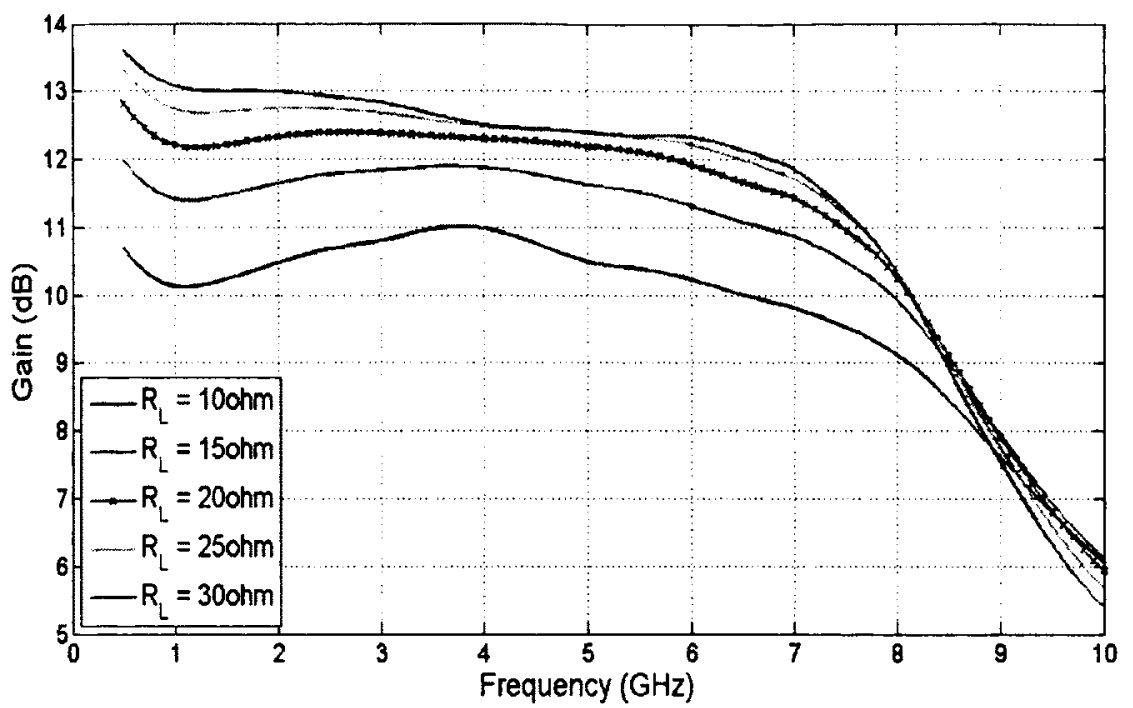

Figure 5.20. Power Gain: sweeping $R_{\mathrm{load}}$ as a function of the frequency.

Then a broadband matching network is implemented to transform $20 \Omega$ to $50 \Omega$ load. Again, tapered line technology is chosen. However, the long length of the tapered line broadband matching network should be considered in practice because of substrate cost. In other words, LTCC (Low Temperature Co-fired Ceramic) or other packaging substrate could be a low cost choice for output matching network. An $19 \mathrm{~mm} \times$ $1.15 \mathrm{~mm}$ output matching network is implemented in simulation, as shown in Figure 5.21. The small signal s-parameter performance of this matching network is shown in Figure 5.22. This optimized network has a return loss $S_{11}$ and $S_{22}$ lower than $-10 \mathrm{~dB}$ over the $0.1 \mathrm{GHz}-11 \mathrm{GHz}$ range and an insertion loss lower than $2 \mathrm{~dB}$.

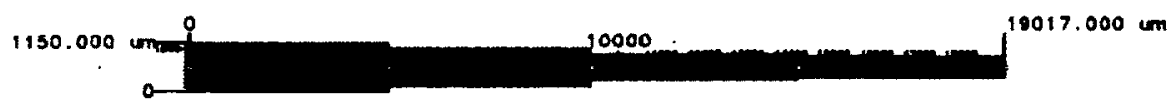

Figure 5.21. Tapered line broadband matching network. 


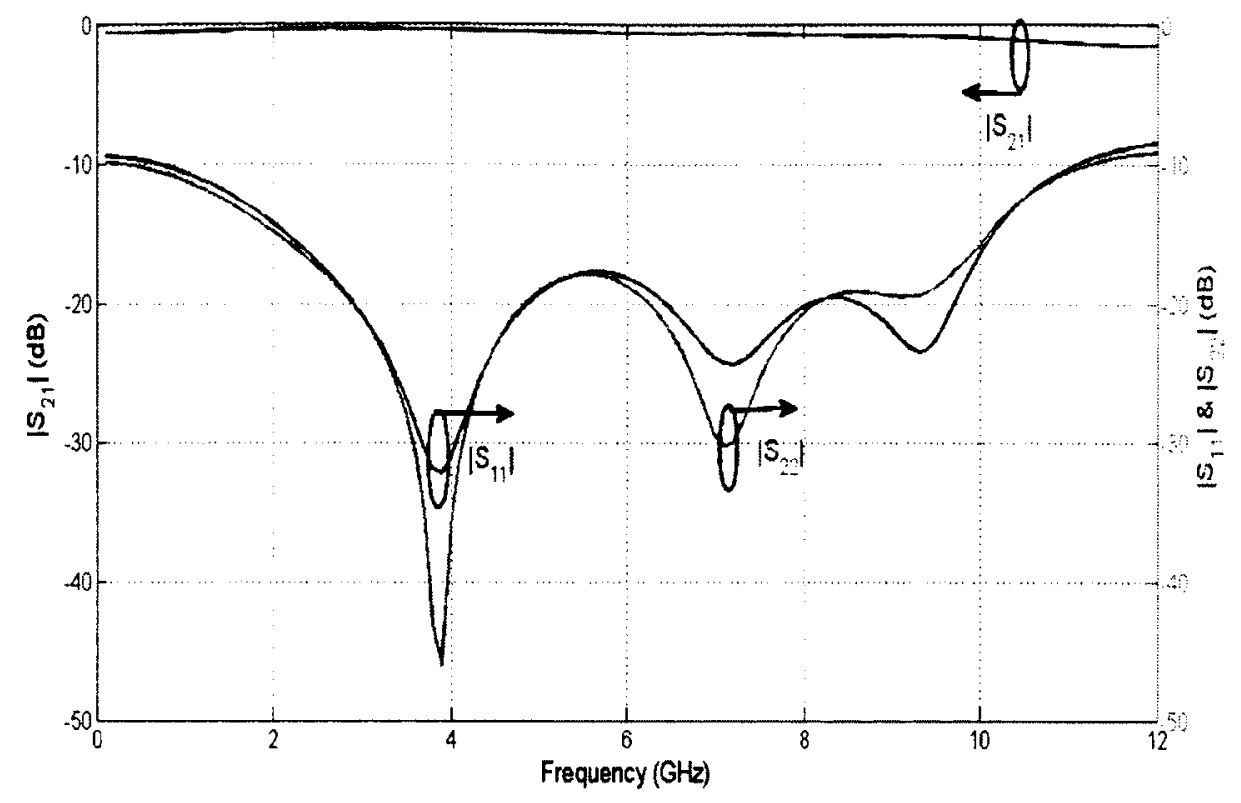

Figure 5.22. S-parameter performance of tapered matching network.

The simulated performance of the first ADPA design with output broadband matching network is presented from Figure 5.23 to Figure 5.25.

Figure 5.23 shows that the stability factor $\mathrm{K}$ and $\mathrm{B} 1$ ensure unconditional stability. Large signal s-parameters are illustrated in Figure 5.24. Gain $\left(S_{21}\right)$ is above $10 \mathrm{~dB}$ over $0.1 \mathrm{GHz}-7.8 \mathrm{GHz}$ frequency range, while $S_{12}$ is below $-20 \mathrm{~dB}$ across the bandwidth confirming the good isolation between input and output ports. The ADPA is seen to be well matched $\left(\mathrm{S}_{11}<-10 \mathrm{~dB}\right)$ from $0.5 \mathrm{GHz}$ to $8 \mathrm{GHz}$, when the output is matched to $20 \Omega$ instead of $50 \Omega$ load. It can be seen from Figure 5.25 that the APDA obtains a maximally flat output power and PAE compared to the first ADPA design, in the trade-off of power decreasing at frequencies lower than $2 \mathrm{GHz}$. A PAE difference of $2.2 \%$ is observed while the output power difference is only $0.5 \mathrm{dBm}$, with $0.3 \mathrm{~dB}$ power gain variation over $2 \mathrm{GHz}-6 \mathrm{GHz}$ frequency range. The 
performance observed here is better than that of commercial devices normally having $2 \mathrm{dBm} \mathrm{P}_{\text {out }}$ difference over the operating frequency range, although causing losses in the output power at low frequencies. Based on the investigation, it is believed that the best way to optimize this design is to separate the entire $7 \mathrm{GHz}$ band into several small bands, and present a reconfigurable matching network for individual applications.

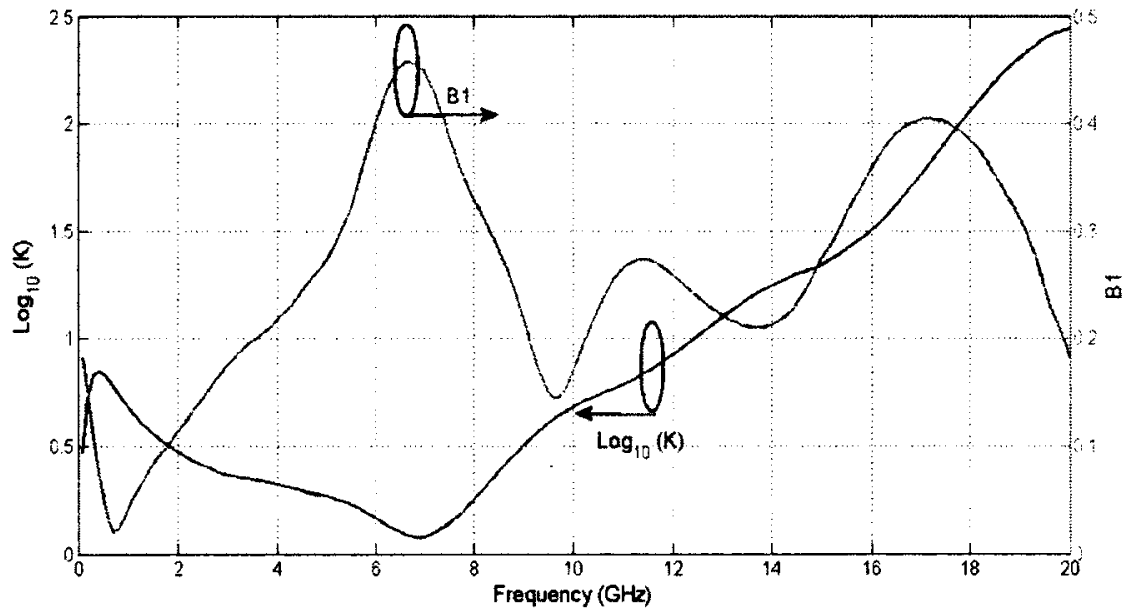

Figure 5.23.

Stability.

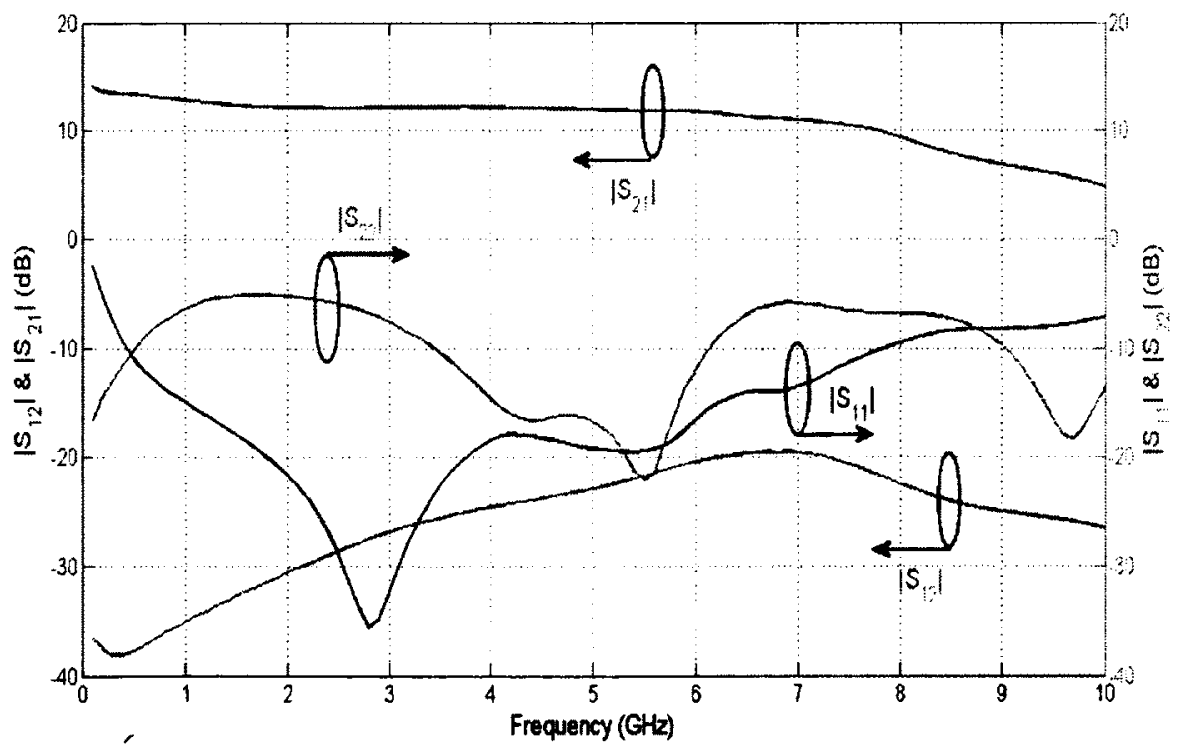

Figure 5.24.

Large signal s-parameters. 


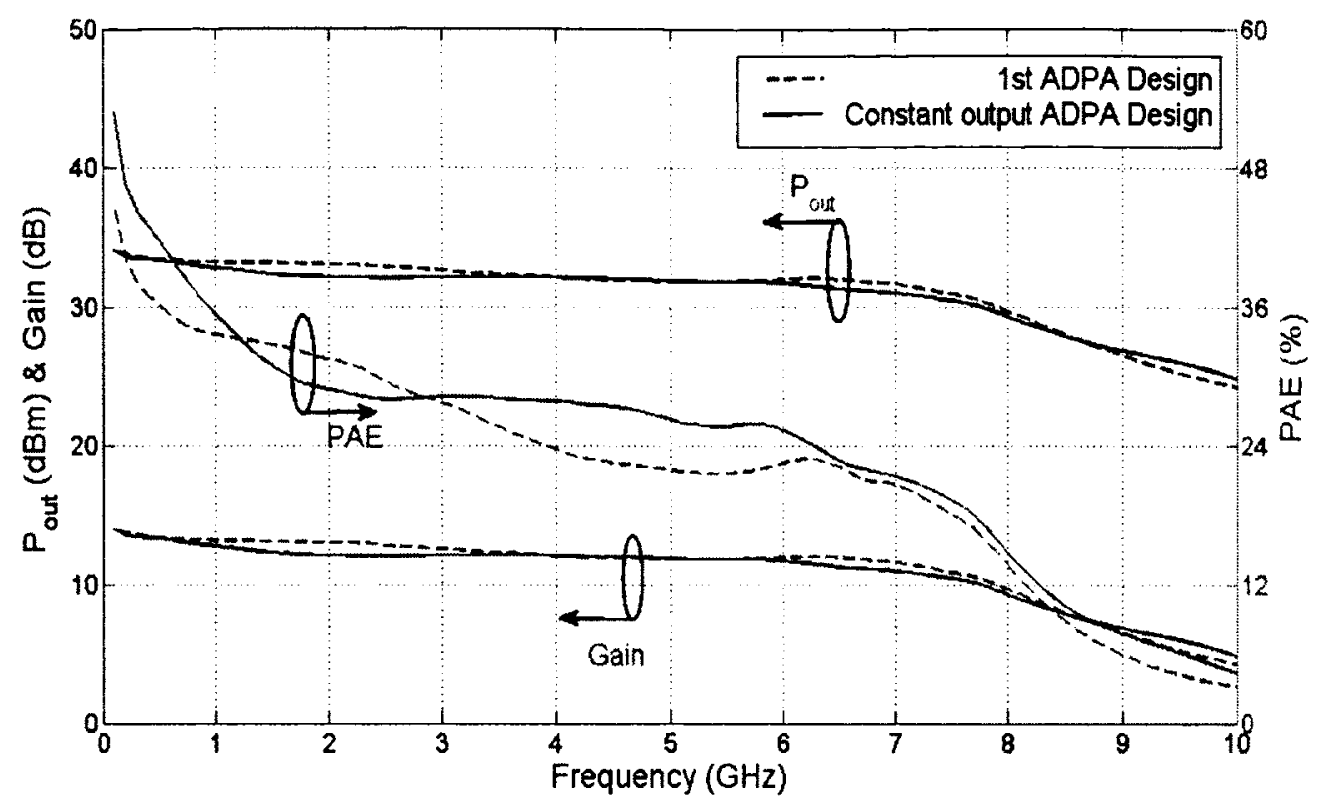

Figure 5.25. Simulated power performance comparison between first and constant output design (first ADPA + broadband matching network).

\subsection{Cascode Tapered Line ADPA}

The cascode ADPA is investigated for potential enhancement of the power amplifier. The inductances of the three drain line sections and the load impedance are swept for maximum $\mathrm{P}_{\text {out }}$ at $4 \mathrm{GHz}$ as shown in Figure 5.26. The maximum simulated PAE is lower than $16 \%$ due to the existence of an upper cascode transistor, although a cascode topology could obtain higher power gain (maximum achievable gain of 15.6 $\mathrm{dB})$ than the common-source amplifier $(10 \mathrm{~dB}-13 \mathrm{~dB})$. The maximum achievable output power is approximately $31 \mathrm{dBm}$. Because of the low PAE and not so attractive output power performance, a cascode structure is not chosen for this work. However, successful implementations of cascode or dual gate GaN devices are reported by other researchers as shown in reference [9], [10] and [11]. 

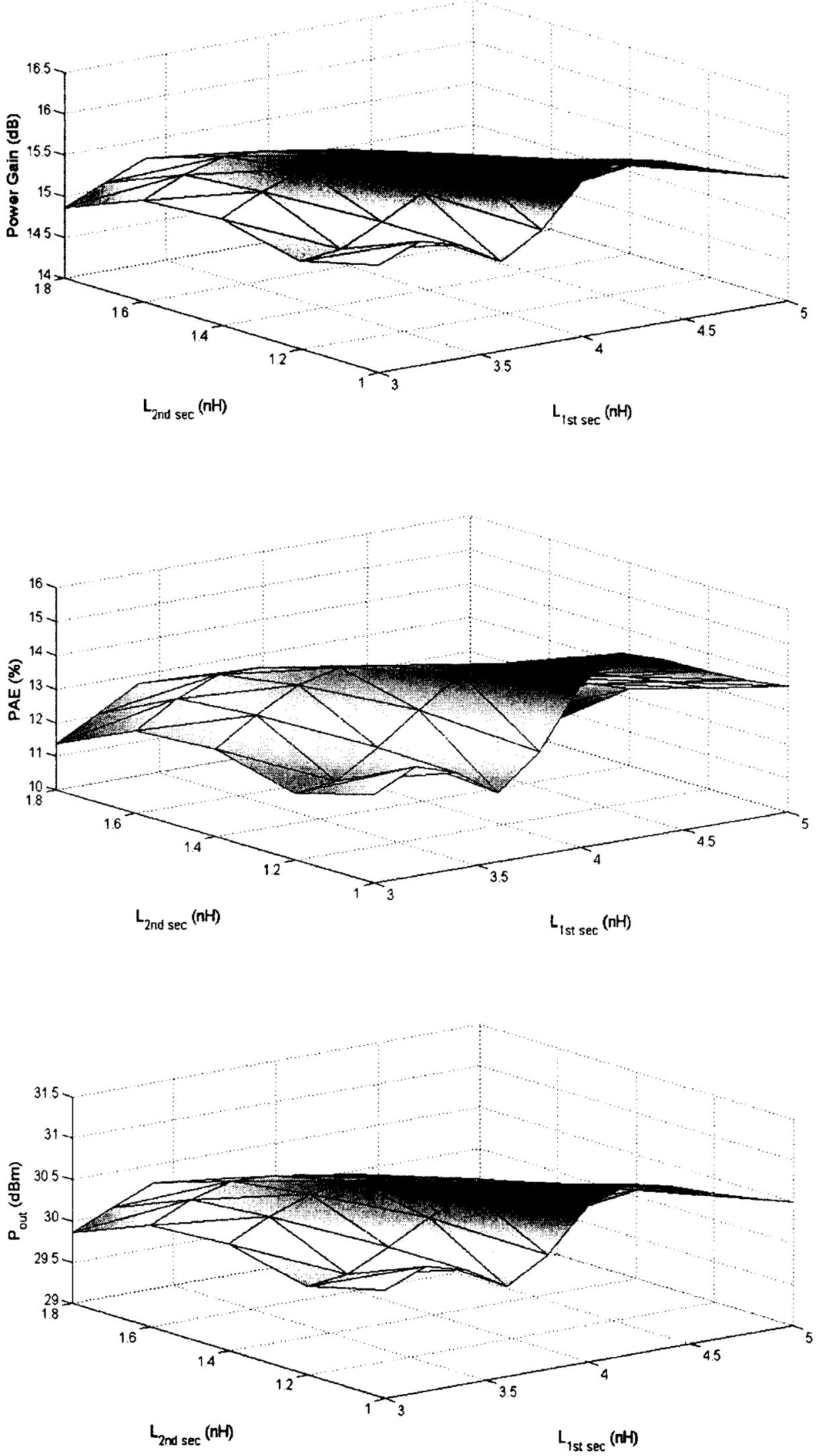

Figure 5.26.

Available power performance of cascode stage at $4 \mathrm{GHz}$. 


\subsection{Stage-Scaled ADPA}

As presented in Chapter 3, a Stage-Scaled uniform distributed power amplifier in $0.13 \mu \mathrm{m}$ SiGe BiCMOS was reported [6] [43], and the key principle is sizing the transistors together with the drain lines in order to maintain the same output power as the unit gain stage. In this section, we will introduce the implementation of this technology in $0.5 \mu \mathrm{m}$ GaN process.

First, the drain lines and HFETs are re-tapered. Because of the modeled HFET size limitation in the available kit, the drain lines are tapered using a factor $z=3 / 2$, and the HFETs are sized using a factor $k=3 / 5$ in the same direction simultaneously to yield a product $\mathrm{k}^{2} \mathrm{z}$ of 1.35 which is slightly different from the $\mathrm{k}^{2} \mathrm{z}=1$ requirement in the uniform stage-scale DPAs [6] [43]. Meanwhile, the phase shift of the first and $2^{\text {nd }}$ drain line sections are adjusted to match the gate lines, which is about $18^{\circ}$ at $4 \mathrm{GHz}$. The $L_{d 3}$ of the first design is kept constant as the last stage in the stage-scaled ADPA design, and the new $L_{d 1}$ and $L_{d 2}$ are tapered as shown in Figure 5.27. Approximately $1.5 \mathrm{nH}$ and $1 \mathrm{nH}$ inductance are obtained for $\mathrm{L}_{\mathrm{d} 1}$ and $\mathrm{L}_{\mathrm{d} 2}$ respectively, while a maximum $Q$ of 12.5 and 10 are achieved. In that, $R_{\mathrm{opt}}$ of the maximum output power is presented at the drain side of each unit gain stage. A maximum of $14^{\circ}$ and $2^{\circ}$ phase shift gap is observed between $L_{d 1} / L_{d 2}$ and $L_{g 2} / L_{g 3}$ respectively over the $0.1 \mathrm{GHz}-6$ $\mathrm{GHz}$ frequency range as seen in Figure 5.28, which means the phase shift is well matched in the $2^{\text {nd }}$ gain stage. The layout of the first stage-scaled ADPA (SSADPA) is presented in Figure 5.29; the width of the HFETs are $150 \mu \mathrm{m}, 250 \mu \mathrm{m}$ and $400 \mu \mathrm{m}$ respectively. 

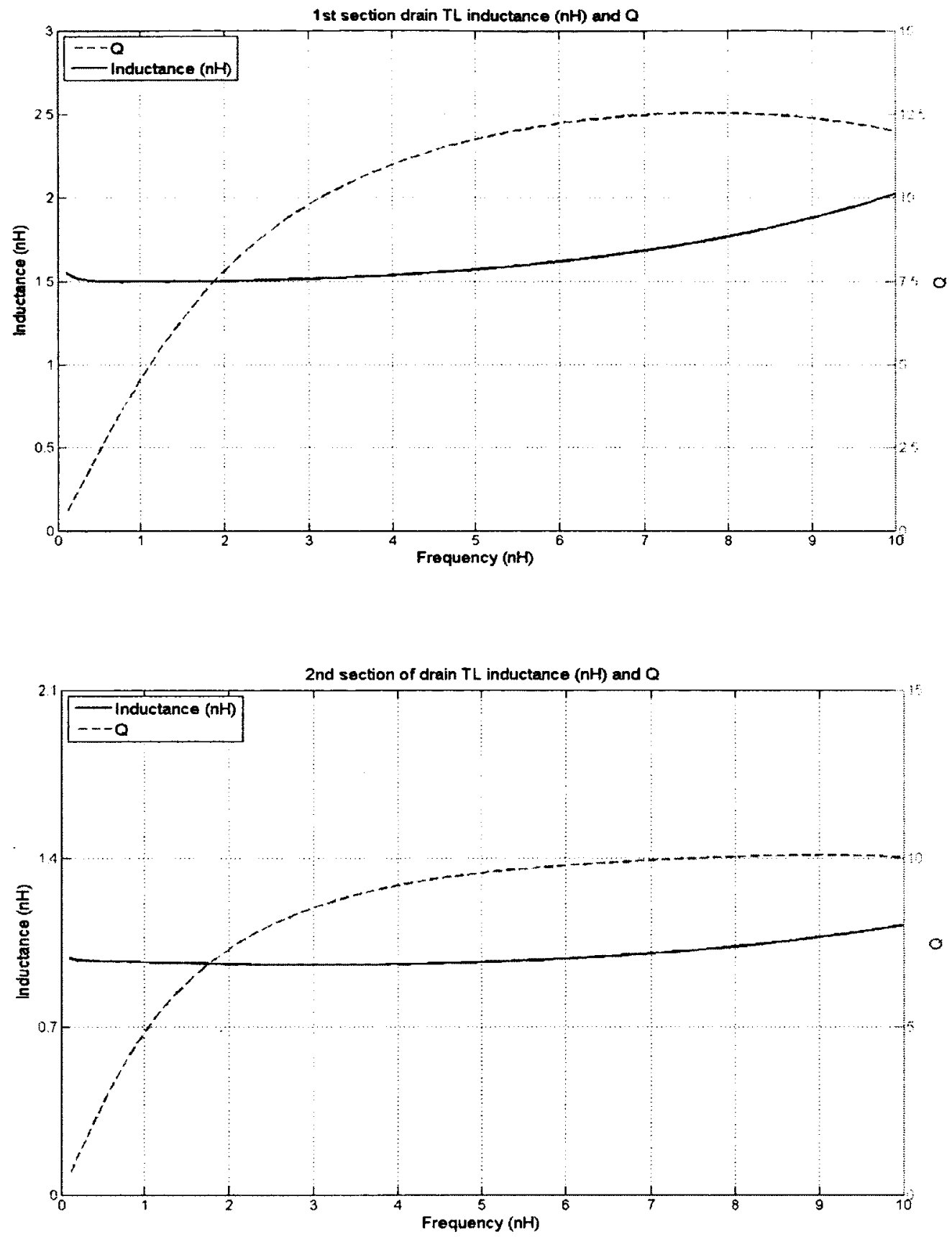

Figure 5.27. Characteristics of $\mathrm{L}_{\mathrm{d} 1}$ and $\mathrm{L}_{\mathrm{d} 2}$ in the stage-scaled ADPA design. 


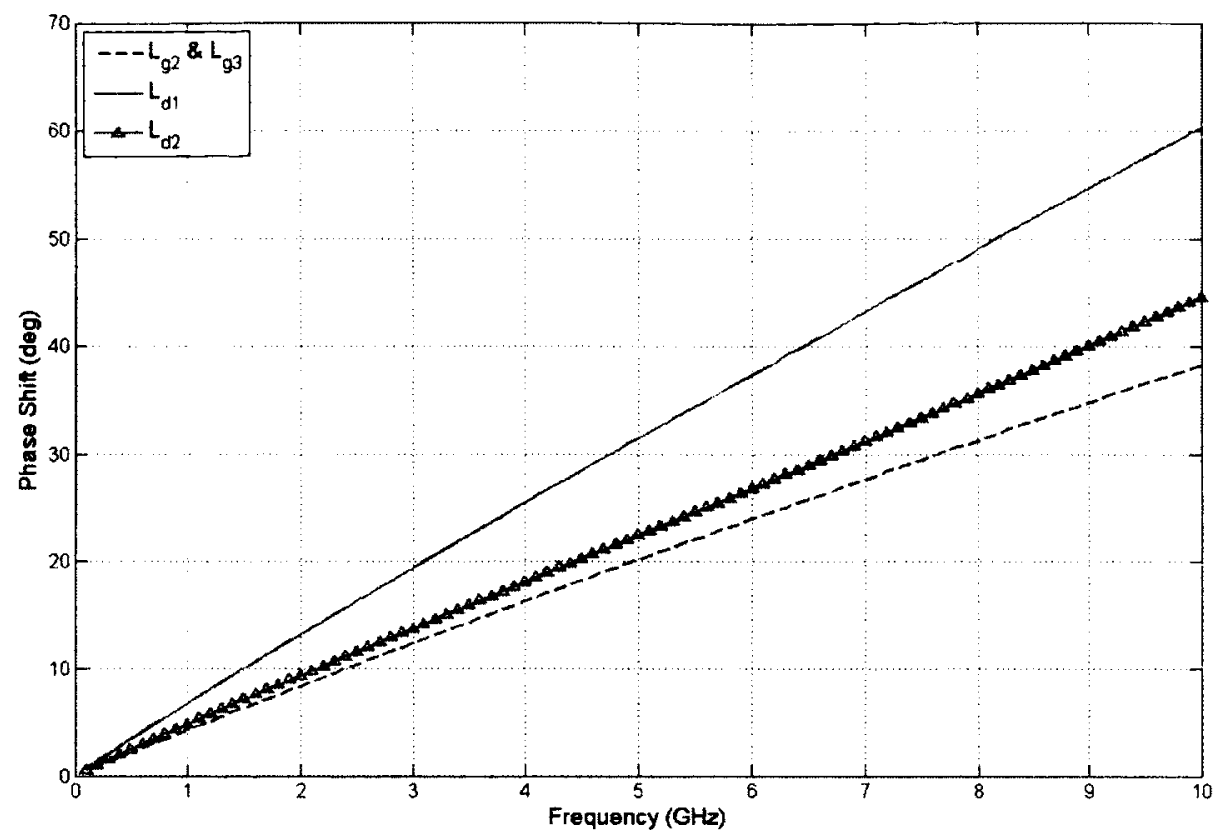

Figure 5.28.

Phase synchronization in SSADPA design.

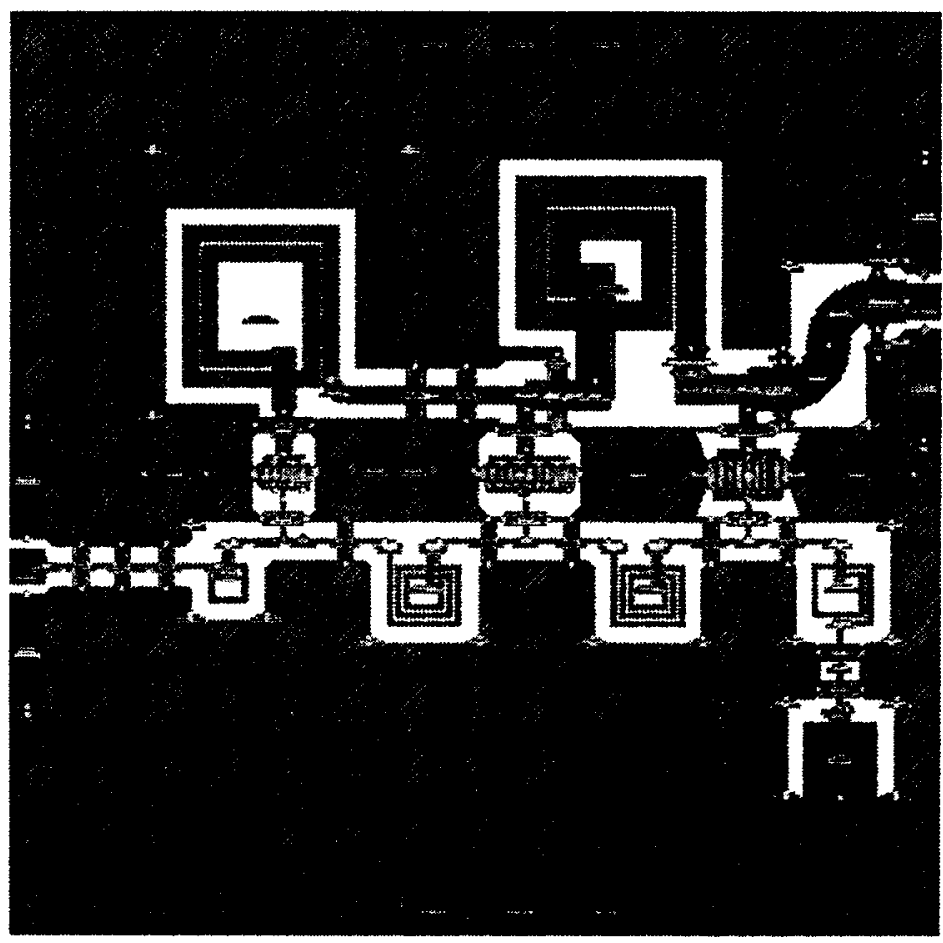

Figure 5.29.

$2 \mathrm{~mm} \times 2 \mathrm{~mm}$ Stage-Scaled ADPA layout using original uniform principle which presented in [6] [43]. 
After that, we re-investigate the design principle of the stage-scaled ADPA. The basic principle here is to size all devices to achieve maximum $\mathrm{P}_{\text {out }}$ at each gain stage. So, the impedance fed by the drain lines in each stage was readjusted, and the sizes of the HFETs were calculated as $400 \mu \mathrm{m}, 150 \mu \mathrm{m}$ and $250 \mu \mathrm{m}$ from the last to the first stage, to ensure the device's $R_{\text {opt }}$ produces $P_{\text {out }}$ of different size HFETs. The layout of the $2^{\text {nd }}$ SSADPA design is shown in Figure 5.30.

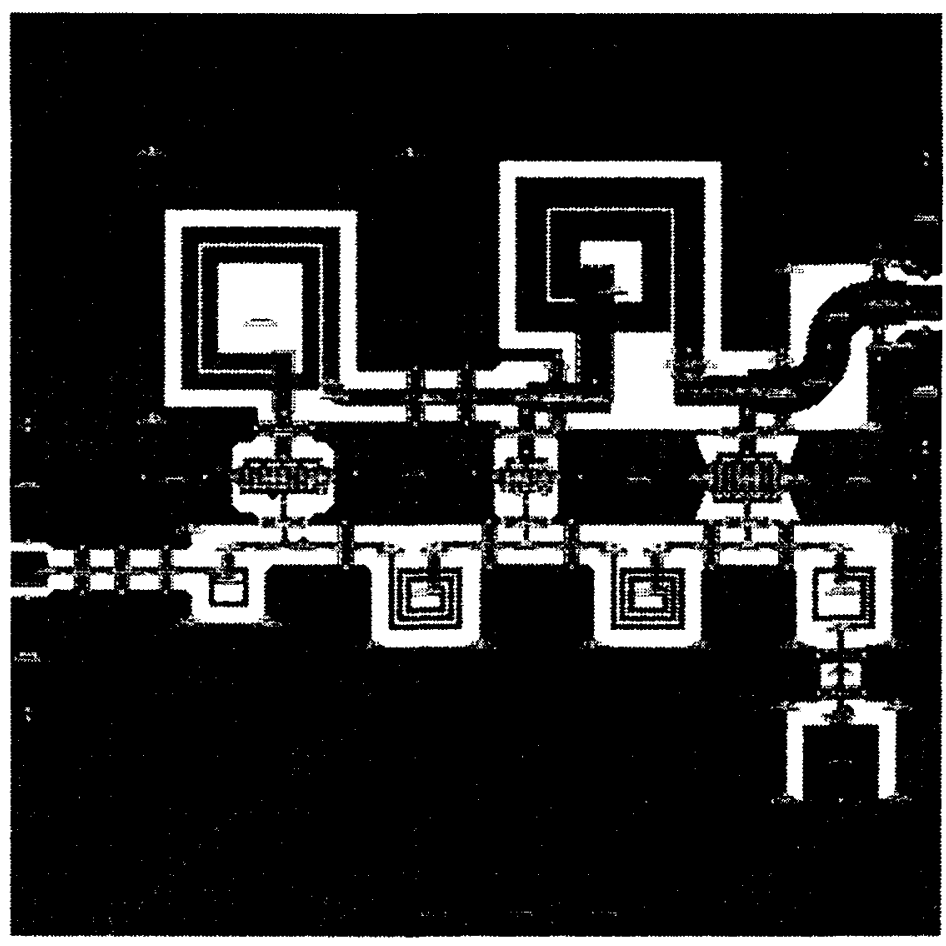

Figure 5.30. $2 \mathrm{~mm} \times 2 \mathrm{~mm}$ Stage-Scaled ADPA layout modified for maximum $\mathrm{P}_{\text {out }}$ of each stage.

A load pull simulation is then performed for both SSADPA designs; the results are similar. The load pull results of the first SSADPA design using the original principle of uniform stage-scaled DPA is illustrated in Figure 5.31 when the SSADPA is biased at $\mathrm{V}_{\mathrm{gs}}=-2.5 \mathrm{~V}, \mathrm{~V}_{\mathrm{ds}}=15 \mathrm{~V}$. It can be concluded from the plots, if the output of the 
SSADPA matches to approximately $30 \Omega$ over a broad-band from $0.1 \mathrm{GHz}$ to $10 \mathrm{GHz}$, the $P_{\text {out }}$ and other power performances could be maximally flat over the $-3 \mathrm{~dB}$ gain bandwidth.
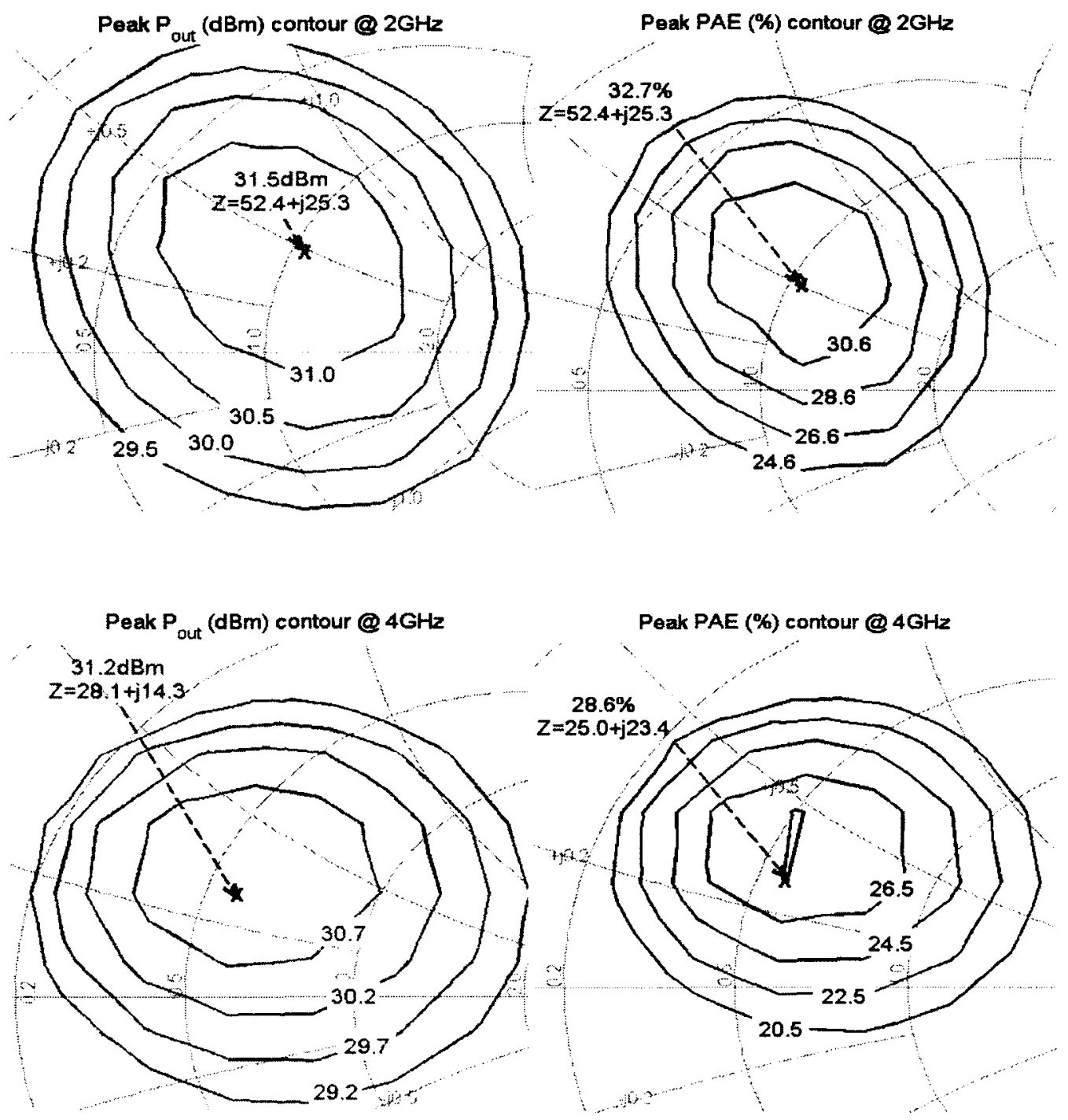

Figure 5.31. Load Pull simulation of the stage-scaled ADPA design using the original uniform SSDA principle. (a) at $2 \mathrm{GHz}$; (b) at $4 \mathrm{GHz}$. 


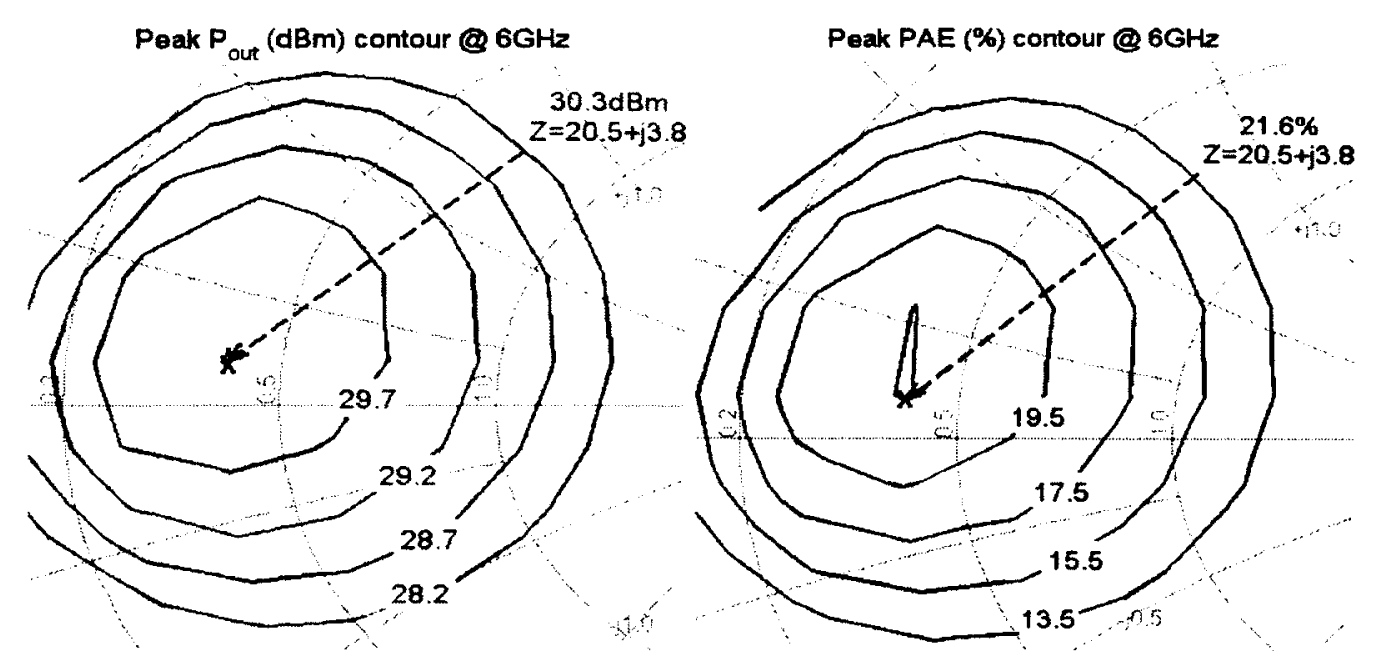

Figure 5.31. (continued). Load Pull simulation of the stage-scaled ADPA design using the original uniform SSDA principle. (c) at $6 \mathrm{GHz}$.

Finally, the power performance of the two stage-scaled ADPAs, where the output is matched to $30 \Omega$ via a $30 \Omega$ to $50 \Omega$ broadband matching network, is compared to the first ADPA design and is presented in Figure 5.32 and Figure 5.33. The ADPA is normally biased at $\mathrm{V}_{\mathrm{gs}}=-2.5 \mathrm{~V}, \mathrm{~V}_{\mathrm{ds}}=15 \mathrm{~V}$. Two designs are studied and both achieve a $3 \mathrm{~dB}$ gain bandwidth of $0.5 \mathrm{GHz}-10 \mathrm{GHz}(3.5 \mathrm{GHz}$ broader than the fabricated ADPA), and deliver $30 \mathrm{dBm}$ RF power over the entire bandwidth. A difference of approximately $1.31 \mathrm{~dB}$ and $8.27 \%$ variations are observed in the $\mathrm{P}_{\text {out }}$ and PAE respectively over the $0.5 \mathrm{GHz}-6 \mathrm{GHz}$ bandwidth in the first SSADPA design, and $1.02 \mathrm{~dB}$ and $7.29 \%$ differences are obtained in $\mathrm{P}_{\text {out }}$ and PAE over the 0.5 $\mathrm{GHz}-9 \mathrm{GHz}$ range in the $2^{\text {nd }}$ SSADPA design. The smallest $P_{\text {out }}$ divergence of 0.17 $\mathrm{dBm}$ and $1.90 \%$ PAE variation are achieved over $1 \mathrm{GHz}-7.5 \mathrm{GHz}$ frequency range in the $2^{\text {nd }}$ SSADPA design, while $P_{\text {out }}$ gain and PAE are above $30 \mathrm{dBm}, 10 \mathrm{~dB}$ and $20 \%$ respectively over the entire bandwidth. 


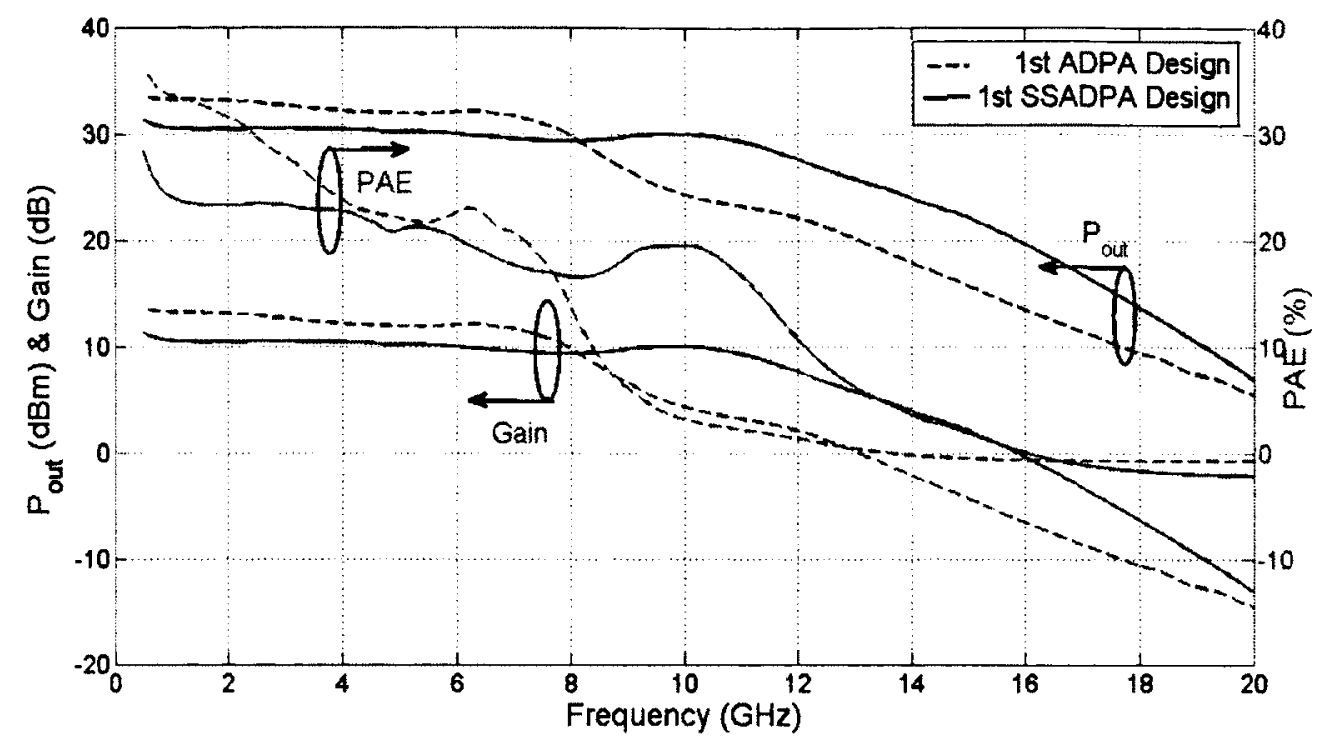

Figure 5.32. EM simulated power performances comparison between the first SSADPA design (with output matching network) and the first ADPA design (fabricated).

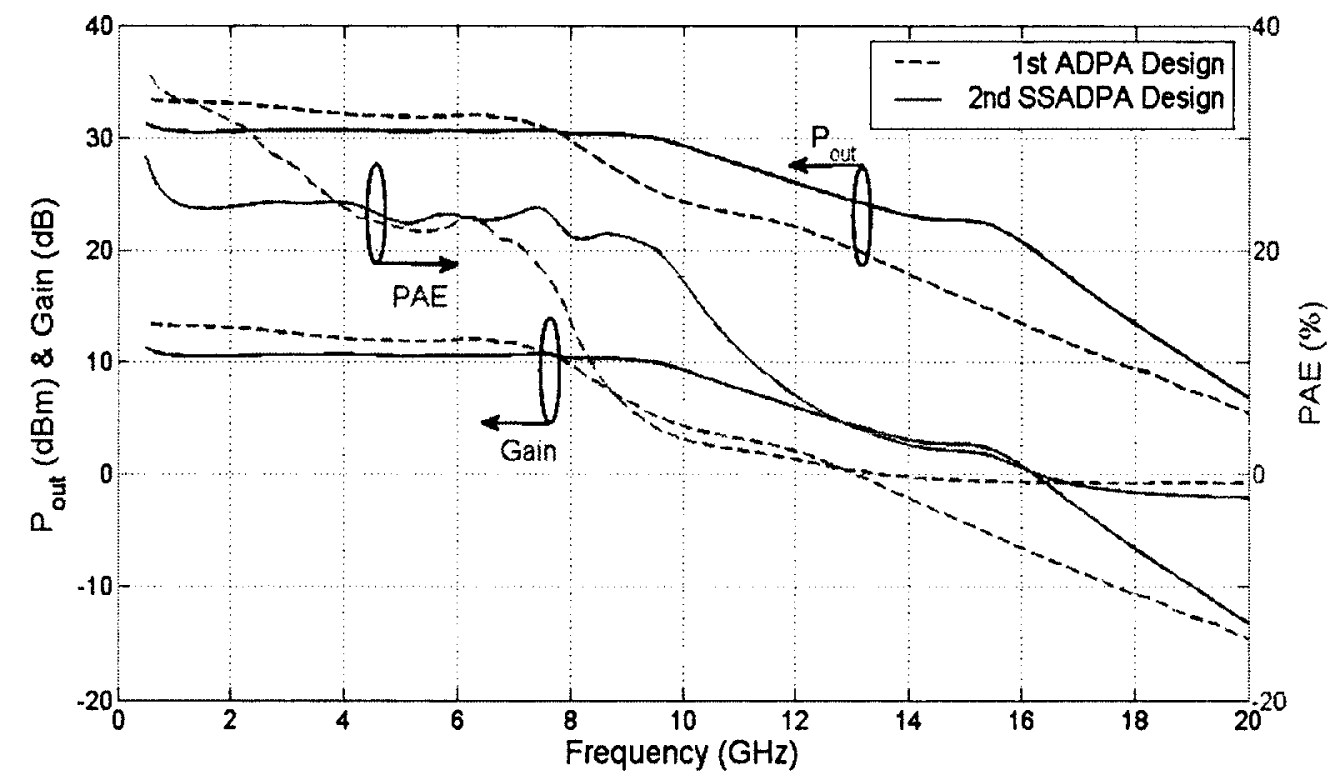

Figure 5.33. EM simulated power performances comparison between the $2^{\text {nd }}$ SSADPA design (with output matching network) and the first ADPA design (fabricated). 


\subsection{Conclusion}

In this chapter, two SSADPA designs were introduced by optimization of simulated results. A difference of $0.17 \mathrm{~dB}$ in the $\mathrm{P}_{\text {out }}$ and a PAE variation of $1.90 \%$ are achieved over the $1 \mathrm{GHz}-7.5 \mathrm{GHz}$ range. The gain was found to offer trade-offs versus broader bandwidth; $10 \mathrm{~dB}$-gain and $30 \mathrm{dBm} \mathrm{P}_{\text {out }}$ are obtained over the $0.5 \mathrm{GHz}-10$ $\mathrm{GHz}$ bandwidth. In future designs, there is still much work needed to follow up on some of the findings presented here, such as optimizing the SSADPA for higher output power. 


\section{Chapter 6: Conclusion and Recommendations}

After presentation of the design work, accomplishments, issues in the design and future work of this work are concluded in this chapter.

\subsection{Accomplishments}

This work has designed a novel high efficient, linear and ultra-broadband GaN MMIC Power Amplifier. This work is the first time an active MMIC device using CPFC GaN500 process is presented. The power amplifier was successfully measured and the results verify the process is reliable. A Tapered Line Asymmetric Distributed structure was successfully implemented, and the ADPA's measured performance demonstrated superior PAE, Gain, BW product for $1 \mathrm{~W}$ output power.

Over the frequency range from $0.5 \mathrm{GHz}$ to $6.5 \mathrm{GHz}$, more than $10 \mathrm{~dB}$ of gain is obtained, and more than $1 \mathrm{~W}$ linear RF power is delivered. Among all the performance parameters studied, a high PAE is most attractive. A peak PAE of $38.1 \%$ is achieved at $0.5 \mathrm{GHz}$ in linear mode, and up to $52.69 \%$ PAE can be obtained while $31.79 \mathrm{dBm}$ RF power is delivered. The performance of this ADPA is compared with other designs listed in Table 6.1.

Two IEEE journal papers are ready to be submitted based on the work of this thesis. 
Table 6.1. Performance Comparison

\begin{tabular}{|c|c|c|c|c|c|c|}
\hline \multirow{2}{*}{ Tech. } & $\begin{array}{c}\text { DC supply } \\
(\mathrm{V})\end{array}$ & Freq. (GHz) & $\begin{array}{c}\text { PAE } \\
(\%)\end{array}$ & Pout (dBm) & $\begin{array}{c}\text { Size } \\
(\mathrm{mm} \times \mathrm{mm})\end{array}$ & Ref \\
\hline \multirow{2}{*}{$0.35 \mu \mathrm{m}$ CMOS } & 2 & 2.4 & 41 & 33 & $1.3 \times 2$ & 16 \\
\cline { 2 - 7 } & 2.5 & 2.4 & 31 & 33.4 & $1.3 \times 2$ & 17 \\
\hline $0.35 \mu \mathrm{m}$ SiGe & 3.3 & $0.6-2.4$ & 45 & 17 & $1 \times 0.8$ & 15 \\
\hline $0.2 \mu \mathrm{m}$ GaN & 15 & $0.05-12.3$ & 20 & 30 & $1.7 \times 1.7$ & 20 \\
\hline GaAs & 10 & $2-18$ & 23 & 30.5 & $3.6 \times 1.7$ & 25 \\
\hline $0.2 \mu \mathrm{m}$ GaN & 15 & $2-18$ & 15 & 33 & $4 \times 2$ & 19 \\
\hline GaN HEMT & 30 & $3-4$ & 28 & 37.8 & $4 \times 2.8 /$ & 18 \\
\hline $0.5 \mu \mathrm{m}$ GaN & 15 & $0.1-5$ & 30 & 30 & $2.2 \times 4.3$ & 21 \\
\hline $0.7 \mu \mathrm{m}$ GaN & 19 & $0.2-7.5$ & 15 & 31.5 & $-1.5 \times 2.8$ & 9 \\
\hline $0.5 \mu \mathrm{m}$ GaN & $15 / 20$ & $0.5-6.5$ & 52.7 & $>30$ & $2 \times 2$ & This \\
\hline
\end{tabular}

Several ADPA enhancements were investigated via simulation. Among those possible enhancements, a stage-scaled ADPA obtained superior constant output power over a $10 \mathrm{GHz}$ bandwidth. A $0.17 \mathrm{~dB} \mathrm{P}_{\text {out }}$ difference and $1.90 \%$ PAE variation were achieved over $1 \mathrm{GHz}-7.5 \mathrm{GHz}$ frequency range, while $10 \mathrm{~dB}$ of gain and $30 \mathrm{dBm}$ $P_{\text {out }}$ were obtained over $0.5 \mathrm{GHz}-10 \mathrm{GHz}$ bandwidth.

\subsection{Issues in the Design}

Although loose dies are mounted on a metal plate while under $\mathrm{CW}$ test, the self-heating effect caused by GaN semiconductor characteristics is still a challenge in our design. Such effects are under-estimated in the HFET model which leads to over performance in the DC $\mathrm{I}-\mathrm{V}$ curve and Harmonic Balance simulation compared to 
measurements in $\mathrm{CW}$-mode. The current decreases very rapidly during measurements when increasing the bias voltage, which results in performance differences between the measured data and the simulation. We suggested that there are two solutions. The first is to improve the GaN HFET model. The second is to test the device in Pulse-mode; the idea comes from the truth that the PA is only consuming high current in a very short time period.

Further, the RF cables available in the Department of Electronics of Carleton University are limited in frequency, which results in jittery data curves captured in the measurement. Furthermore, the test equipment is limited. For example, the signal generators have not been calibrated for over two years (they should be calibraged annually by the manufacturers). Also, a modulated signal source is not available.

\subsection{Future Work}

Higher PAE and output power can be obtained by more carefully sizing tapered lines, and linearity can be improved in maximum PAE mode. A stage-scale structure could be optimized especially when much more different size HFETs are modeled. A voltage controlled switchable matching network could be added to the ADPA's input and output side for better performance, such as harmonic distortion, matching and power gain in specific applications. Also, the other blocks such as digital voltage controller, LNA, Up/Down Converter (mixer) and PLL which were presented in Chapter 2.5 should be implemented. And finally, all of those blocks should be combined as a practical transceiver. 


\section{Bibliography}

[1.] Virdee B.S., Virdee A.S., Banyamin B.Y., "Broadband Microwave Amplifiers", Boston, London, 2004 (ISBN: 1-58053-892-4).

[2.] Meyer D., "European Commission proposes TV spectrum for WiMax". zdnetasia.com. Retrieved 2008-01-08.

[3.] Rogers J., Plett C., "Radio Frequency Integrated Circuit Design", Boston, London, 2003 (ISBN: $1-58053-502-x)$.

[4.] Quay R., "Gallium Nitride Electronics", Freiburg, Germany, 2008 (ISBN: $978-3-540-71890-1)$

[5.] Robertson I.D., Lucyszyn S., "RFIC and MMIC design and technology", the Institution of Electrical Engineer.

[6.] Chen J.S., Niknejad A.M., "A stage-scaled distributed power amplifier achieving $110 \mathrm{GHz}$ bandwidth and $17.5 \mathrm{dBm}$ peak output power" IEEE Radio Frequency Integrated Circuits (RFIC) Symposium 2010, pp. $347-350$.

[7.] Dambrine G., Cappy A., Heliodore F., Playez E., "A new method for determining the FET small-signal equivalent circuit" IEEE Microwave Theory and Techniques (MTT) Transaction 1988, pp. $1151-1159$.

[8.] Cripps S.C., "RF Power Amplifiers for Wireless Communications" (2 $2^{\text {nd }}$ Edition), Artech House, Boston, London, 2006.

[9.] Ramakrishna V., Keller S., Mishra U., Rodwell M.J.W, Long S.I., "Broadband GaAs MESFET and GaN HEMT Resistive Feedback Power Amplifiers" IEEE 
Journal of Solid-State Circuits (JSSC) 2000, pp. 1285 - 1292.

[10.] Santhakumar R., Thibeault B., Higashiwaki M., Keller S., Chen Z., Mishra U.K., York R.A., "Two-Stage High_Power Distributed Amlifier Using Dual-Gate GaN HEMTs" IEEE Microwave Theory and Techniques (MTT) Transaction 2011, pp. $2059-2063$.

[11.] Quary R., Tessmann A., Kiefer R., Maroldt S., Haupt C., Nowotny U., Weber R., Massler H., Schwantuschke D., Eggebert M.S., Leuther A., Mikulla M., Ambacher O., "Dual-Gate GaN MMICs for MM-Wave Operation" IEEE Microwave and Wireless Components Letters 2011, pp. 95 - 97.

[12.] Kemerley R. T., Wallace H. B., and Yoder M. N., "Impact of wide bandgap microwave devices on DoD systems" Proceedings of the IEEE June 2002, vol. 90, pp. $1059-1064$.

[13.] Tolbert L. M., Ozpineci B., Islam S. K., and Chinthavali M. S., "Wide bandgap semiconductors for utility applications" Proc. Power and Energy Systems. ACTA Press Feb. 2003, USA.

[14.] Trew R. J., "SiC and GaN transistors - Is there one winner for microwave power applications?" Proceedings of the IEEE June 2002, vol. 90, pp. $1032-1047$.

[15.] Li Y., Lopez J., Lie D.Y.C, Chen K., Wu S., Yang T.Y., "A broadband SiGe power amplifier in an efficient polar transmitter using envelope-tracking for mobile WiMAX" IEEE Silicon Monolithic Integrated Circuits in RF Systems (SiRF) 2011, pp.137- 140.

[16.] Aoki I., Kee S.D, Rutledge D., Hajimiri A., "Fully integrated CMOS power 
amplifier design using the distributed active-transformer architecture" IEEE Journal of Solid-Stage Circuits (JSSC) 2000, pp. $57-60$.

[17.] Aoki I., Kee S.D, Rutledge D., Hajimiri A., "A 2.4-GHz, 2.2-W, 2-V fully-integrated CMOS circular-geometry active-transformer power amplifier" IEEE conference on Custom Integrated Circuits 2001, pp. 57-60.

[18.] Suijker E.M., Sudow M., Fagerlind M., Rorsman N., Hek A.P., Vliet F.E., "GaN MMIC Power Amplifiers for S-band and X-band" IEEE $38^{\text {th }}$ Microwave Conference in Europe 2008, pp. 297 - 300.

[19.] Santhakumar R., Thibeault B., Higashiwaki M., Keller S., Chen Z, Mishra U.K, York R.A., "Two-Stage High-Gain-Power Distributed Amplifier Using Dual-Gate GaN HEMTs" IEEE Microwave Theory and Techniques (MTT) Transactions 2011, pp. $2059-2063$.

[20.] Kobayashi K.W., Chen Y.C., Smorchkova I., Tsai R., Wojtowicz M., Oki A., "1-Watt Conventional and Cascode GaN-SiC Darlington MMIC Amplifiers to $18 \mathrm{GHz}$ " IEEE Radio Frequency Integrated Circuits (RFIC) Symposium 2007, pp. 585 - 588.

[21.] Geller B., Hanson A., Chaudhari A., Edwards A., Kizilyalli I.C., "A Broadband Low Cost GaN-on-Silicon MMIC Amplifier" IEEE RFIC Symposium 2008, pp.527 530.

[22.] Krishnamurthy K., Vetury R., Keller S., Mishra U., Rodwell M.J.W., Long S.I., "Broadband GaAs MESFET and GaN HEMT Resistive Feedback Power Amplifiers" IEEE Journal of Solid-state Circuits (JSSC) 2000, vol. 35, no. 9, pp. 1285 - 1292.

[23.] Kobayashi K.W., Chen Y.C., Smorchkoova I., Tsai R., Wojtowicz M., Oki A., 
"1-Watt Conventional and Cascoded GaN-SiC Darlington MMIC Amplifiers to 18GHz" IEEE Radio Frequency Integrated Circuits (RFIC) Symposium 2007, pp. 585 $-588$.

[24.] Kobayshi K. W., Chen Y. C., Smorchkova I., Heying B., Luo W. B., Sutton W., Wojtowicz M., and Oki A., "Multi-decade GaN HEMT cascode-distributed power amplifier with baseband performance" IEEE Radio Frequency Integrated Circuits (RFIC) Symposium 2009, pp. 369-372.

[25.] Cardente C., Colantonio P., Paolo F.D., Giannini F., Giofre R., "Multi-Octave High Efficiency Power Amplifier in GaAs Technology" Integrated Nonlinear Microwave and Millimeter-Wave Circuits Workshop 2008, pp. 137 - 140.

[26.] Sayginer M., Yazgi M., Kuntman H.H., Virdee B.S., "1-8 GHz High Efficiency Single Stage Travelling Wave Power Amplifier" Electrical and Electronics Engineering (ELECO) 7th International Conference 2011, pp. II-85 - II-88.

[27.] Quaglia R., Camarchia V., Pirola M., Guerrieri S.D., Tinivella R., Ghione G., Pagani M., “7GHz GaN MMIC power amplifier for Microwave Radio links with 45\% drain efficiency in a wide power range" IEEE Integrated Nonlinear Microwave and Millimeter-Wave Circuits (INMMIC) conference workshop 2010, pp. 160 - 163.

[28.] Campbell C., Lee C., Williams V., Kao M.Y, Tserng H.Q., Saunier P., "A Wideband Power Amplifier MMIC Utilizing GaN on SiC HEMT Technology" IEEE Compound Semiconductor Integrated Circuits Symposium 2008, pp. 1 - 4 .

[29.] Meliani C., Behtash R., Wiirfl J., Heinrich W., Trankle G., “A Broadband GaN-MMIC power amplifier for L to X Bands" IEEE Microwave Integrated Circuit 
Conference 2007, pp. $147-150$.

[30.] Kuhn J., Raay F., Quay R., Kiefer R., Maier T., Stibal R., Mikulla M., Eggebert M.S., Bronner W., Schlechtweg M., Ambacher O., Thumm M., "Design of highly-efficient GaN X-band-power-amplifier MMICs" IEEE International Microwave Symposium Digest (MTT-S) 2009, pp. $661-664$.

[31.] Darwish A.M., Hung H.A., Viveiros E., Kao M.Y, "Multi-octave GaN MMIC amplifier" IEEE International Microwave Symposium Digest (MTT-S) 2010, pp. 141 -144 .

[32.] Conlon J.P., Zhang N., Poulton M.J., Shealy J.B., Vetury R., Green D.S., Brown J.D., Gibb S., "GaN Wide Band Power Integrated Circuits" IEEE Compound Semiconductor Integrated Circuit Symposium 2006, pp. 85 - 88.

[33.] Schuh P., Leberer R., Sledzik H., Schmidt D., Oppermann M., Adelseck B., Brugger H., Quay R., Raay R., Eggebert M.S., Kiefer R., Bonner W., "Linear broadband GaN MMICs for Ku-band Applications" IEEE International Microwave Symposium Digest (MTT-S) 2006, pp. 1324 - 1326.

[34.] Chen T.S, Zhang B., Jiao G., Ren C.J., Chen C., ShaoK., Yang N.B., "X-Band $11 \mathrm{~W}$ AlGaN/GaN HEMT power MMICs" IEEE Microwave Integrated Circuit Conference 2007, pp. $162-164$.

[35.] Lee J.W., Lin J.F., "Series-biased CMOS power amplifier operating at high voltage for $24 \mathrm{GHz}$ radar applications" IEEE SoC Design Conference (ISOCC) International 2010 , pp. $360-363$.

[36.] Ku B.H., Baek S.H., Hong S.C., "A X-band CMOS power amplifier with 
on-chip transmission line transformers" IEEE Radio Frequency Integrated Circuits (RFIC) Symposium 2008, pp. $523-526$.

[37.] Lu. C., Pham A.V.H., Shaw M., Saint C., "Linearization of CMOS Broadband Power Amplifiers Through Combined Multigated Transistors and Capacitance Compensation" IEEE Microwave Theory and Techniques (MTT) Transaction 2007, pp. $2320-2328$.

[38.] Fathi M., Su D.K., Wooley B.A., “A stacked 6.5-GHz 29.6-dBm power amplifier in standard 65-nm CMOS" IEEE Custom Integrated Circuits Conference (CICC) 2010, pp. $1-4$.

[39.] Haldi P., Chowdhury D., Reynaert P., Liu G., Niknejad A.M., “A 5.8 GHz IV Linear Power Amplifier Using a Novel On-Chip Transformer Power Combiner in Standard 90 nm CMOS" IEEE Journal of Solid-State Circuits (JSSC) 2008, pp. 1054 $-1063$.

[40.] Eo Y.S., Lee K.D., “A 2.4GHz/5.2GHz CMOS power amplifier for dual-band applications" IEEE International Microwave Symposium Digest (MTT-S) 2004, pp. $1539-1542$ Vol.3.

[41.] Vasylyev A., Weger P., Simburger W., "Ultra-broadband $20.5-31 \mathrm{GHz}$ monolithically-integrated CMOS power amplifier" IEEE Electronics Letters 2005, pp. $1281-1282$

[42.] Wang H., Sideris C., Hajimiri A., "A 5.2-to-13GHz class-AB CMOS power amplifier with a $25.2 \mathrm{dBm}$ peak output power at $21.6 \%$ PAE" IEEE International Solid-State Circuits Conference Digest of Technical Papers (ISSCC) 2010, pp. 44 - 
45.

[43.] Chen J.S., Niknejad A.M., "Design and Analysis of a Stage-Scaled Distributed Power Amplifier" IEEE Microwave Theory and Techniques (MTT) Transaction 2011, pp. $1274-1283$.

[44.] Ladbrooke P.H., "MMIC Design: GaAs FETs and HEMTs", Norwood, MA, Artech House, 1989 (ISBN-10: 0890063141).

[45.] Sarma D.G., "On distributed amplification”, Proceedings of the IEE, 1955, vol. 102B, pp. $689-697$.

[46.] Hua D., Zhang S.A., Chen Y.Y., Zhang Q., "A 25-GHz 9-dB distributed amplifier in CMOS technology", Electric Information and Control Engineering (ICEICE), 2011, pp. $12-15$. 


\section{Appendix}

\section{GaN500 (CPFC) Process}

A simplified cross-section of the HFET is shown as Figure A.1, with approximate dimensions.

\begin{tabular}{|c|c|c|}
\hline Source contact & Gate & Drain contact \\
\hline AIGaN & & $20 \mathrm{~nm}$ \\
\hline AlN & & $1 \mathrm{~nm}$ \\
\hline GaN & & $200 \mathrm{~nm}$ \\
\hline GaN buffer layer & & 2um \\
\hline Nucleation layer & & $20 \mathrm{~nm}$ \\
\hline & ubstrate & \\
\hline
\end{tabular}

Figure A.1 Cross-section of HFET, showing contacts and epitaxial structures

The Gallium Nitride $(\mathrm{GaN}) /$ Aluminium Gallium Nitride (AlGaN) epitaxial layers are grown on Silicon Carbide ( $\mathrm{SiC}$ ) wafers. The thickness of the $\mathrm{SiC}$ substrate is $400 \mathrm{um}$ with $12.5 \%$ fabrication tolerance. In simulation, we used the recommended model for the substrate MSUB (Microstrip Substrate) in ADS. The set-up of GaN500 process is listed in Table A.1, and the ADS MSUB substrate model structure is illustrated in Figure A.2. 
Table A.1 ADS substrate model MSUB definition of GaN500 process

\begin{tabular}{|c|c|c|c|}
\hline Name & Description & Value & Units \\
\hline $\mathrm{H}$ & Substrate thickness & 400 & micron \\
\hline Er & Relative dielectric constant & 9.5 & none \\
\hline Mur & Relative permeability & 1 & none \\
\hline Cond & Conductor conductivity & $4.10 \mathrm{E}+07$ & S/meter \\
\hline Hu & Cover height & $3.90 \mathrm{E}+34$ & none \\
\hline $\mathrm{T}$ & Conductor thickness & 1 & micron \\
\hline TanD & Dielectric loss tangent & 0 & none \\
\hline Rough & Conductor surface roughness & 0 & Mil \\
\hline DielectricLossModel & Model for calculating dielectric loss & 1 & none \\
\hline FreqForEpsrTanD & Frequency at which $\varepsilon_{r}$ and TanD are specified & $1.00 \mathrm{E}+09$ & $\mathrm{~Hz}$ \\
\hline LowFreqForTanD & Low roll-off frequency for TanD & $1.00 \mathrm{E}+03$ & $\mathrm{~Hz}$ \\
\hline HighFreqfor TanD & High roll-off frequency for TanD & $1.00 \mathrm{E}+12$ & $\mathrm{~Hz}$ \\
\hline
\end{tabular}

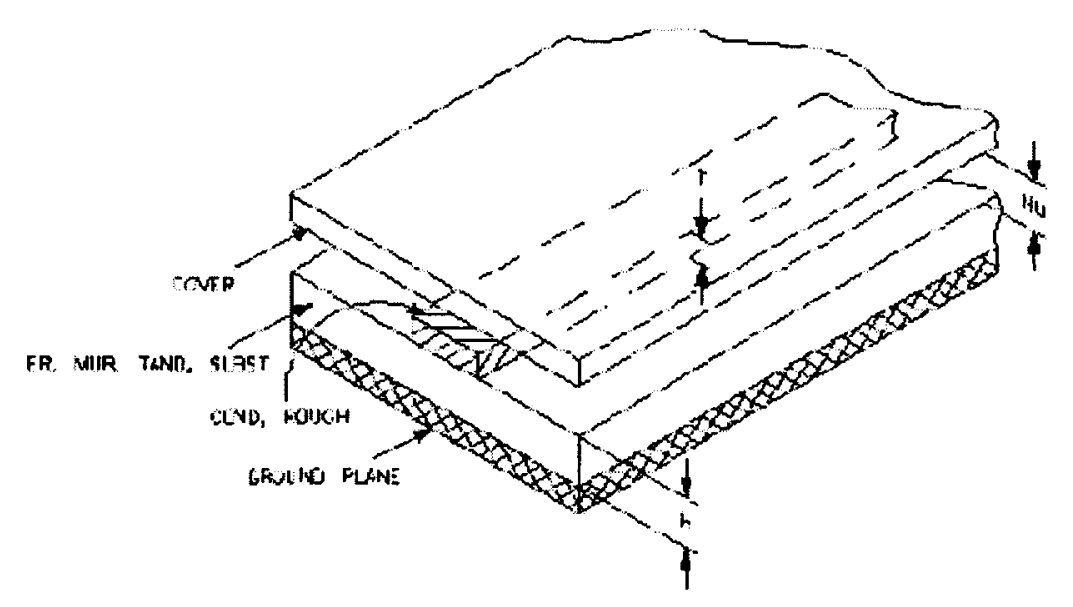

Figure A.2 ADS substrate illustration

Nine layers are defined based on the mask levels used at the various steps of the process as Table A.2. 
Table A.2 Process layer

\begin{tabular}{|c|c|}
\hline Layer Number & Loyer Name \\
\hline 1 & MESA \\
\hline 2 & OHM!C \\
\hline 3 & GATE \\
\hline 4 & VIAI \\
\hline 5 & NICHROME \\
\hline 6 & IME \\
\hline 7 & VIA2 \\
\hline 8 & BRIDGE \\
\hline 9 & 2ME \\
\hline
\end{tabular}

The nine masks listed in Table A.2 are applied to the HFET in the processing sequence. First, the OHMIC mask is used to define the contact area and deposit the contacts. Then contacts are alloyed at high temperature to ensure low resistance contact is made. Second, the MESA mask is used to define the active area of the device, the exposed area will be etched. Then, the GATE mask and VIA1 masks are applied to deposit the gate metal, and a thin layer of dielectricl together with vial hole which connect contact to metall is implemented. After that, a thin layer of NICHROME $(50 \Omega / s q)$ is formed where resistors are needed. Next, 1ME and VIA2 masks are applied to build metall (lum of gold) and a thin layer of dielectric2 together with via2 hole which connect contact to metal2. Finally, the BRIDGE mask and $2 \mathrm{ME}$ mask are applied in sequence to define a special resist layer which isolates the $1 \mathrm{ME}$ and $2 \mathrm{ME}$ layers if there is a requirement, and to deposit the lum thick metal2 gold layer. The layout view of a 2-gate HFET $(2 \times 200 \mu \mathrm{m})$ with airbridge is shown as Figure A.3. 


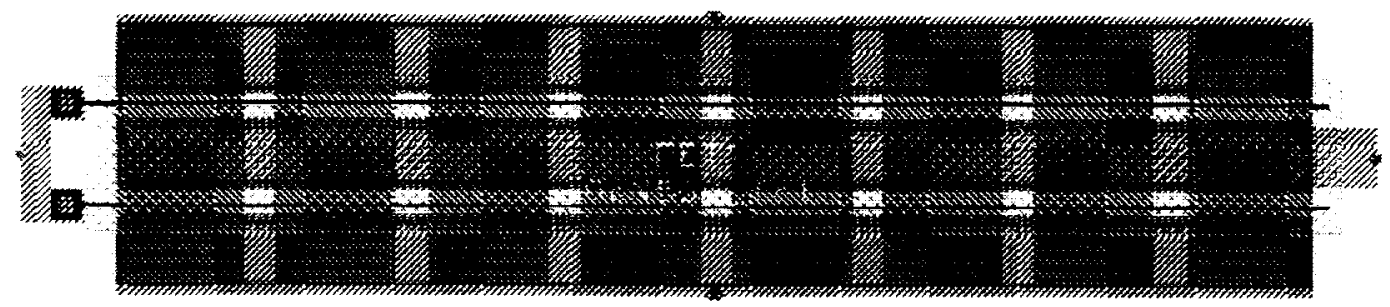

Figure A.3 Layout view of 2-gate HFET with airbridge

In $\mathrm{ADS}$, we use 3D EM-Momentum simulator for post-layout simulation. The substrate and layout layers set-up is shown in Table A.3.

Table A.3 ADS 3D EM-Momentum substrate and layout layer set-up of GaN500 process

\begin{tabular}{|c|c|c|c|c|c|c|}
\hline \multicolumn{4}{|c|}{ Subtrate Layers } & \multicolumn{3}{|c|}{ Layout Layers } \\
\hline Name & $\begin{array}{l}\text { Trak } \\
\text { Ln? }\end{array}$ & $\begin{array}{c}\text { Fermitity } \\
\text { E? }\end{array}$ & $\begin{array}{c}\text { Fermeat } t y \\
\text { lul }\end{array}$ & hare & $\begin{array}{l}\text { Thik } \\
\text { tum }\end{array}$ & $\begin{array}{l}\text { corsuter } \\
\text { semersin }\end{array}$ \\
\hline air & oper & 1 & 1 & strp-2ME & 1 & 4.197 \\
\hline air brifge & 1 & 1 & 1 & $V I A Z$ & - & 4.197 \\
\hline sin_1 & 0.1 & 5.5 & 1 & $\begin{array}{l}\text { StrP-1ME } \\
\text { HCHROME }\end{array}$ & 1 & 4.187 \\
\hline sin_o & 0.05 & 5.5 & 1 & VIS: & - & $4.1 \leq 7$ \\
\hline GaN & 500 & \pm .5 & $\Sigma$ & STP-MESA & 0.1 & $300 \mathrm{~s} i=0$ \\
\hline GND & $-2 \operatorname{cs} 2$ & $p=f \in t$ & - & & & \\
\hline
\end{tabular}

Because of the properties of the material and process introduced above, high frequency and high voltage performances are observed. According to the NRC measurement data of a $2 \times 40 \mu \mathrm{m}$ HFET device with $0.5 \mu \mathrm{m}$ gate length on PCM standard die, the threshold voltage and the maximum $g_{m}$ is normally $-4.1 \mathrm{~V}$ and 0.22 
$\mathrm{S} / \mathrm{mm}$ respectively, and maximum $J_{\mathrm{dss}}$ is $1 \mathrm{~A} / \mathrm{mm}$, which is suitable for high power design.

In $R F$ performance, $f_{T}$ and $f_{\max }$ values are measured from the extrapolation of $\mathrm{H} 21$ (Forward Current Gain) and MAG (Maximum Available Voltage Gain) derived from s-parameter measurements when biasing the HFET at $\mathrm{V}_{\mathrm{ds}}=10 \mathrm{~V}, \mathrm{~V}_{\mathrm{gs}}=-2 \mathrm{~V}$. High frequency applications become possible because of the $75 \mathrm{GHz} \mathrm{f}_{\max }$ and $27 \mathrm{GHz} \mathrm{f}_{\mathrm{T}}$. In addition, the PCM measurement is performed by selecting nine tiles which form a rectangular array centered on the test wafer. The location of the measured die depends on the dimension of the tile. The PCM measurement is implemented in order to expect fabrication variation in device parameters across the wafer, and from wafer to wafer.

Then, the breakdown voltage of the device is investigated, especially $\mathrm{BV}_{\mathrm{gdo}}$. Again, thanks to the measurement data which NRC supplied, on the best wafers $B V_{\text {gdo }}$ values in excess of $100 \mathrm{~V}$ have been obtained with a gate-drain spacing of 2 um or greater, which strongly support high voltage applications. Slightly lower breakdown voltages were observed on devices from the same wafer with a gate-drain spacing of $1 \mu \mathrm{m}$. However, the results are somewhat variably affected by the process and device leakage current. 